\title{
DETAILED DESIGN REPORT FOR AN OPERATIONAL PHASE PANEL-CLOSURE SYSTEM
}

DOENIPP-96-2150

Any comments or questions regarding this report should be directed to the U.S. Department of Energy

WIPP Project Office

P.O. Box 3090

Carlsbad, New Mexico 88221

or to the Manager

Engineering Department

Westinghouse Electric Corporation

Waste Isolation Division

P.O. Box 2078

Carlsbad, New Mexico 88221

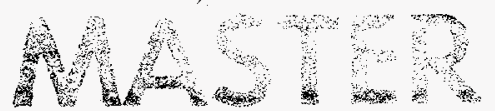

This report was prepared for the U.S. Department of Energy by the Engineering Department of the Management and Operating Contractor, Waste Isolation Pilot Plant, under Contract No. DEAC04-86AL31950. 


\section{DISCLAIMER}

This report was prepared as an account of work sponsored by an agency of the United States Government. Neither the United States Government nor any agency thereof, nor any of their employees, makes any warranty, express or implied, or assumes any legal liability or responsibility for the accuracy, completeness, or usefulness of any information, apparatus, product, or process disclosed, or represents that its use would not infringe privately owned rights. Reference herein to any specific commercial product, process, or service by trade name, trademark, manufacturer, or otherwise does not necessarily constitute or imply its endorsement, recommendation, or favoring by the United States Government or any agency thereof. The views and opinions of authors expressed herein do not necessarily state or reflect those of the United States Government or any agency thereof. 


\section{DISCLAIMER}

Portions of this document may be illegible in electronic image products. Images are produced from the best available original document. 
This document has been reproduced directly from the best possible copy.

It is available to DOE and DOE contractors at the following addresses:

Office of Scientific and Technical Information

P.O. Box 62

Oak Ridge, TN 37831

Prices available from (615) 576-8401

Available to the public from the National Technical Information Services

U. S. Department of Commerce

5285 Port Royal Road

Springfield, VA 22161 


\section{Certification}

I certify under penalty of law that this document was prepared under my supervision for Westinghouse Electric Corporation, Waste Isolation Division, Waste Isolation Pilot Plant, by IT Corporation according to the IT Environmental Engineering and Services Quality Assurance Program. This program is designed to assure that qualified personnel properly gather and evaluate the information submitted. Based on my inquiry of the persons directly responsible for gathering the information, the information submitted is, to the best of my knowledge and belief, true, accurate, and complete.

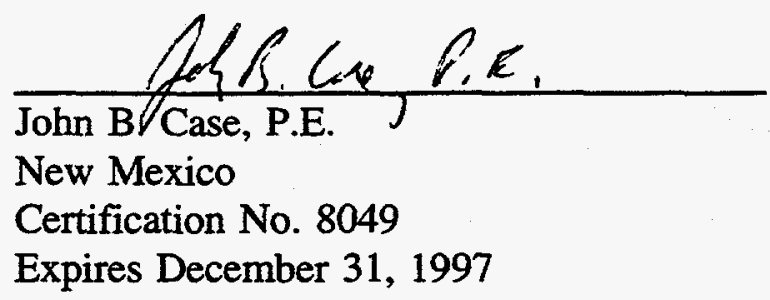




\section{Executive Summary}

Scope. Under contract to Westinghouse Electric Corporation (Westinghouse), Waste Isolation Division (WID), IT Corporation has prepared a detailed design of a panel-closure system for the Waste Isolation Pilot Plant (WIPP). Preparation of this detailed design of an operational-phase closure system is required to support a Resource Conservation and Recovery Act (RCRA) Part B permit application and a no-migration variance petition. This report describes the detailed design for a panel-closure system specific to the WIPP site. The recommended panel-closure system will adequately isolate the waste-emplacement panels for at least 35 years.

Purpose. This report provides detailed design and material engineering specifications for the construction, emplacement, and interface-grouting associated with a panel-closure system at the WIPP repository, which would ensure that an effective panel-closure system is in place for at least 35 years. The panel-closure system provides assurance that the limit for the migration of volatile organic compounds (VOC) will be met at the point of compliance, the WIPP site boundary. This assurance is obtained through the inherent flexibility of the panelclosure system. The panel-closure system will be located in the air-intake and air-exhaust drifts (Figure ES-1). The system components have been designed to maintain their intended functional requirements under loads generated from salt creep, internal pressure, and a postulated methane explosion. The design complies with regulatory requirements for a panelclosure system promulgated by RCRA and the Mine Health and Safety Administration (MSHA). The design uses common construction practices according to existing standards.

Background. The engineering design considers a range of expected subsurface conditions at the location of a panel-closure system. The geology is predominantly halite with interbedded anhydrite at the repository horizon. During the operational period, the panelclosure system would be subject to creep from the surrounding host rock that contains trace amounts of brine.

During the conceptual design stage, two air-flow models were evaluated: (1) unrestricted flow and (2) restricted flow through the panel-closure system. The "unrestricted" air flow model is defined as a model in which the gas pressure that develops is at or very near atmospheric pressure such that there exists no back pressure in the disposal areas. Flow is unrestricted in this model. The "restricted" air flow model is defined as a model in which the 


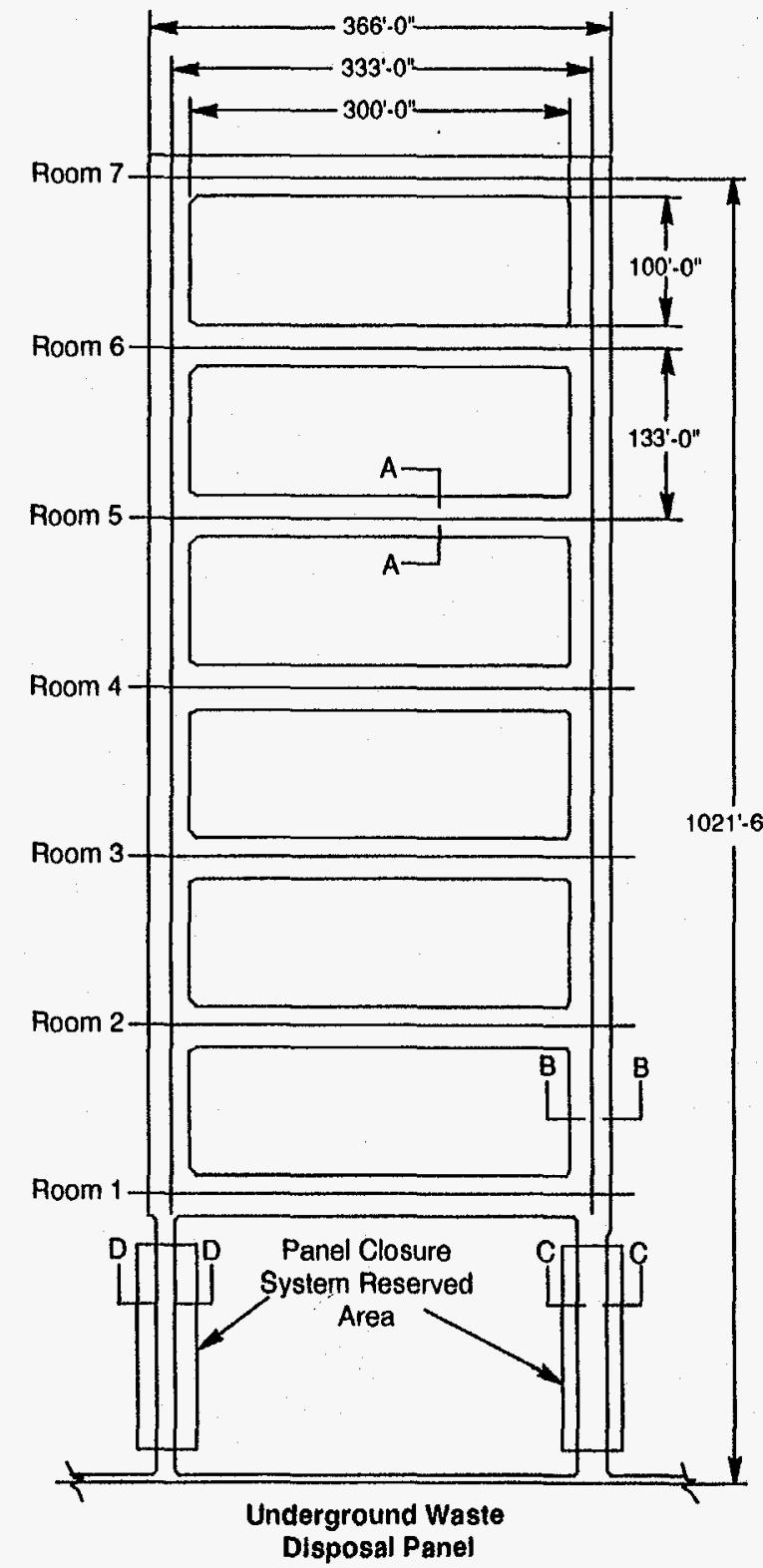

Note: Figure is Not to Scale All Dimensions Shown are Nominal
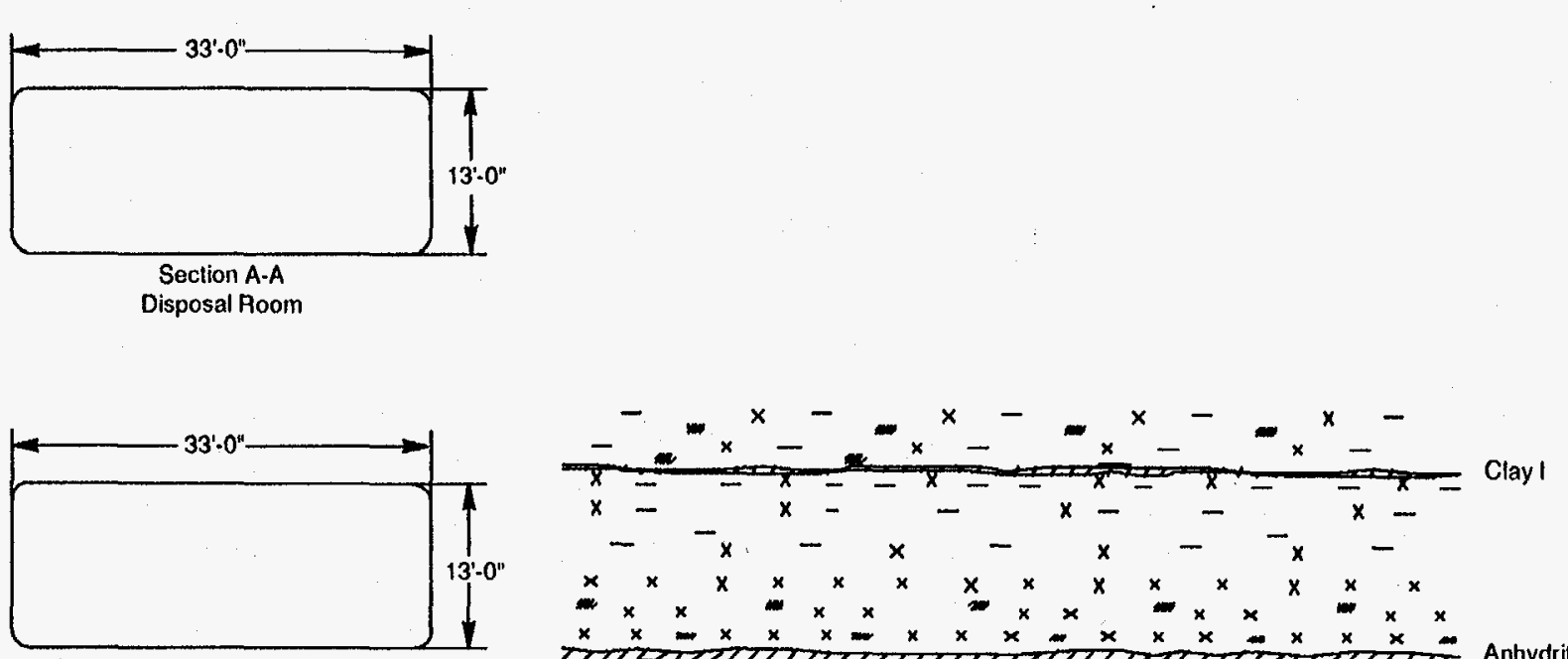
$x$
$\times$

Section B.B - Alay
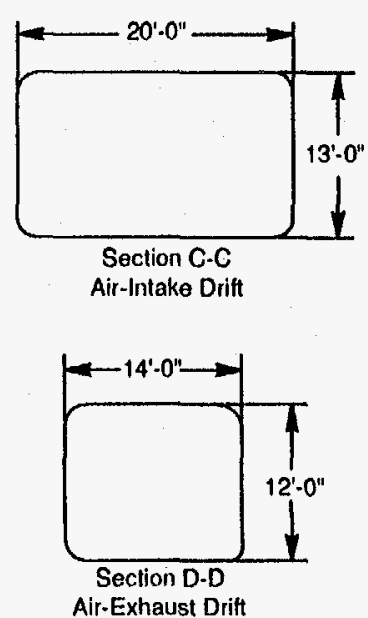

Typlcal Excavation Sections

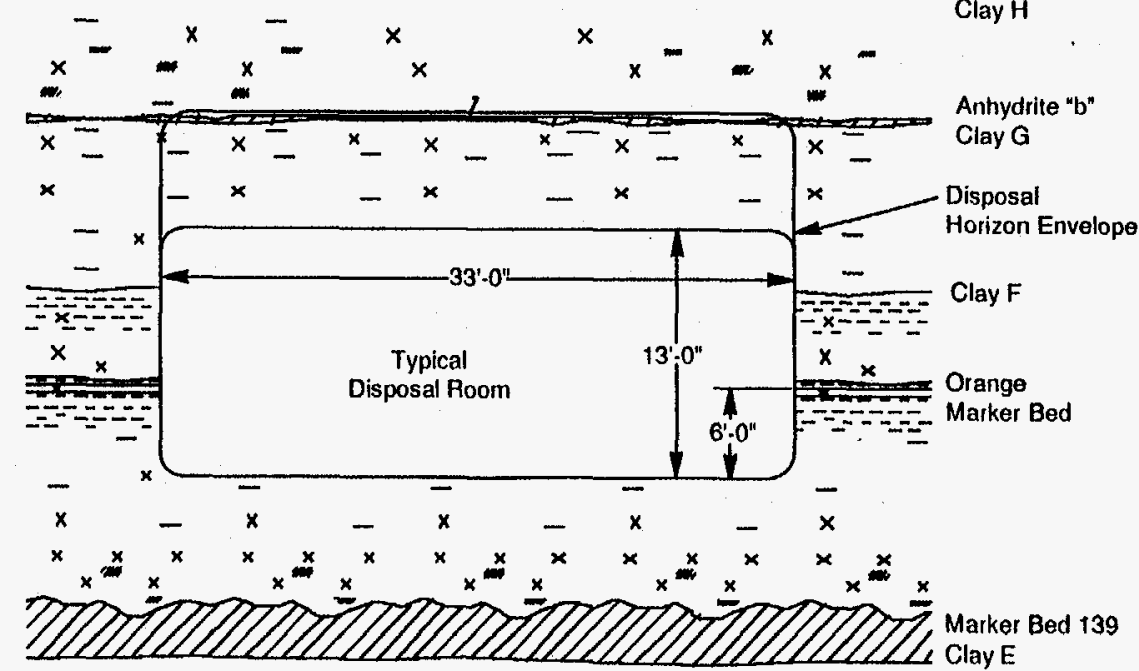

Dlsposal Horizon Stratigraphy
Figure ES-1

Typical Facilities-Typical Disposal Panel (After Westinghouse, 1995c) 
back pressure in the waste emplacement panels develops due to the restriction of flow through the barrier, and the surrounding disturbed rock zone. The analysis was based on an assumed gas generation rate of 8,200 moles per panel per year ( 0.1 moles per drum per year) due to microbial degradation, an expected volumetric closure rate of 28,000 cubic feet ( 800 cubic meters) per year due to salt creep, the expected headspace concentration for a series of nine VOCs, and the expected air dispersion from the exhaust shaft to the WIPP site boundary. The analysis indicated that the panel-closure system would limit the concentration of each VOC at the WIPP site boundary to a small fraction of the health-based exposure limits during the operational period.

Alternate Designs. Various options were evaluated considering active systems, passive systems, and composite systems. Consideration of the aforementioned factors led to the selection of a passive panel-closure system consisting of: (1) a standard concrete barrier, rectangular in shape, or (2) an enlarged tapered concrete barrier. Options (1) and (2) will be grouted at the interface and may contain an explosion-isolation wall or a constructionisolation wall. This system provides flexibility for a range of ground conditions likely to be encountered in the underground repository. No other special requirements for engineered components beyond the normal requirements for fire suppression and methane explosion or deflagration containment exist for the panel-closure system during the operational period.

The panel-closure system design incorporates mitigative measures to address the treatment of fractures and therefore minimizes the potential migration of contaminants. The design option for mitigating fractures includes excavating the disturbed rock zone (DRZ) and emplacing an enlarged concrete barrier.

To be effective, the excavation and installation of the panel-closure system must be completed within a short time frame to minimize disturbance to the surrounding salt. A rigid concrete barrier will promote interface stress buildup, as fractures are expected to heal with time. For this purpose, the main concrete barrier would be tapered to reduce shear stress and to increase compressive stress along the interface zone. If ground conditions are more favorable, the design can be simplified to a standard concrete barrier with an explosion-isolation or construction-isolation wall without DRZ removal. ${ }^{1}$

${ }^{1} \mathrm{DRZ}$ removal is used in the context of the removal of fractured rock. 
Design Classification. Procedure WP 09-CN3023 (Westinghouse, 1995a) was used to establish a design classification for the panel-closure system. It uses a decision-flow-logic process to designate the panel-closure system as a Class IIIB structure. This is because during the methane explosion the concrete barrier would not fail.

Design Evaluations. To investigate several key design issues, design evaluations were performed. These design evaluations can be divided into those that satisfy (1) the operational requirements of the system and (2) the structural and material requirements of the system.

The conclusions reached from the evaluations addressing the operational requirements are as follows:

- Based on an air-flow model used to predict the mass flow rate of carbon tetrachloride through the panel-closure system for the alternatives, the air-flow analysis suggests that the fully enlarged barrier provides the highest protection for restricting VOCs during the operational period of 35 years.

- Results of the Fast Lagrangian Analysis of Continua (FLAC) analyses show that the recommended enlarged configuration is a circular rib-segment excavated to Clay $G$ and under MB 139. Interface grouting would be performed at the upper boundary of the concrete barrier.

- The results of the transverse plane-strain models show that higher stresses would form in MB 139 following excavation, but that after installation of the panelclosure system, the barrier confinement will result in an increase in barrierconfining stress and a reduction in shear stress. The main concrete barrier would provide substantial uniform confining stresses as the barrier is subjected to secondary salt creep.

- The removal of the fractured salt prior to installation of the main concrete barrier would reduce the potential for flexure. The fracturing of MB 139 and the attendant fracturing of the floor could reduce structural load resistance (structural stiffness), which could initially result in barrier flexure and shear. With the removal of MB 139, the fractured salt stiffens the surrounding rock and results in the development of more uniform compression.

- The trade-off study also showed that a panel-closure system with an enlarged concrete barrier with the removal of the fractured salt roof and anhydrite in the floor was found to be the most protective.

The conclusions reached from the design evaluations addressing the structural and material requirements of the panel-closure system are as follows: 
- Existing information on the heat of hydration of the concrete supports placing concrete with a low cement content to reduce the temperature rise associated with hydration. Plasticizers might be used to achieve the required slump at the required strength. A thermal analysis, coupled with a salt creep analysis, suggests installation of the enlarged barrier at or below ambient temperatures to adequately control hydration temperatures.

- In addition to installation at or below ambient temperatures, the concrete used in the main barrier would exhibit the following:

- An 8 inch (0.2 meter) slump after 3 hours of intermittent mixing

- A less-than-25-degree Fahrenheit heat rise prior to installation

- An unconfined compressive strength of 4,000 pounds per square inch (psi) (28 megapascals [MPa]) after 28 days

- Volume stability

- Minimal entrained air.

- The trace amounts of brine from the salt at the repository horizon will not degrade the main concrete barrier for at least 35 years.

- In 20 years, the open passage above the waste stack would be reduced in size. Further, rooms with bulkheads at each end would be isolated in the panel. It is unlikely that a long passage with an open geometry would exist; therefore, the dynamic analysis considered a deflagration with a peak explosive pressure of 240 psi (1.7 MPa).

- The heat-transfer analysis shows that elevated temperatures would occur within the salt and the explosion-isolation wall; however, the elevated temperatures will be isolated by the panel-closure system. Temperature gradients will not significantly affect the stability of the wall.

- The fractures in the roof and floor could be affected by expanding gas products reaching pressures on the order of $240 \mathrm{psi}(1.7 \mathrm{MPa})$. Because the peak internal pressure from the deflagration is only one fifth of the pressure, fractures could not propagate beyond the barrier.

A composite system is selected for the design with various components to provide flexibility. These design options are described below. 
Design Options. Figure ES-2 illustrates the options developed to satisfy the requirements for the panel-closure system. The basis for selecting an option depends on conditions at the panel-closure system locations as would be documented by future subsurface investigations.

These design options provide flexibility in satisfying the design migration limit for the flow of VOCs out of the waste-emplacement panel. An enlarged concrete barrier would be selected for the air-intake and air-exhaust drifts that have fractured rock to eliminate significant flow of VOCs. Several methods are available for detecting the location and extent of fractures in the DRZ for optimum placement of an enlarged concrete barrier. These detection methods include ground-penetrating radar (GPR) and inspection of observation boreholes.

For future waste panels, GPR would be used to monitor fracture development. Radar surveys would be conducted shortly after excavation to provide a baseline for comparison to future radar surveys. GPR would be used periodically to monitor the development of brittle deformation in the new air-intake and air-exhaust drifts of a panel.

Observation boreholes would be drilled into the roof or floor of an excavation and would be inspected for fractures and bed separation. Observations in the boreholes can be made with a small video camera, or a simple scratch rod.

While no specific requirements exist for barricading inactive waste areas under the MSHA, their intent is to safely isolate these abandoned areas from active workings using barricades of "substantial construction." A previous analysis (DOE, 1995) examined the issue of methane gas generation from transuranic waste and the potential consequence in closed areas. The principal concern is whether an explosive mixture of methane with an ignition source would result in deflagration. If a methane explosion is considered possible, a concrete block wall of sufficient thickness will be used to resist dynamic and salt creep loads. A construction isolation wall will be used in the absence of explosive conditions.

It was shown (DOE, 1995) that an explosive atmosphere may exist after approximately 20 years. A panel-closure system with a closure life less than 20 years would not require an explosion-isolation wall, because an explosive mixture could not accumulate. A constructionisolation wall will suffice to provide isolation during construction of the main concrete barrier. 


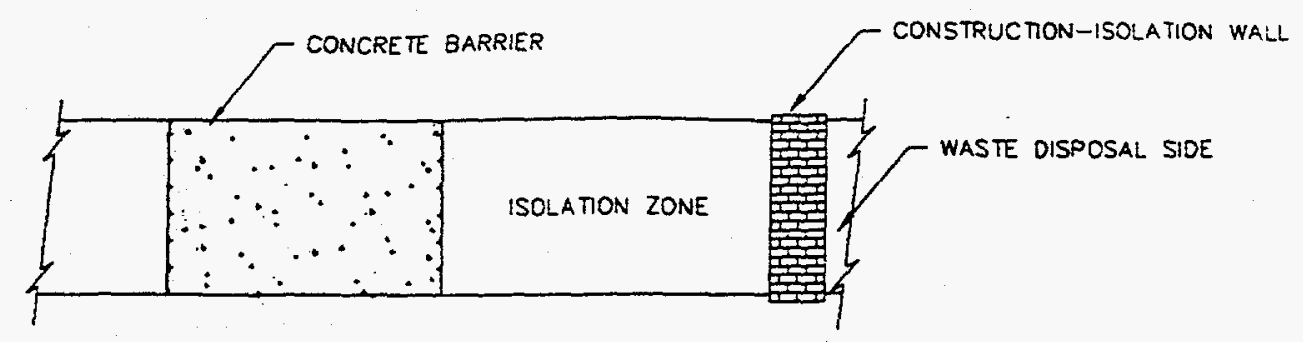
$\frac{\text { A. CONCRETE BARRIER WITHOUT DRZ REMOVED }}{\text { AND CONSTRUCTION ISOLATION WALL }}$

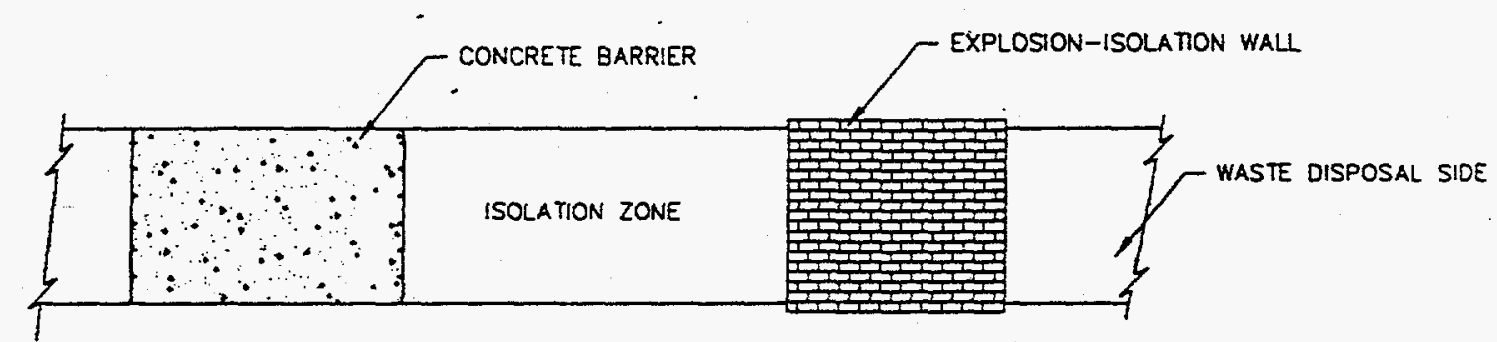

B. CONCRETE BARRIER WITHOUT DRZ REMOVED AND EXPLOSION ISOLATION WALL

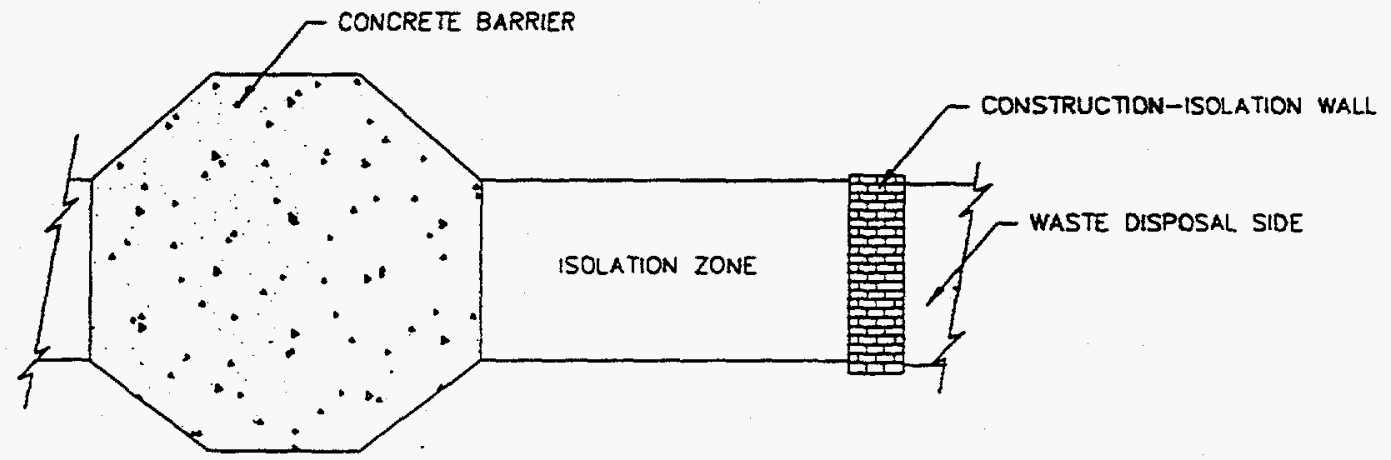

$\frac{\text { C. CONCRETE BARRIER WITH DRZ REMOVED }}{\text { AND CONSTRUCTION ISOLATION WALL }}$

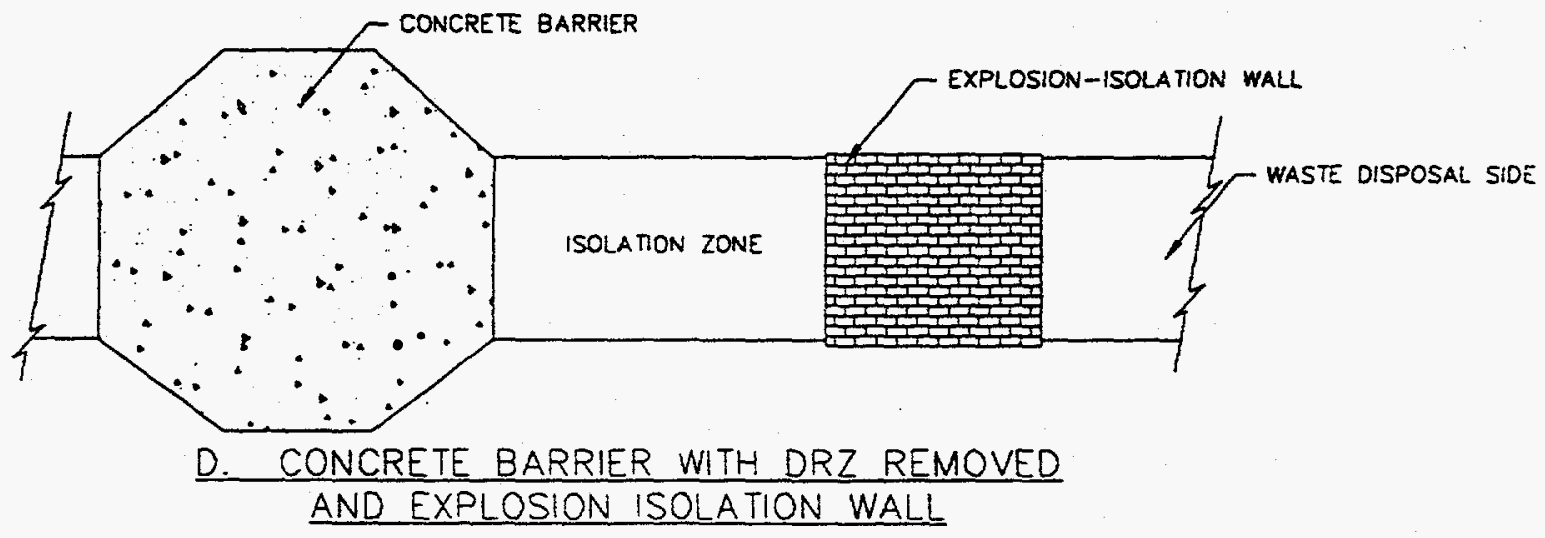

Figure ES-2

Main Barrier with Wall Combinations 
Design Components. The enlarged concrete barrier will be located at the optimum location in the air-intake and air-exhaust drifts following observation of subsurface conditions. The enlarged concrete barrier will be composed of plain concrete with sufficient unconfined compressive strength. The barrier will consist of a circular rib segment excavated into the surrounding salt where the central portion of the barrier will extend just beyond Clay G and MB 139. FLAC analyses showed that plain concrete will develop adequate confined compressive strength.

The enlarged concrete barrier will be placed in four cells, with construction joints formed perpendicular to the direction of potential air flow. The concrete will be placed through 6inch ( 15.2 centimeter) diameter steel pipes and will be vibrated from outside the formwork. The formwork is designed to withstand the hydrostatic loads that would occur during installation with minimal bracing onto exposed salt surfaces. This will be accomplished by a series of steel plates that are stiffened by angle iron, with load reactions carried by spacer rods. Some exterior bracing will be required when the concrete is poured into the first cell at the location for the enlarged concrete barrier. All structural steel will be American Society of Testing and Materials [grade] A36 in conformance with the latest standards specified by the American Institute for Steel Construction. After concrete placement, the formwork will be left in place and will stiffen the enlarged concrete barrier if nonuniform reactive loadings should occur after panel closure.

After completion of the enlarged concrete barrier installation, it will be grouted through a series of grout supply and air return lines that terminate in grout boxes. The boxes will be mounted near the top of the barrier. The grout will be injected through one set of lines and returned through a second set of air lines.

An explosion-isolation wall, constructed with concrete-blocks, will mitigate the effects of a methane explosion. The explosion-isolation wall would consist of 3,500 psi (24 MPa) concrete blocks mortared together with a bonding agent. The concrete-block wall design complies with MSHA requirements, because it consists of noncombustible materials of "substantial construction." The concrete-block walls will be keyed into the salt. For the WIPP, an explosion-isolation wall is designed to resist loading from salt creep. 
The compliance of the detailed design was evaluated against the design requirements established for the panel-closure system. The design complies with all aspects of the design basis established for the panel-closure system. 


\section{Table of Contents}

Executive Summary $\ldots \ldots \ldots \ldots \ldots \ldots \ldots \ldots \ldots \ldots \ldots \ldots \ldots \ldots \ldots \ldots \ldots \ldots$

List of Tables $\ldots \ldots \ldots \ldots \ldots \ldots \ldots \ldots \ldots \ldots \ldots \ldots \ldots \ldots \ldots$ iv

List of Figures $\ldots \ldots \ldots \ldots \ldots \ldots \ldots \ldots \ldots \ldots \ldots \ldots \ldots \ldots \ldots \ldots$

List of Abbreviations/Acronyms $\ldots \ldots \ldots \ldots \ldots \ldots \ldots \ldots \ldots \ldots \ldots \ldots$ vi

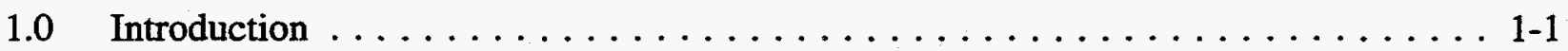

1.1 Scope $\ldots \ldots \ldots \ldots \ldots \ldots \ldots \ldots \ldots \ldots \ldots \ldots \ldots \ldots \ldots \ldots \ldots \ldots$

1.2 Design Classification $\ldots \ldots \ldots \ldots \ldots \ldots \ldots \ldots \ldots \ldots \ldots$

1.3 Regulatory Requirements . . . . . . . . . . . . . . . . . . . . . 1-4

1.3.1 Resource Conservation and Recovery Act (40 CFR 264, 268, and

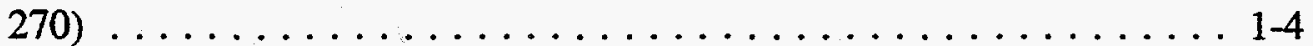

1.3.2 Protection of the Environment and Human Health . . . . . . . . 1-4

1.3.3 Closure Requirements (20 New Mexico Administrative Code 4.1, Subpart V) ........................ 1-4

1.3.4 Mining Safety and Health Administration ............. 1-6

1.4 Report Organization . . . . . . . . . . . . . . . . . . . 1-6

2.0 Design Evaluations . . . . . . . . . . . . . . . . . . . . . . . 2-1

2.1 Analyses Addressing Operational Requirements . . . . . . . . . . . . 2-1

2.1.1 Air-Flow Analyses . . . . . . . . . . . . . . . . 2-2

2.1.1.1 Evaluation Procedure ................ 2-2

2.1.1.2 Modeling Results . . . . . . . . . . . . . 2-7

2.1.1.3 Conclusions . . . . . . . . . . . . . . . . 2-9

2.1.2 Advection/Dispersion Evaluation $\ldots \ldots \ldots \ldots \ldots \ldots \ldots$ 2-9 . . . . . .

2.1.2.1 Evaluation Procedure . . . . . . . . . . . . . . 2-9

2.1.2.2 Modeling Results . . . . . . . . . . . . . . 2-12

2.1.2.3 Conclusion . . . . . . . . . . . . . . 2-14

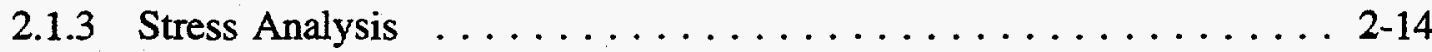

2.1.3.1 Evaluation Procedure . . . . . . . . . . . . 2-14

2.1.3.2 FLAC Models . . . . . . . . . . . . . 2-15

2.1.3.3 Stress Analysis of the Concrete Barrier on an Elastic Foundation .................. 2-17

2.1.3.4 Interface Stress Buildup . . . . . . . . . . . 2-21

2.1.4 Tradeoff Study of Formation Grouting versus DRZ Removal . . . 2-21 2.2 Structural and Material Requirements . . . . . . . . . . . . . 2-26 


\section{Table of Contents (Continued)}

2.2.1 Material-Compatibility Evaluations $\ldots \ldots \ldots \ldots \ldots \ldots \ldots \ldots 2-26$

2.2.1.1 Evaluation Procedure . . . . . . . . . . . . . . 2-26

2.2.1.2 Concrete-Barrier Material Candidates . . . . . . . 2-26

2.2.1.3 VOC Interaction . . . . . . . . . . . . . . . 2-29

2.2.1.4 Cement Hydration . . . . . . . . . . . . . . . 2-29

2.2.1.5 Conclusions . . . . . . . . . . . . . . . . 2-29

2.2.2 Heat-Generation Evaluations $\ldots \ldots \ldots \ldots \ldots \ldots \ldots \ldots \ldots .2-30$

2.2.2.1 Evaluation Procedure . . . . . . . . . . . . . 20

2.2.2.2 Modeling Results $\ldots \ldots \ldots \ldots \ldots \ldots \ldots \ldots .2-32$

2.2.2.3 Conclusions . . . . . . . . . . . . . . . 2-34

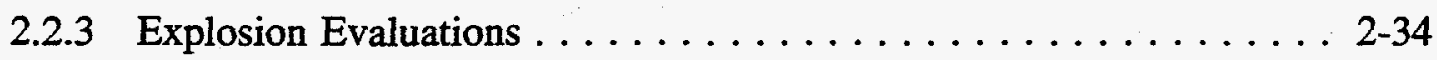

2.2.3.1 Evaluation Procedure $\ldots \ldots \ldots \ldots \ldots \ldots \ldots . . \ldots \ldots .2-34$

2.2.3.2 Analysis Results $\ldots \ldots \ldots \ldots \ldots \ldots \ldots \ldots \ldots \ldots .2-36$

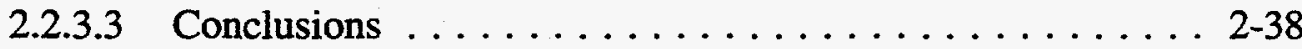

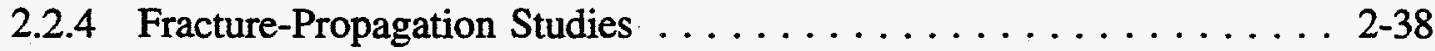

2.2.4.1 Evaluation Procedure . . . . . . . . . . . . . . .

2.2.4.2 Evaluation Results $\ldots \ldots \ldots \ldots \ldots \ldots \ldots \ldots \ldots . \ldots \ldots . \ldots \ldots$

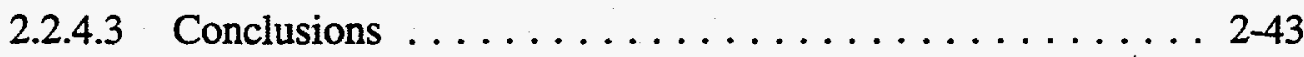

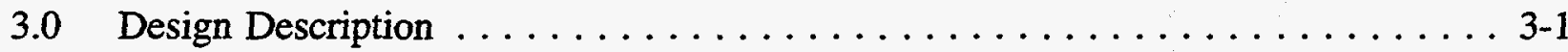

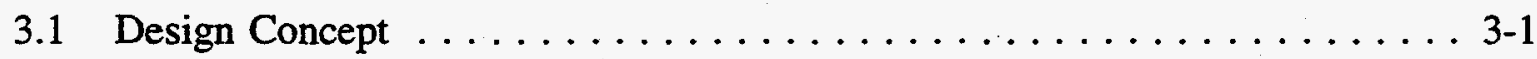

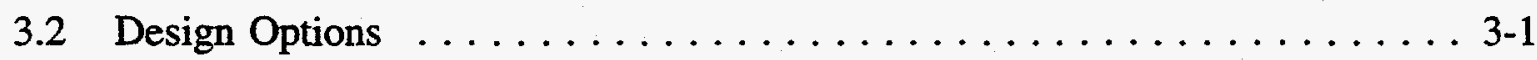

3.2.1 Selection of the Concrete Barrier $\ldots \ldots \ldots \ldots \ldots \ldots \ldots \ldots \ldots \ldots \ldots \ldots$

3.2.2 Selection of an Explosion- or Construction-Isolation Wall . . . . . . 3-4

3.3 Design Components . . . . . . . . . . . . . . . . 3-5

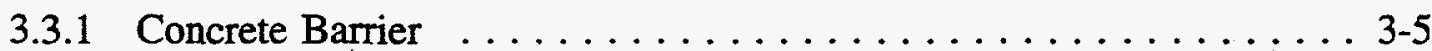

3.3.2 Explosion- and Construction-Isolation Walls $\ldots \ldots \ldots \ldots \ldots \ldots .3-5$

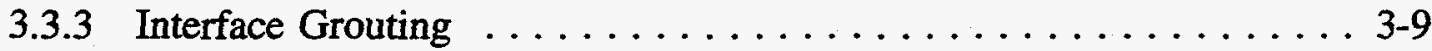

3.4 Panel-Closure System Construction . . . . . . . . . . . . . 3-9

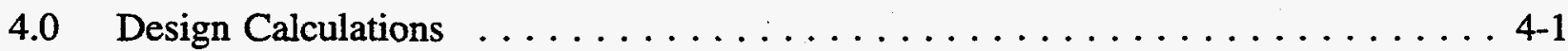

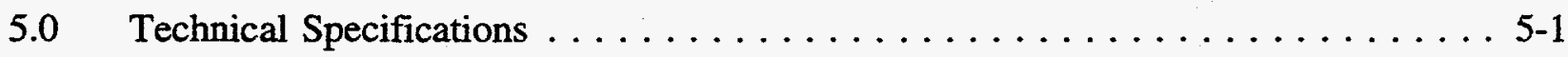

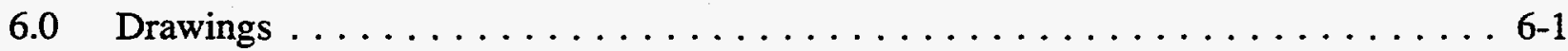

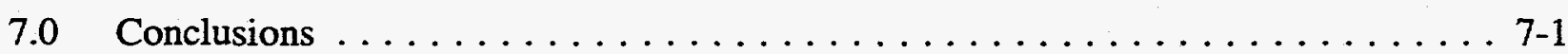

8.0 References $\ldots \ldots \ldots \ldots \ldots \ldots \ldots \ldots \ldots \ldots \ldots \ldots \ldots \ldots$ 8 1 


\section{Table of Contents (Continued)}

Appendix A-Derivation of Relationships for the Air-Flow Models Appendix B-Calculations in Support of Panel Gas Pressurization Due to Creep Closure Appendix C-FLAC Modeling of the Panel Closure System Appendix D-Brine/Cement Interactions Appendix E-Previous Studies of Panel-Closure System Materials Appendix F-Heat Transfer Model, Derivation Methane Explosion Appendix G-Technical Specifications Appendix $\mathrm{H}-$ Design Drawings 
Table

$2-1$

$2-2$

2-3

$2-4$

$2-5$

4-1

5-1

6-1

$7-1$

\section{Title}

Intrinsic Permeability of Flow Components

Air Conductance Through System Components

Salt-Saturated Grout (BCT-1F)

Salado Mass Concrete

Thermal and Thermomechanical Properties for SHAFT.SEAL

Analysis

Constuctability Design Calculations Index

Technical Specifications for the WIPP Panel-Closure System

Panel-Closure System Drawings

Compliance of the Design with the Design Requirements 
Figure

ES-1

ES-2

1-1

1-2

1-3

2-1

2-2

2-3

2-4

2-5

2-6

2-7

2-8

2-9

2-10

2-11

2-12

2-13

2-14

2-15

2-16

2-17

2-18

2-19

3-1

3-2

3-3

3-5

3-6
Title

Typical Facilities-Typical Disposal Panel

Main Barrier with Wall Combinations

Typical Facilities-Typical Disposal Panel

Design Process for the Panel-Closure System

Design Classification of the Panel-Closure System

Closed-Panel Release Rate Versus Limit Comparison for Carbon

Tetrachloride and Other VOCs

Closed-Panel Release Rate Versus Limit Comparison for Other

VOCs

Air-Flow Analyses Using Several Alternatives

Breakthrough Time for VOCs Through Several Media

Transverse Model for FLAC Analysis

Axisymmetric Models for FLAC Analysis

Stress Analysis of a Barrier with DRZ Removal

Stress Analysis of a Barrier on Elastic Foundation

Reactive Barrier Loads

Development of Interface Stress in the Large $91 \mathrm{~cm}$-diameter

Plug

Effect of Enlarging Barrier on Interface Stress

Heat of Hydration for Expansive Salt Concrete

Temperature and Stress Distributions for Concrete Barrier

Methane Concentrations in the Waste Panel Over Time

Pressure Pulse Versus Time

Dynamic Load Factor Versus Frequency of Concrete Wall as a

Plate

Temperature Variation with Time for Gas, Salt, and Explosion-

Isolation Walls

Temperature Distribution with Time for Concrete Wall

Temperature Distribution with Time for Salt

Main Concrete Barrier with Wall Combinations

Concrete Barrier with DRZ Removal

Concrete Barrier Without DRZ Removal

Explosion-Isolation Wall

Grouting Details 


\section{List of Abbreviations/Acronyms}

$\begin{array}{ll}\text { ACI } & \text { American Concrete Institute } \\ \text { AISC } & \text { American Institute for Steel Construction } \\ { }^{*} \text { CFR } & \text { Code of Federal Regulations } \\ \text { cm } & \text { centimeter } \\ { }^{\circ} \mathrm{C} & \text { degrees celsius } \\ { }^{\circ} \mathrm{F} & \text { degrees Fahrenheit } \\ \text { DOE } & \text { U.S. Department of Energy } \\ \text { DRZ } & \text { disturbed rock zone } \\ \text { EEP } & \text { Excavation Effects Program } \\ \text { ESC } & \text { expansive salt-saturated concrete } \\ \text { FLAC } & \text { Fast Lagrangian Analysis of Continua } \\ \text { ft } & \text { foot (feet) } \\ \text { GPR } & \text { ground-penetrating radar } \\ \text { Kips } & \text { 1,000 pounds } \\ \text { m } & \text { meter(s) } \\ \text { MB 139 } & \text { Marker Bed 139 } \\ \text { MPa } & \text { megapascal(s) } \\ \text { MSHA } & \text { Mine Safety and Health Administration } \\ \text { NaCl } & \text { sodium chloride } \\ \text { NMVP } & \text { no-migration variance petition } \\ \text { psi } & \text { pound(s) per square inch } \\ \text { RCRA } & \text { Resource Conservation and Recovery Act } \\ \text { SMC } & \text { Salado Mass Concrete } \\ \text { TRU } & \text { transuranic } \\ \text { VOC } & \text { volatile organic compound(s) } \\ \text { Westinghouse } & \text { Westinghouse Electric Corporation } \\ \text { WID } & \text { Waste Isolation Division } \\ \text { WIPP } & \text { Waste Isolation Pilot Plant } \\ & \end{array}$




\subsection{Introduction}

The Waste Isolation Pilot Plant (WIPP), a U.S. Department of Energy (DOE) research facility located near Carlsbad, New Mexico, was established to demonstrate the safe disposal of defense-generated transuranic (TRU) waste. The WIPP repository is approximately 2,150 feet (ft) (655 meters [m]) below the surface, in the Salado Formation. The WIPP facility consists of a northern experimental area, a shaft-pillar area, and a waste-emplacement area.

One important aspect of future repository operations at the WIPP is the activities associated with closure of waste-emplacement panels. Each panel consists of air-intake and air-exhaust drifts, panel-access drifts, and seven rooms (Figure 1-1). After completion of wasteemplacement activities, each panel will be closed, while waste emplacement may be occurring in the other panel(s). The closure of individual panels during the operational period will be conducted in compliance with project-specific health, safety, and environmental performance criteria.

\subsection{Scope}

This report provides information on the detailed design and material engineering specifications for the construction, installation, and interface grouting associated with a panelclosure system for a minimum operational period of 35 years. The panel-closure system design provides assurance that the limit for the migration of volatile organic compounds (VOC) will be met at the point of compliance, the WIPP site boundary. This assurance is obtained through the inherent flexibility of the panel closure system. The panel-closure system will be located in the air-intake and air-exhaust drifts to each panel (Figure 1-1). The panel-closure system design maintains its intended functional requirements under loads generated from salt creep, internal panel pressure, and a postulated methane explosion. The design complies with regulatory requirements for a panel-closure system promulgated by the Resource Conservation and Recovery Act (RCRA) and Mine Safety and Health Administration (MSHA).

Figure 1-2 illustrates the design process used for preparing the detailed design. The design process commenced with the evaluation of the performance requirements of the panel-closure system through review of the work performed in developing the conceptual design and the "Underground Hazardous Waste Management Unit Closure Criteria for the Waste Isolation Pilot Plant Operation Phase" (Westinghouse, 1995b). The various design evaluations were 

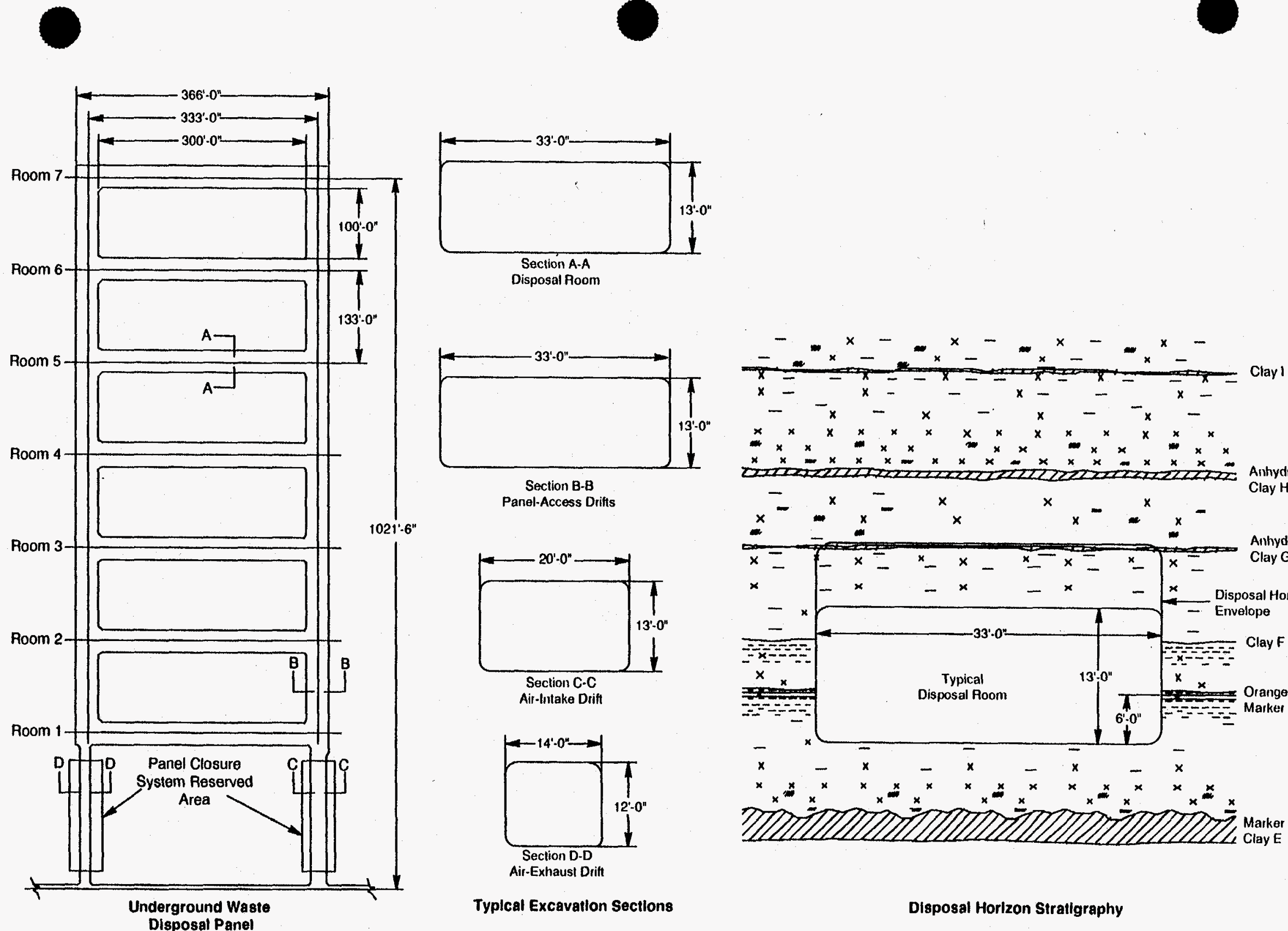

Section B-B

Panel-Access Drifts

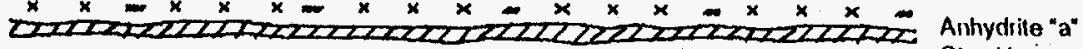
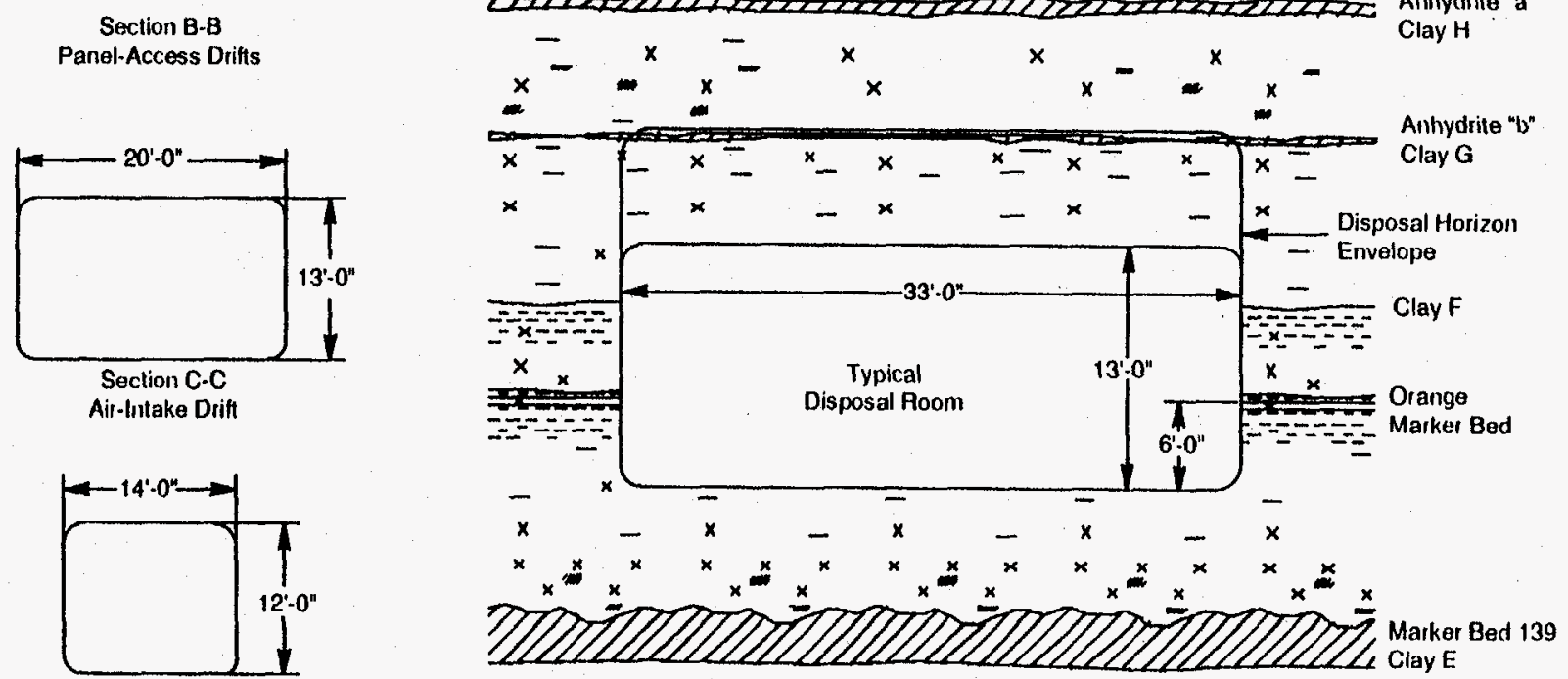

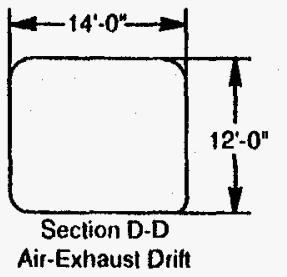

Typical Excavation Sections

Disposal Horizon Stratigraphy

Figure 1-1

Typical Facilities-Typical Disposal Panel

(After Westinghouse, 1995c) 


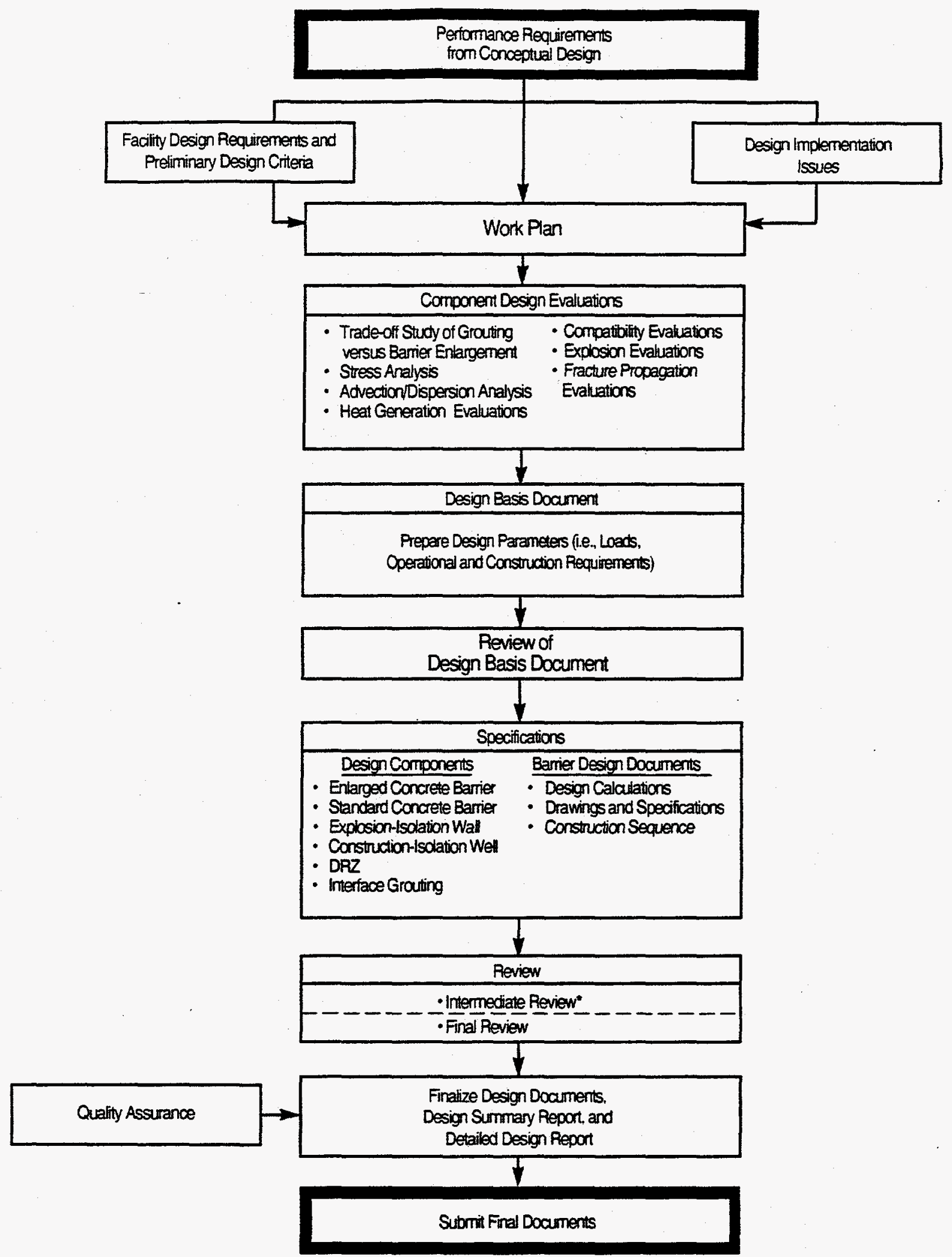

Figure 1-2

Design Process for the Panel-Closure System 
performed to address specific design-implementation issues identified by the project. The results of these design evaluations are presented in this report.

\subsection{Design Classification}

Procedure WP 09-CN3023 (Westinghouse, 1995a) was used to establish a design classification for the panel-closure system. The design classification for the panel-closure system evolved from addressing the short-term operational issues regarding the reduction of VOC migration. Figure 1-3 shows the decision flow logic process used to designate the panel-closure system as a Class IIIB structure.

\subsection{Regulatory Requirements}

The following subsections discuss the regulatory requirements specified in RCRA and MSHA for the panel-closure system.

\subsubsection{Resource Conservation and Recovery Act (40 CFR 264, 268, and 270)} In accordance with Title 40, Code of Federal Regulations (CFR), Part 264, Subpart X (40 CFR 264, Subpart X), "Miscellaneous Units," and 40 CFR 270.23, "Specific Part B Information Requirements for Miscellaneous Units," a RCRA Part B permit application has been submitted for the WIPP facility. According to 40 CFR 268.6, the DOE has opted to pursue a no-migration variance petition (NMVP) instead of treating waste to meet the land disposal restrictions (40 CFR 268) (EPA, 1995).

\subsubsection{Protection of the Environment and Human Health}

Both the draft NMVP and the WIPP RCRA Part B permit application indicate that VOCs must not exceed health-based standards beyond the WIPP site boundary. Worker exposure to VOCs, and VOC emissions will not pose greater than a $10^{-6}$ excess cancer risk to the nearest resident in order to meet health-based standards. The panel-closure system design incorporates measures to mitigate VOC migration for compliance with these standards.

\subsubsection{Closure Requirements (20 New Mexico Administrative Code 4.1, Subpart $V$ )}

The DOE will notify the Secretary of the New Mexico Environment Department in writing at least 60 days prior to the date on which partial and final closure activities are scheduled to begin. 
A. Select a system structure or component for classification.

(Start with a mitigating item)

$B$. is the system, structure. or component required to mitigate the consequences of an accident?

C. Would the system, structure, or component failure result in loss of safety functions of a Design Ciass I components?

D. Does the system, structure, or component provide any function related to nuclear materials?

E. Select a conservative accident scenario and perform salety analysis.

F. Does the cumulative radiological consequences following the accident exceed 25 Rem whole body or 75 Rem organ dose commitment to an individual at the Zone I boundary

G. Does the structure, system, operation or component conform to the Class II criteria as defined in Attachment 2?

$H$. Would the structure, system, operation or component failure result in loss of the required function of a Class II component?

1. Are special design requirements necessary to ensure that failure of the system, structure, or component will NOT resutt in a significant shutdown of the facility or inhibit accessibility or maintainability of required equipment or have special significance to health and salety of operations personnel?

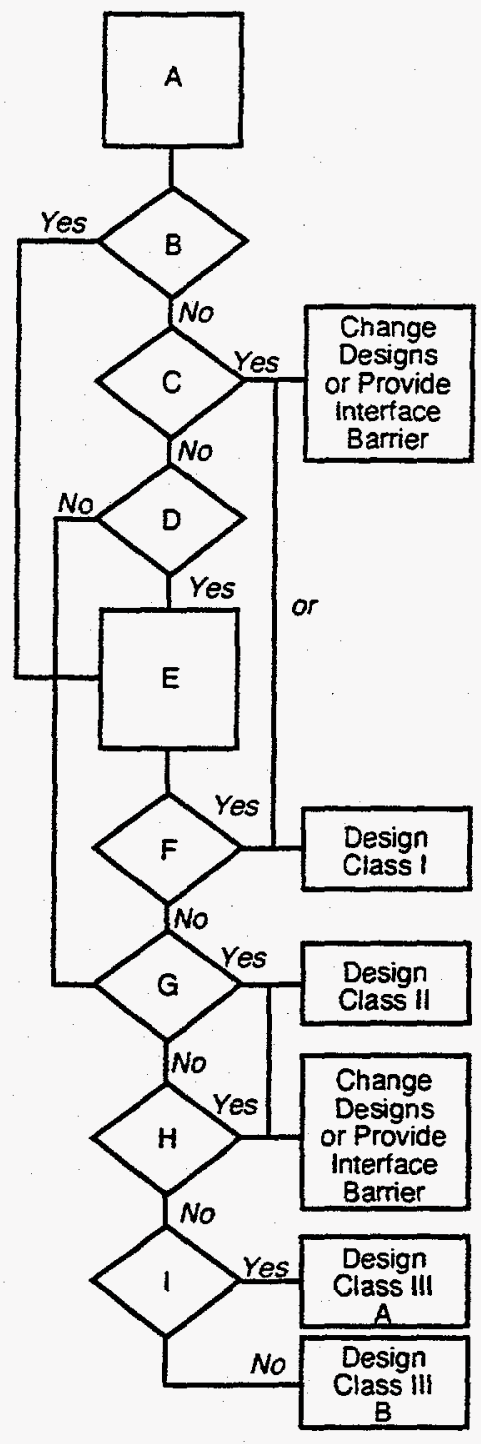

B. Y YES $\underline{X}$ NO

Descibe requirement

C. YES $\mathrm{X}$ NO

Failure mode and affected class I component

D.

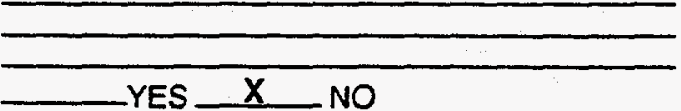

Describe function

E.

YES N/A NO

Attach safety analysis

F.

Calculate dose rates

NO

N/A

(Attach calculations to this form)

G. $Y$ YES NO

Criteria

N/A

H. YES $\mathrm{X}$ NO

Failure mode and affected Class /I component

I.

Requirements

Figure 1-3

Design Classification of the Panel-Closure System

(Modified from Westinghouse, 1995a) 


\subsubsection{Mining Safety and Health Administration}

The significance of small natural-gas occurrences within the WIPP repository is within the classification of Category IV for natural gas under the MSHA (30 CFR 57, Subpart T) (MSHA, 1987). These regulations include the hazards of methane gas and volatile dust. Category IV "applies to mines in which non-combustible ore is extracted and which liberate a concentration of methane that is not explosive nor capable of forming explosive mixtures with air based on the history of the mine or the geological area in which the mine is located." For "barriers and stoppings," the regulations provide for noncombustible materials (where appropriate) for the specific mine category and require that "barriers and stoppings" be of "substantial construction." Substantial construction implies construction of such strength, material, and workmanship that the barrier could withstand air blasts, methane detonation or deflagration, blasting shock, and ground movement expected in the mining environment.

\subsection{Report Organization}

This report presents the engineering package for the detailed design of the panel-closure system. Chapter 2.0 presents the design evaluations. Chapter 3.0 describes the design and Chapter 4.0 presents the Constructability Design Calculations Index. Chapter 5.0 shows the technical specifications. Chapter 6.0 presents the design drawings. The conclusions are presented in Chapter 7.0 and the references presented in Chapter 8.0. Appendices to this report provide detailed information to support the information contained in Chapters 2.0 through 7.0 of this report. 


\subsection{Design Evaluations}

This chapter presents the results of the various design evaluations that support the panelclosure system: (1) analyses addressing the operational requirements, and (2) analyses addressing the structural and material requirements. The first group includes air-flow analyses, an advection/dispersion analysis, and stress analyses using the Fast Lagrangian Analysis of Continua (FLAC) (Itasca, 1995), which support a trade-off study comparing grouting to removal of fracture zones in both the roof and floor. The second group addresses the issue of material compatibility with the host rock and heat-generation that may cause thermal cracking in the main concrete barriers during cement hydration. The second group also includes methane-explosion and fracture-propagation evaluations to address the dynamic pressure and subsequent temperatures generated by a postulated methane explosion.

\subsection{Analyses Addressing Operational Requirements}

The panel-closure system incorporates design features to address a range of ground conditions, including the most severe ground conditions expected in the air-intake and airexhaust drifts. The alternatives for dealing with the most severe ground conditions include excavating the fractured disturbed rock zone (DRZ) ${ }^{2}$ and installing an enlarged concrete barrier or partially enlarged concrete barrier with interface grouting or emplacing a standard concrete barrier with formation grouting. To evaluate the effectiveness of these alternatives for a panel-closure system, air-flow analyses and structural analyses were performed. The airflow analyses examined the flow of VOCs through the panel-closure system for these alternatives.

The flow of VOCs is influenced by interface stress development. At the interface, the flow was assumed to be equivalent to a fracture zone. To investigate interface-stress development and the influence of barrier shape, structural analyses were performed for the main concrete barrier. These structural analyses were then used to determine the loads on the main concrete barrier.

The following sections address the air-flow analyses, the advection/dispersion analysis, and the stress analyses that support the trade-off study for designs with or without DRZ removal for overall protection of human health and the environment and compliance at the WIPP site boundary.

\footnotetext{
${ }^{2} \mathrm{DRZ}$ removal is used in the context of the removal of fractured rock in the DRZ.
} 


\subsubsection{Air-Flow Analyses}

The purpose of the air-flow analysis was to evaluate the trade-offs among a standard concrete barrier with formation grouting, a partially enlarged concrete barrier with partial DRZ removal (roof), and a fully enlarged concrete barrier with complete DRZ removal. Subsequent analyses were performed to evaluate air flow for these alternatives. The air-flow model (DOE, 1995) was used to evaluate the effective intrinsic barrier permeability of the main concrete barrier for these alternatives and to assess VOC flow performance.

In previous studies (DOE, 1995), two air-flow models were evaluated: 1) unrestricted flow, and 2) restricted flow through a panel-closure system. Unrestricted air flow is defined as flow in which the gas pressure develops at or very near atmospheric pressure. No back pressure exists in the waste emplacement areas. Restricted flow is defined as flow in which a back pressure develops due to the restriction of flow through the barrier and the surrounding disturbed rock zone. The analyses were based on an assumed gas generation rate of 8,200 moles per panel per year ( 0.1 moles per drum per year) due to microbial degradation, an expected volumetric closure rate of $28,000 \mathrm{ft}^{3}\left(800 \mathrm{~m}^{3}\right)$ per year due to salt creep, the expected headspace concentration for nine VOCs, and the expected air dispersion from the exhaust shaft to point of compliance, the WIPP site boundary. The previous analyses indicated that the panel-closure system would limit the concentration (Figures 2-1 and 2-2) of each VOC to a small fraction of the health-based exposure levels during the operational period at the WIPP site boundary.

\subsubsection{Evaluation Procedure}

In the following analysis, the gases generated in the waste-emplacement area are in part compressed in the void space within a panel and in part flow into the main return air. The following assumptions were made in this model:

- That the gases (including VOCs) within the void space will obey the ideal gas law. The gases will be generated at a rate of 0.1 moles per drum per year and will be stored by an increase in gas pressure. The rate of pressure buildup will be so gradual that it occurs at constant temperature.

- That volumetric reduction due to creep will reduce the void space at a rate of $28,000 \mathrm{ft}^{3}\left(800 \mathrm{~m}^{3}\right)$ per year and will result in pressurization.

- That the flow of gas out of the panel will obey Darcy's law under quasisteadystate conditions. Under quasisteady-state conditions, the air pressure within the panel-closure system will change so gradually that the compressive storage of the air within the void space of the panel-closure system could be neglected. 


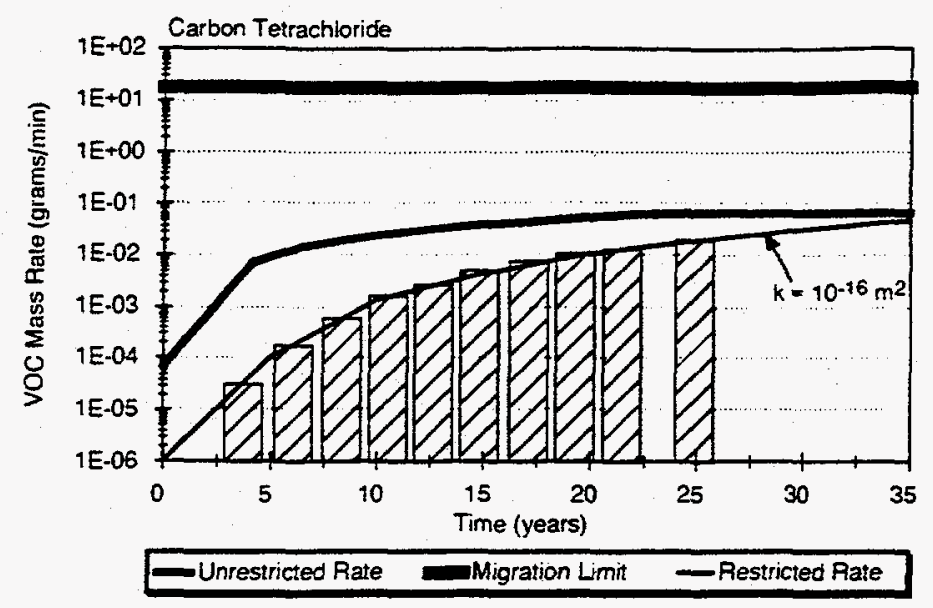

Carbon Disulfide
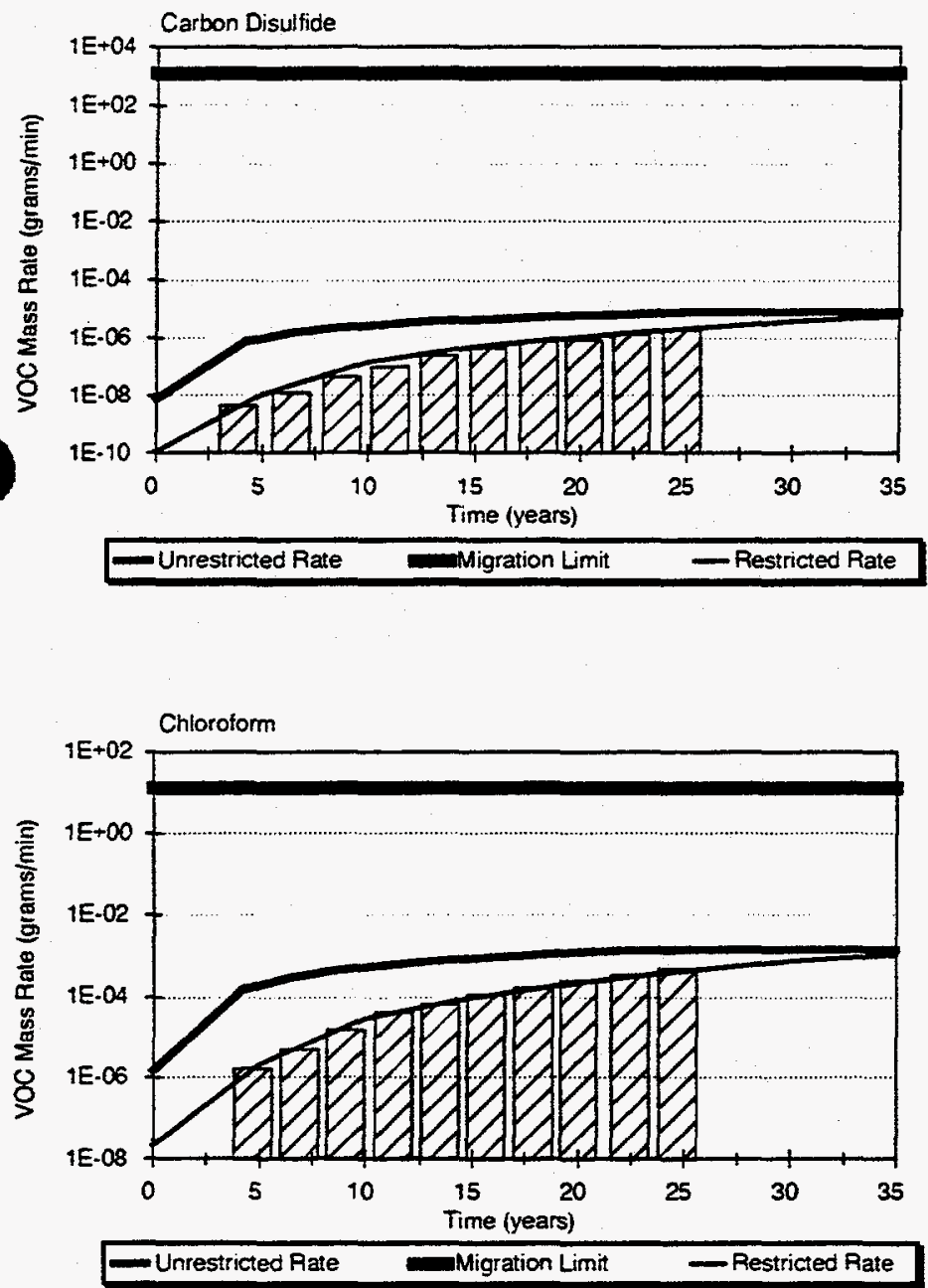

Chiorobenzene
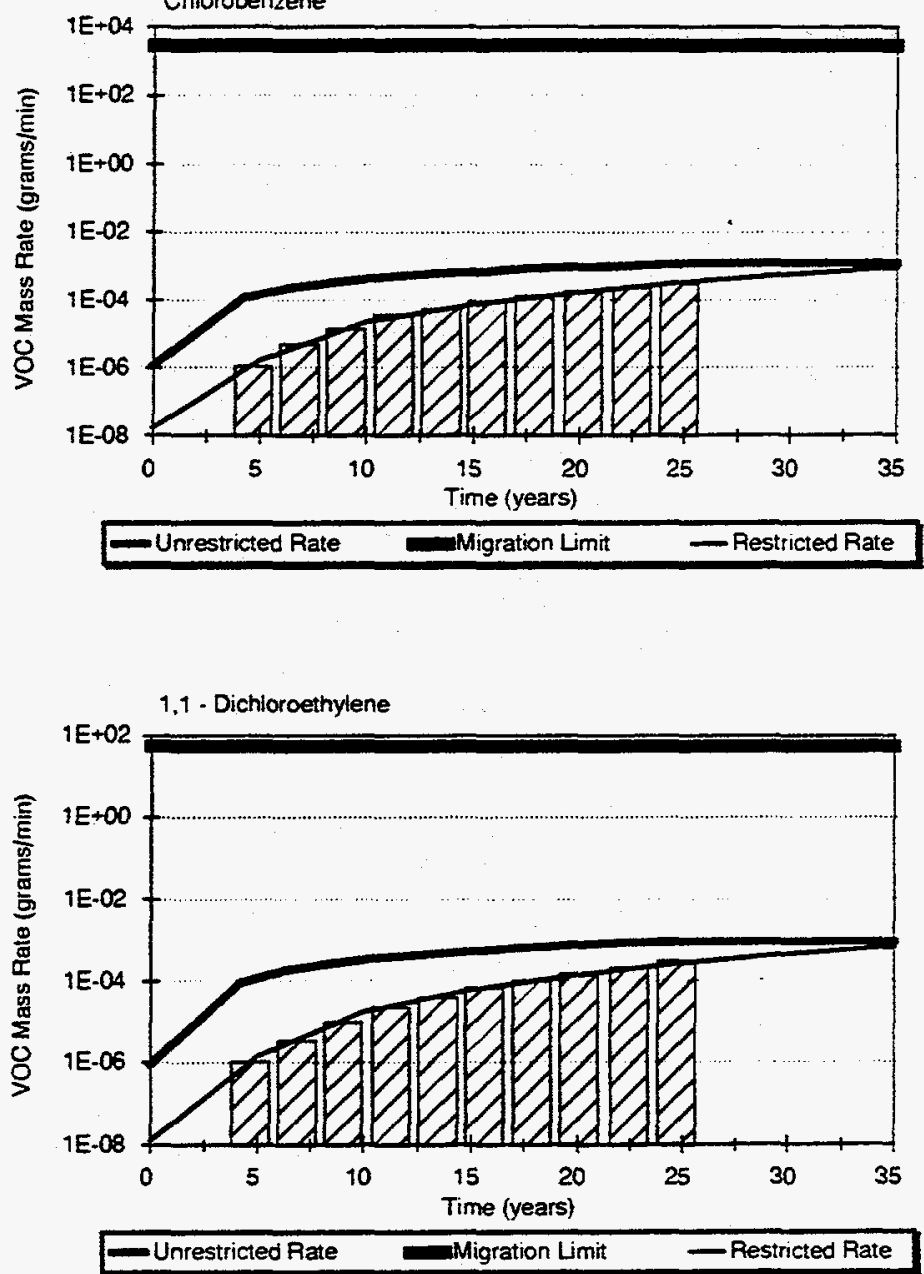

Figure 2-1

Closed-Panel Release Rate Versus Limit Comparison for Carbon Tetrachloride and Other VOCs

(After DOE, 1995) 

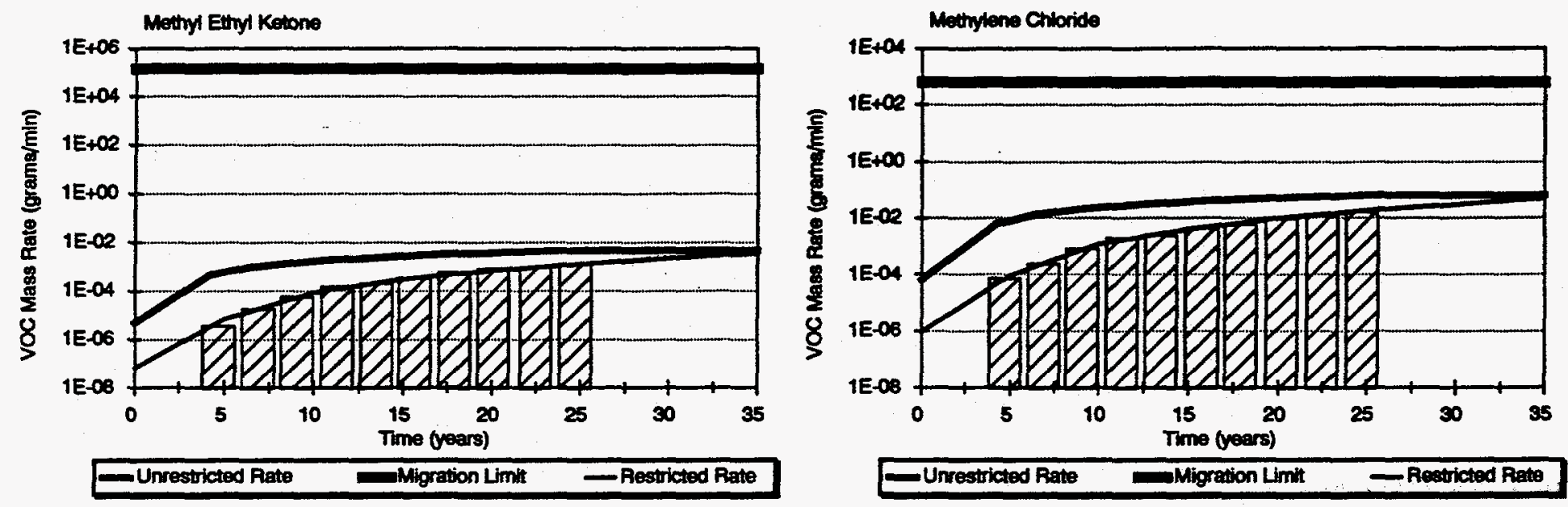

1,1,2,2 - Tetrectioroethane
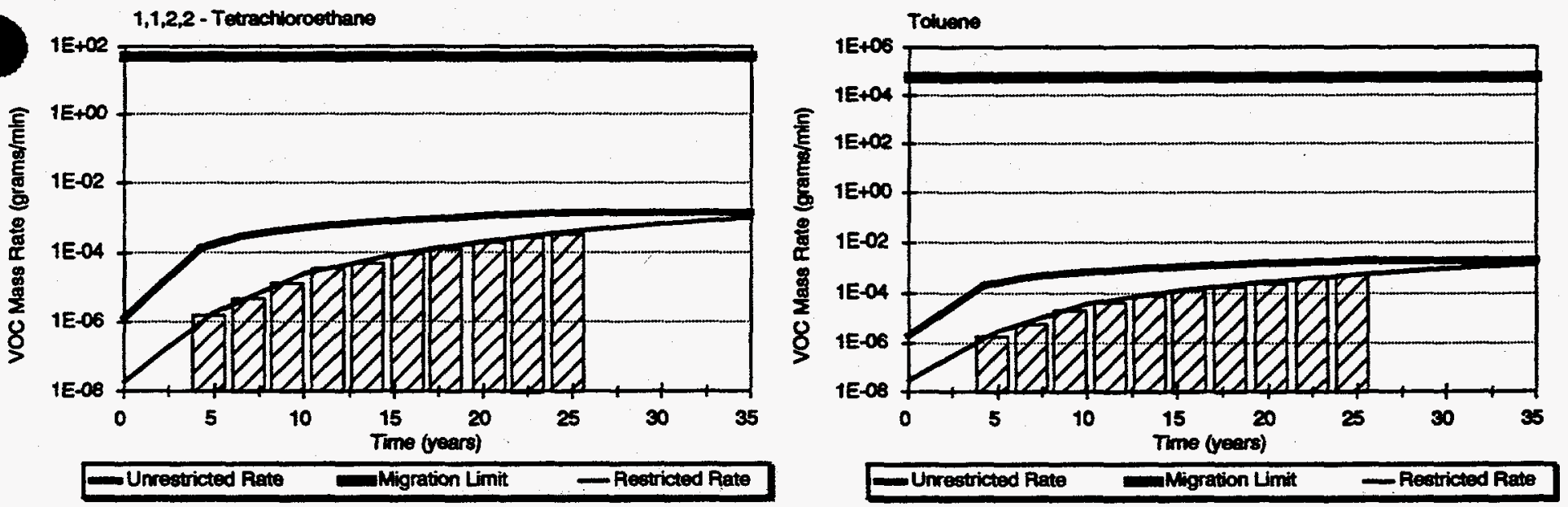

Figure 2-2

\section{Closed-Panel Release Rate Versus Limit Comparison for Other VOCs (After DOE, 1995)}


- That the rates of gas generation, air outflow, and change in compressive storage will balance.

- That hydrodynamic dispersion will be neglected in the analysis.

- That the analysis will consider the superposition of flow rates from individual panels according to the operating schedule for an operational life of at least 35 years.

The air flow under these assumptions follows a nonlinear first-order ordinary differential equation. The model is characterized by molar gas generation and a reduction in void volume that results in an increase in air pressure.

The problem can be stated by solving the system of nonlinear ordinary differential equations as derived in Appendix A:

$$
\frac{d P}{d t}=R * T * \frac{\left(g_{r}-\frac{P}{R T} * C * \frac{P-P_{a t m}}{\gamma}\right) * V-n \frac{d V}{d t}}{V^{2}}
$$

$$
\frac{d n}{d t}=g_{r}-\frac{P}{R * T} * C * \frac{P-P a t m}{\gamma}
$$

where

$$
\begin{array}{ll}
\mathrm{dt} & =\text { Change in time (years) } \\
\mathrm{R} & =\text { Universal gas constant } \\
\mathrm{T} & =\text { Absolute temperature } \\
\mathrm{n} & =\text { Moles of gas in the panel that is a function of time } \\
\mathrm{P} & =\text { Pressure } \\
\mathrm{P}_{\mathrm{atm}} & =\text { Atmospheric pressure } \\
\mathrm{C} & =\text { Conductance of the panel-closure system }=K_{s} * \frac{A}{L} \\
\mathrm{~K}_{\mathrm{s}} & =\text { Air conductivity of the panel-closure system } \\
\mathrm{A} & =\text { Cross sectional area of the panel-closure system } \\
\mathrm{L} & =\text { Flow path length of the panel-closure system } \\
\gamma & =\text { Air density } \\
\mathrm{g}_{\mathrm{r}} & =\text { Gas generation rate } \\
\mathrm{V} & =\text { Panel volume }
\end{array}
$$




$$
\begin{aligned}
& \frac{d V}{d t} \quad=\text { Panel volumetric-closure rate } \\
& \frac{d P}{d t} \quad=\text { Panel-pressure rate } \\
& \frac{d n}{d t} \quad=\text { Panel-molar storage rate. }
\end{aligned}
$$

The above relationships are subject to the following initial conditions: (1) that the pressure in the panel will be atmospheric, and (2) the moles equals the moles of gas occupying the initial panel void volume at the temperature of the repository.

The analysis assumed that the volume of the waste is equal to the total waste capacity of a panel $\left(600,000 \mathrm{ft}^{3}\left[16,990 \mathrm{~m}^{3}\right]\right)$ (DOE, 1994a) times the assumed average solid volume of the waste drums (23 percent) (IT, 1994). The analysis uses a solid waste volume equal to $138,000 \mathrm{ft}^{3}\left(3,910 \mathrm{~m}^{3}\right)$ for the panel and this volume remains constant during the operational life of the panel. The analysis then evaluates the void volume at panel closure, approximately four years after panel excavation.

The waste-emplacement capacity of a panel includes the seven rooms and the panel-access drifts from Room 1 to Room 7. The analysis uses closure rate and total closure data from the Geotechnical Analysis Report (DOE, 1994b). A combination of field data and empirical analysis is used to determine long-term closure rates for 35 years as presented in Appendix B.

The effective conductivity $\left(\mathrm{K}_{\mathrm{s}}\right)$ can be further expressed in terms of an effective intrinsic panel-closure system permeability as (Freeze and Cherry, 1979):

$$
K_{s}=\frac{k_{s} * \rho * g}{\mu}
$$

where

$$
\begin{array}{ll}
\mathrm{K}_{\mathrm{s}} & =\text { Air conductivity } \\
\mathrm{k}_{\mathrm{s}} & =\text { Effective concrete barrier permeability }\left(\mathrm{m}^{2}\right)
\end{array}
$$




$\begin{array}{ll}\rho & =\text { Mass density } \\ \mathrm{g} & =\text { Acceleration due to gravity } \\ \mu & =\text { Absolute viscosity. }\end{array}$

The calculations assumed that the cross-sectional area for flow through the DRZ and the panel-closure system will equal 9 times the air-intake and air-exhaust area or that the DRZ extends out 3 radii from the center. Case and Kelsall (1986) evaluated permeability measurements performed by Peterson et al. (1985). These data showed a zone of increased permeability $\left(10^{-18}\right.$ to $10^{-20} \mathrm{ft}^{2}\left[10^{-19} \mathrm{~m}^{2}\right.$ to $\left.10^{-21} \mathrm{~m}^{2}\right]$ ) from ( 3 to $42 \mathrm{ft}$ [ 1 to $14 \mathrm{~m}$ ). The boundary of the DRZ used in the analysis falls within their range.

The effective intrinsic permeability was calculated by considering the permeabilities over their respective areas of the various media, as presented in Table 2-1. The assumed flow path length equaled $26 \mathrm{ft}(7.92 \mathrm{~m})$. The effective permeability was equal to $1 \times 10^{-15} \mathrm{ft}^{2}$ $\left(10^{-16} \mathrm{~m}^{2}\right)$ for the standard concrete barrier with formation grouting. For an enlarged concrete barrier with complete DRZ removal, the effective permeability would equal $1 \times 10^{-16} \mathrm{ft}^{2}\left(10^{-17} \mathrm{~m}^{2}\right)$.

Table 2-1

Intrinsic Permeability of Flow Components

\begin{tabular}{|l|c|c|l||}
\hline \multirow{2}{*}{\multicolumn{1}{c|}{ Component }} & \multicolumn{2}{c|}{ Intrinsic Permeability } & \multicolumn{1}{|c|}{ Reference } \\
\cline { 2 - 4 } & $\mathrm{tt}^{2}$ & $\mathrm{~m}^{2}$ & \multicolumn{1}{|c|}{ Reok and Case, 1991 } \\
\hline \hline Dilated salt & $10^{-18}$ & $10^{-19}$ & Cook \\
\hline Fractured salt (grouted) & $10^{-15}$ & $10^{-16}$ & DOE, 1995 \\
\hline Clay seams & $10^{-16}$ & $10^{-17}$ & Freeze and Cherry, 1979 \\
\hline Concrete barrier & $10^{-18}$ & $10^{-19}$ & Gulick and Wakeley, 1989 \\
\hline Marker Bed 139 & $10^{-15}$ & $10^{-16}$ & DOE, 1995 \\
\hline Interface zone & $10^{-10}$ & $10^{-11}$ & Fernandez et al., 1994 \\
\hline
\end{tabular}

\subsubsection{Modeling Results}

Figure 2-3 shows that, after closure, the pressure within the panel will build up gradually, due to the large compressibility of the panel void space relative to the air flow rate out of the 


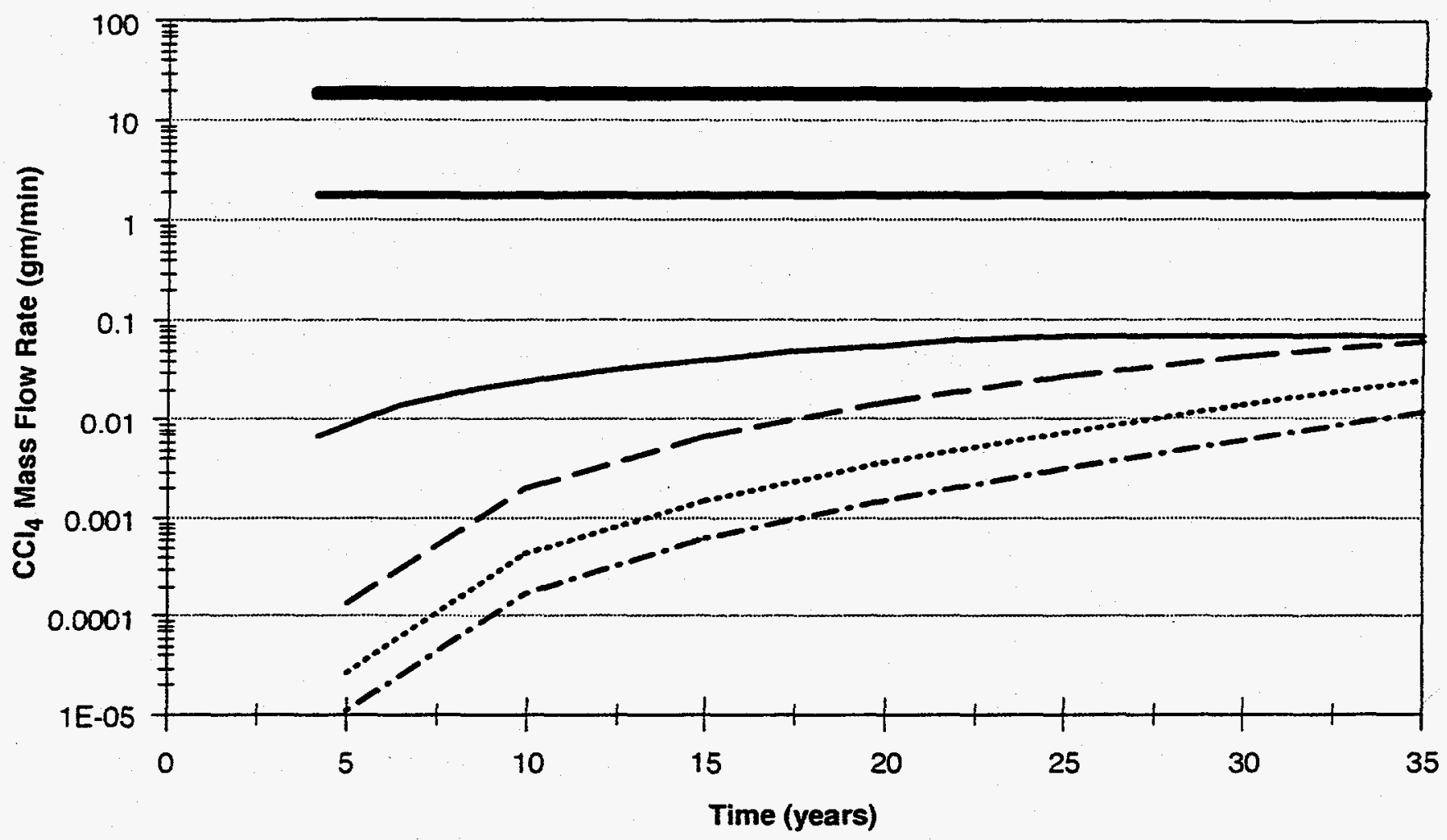

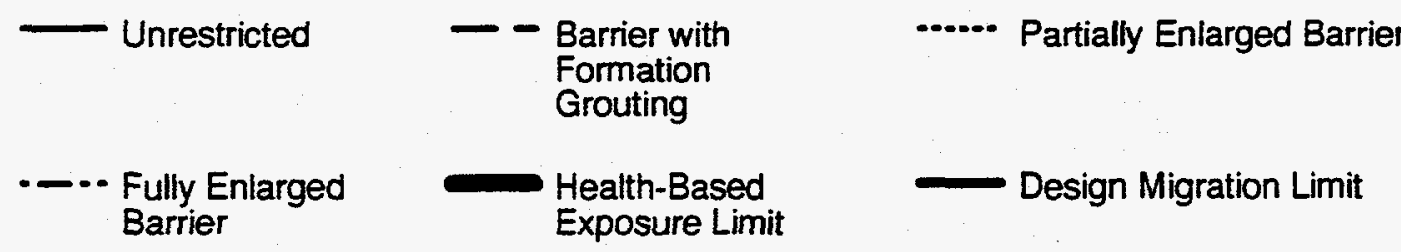

Figure 2-3

Air-Flow Analyses Using Several Alternatives 
panel. The panel-closure system will be effective in restricting flow to a value less than the unrestricted flow rate during this period.

\subsubsection{Conclusions}

The air-flow model (DOE, 1995) was used to predict the performance of a grouted standard concrete barrier, a partially enlarged concrete barrier, and a fully enlarged concrete barrier for the mass flow rate of carbon tetrachloride. The analysis suggests that the alternate barrier systems would be effective in restricting air flow over the operational period and that the panel-closure system will restrict flow to at least 1 order of magnitude below the health-based migration limit in preventing the release of VOCs (Figure 2-3).

\subsubsection{Advection/Dispersion Evaluation}

The purpose of the advection/dispersion evaluation was to assess contaminant transport time through various media. The panel-closure system will be constructed to reduce the air flowrate by using compressive storage in the panel void space. The model (DOE, 1995) showed that the panel-closure system will restrict transient flow for at least the operational period to an effective gas-generation rate that is substantially less than the steady state flow rate of about $35,000 \mathrm{ft}^{3}\left(1,000 \mathrm{~m}^{3}\right)$ per year.

\subsubsection{Evaluation Procedure}

As panel pressure develops with time, the gases generated from the waste will travel through the panel-closure system to the active underground workings. The model (DOE, 1995) considered that the VOC concentration front will instantaneously develop in the active underground workings and the gases would advect due to velocity variations as panel pressures increased. The more detailed analysis presented below considers the flow distribution and how the concentration of VOCs would be affected by the mechanisms of advection and dispersion. If movement were slow through the panel-closure system, the breakthrough would be delayed.

The relative significance of each of the air-flow zones can be evaluated by studying flow conductance. The flow conductance through the panel-closure system is given by the equation:

$$
C=\sum \frac{K_{i} * A_{i}}{L_{i}}
$$


where:

$$
\begin{array}{ll}
\mathrm{C} & =\text { Flow conductance } \\
\mathrm{K}_{\mathrm{i}} & =\text { Air conductivity of the } \mathrm{i}^{\text {th }} \text { component } \\
\mathrm{A}_{\mathrm{i}} & =\text { Cross sectional area of the } \mathrm{i}^{\text {th }} \text { component } \\
\mathrm{L}_{\mathrm{i}} & =\text { Length. }
\end{array}
$$

The conductance through the panel-closure system will depend on the cross-sectional area and the length. Table 2-2 summarizes the values for each component. The calculations show that flow through fractured salt and MB 139 will dominate the conductance.

Table 2-2

\section{Air Conductance Through System Components}

\begin{tabular}{||l|c|c|c|c|}
\hline \multicolumn{1}{|c|}{ Component } & $\begin{array}{c}\text { Effective } \\
\text { Porosity }\end{array}$ & $\begin{array}{c}\text { Air Conductivity } \\
\text { (meters per second) }\end{array}$ & $\begin{array}{c}\text { Approximate } \\
\text { Cross-Sectional } \\
\text { Area } \\
\text { (meter) }\end{array}$ & $\begin{array}{c}\text { Conductance } \\
\text { per Unit } \\
\text { Length } \\
\text { (meter } \\
\text { per } \\
\text { second) }\end{array}$ \\
\hline \hline Dilated salt & 0.001 & $6.2 \times 10^{-14}$ & 170 & $1.0 \times 10^{-11}$ \\
\hline Fractured salt & 0.040 & $6.2 \times 10^{-10}$ & 16 & $9.9 \times 10^{-9}$ \\
\hline Clay seams & 0.400 & $6.2 \times 10^{-12}$ & 0.09 & $5.6 \times 10^{-13}$ \\
\hline Marker Bed 139 & 0.040 & $6.2 \times 10^{-11}$ & 11 & $6.8 \times 10^{-10}$ \\
\hline Concrete barrier & 0.200 & $6.2 \times 10^{-14}$ & 27 & $1.7 \times 10^{-12}$ \\
\hline
\end{tabular}

The contaminant breakthrough of VOCs through the panel-closure system under the assumption of advection will occur when the contaminant front traversed the length. The average linear velocity equals the Darcy flux divided by the effective porosity for the various flow components. The average linear velocity that varies with time is given by:

$$
V(p(t))_{a v g_{i}}=\frac{K_{i} *\left(p(t)-p_{a t m}\right)}{n_{e} * L * \gamma}
$$


where:

$$
\begin{array}{ll}
\mathrm{V}(\mathrm{p}(\mathrm{t}))_{\mathrm{avg}_{\mathrm{i}}} & =\text { Average linear velocity for the } \mathrm{i}^{\text {th }} \text { component } \\
\mathrm{K}_{\mathrm{i}} & =\text { Air conductivity } \\
\mathrm{p}(\mathrm{t}) & =\text { Panel pressure as a function of time } \\
\mathrm{p}_{\mathrm{atm}} & =\text { Atmospheric pressure } \\
\mathrm{L} & =\text { Length of the barrier } \\
\gamma & =\text { Air density } \\
\mathrm{n}_{\mathrm{e}} & =\text { Effective porosity. }
\end{array}
$$

The second evaluation of the air-flow modeling evaluated the effects of hydrodynamic dispersion on contaminant transport, using a one-dimensional dispersion model. This model was chosen to evaluate the effects of dispersion on VOC migration rates through the panelclosure system. To isolate the effects of mechanical dispersion, molecular diffusion was considered insignificant. The advection-dispersion equation is given by Freeze and Cherry (1979):

$$
C=\frac{C_{0}}{2}\left[\operatorname{erfc}\left(\frac{L-V_{x} * t}{2 \sqrt{D_{L} * t}}\right)+\exp \left(\frac{V_{x}}{D_{l}}\right) \operatorname{erfc}\left(\frac{L+V_{x} * t}{2 \sqrt{D_{L} * t}}\right)\right]
$$

where:

$$
D_{L}=a_{L} V_{x}+D^{*}
$$

and

$$
\begin{aligned}
& \text { erfc }=\text { Complimentary error function } \\
& \mathrm{D}_{\mathrm{L}}=\text { Longitudinal coefficient of dispersion } \\
& \mathrm{a}_{\mathrm{L}}=\text { Dispersivity } \\
& \mathrm{V}_{\mathrm{x}}=\text { Average linear velocity } \\
& \mathrm{C}^{*}=\text { Concentration of contaminant at time } \mathrm{t} \\
& \mathrm{D}^{*}=\text { Molecular diffusion } \\
& \mathrm{C}_{0}=\text { Initial concentration } \\
& \mathrm{t}=\text { Time } \\
& \mathrm{L}=\text { Length. }
\end{aligned}
$$


- That the air-flow velocity will be constant.

- That the gases (including VOCs) within the void space will obey the ideal gas law.

- That the flow of air out of the panel will obey Darcy's law under quasisteadystate conditions. Under quasisteady-state conditions, the air pressure within the panel-closure system will change so gradually that the compressive storage of air within the void space of the air-intake and air-exhaust drifts will be neglected.

- That two-phase flow and interactions between air and brine will be neglected, although the resaturation of salt would tend to reduce the flow of VOCs through the barrier system.

The air-flow velocity was calculated for each component of the panel-closure system using the maximum pressure determined from the air-flow model (DOE, 1995). Once a constant velocity was calculated for each component, the concentration as a function of time was determined for each of the panel-closure system components: fractured salt, fractured anhydrite, clay seams, and the standard concrete barrier. ${ }^{3}$ To study the effects of dispersion, a range of different dispersivities was used. Mass flow as a function of time was then determined for carbon tetrachloride and was summed over all components of the panel-closure system.

\subsubsection{Modeling Results}

In the model presented for air flow, the pressure varies as a function of time for flow through the panel-closure system. This will result in a change in the average linear velocity as a function of time that was calculated for each of the various components: fractured salt, MB 139, clay seams, and the panel-closure system. The average linear velocity was then integrated over time.

Breakthrough times for a panel-closure system length of $40 \mathrm{ft}(12 \mathrm{~m})$ were computed (Figure 2-4). The analysis suggests that contaminant breakthrough through fracture zones may occur within one to several years, while contaminant breakthrough in the barrier and the dilated salt would not be expected during the WIPP operational period. The analysis shows that for fractured components with high air conductivity and low fracture porosity, large linear velocities result, with breakthrough occurring within months of panel closure. For the

\footnotetext{
${ }^{3}$ No credit is taken for the explosion isolation or construction isolation wall which is a conservative assumption.
} 


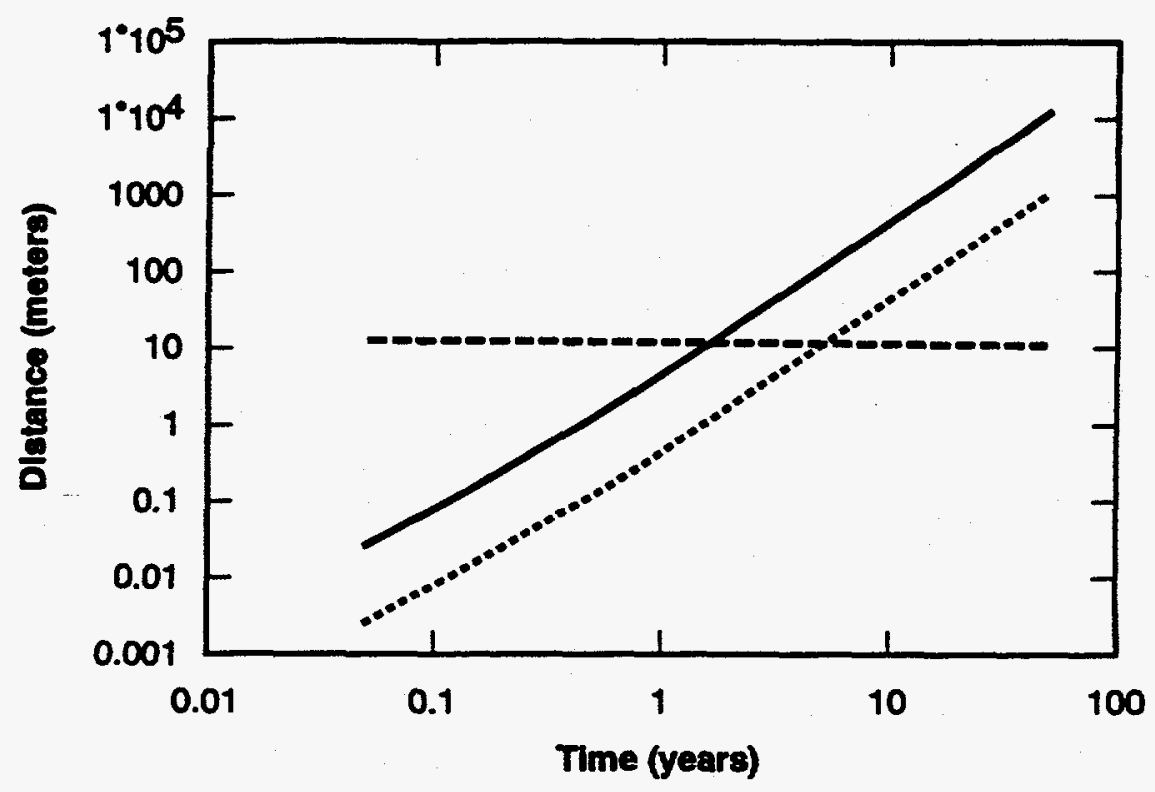

- Fractured Salt

.......... MB 139

-.-- Path Length

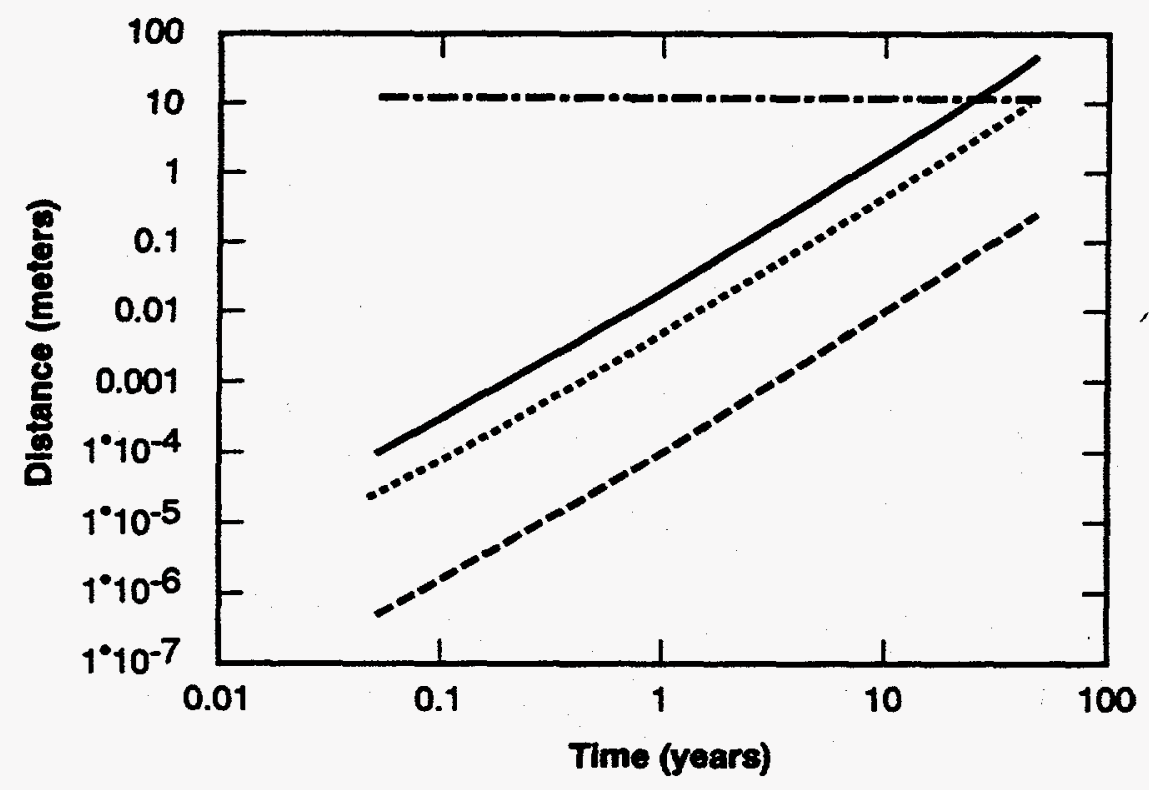

Dilated Salt

........ Clay Seams

----- Concrete

-..- Path Length

Figure 2-4

Breakthrough Time for VOCs through Several Media 
other components, with much lower air conductivity and higher effective porosity the breakthrough would occur many years after panel closure.

In summary, the results of more detailed air-flow modeling suggest the appropriateness of the model for the instantaneous breakthrough of contaminants and the insignificance of dispersion. The results of the air-flow model emphasize the importance of treating fracture zones, either by removal or by grouting for restricting the flow of VOCs.

The results from the second evaluation support the conclusion that breakthrough of VOCs will occur rapidly through the dominant paths of the fractured salt and fractured anhydrite. Because of this, the effects of dispersion will be insignificant on the VOC mass flux.

\subsubsection{Conclusion}

In conclusion, because air-flow modeling results show that breakthrough will occur rapidly and that the effects of hydrodynamic dispersion will be insignificant, the air-flow model (DOE, 1995) is conservative and appropriate.

\subsubsection{Stress Analysis}

The purpose of the stress analysis was to evaluate the interaction of the main concrete barrier of the panel-closure system with the surrounding salt for different combinations and geometries. The panel-closure system will consist of: (1) a standard concrete barrier or (2) an enlarged concrete barrier. Options (1) and (2) will contain interface grouting and be combined with an explosion-isolation or construction-isolation wall. The walls will isolate the concrete barrier from the waste-emplacement panel and the effects of a postulated methane explosion. Stresses are expected to develop in the concrete-barrier component due to continued primary and secondary creep closure of the air-intake and air-exhaust drifts after installation of the concrete barrier. An estimate of the stress levels expected in the concrete barrier determined the deformability and strength required for the concrete. The development of stresses in the salt around the concrete barrier was also evaluated to estimate the time required for DRZ healing for these options.

\subsubsection{Evaluation Procedure}

The evaluation was performed using the FLAC computer code (Itasca, 1995). Six detailed structural-analysis models were prepared to evaluate the salt/structural interaction of the proposed system. These models included two transverse-plane strain models across the airintake and air-exhaust drifts associated with a waste-emplacement panel, two long 
axisymmetric models, and two short axisymmetric models. The properties used in these models were taken from the Backfill Engineering Analysis Report (IT, 1994) as presented in Appendix C.

\subsubsection{FLAC Models}

Since 1991, FLAC has been used to model underground excavations at the WIPP. FLAC is a two-dimensional, explicit finite difference code that simulates the behavior of rock and soillike structures. The WIPP Reference Creep Law is built into FLAC and has been verified to U.S. Nuclear Regulatory Commission standards (Itasca, 1995). In addition, FLAC has been verified against the WIPP Second Benchmark Problem (Krieg, 1984). The following subsections describe the geometry and boundary conditions of the model used in the FLAC analysis.

Plane-Strain Model Geometry. Two cross-sectional transverse plane-strain models were run using the air-intake and air exhaust drift geometries. These models used a simplified stratigraphy for approximately $250 \mathrm{ft}(75 \mathrm{~m})$ above and below the excavation horizon (Figure 2-5). The models included the interaction of the excavation and the main concrete barrier with MB 139 over time. The cross-sectional dimension of the air-intake drift is 13 by $20 \mathrm{ft}$ ( 4 by $6 \mathrm{~m}$ ), while the air-exhaust drift is 12 by $14 \mathrm{ft}(3.6 \mathrm{~m}$ by $4.3 \mathrm{~m})$. Each model was run with the initial excavation and allowed to creep for a period of 5 years, ${ }^{4}$ the time expected for panel excavation and waste emplacement. After 5 years, the drift at the concrete barrier location was excavated just beyond Clay $\mathrm{G}$ and Clay $\mathrm{E}$, removing MB 139 , and the ribs were excavated to curved segments between these clays. Each model was then run for an additional month simulating the time required to excavate the enlarged area and install the concrete barrier. After the enlarged excavation was open for one month, the model was continued with the installed concrete barrier. The actual construction schedule may be longer for the enlarged barrier; however, the effects on long-term interface stress buildup will be insignificant. As the stresses increased in the concrete barrier and the surrounding salt the model was run for an additional 35 years, representing the required period of performance for a concrete barrier.

\footnotetext{
${ }^{4}$ For Panel One, the period between excavation and barrier emplacement would be greater than 5 years. A longer period of time might result in more bed separation. However, since fractured salt is removed to Clay $G$ and the barrier is placed over a short period, the design is considered robust, and the effects of a longer period for Panel One are insignificant.
} 


\section{Legend \\ $\Delta$ Fixed node \\ of Roller \\ $\downarrow \downarrow$ Stress boundary}

Material Models

Concrete bulkhead

77 WIPP salt

Mohr-Coulomb Anhydrite Beds

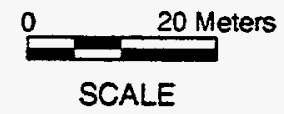

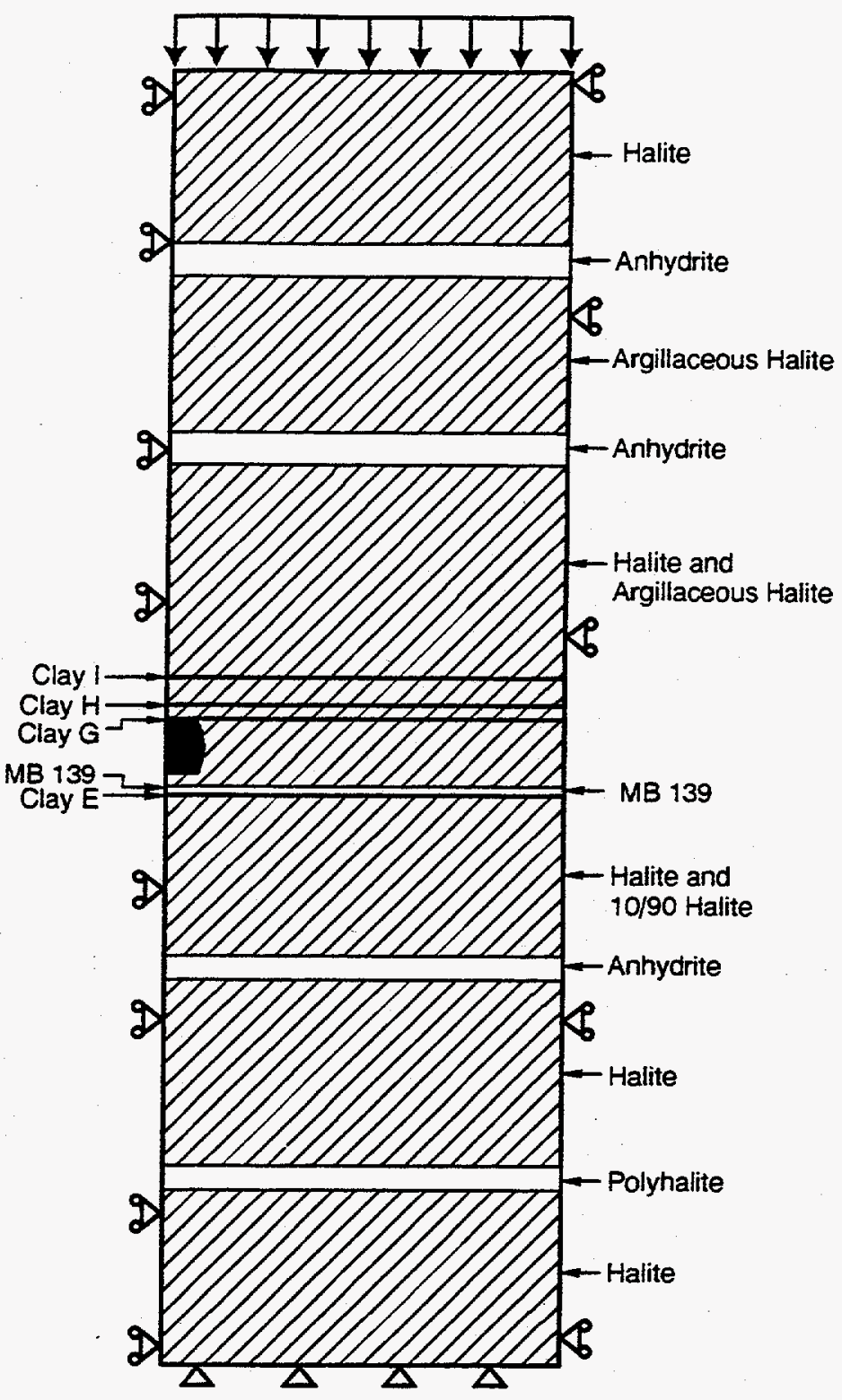

Figure 2-5 Transverse Model for FLAC Analysis 
Axisymmetric Models. Four axisymmetric models were run to evaluate the long-term loadings expected on the ends of the concrete barrier. The models (Figure 2-6) were simplified using a homogeneous salt and radial loading. The model for the concrete barrier was symmetrical around the central axis. The cases illustrate that the presence of the barrier ends will result in a longer cylindrical barrier, and that the shorter barrier with the two plug ends will result in a more tapered shape.

Material Properties Used in Modeling. The material properties used for the reference stratigraphy presented in the Backfill Engineering Analysis Report (IT, 1994) were used in the FLAC analysis. These properties (Appendix C) included the elastic, primary creep, and secondary creep constitutive properties of the halite, polyhalitic halite, and argillaceous halite. They also included the elastic properties of the anhydrite and the concrete.

Modeling Results-Transverse Plane-Strain Models. The results of the transverse plane-strain models suggest that higher stresses will form in MB 139 following excavation, but that after barrier emplacement, an increase in barrier-confining stress and a reduction of shear stress will occur in and around the barrier. The results further suggest that substantial uniform confining stresses will develop as the barrier is subjected to the secondary salt creep.

Modeling Results-Axisymmetric Models. The results of the axisymmetric models agree with the results of the transverse models for the prediction of interface stress and suggest the appropriateness of an axisymmetric model to evaluate the long-term stress abutment zone effects. The modeling results for the longer cylindrical barrier suggest that the radial stresses increase by a factor of 2 at the ends of the barrier. The high-stress concentration at the ends of the barrier extends a distance of several meters. Tensile stress develops at the ends of the longer cylindrical barrier. The short axisymmetric barrier, with the design achieving a more tapered configuration, shows that a more uniform state of compression develops all around the barrier. The principal stress results after a period of 30 years for this barrier with DRZ removal are presented in Figure 2-7. These results show that the barrier is in a state of overall compression.

\subsubsection{Stress Analysis of the Concrete Barrier on an Elastic Foundation} An analysis was performed treating the concrete barrier as a beam on an elastic foundation. After several years it is expected that loads would develop uniformly in the concrete barrier; however, the concrete barrier may be subjected initially to nonuniform loading (Figure 2-8). 


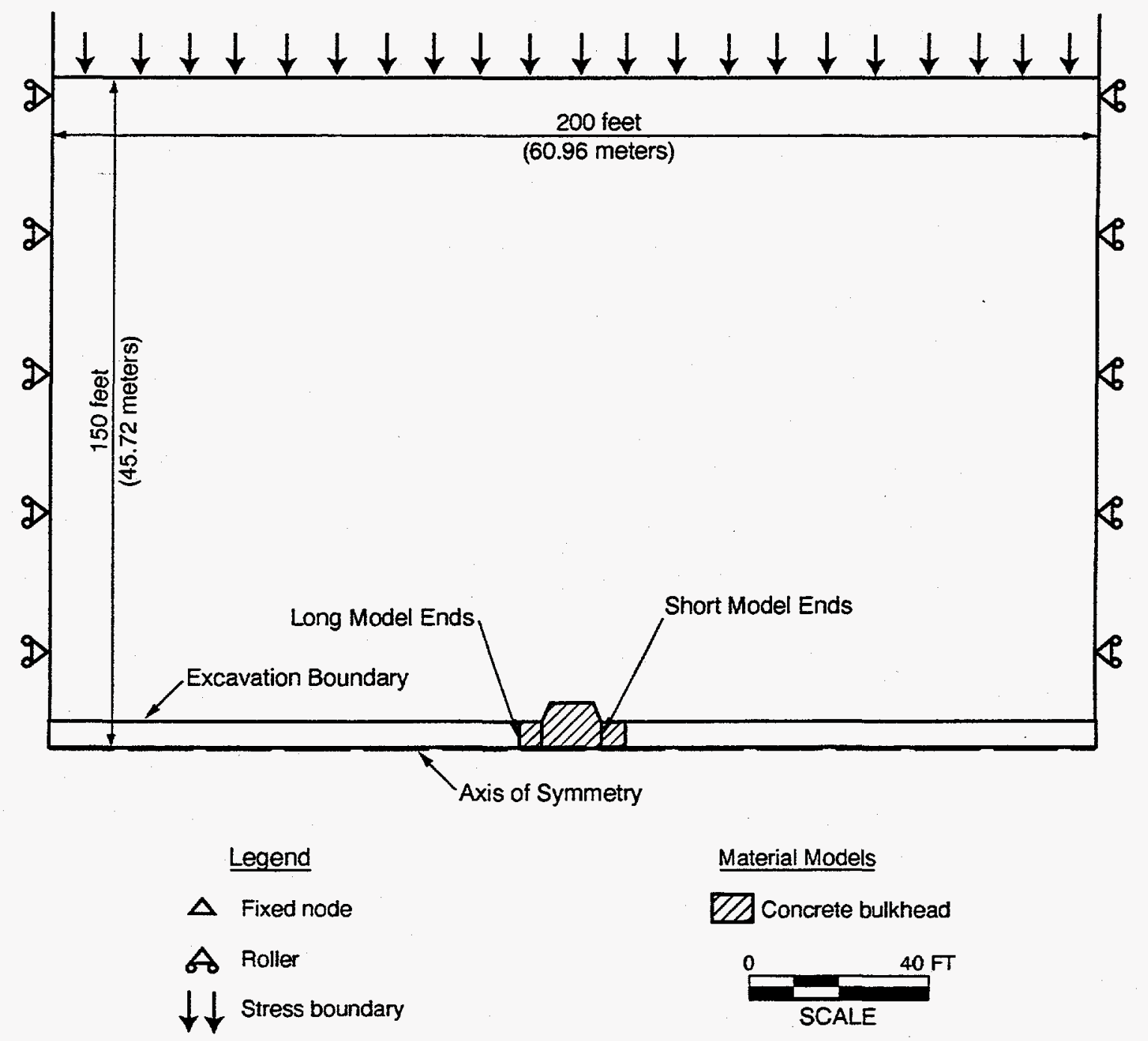

Figure 2-6

Axisymmetric Models for FLAC Analysis 
JOB TITLE : Short Axisymmetric Model for Intake Drift - 30 Years After Plug Emplacement

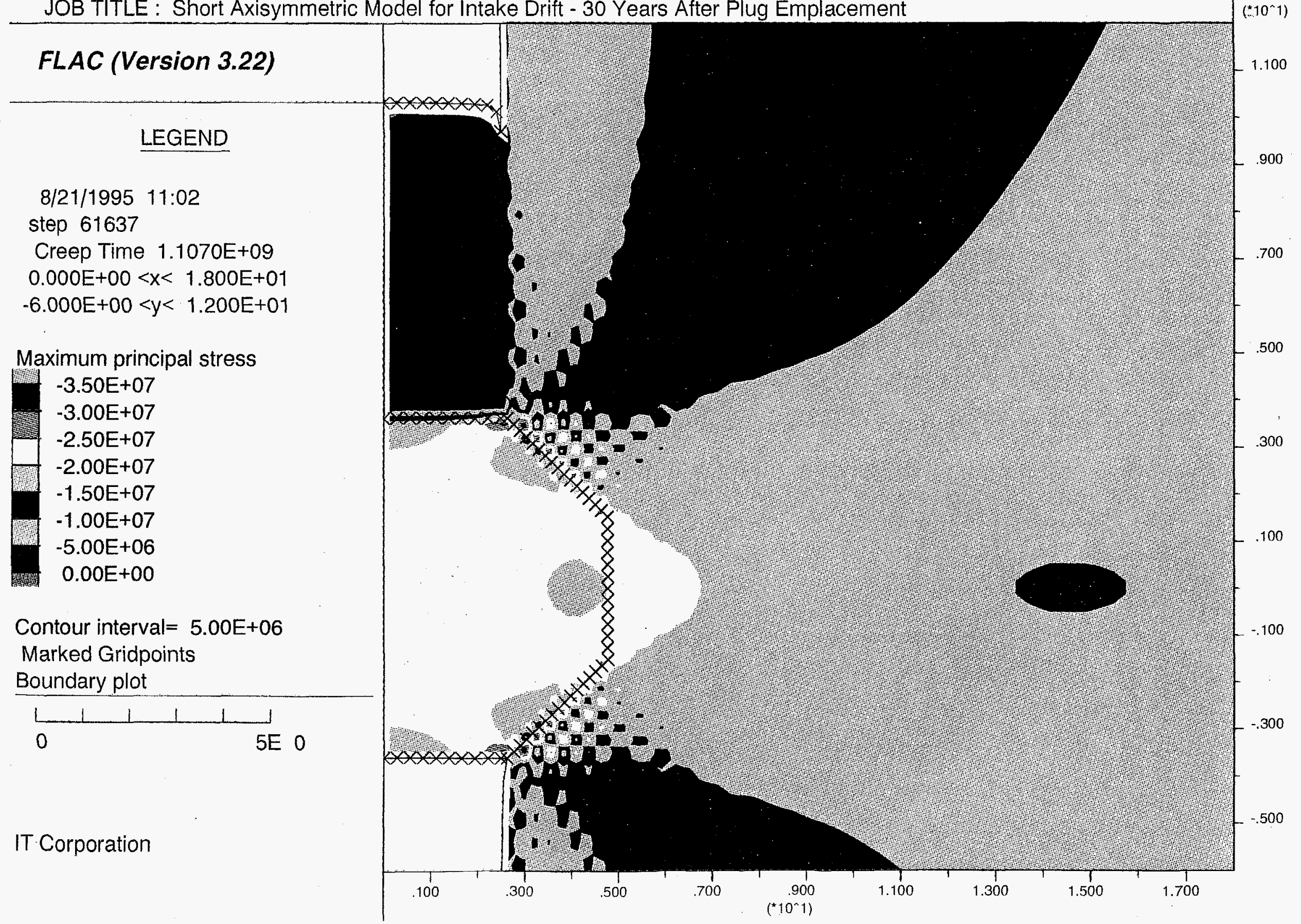




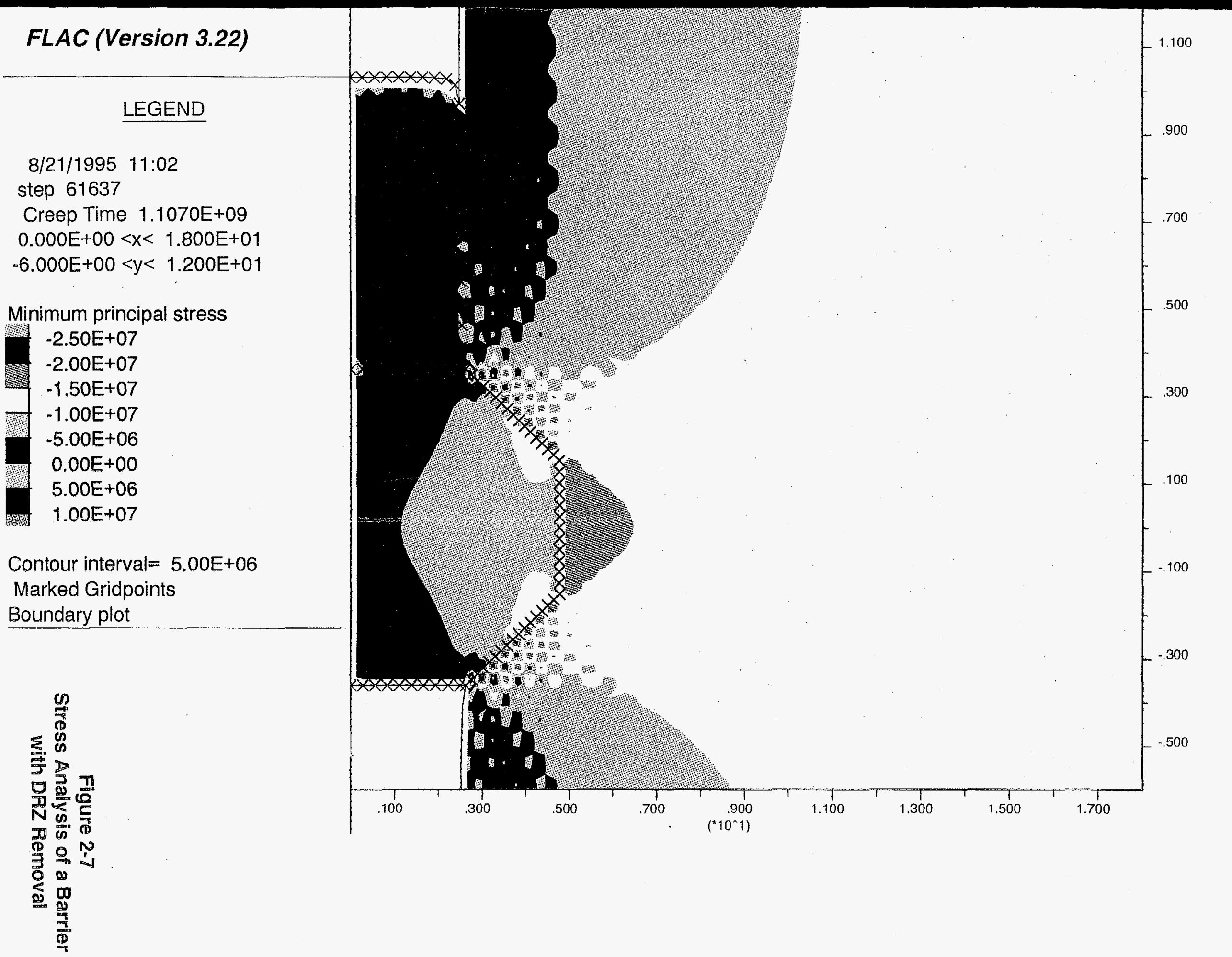




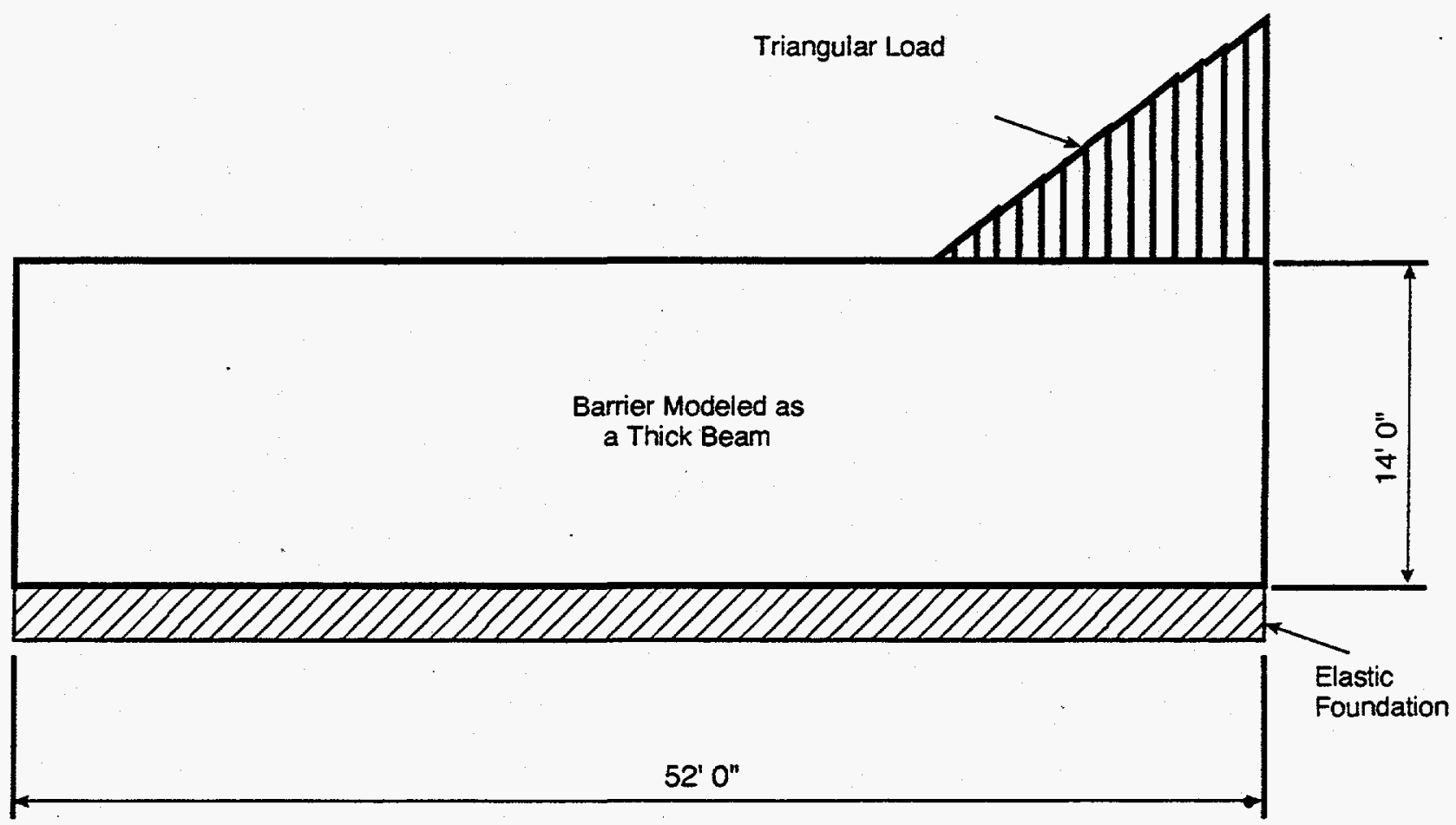

Figure 2-8

Stress Analysis of a Barrier on Elastic Foundation 
The analysis of the concrete barrier on an elastic foundation shows that, for various assumed loadings that will develop, the amount of flexure and transverse shear was minimal and would result in insignificant nonuniform load reactions and failure of plain concrete in flexural tension or shear (Figure 2-9). The only manner in which flexure will develop would be through nonuniform loading. The assumed approximate stress gradient for the first room for the Chabannes solution (DOE, 1995) at a distance of $80 \mathrm{ft}(24 \mathrm{~m})$ equals 300 pounds per square inch (psi) (2.1 megapascals [MPa]) over $50 \mathrm{ft}(15 \mathrm{~m})$. The analysis evaluated the effects of varying the modulus of subgrade reaction for the barrier (equal to 500,000 psi $[3,500 \mathrm{MPa}])$. The results suggest that the potential for flexural tension and shear will be greater when loads were resisted by fractured salt. The removal of fractured salt from the central portion of the excavation should result in a more uniform loading on the barrier and stiffer resistance in reaction that reduces short-term flexural tension and shear.

\subsubsection{Interface Stress Buildup}

Previous small-scale sealing studies (Case and Kelsall, 1986) showed that stress in seals in contact with salt develop rapidly (Figure 2-10). As an example, in the $3 \mathrm{ft}$ - (91-centimeter [cm])-diameter plug for the Small Scale Seal Performance Test, interface stress developed to about 1,000 psi ( $7 \mathrm{MPa}$ ) within 1,000 hours. An analysis was conducted to evaluate the effects of concrete barrier stiffness on the recovery of the DRZ for the alternatives. The technical approach to the standard analysis considered an infinitely long cylindrical concrete barrier $^{5}$ in an infinite medium (DOE, 1995). Figure 2-11 illustrates that interface stresses for the standard concrete barrier with formation grouting would develop more slowly than the enlarged concrete barrier, resulting in less healing of the surrounding DRZ for at least the 35-year operational period.

\subsubsection{Tradeoff Study of Formation Grouting versus DRZ Removal}

The purpose of this study was to evaluate the tradeoffs of formation grouting versus DRZ removal for the alternatives for overall protection of human health and the environment. The tradeoff study considered compliance with the design migration limit, barrier effectiveness, and implementability of the design at the WIPP. This evaluation was performed qualitatively through examination of the results of air-flow and stress analyses as presented in previous sections. The alternatives included a standard concrete barrier with formation grouting, a

\footnotetext{
${ }^{5}$ A cylindrical concrete barrier develops interface stress less rapidly than a spherical concrete barrier. However, the analysis of a cylindrical barrier provides a relative comparison of the effects of fractured salt on the development of interface stress for a long cylindrical barrier.
} 
Fractured Salt

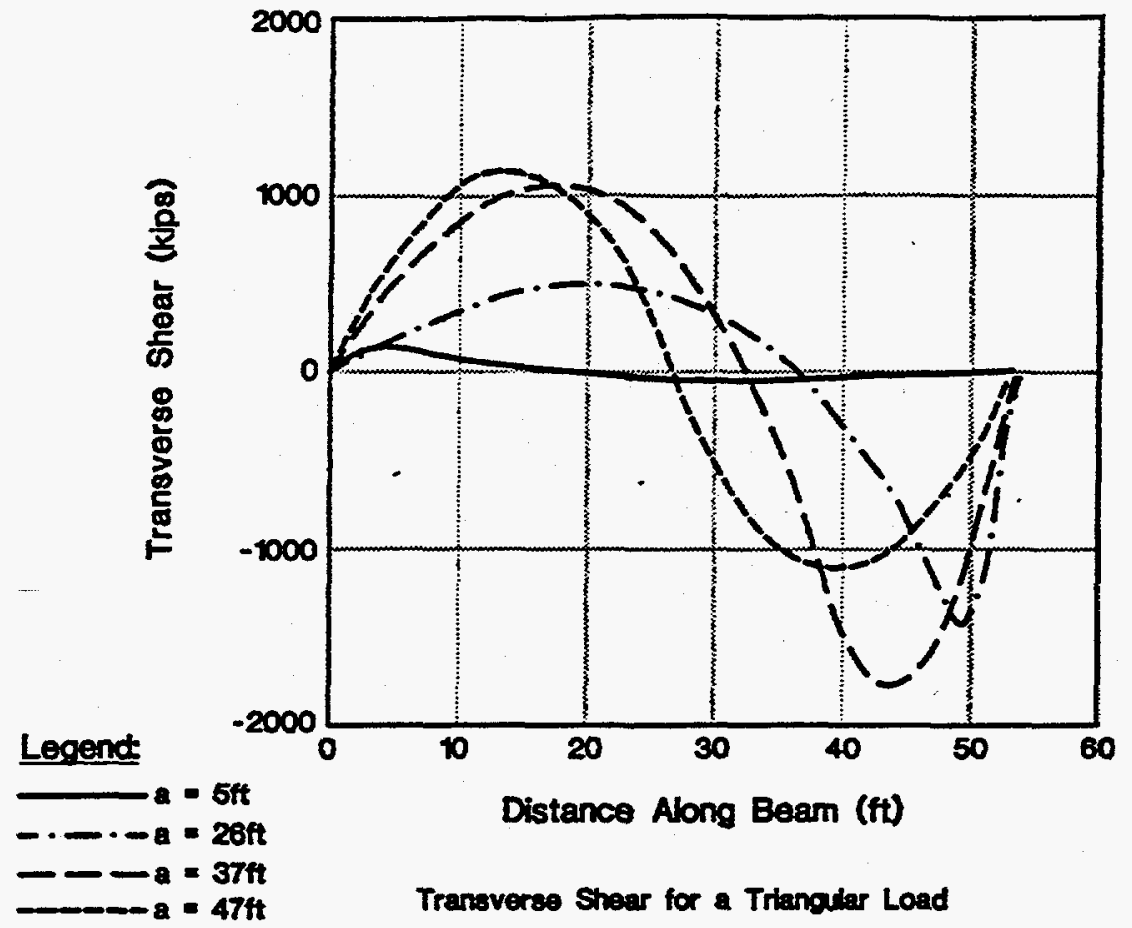

Untractured Salt

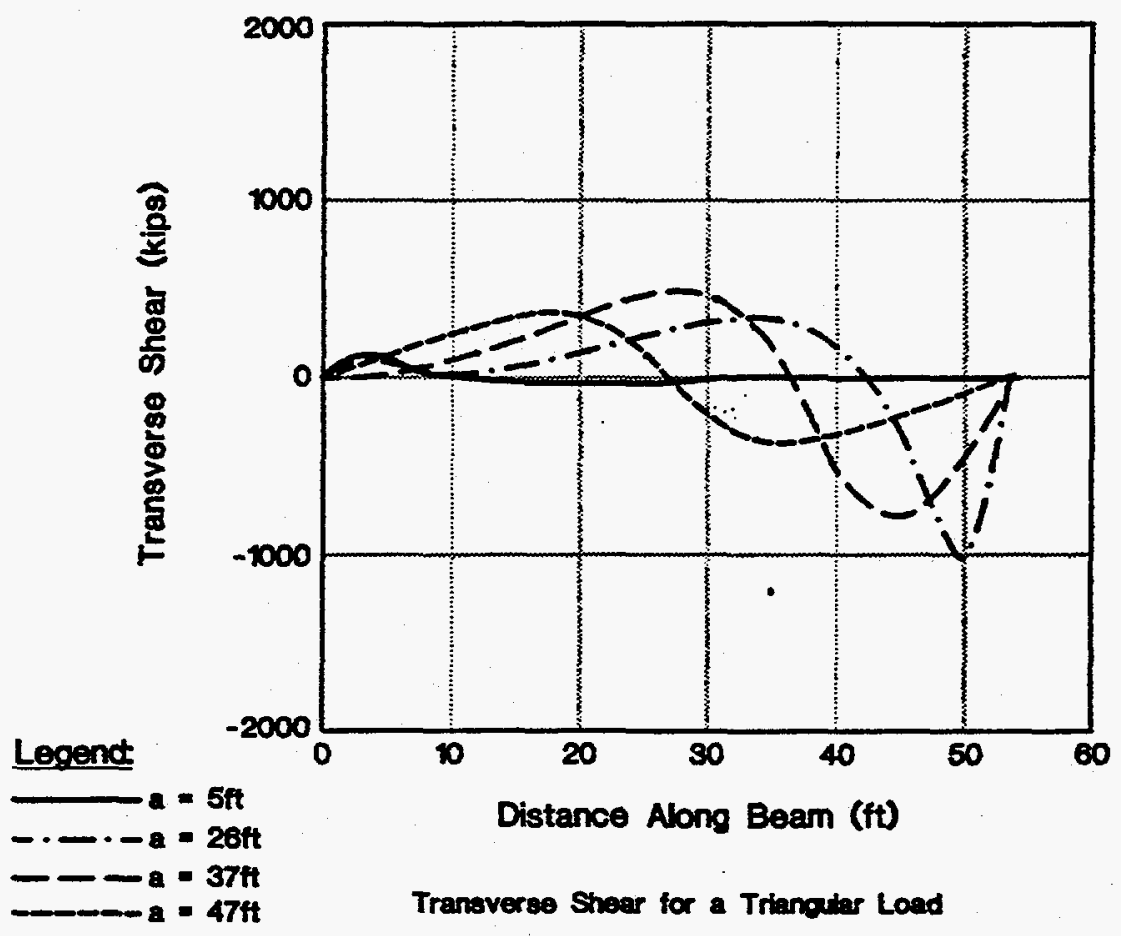

Figure 2-9

Reactive Barrier Loads 


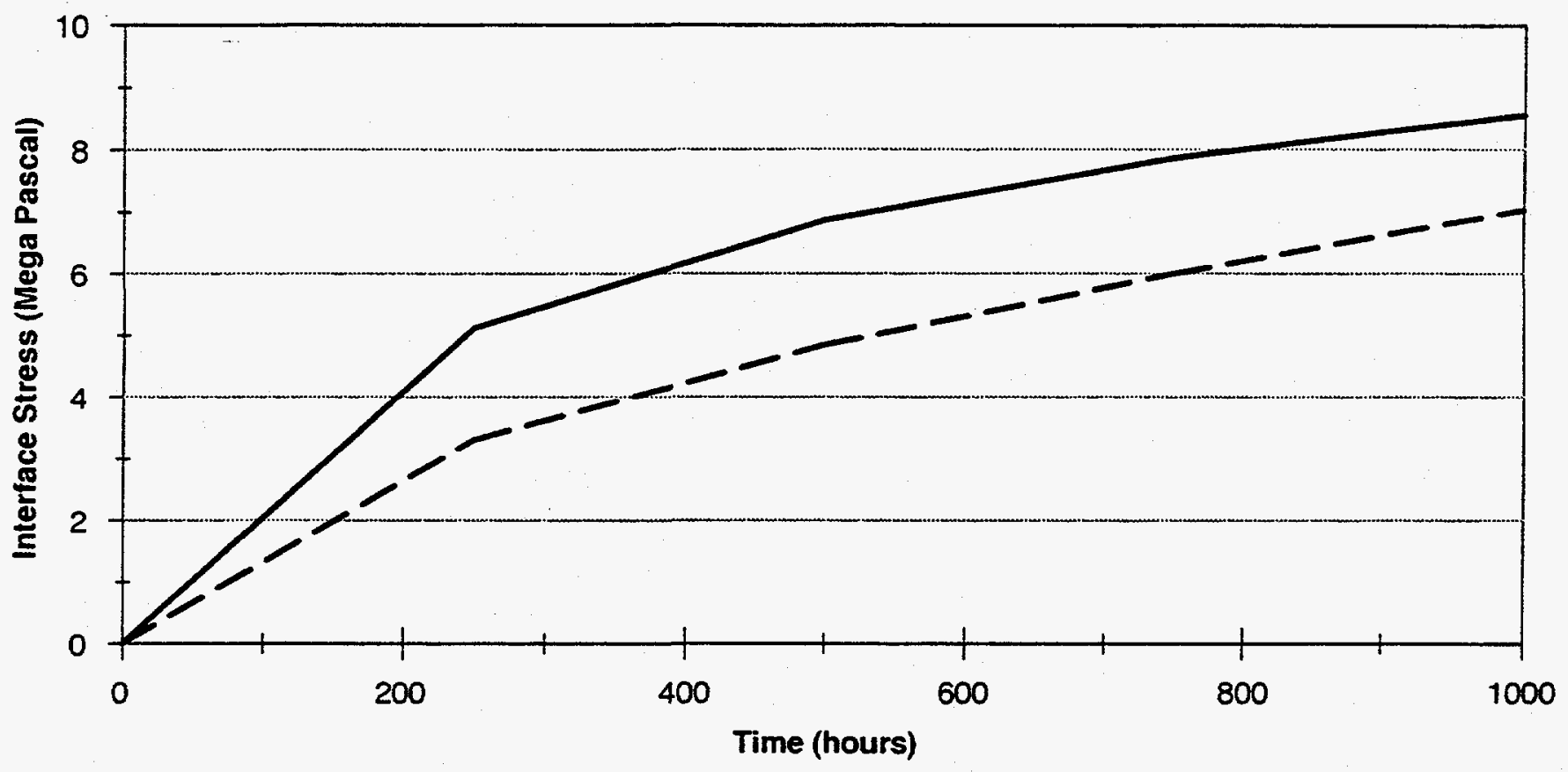

- Measured — Predicted

Figure 2-10

Development of Interface Stress in the Large 91-cm-Diameter Plug

(After Case and Kelsall, 1986) 


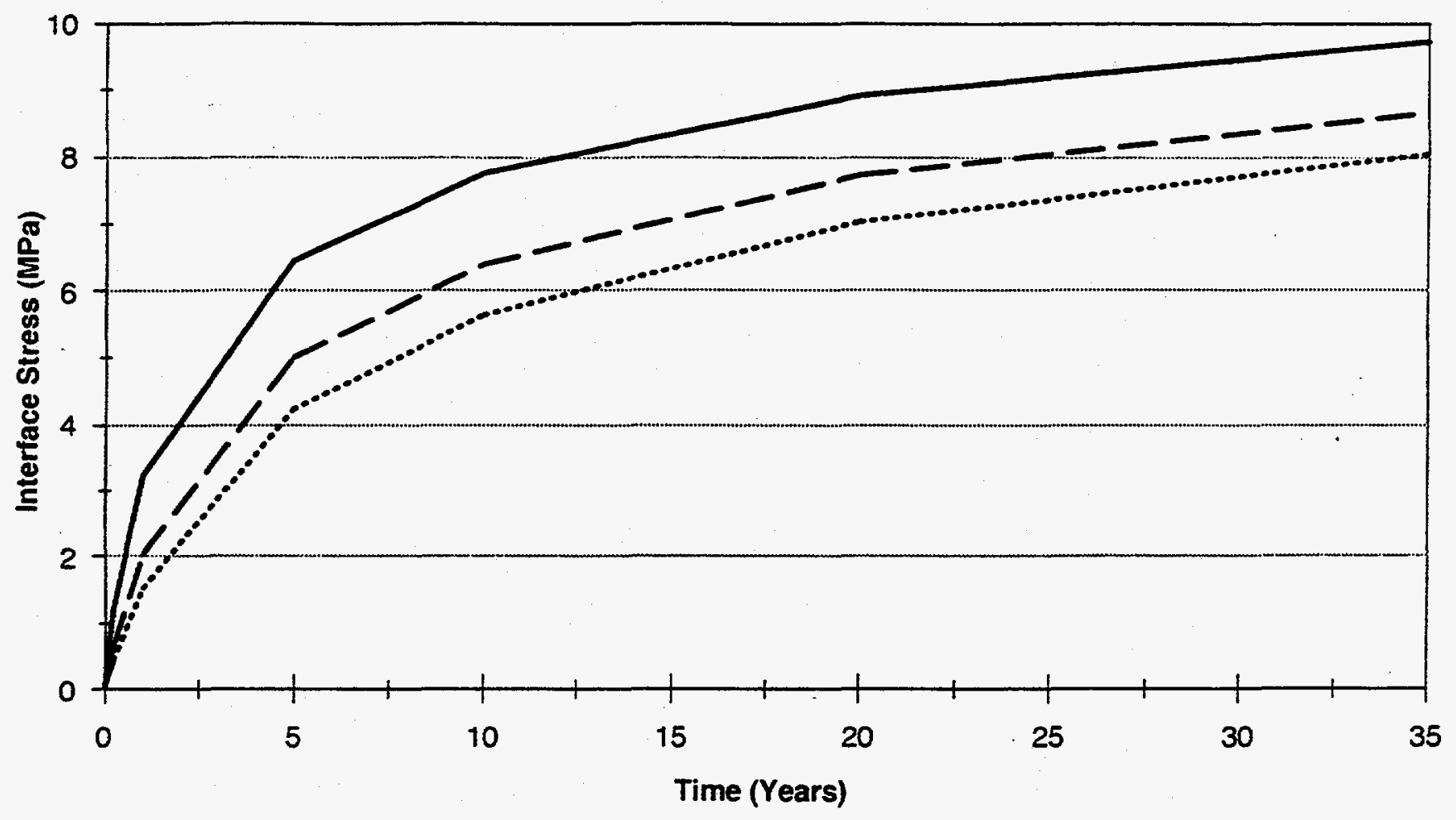

$\begin{array}{ll}\text { Enlarged } \\ \text { Concrete } \\ \text { Barrier }\end{array}-\begin{aligned} & \text { Partially Enlarged } \\ & \text { Concrete } \\ & \text { Barrier }\end{aligned}$

Figure 2-11

Effect of Enlarging Barrier on Interface Stress 
partially enlarged concrete barrier with DRZ removal in the roof, and a fully enlarged barrier with complete DRZ removal. In all cases, the most severe ground conditions were considered. Existing information and the previous modeling efforts were combined to provide insight to the performance of the alternatives.

Bench-scale tests done by Terra-Tek showed the importance of interface zone permeability (Fernandez, et al., 1994). For sealed boreholes, flow occurs either through the seal matrix or through the interface zone. These tests showed that the "effective barrier permeability" for flow through the interface zone to be 1 to 2 orders of magnitude greater than the permeability of the plug material. This result supports the theory that the interface zone behaves like a fracture, in that at low effective stress levels, the interface opens and exhibits high conductivity. At higher stress levels, the interface closes and exhibits a much lower conductivity that is independent of effective stress. These studies suggest that the excavation of a more circular shape that reduces stress concentrations and the emplacement of a sufficiently strong barrier that would reduce shear stresses, and increase confining stresses at the interface zone is preferable.

The discussion presented above allows an evaluation of the compliance of the alternatives with the design migration limit and a qualitative evaluation of the effectiveness of the alternatives in light of the previous stress analyses performed. The stress analyses performed suggested that for the barrier with formation grouting, there is a greater potential for barrier flexure when fractures in the surrounding rock are present, and that the interface stress would develop more slowly because of the compliance of these fractures. This will then result in potentially higher VOCs flow through the interface zone, and reduced effectiveness. The development of lower interface stresses would result in lower confining stresses in the surrounding DRZ, and a slower rate of DRZ healing.

In evaluating the tradeoffs among the alternatives, it was noted that all three alternatives could be implemented. Technologies exist for the placement of a barrier with formation grouting (DOE, 1995). Further, methods are available for the excavation of an enlarged barrier with DRZ removal. Fernandez et al., 1989 evaluated various techniques for enlargement of barriers. These included the use of expansive agents, and hydraulic splitters in addition to the methods for continuous mining. The use of expansive agents could be used in the floor to excavate to below MB 139. While the use of these more labor intensive methods would take longer and make barrier emplacement more difficult, the techniques are 
nevertheless available. The alternatives involving rock removal can be implemented in the underground WIPP repository.

In conclusion, the evaluations addressing the operational requirements of the panel-closure system show that, for the most severe ground conditions to be encountered, the maximum protection is provided when an enlarged concrete barrier is used. The severity of the ground conditions relate to the size and age of the air-intake and air-exhaust drifts, and the distance to the room intersections. The longer the time period between excavation, and panel closure, the greater the degree of fracturing that could occur. For example, the period of time for Panel 1 has been much longer than the four year period currently planned for other panels. Where the time between excavation and panel is short, fracturing may be absent or inconsequential, and the design can be simplified to a standard barrier with no DRZ removal.

\subsection{Structural and Material Requirements}

This section presents evaluations relating to the structural and material requirements for the panel-closure system.

\subsubsection{Material-Compatibility Evaluations}

The purpose of the material-compatibility evaluations is to select the most suitable concrete and grout materials for a panel-closure system. This section evaluates the concrete and grout compositions and their geochemical compatibility with the host rock and brine. This section also evaluates the geotechnical properties and permeabilities of a concrete/grout to liquid phase and gaseous phase contaminants (brine and VOCs, respectively).

\subsubsection{Evaluation Procedure}

Project information was reviewed for appropriate concrete-barrier materials that would minimize VOC migration and cement hydration for candidate materials.

\subsubsection{Concrete-Barrier Material Candidates}

The selection of candidate materials for use as concrete and grout in a panel-closure system requires that numerous criteria be satisfied in terms of the 35-year period of performance. The materials must be chemically compatible with the host rock and brine (Salado Formation) without chemical degradation. Concrete used in the main concrete barrier must be sufficiently strong enough to support lithostatic loads and resist the compressive stress of the creeping salt. The concrete must cure at a low heat of hydration. If the concrete evolves heat too rapidly (i.e., greater than 14 degrees celsius $\left({ }^{\circ} \mathrm{C}\right)\left(25\right.$ degrees Fahrenheit $\left.\left[{ }^{\circ} \mathrm{F}\right]\right)$, it may 
experience rapid slump loss before hardening and excessive thermal stress after hardening. Slump loss directly affects the workability and pumpability of the concrete. The workability of the concrete must allow ample time and the pumpability must be adequate for installation. The most desirable characteristics for achieving adequate pumpability were a 4-hour working time (Wakeley et al., 1994). The concrete must perform under large-scale installation conditions. Grout must form a tight seal between the concrete barrier and the host rock.

Wakeley et al. (1993) studied and developed (Gulick and Wakeley, 1989) salt-saturated concrete and grout in the floor of the WIPP repository for six years (Appendix D). Then the concrete and grout plugs along with some host rock were overcored. The study concluded that little or no deterioration occurred to the concrete or grout. Overall the compressive strengths increased with time with the lowest values from samples taken in the DRZ. Reaction rims with increased permeability were noted on anhydrite surrounding the plugs, suggesting interaction between the grout or concrete and host rock. There was also evidence of halite dissolution in the anhydrite zone near the plugs; however, the presence of halite facilitated better bonding between the grout or concrete and the host rock. Crystallization of new phases was also noted on free surfaces, indicating that strongly ionic, magnesium-bearing fluids were present and moving. The movement of the fluid improved the bonding with the host rock.

Gulick and Wakeley (1989) proposed expansive salt-saturated concrete (ESC) (Appendix E) and grout mixtures that yielded favorable results for suitability in a panel-closure system. The formulation for their grout mixture is indicated in Table 2-3.

Table 2-3

Salt-Saturated Grout (BCT-1F)

\begin{tabular}{||l|c|}
\hline \multicolumn{1}{|c|}{ Component } & Percent of Total Mass \\
\hline \hline Class H cement & 48.3 \\
\hline Class C fly ash & 16.2 \\
\hline Cal seal@ (plaster) & 5.7 \\
\hline Sodium chloride & 7.9 \\
\hline Dispersant & 0.78 \\
\hline Defoamer & 0.02 \\
\hline Water & 21.1 \\
\hline
\end{tabular}


Class $\mathrm{H}$ cement is a standard oil-well cement that has been used extensively in grouts and concretes in underground applications. Class $\mathrm{C}$ fly ash contributes expansive properties to concrete. Cal Seal ${ }^{\circledR}$ (a plaster of paris, manufactured by Halliburton) also develops expansive properties in mixtures containing Class $\mathrm{H}$ cement. Expansive components that are added to the concrete or grout mixtures enhance bonding with the host rock.

Wakeley et al. (1993) later researched concrete mixtures that would behave optimally under the type of large-scale installation conditions associated with the panel-closure system. The concrete mixture was also designed to keep the temperature due to heat of hydration less than $14^{\circ} \mathrm{C}\left(25^{\circ} \mathrm{F}\right)$. The concrete mixture that resulted from this study was termed the Salado Mass Concrete (SMC), and it superseded ESC as the performance mixture (Wakeley et al., 1993). Table 2-4 summarizes the SMC composition.

Table 2-4

Salado Mass Concrete

\begin{tabular}{||l|c|}
\hline \multicolumn{1}{|c|}{ Component } & Percent of Total Mass \\
\hline \hline Class H cement & 4.93 \\
\hline Chem Comp III & 2.85 \\
\hline Class F fly ash & 6.82 \\
\hline Fine aggregate & 33.58 \\
\hline Coarse aggregate & 43.02 \\
\hline Sodium chloride & 2.18 \\
\hline Defoaming agent & 0.15 \\
\hline Sodium citrate & 0.09 \\
\hline Water & 6.38 \\
\hline
\end{tabular}

Class $\mathrm{F}$ fly ash increases the aluminum content of the concrete mixture, which decreases the heat of hydration and increases the setting speed. A mixture of fine and coarse aggregate decreases the porosity of the concrete, and the fine aggregate contributes more silica over time. 
For Class $\mathrm{M}$ cement and Class $\mathrm{F}$ fly ash addition of sodium chloride to the mixture ensures that the water content of the concrete is in equilibrium with the host rock to minimize dissolution, and inhibit deterioration of the concrete. The use of defoaming agents inhibit air entrainment in the concrete mixture.

Wakeley et al. (1994) studied under laboratory conditions the effects of various compositions of brines and concretes, including the SMC formulation. The study evaluated the susceptibility of concretes to chemical degradation by brines. Both pastes containing no aggregate, and mortars containing fine aggregate were formulated and tested in simulated brines containing magnesium and sulfate concentrations representing the brines at the repository horizon. The study concluded that high-magnesium brines exacerbated the deterioration of pastes and mortars; mortars deteriorated more rapidly than pastes. This study concluded that loss of calcium was the primary cause of weakened concrete materials. The use of salt in mortars with an expansive component slowed the rate of deterioration. These experiments were carried out under extreme experimental conditions unrepresentative of the trace amount of brine that will be encountered during large-scale installation of the concrete barriers.

\subsubsection{VOC Interaction}

Theoretically, if the $\mathrm{pH}$ of the VOCs is too low, it could negatively impact the structural integrity of the concrete barrier. The higher the $\mathrm{VOC} \mathrm{pH}$, the less likelihood for physical degradation of the concrete barrier. Using a portland cement with a $\mathrm{pH}$ greater than 12 should ensure the integrity of the concrete barrier.

\subsubsection{Cement Hydration}

Mathewson (1981) reported that the aggregate mineralogy significantly affects the curing/hydrating process by generating heat and alkali fluids, which can have deleterious effects on the strength of the concrete. Minerals susceptible to an alkali-aggregate reaction are hydrated silicates, opaline shale, chert, siliceous limestones, thyolite, and dacite. Nonreactive minerals include quartz, feldspar, calcite, and the ferromagnesium minerals.

\subsubsection{Conclusions}

Previous studies suggest the application of the SMC to the design of the panel-closure system. This concrete possesses characteristics of low heat of hydration and workability. Because of the trace amounts of brine and the impermeable nature of the concrete, a standard concrete with a low heat of hydration and similar workability was considered acceptable. Therefore, 
the design specifies a plain cement concrete mix that must be verified with testing. The cement will be Portland cement, type II modified, with pozzalan or type IV, to limit the heat of hydration of the resultant mix.

\subsubsection{Heat-Generation Evaluations}

Heat-generation studies evaluated the effects of the heat of hydration for the installation of the concrete barrier. The curing of concrete is facilitated by hydration in that the water present in the mixture reacts with calcium and silica to incorporate water into the resulting mineral phase. This process is an exothermic reaction, resulting in a temperature increase in the concrete barrier and host rock. This temperature increase causes a thermal expansion of the concrete barrier and increases the interface stress. As the concrete cools, the interface stress decreases, and tensile strain may occur at the interface.

\subsubsection{Evaluation Procedure}

The one-dimensional radial numerical and analytical model SHAFT.SEAL (Case et al., 1992) solves for temperature and stress as a function of radial position, in either the barrier or the surrounding host rock. The model uses the implicit finite-difference method (Carnahan et al., 1990) to analyze the temperature rise and fall following completion of the hydration. The model assumes radial conductive heat transfer to the surrounding host rock.

The analysis used thermal and thermomechanical properties from previous modeling efforts (Case and Kelsall, 1986; Van Sambeek and Stormont, 1987). The proposed concrete mixture exhibits a double-humped hydration curve (Figure 2-12) (Van Sambeek and Stormont, 1987). The first "hump" results from a reaction that occurs shortly after the mixing of the concrete. The double-hump manifestation in the temperature-versus-time data of the expansive saltbased concrete reduces the maximum temperature by increasing the time over which the hydration takes place. This is beneficial in large volumes of concrete where the dissipation of heat in the interior of the concrete barrier is slow. The analyses used input properties for the candidate material as determined from laboratory studies (Van Sambeek and Stormont, 1987), with modifications made to account for a reduced heat of hydration for the SMC. Table 2-5 summarizes the properties used in the analysis. The placement temperature was selected at ambient temperature. 


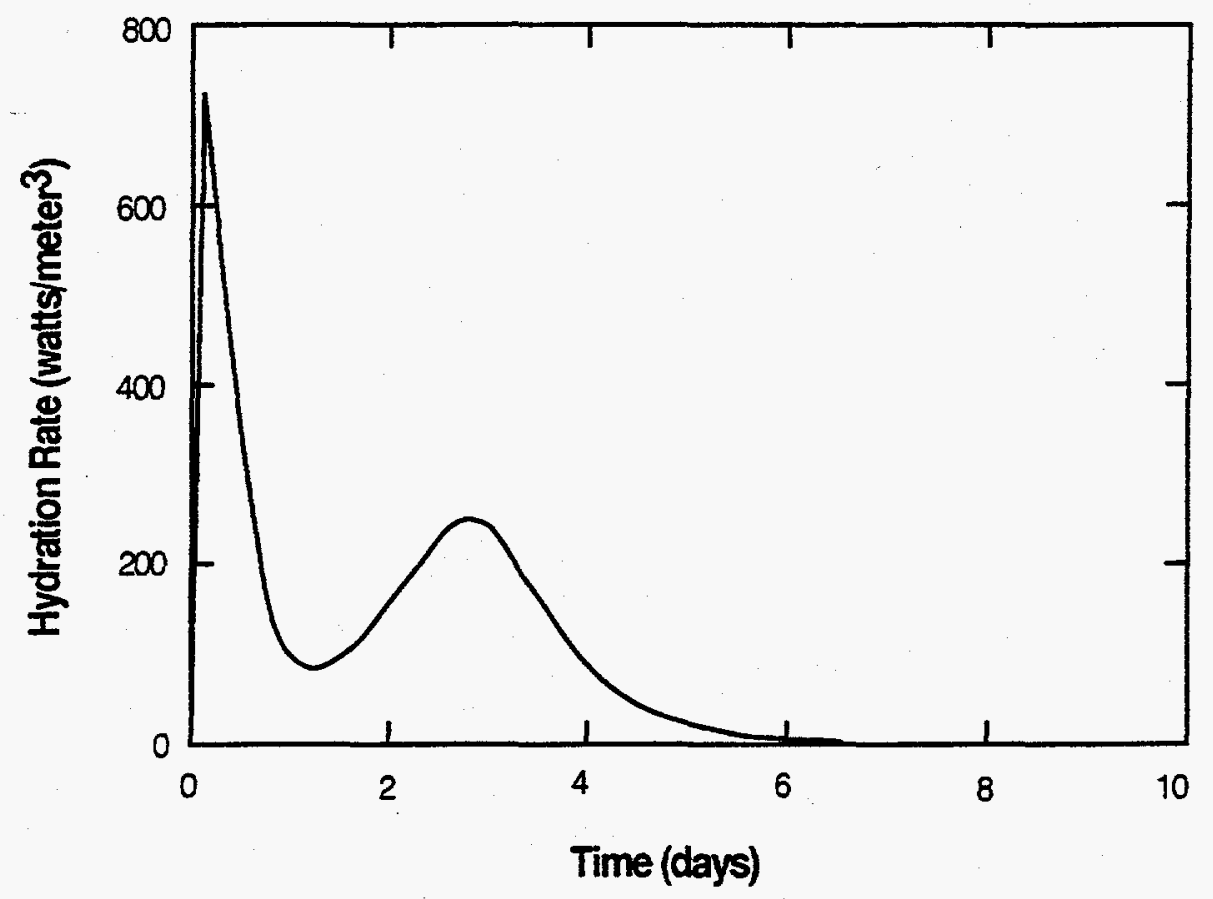

Figure 2-12

Heat of Hydration for Expansive Salt Concrete

(After Van Sambeek and Stormont, 1987) 
Table 2-5

Thermal and Thermomechanical Properties

for SHAFT.SEAL Analysis

\begin{tabular}{|c|c|}
\hline Property & Value \\
\hline $\begin{array}{l}\text { Barrier properties: } \\
\text { Plug diameter }\end{array}$ & 10 meters \\
\hline Concrete placement temperature & $28^{\circ} \mathrm{C}$ \\
\hline $\begin{array}{l}\text { Concrete Properties: } \\
\text { Specific heat } \\
\text { Thermal conductivity } \\
\text { Density } \\
\text { Young's Modulus } \\
\text { Poisson's ratio } \\
\text { Thermal expansion coefficient }\end{array}$ & $\begin{array}{c}980 \text { joules/(kilogram-Celsius) } \\
2.1 \text { watts/(meters-Celsius) } \\
2,280 \text { kilograms/cubic meter } \\
28,000 \mathrm{MPa} \\
0.20 \\
12.6 \times 10^{-6} 1 /{ }^{\circ} \mathrm{C}\end{array}$ \\
\hline $\begin{array}{l}\text { Rock properties: } \\
\text { Specific heat } \\
\text { Thermal conductivity } \\
\text { Density } \\
\text { Rock temperature } \\
\text { Young's Modulus } \\
\text { Poisson's ratio } \\
\text { Thermal expansion coefficient }\end{array}$ & $\begin{array}{c}860 \text { joules/(kilogram-Celsius) } \\
4.94 \text { watts/(meters-Celsius) } \\
2,300 \text { kilograms/cubic meter } \\
28^{\circ} \mathrm{C} \\
31,000 \mathrm{MPa} \\
0.25 \\
45.0 \times 10^{-6} 1 /{ }^{\circ} \mathrm{C}\end{array}$ \\
\hline
\end{tabular}

\subsubsection{Modeling Results}

The modeling results include the temperature and stress distributions in the concrete barrier and the surrounding host rock at various times (Figure 2-13). The thermal analysis shows that temperatures initially rise uniformly due to cement hydration, maintaining a high radial thermal gradient within the interface zone. Thermal gradients decreased with time as hydration nears completion, and the heat thermally diffuses to the surrounding rock. After 28 days, temperatures rose to about $45^{\circ} \mathrm{C}\left(102^{\circ} \mathrm{F}\right)$, inducing a thermal gradient and thermal stress at the interface zone. After this time, the temperatures fell and approached the in situ rock temperature after an additional 28 days. The temperatures suggest that the heat pulse will be short and that the placement of the concrete, combined with the high thermal diffusivity of the salt, will control hydration temperatures to an acceptable level. The stress analysis suggests that tensile stress in the concrete will be offset by the rapid buildup of compressive stress, due to salt creep of the host rock. 


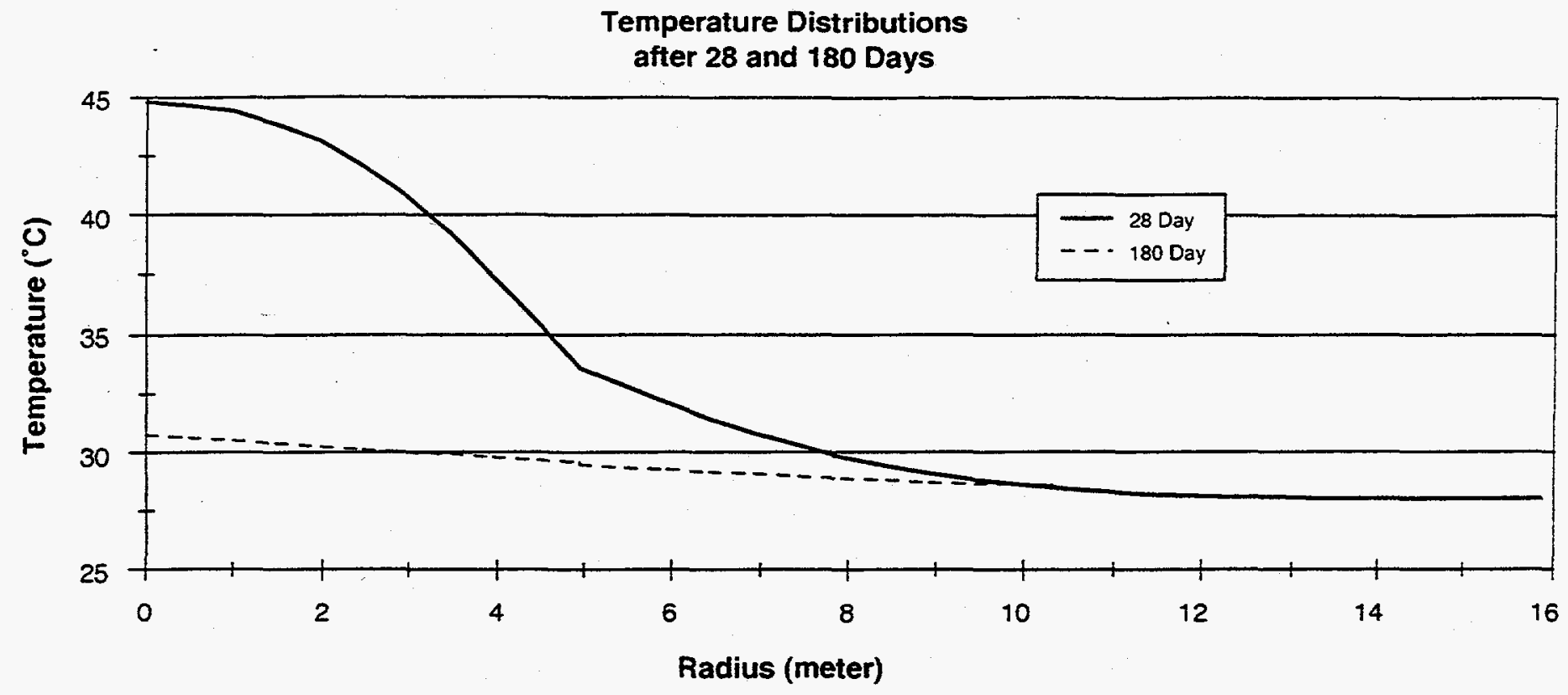

Stress Distributions after 28 and 180 Days

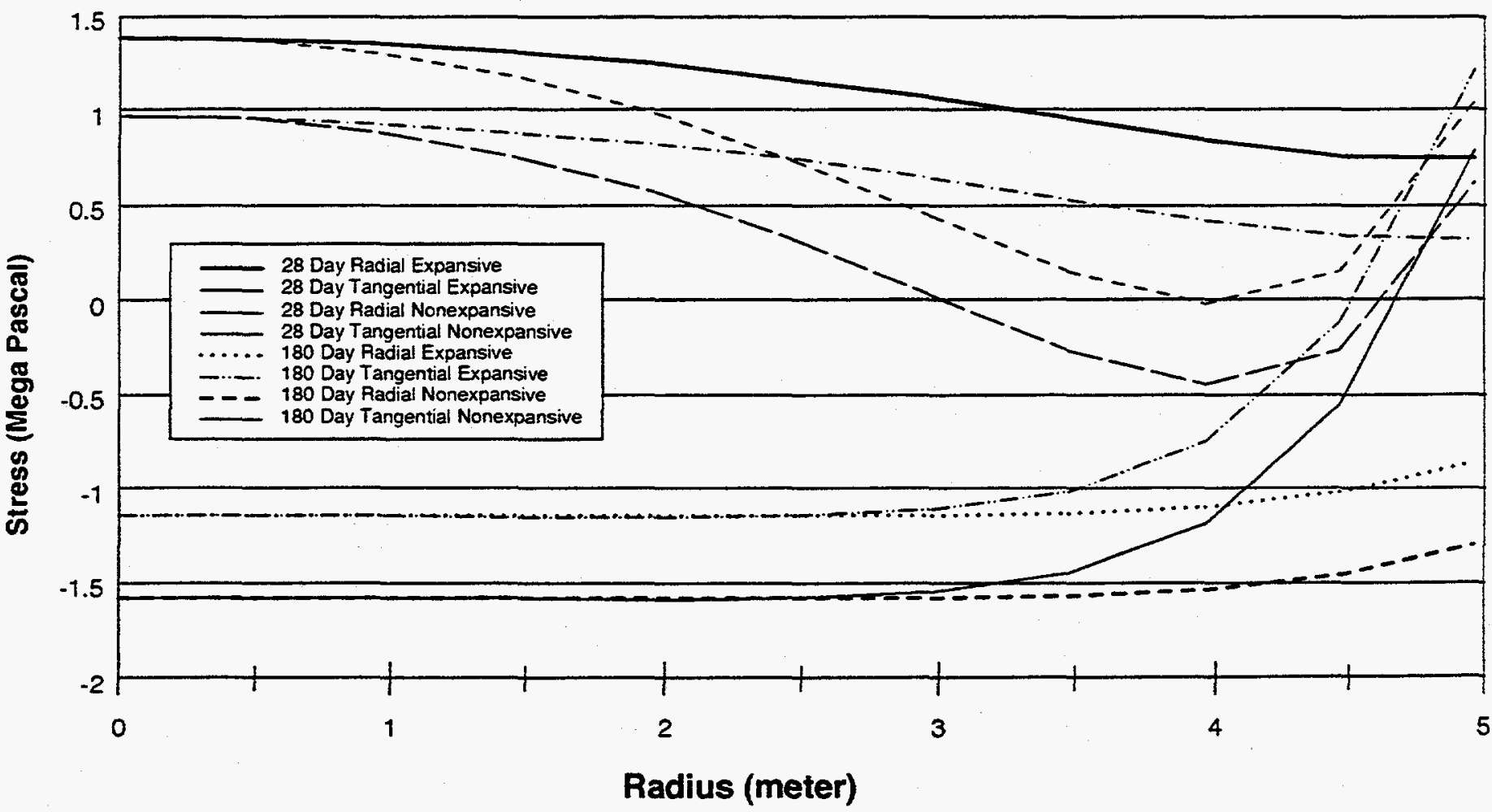

Figure 2-13

Temperature and Stress Distributions for Concrete Barrier 


\subsubsection{Conclusions}

Hydration temperatures will be controlled through the selection of an appropriate concrete to reduce the potential for tensile cracking and separation at the interface zone. A thermal analysis using information on the heat of hydration of the concrete coupled with a salt-creep analysis suggests that, for the size of pour, placing the concrete at ambient temperature will control hydration temperatures. Finally, because steel formwork will be used during installation, such formwork will conduct heat away from the face of the concrete and thereby cool the concrete.

\subsubsection{Explosion Evaluations}

The methane-explosion evaluation focused on the pressure and thermal effects of such an explosion on the explosion-isolation wall. The DOE (1995) suggests that gas-generation rates, due to microbial degradation, might range from 0.01 to 0.1 moles per drum per year, with methane comprising 70 percent of the gas. It is estimated that the potential for a methane explosion would not occur prior to closure of the first waste-emplacement panel for a gas generation rate of 0.1 moles per drum per year. Such an explosion could occur approximately 20 years after closure of the first panel. This time is determined by comparing the percent volume concentration to the explosive limits for methane as shown in Figure 2-14.

If the composition of the air in the closed panel were 18 percent oxygen, the explosive range will be from about 5 to 15 percent methane by volume. Above 15 percent methane, the atmosphere in an abandoned waste-emplacement panel would be "fuel rich" and would not be capable of sustaining an explosion. With a reduction in the amount of oxygen available, the explosive range narrows, and the potential will be nonexistent below a 12 percent oxygen composition.

A methane explosion would generate an initial pressure transient that would impinge on the explosion-isolation wall. Subsequently, temperatures would rise in the panel, as well as raise the temperature in the explosion-isolation wall.

\subsubsection{Evaluation Procedure}

Two analyses were conducted to evaluate methane-explosion effects: 1) a dynamic analysis, and 2) a thermal heat-transfer analysis of the explosion-isolation wall. After an explosion, the explosion-isolation wall would be subjected to short-term dynamic loading. The design pressure can be calculated as the maximum pressure times the dynamic load factor (Biggs, 1964). The dynamic load factor will depend on the shape of the pressure-time transient. An 


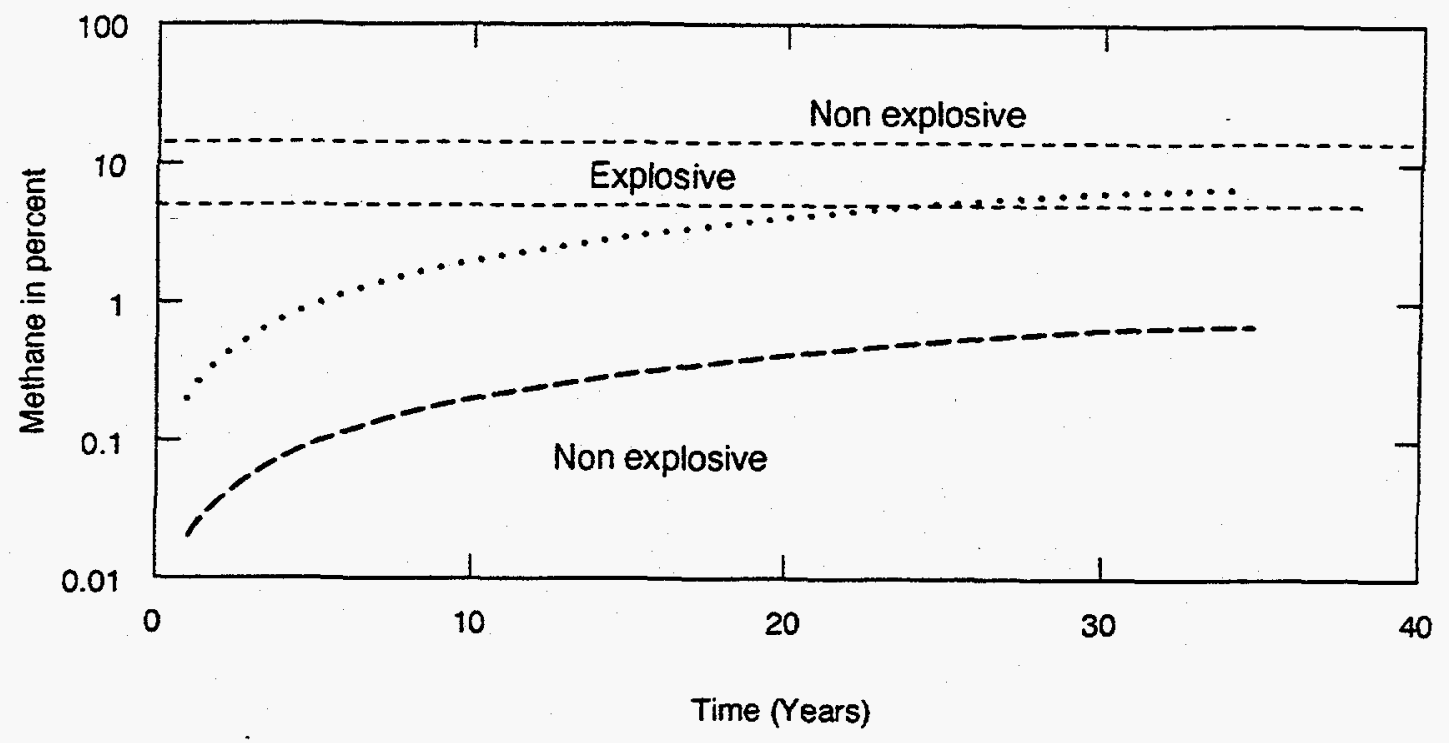

Gas generation rate $=0.1$ moles/drum $/$ year

Gas generation rate $=0.01$ moles $/$ drum/year

Figure 2-14

Methane Concentrations in the Waste Panel Over Time (After DOE, 1995) 
explosion will result in a wave front that will rise instantaneously and then drop gradually. In this study, the transient pressure pulse is idealized as having an instantaneous rise and an exponential decay (Figure 2-15).

In the event of a hydrocarbon explosion: either (1) deflagration will result in a rapid rise of pressure, with no transition to a detonation, or (2) a detonation wave front will propagate as a supersonic shockwave. The transition to a detonation is a function of two parameters:

(1) the methane concentration at the time of the explosion, and (2) the ability for a wave front to form. In underground excavations, the latter condition typically requires a reasonably long passage through which the combustion wave travels and transforms to a detonation. After 20 years, the open passage above the waste stack will be reduced in size, and it is unlikely that a long passage with an open geometry will exist. Further, individual rooms will be isolated by bulkheads at each end. Therefore, the dynamic analysis considers a deflagration.

The second analysis involves a thermal analysis with a heat-transfer model (Appendix F). The heat-transfer model under the postulated explosion within the panel considers the heat balance between the gas and the walls of the panel for a stoichiometric mixture of methane. The rate at which the gas temperature will rise within the panel depends on (1) the number of moles of methane, (2) the specific heat capacity of the gas and the heat transfer to the salt and the walls through radiation, (3) convection along the vertical and horizontal surfaces, and (4) conduction within the salt and walls. Because the properties involved in the heat transfer analysis are temperature-dependent, a numerical model was run using the explicit finite difference method. The model provided the necessary information for evaluating thermal effects in selecting the size of the explosion-isolation wall.

\subsubsection{Analysis Results}

The peak explosive pressure was taken from the pressure rising from a deflagration that is about 8 times the ambient pressure ( 2 atmospheres) at the time of the explosion. This results in a peak pressure of $240 \mathrm{psi}(1.7 \mathrm{MPa}){ }^{6}$

The dynamic load factor will depend on the natural frequency of the explosion-isolation wall. The value for the dynamic load factor approaches a value of 2 , with increased natural

\footnotetext{
${ }^{6}$ The analysis is conservative in that the presence of the waste drums would result in dampening of the explosion.
} 


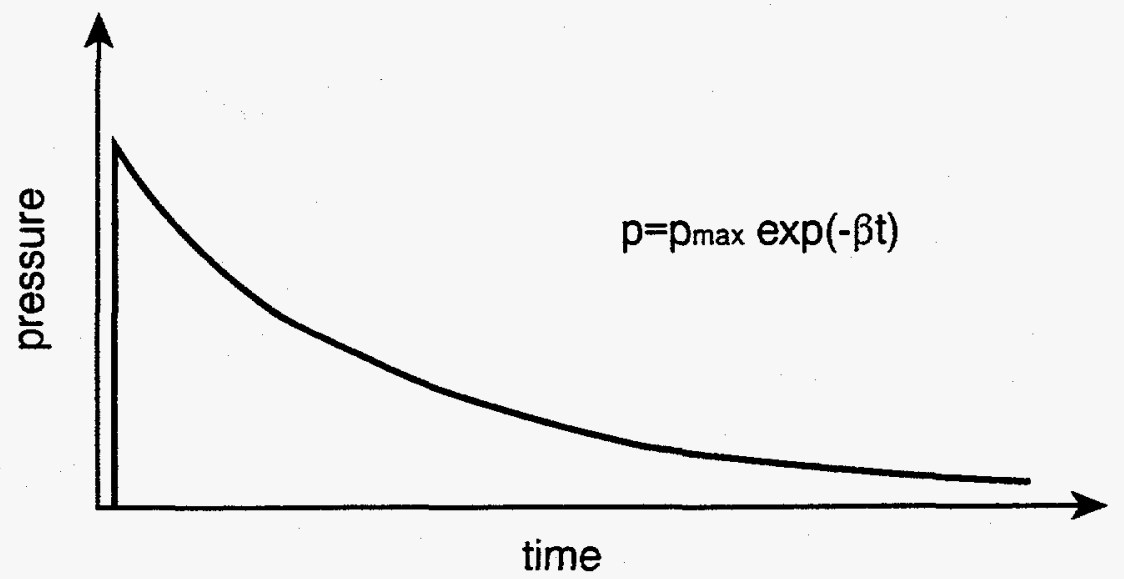

$$
\begin{aligned}
& \text { LEGEND } \\
\mathrm{p} & =\text { Pressure } \\
p_{\max }= & \text { Maximum pressure } \\
t & =\text { Time } \\
\beta & =\text { Shape factor for experimental curve }
\end{aligned}
$$

Figure 2-15

Pressure Pulse Versus Time 
frequency for a variety of exponential curves (Figure 2-16). Based upon this loading, an explosion-isolation wall was designed to adsorb the energy from such an explosion.

The thermal-analysis results are presented in Figures 2-17 through 2-19. Figure 2-17 shows the gas temperature, the salt-wall temperature, and concrete wall temperature following the explosion. In the analysis, the gas reached a temperature of 2,500 Kelvin after about 20 seconds and then declined with time. The gas approached ambient temperatures after about 1.5 hours. Figures 2-18 and 2-19 show the temperature distribution as a function of distance into the walls. The results show that, at the initial time, the heat transfer from combustion gas to the salt and walls will result in a large temperature gradient at the wall. At later times, heat will be conducted through the wall, and the salt and the thermal gradient will be reduced. After 2 hours, the elevated temperature in the wall will propagate a maximum of 6 inches $(15 \mathrm{~cm})$ into the wall. Because the explosion-isolation wall is designed to resist creep deformation, temperature gradients will not significantly affect the stability of the wall.

\subsubsection{Conclusions}

The explosion-isolation wall was designed for a peak deflagration pressure of $240 \mathrm{psi}$ (1.7 MPa) under pseudostatic conditions, with a dynamic load factor of 2.0. Because the explosion-isolation wall is designed to resist creep deformation, temperature gradients will not significantly affect the stability at the wall.

\subsubsection{Fracture-Propagation Studies}

The fracture-propagation studies evaluated the potential for fracture propagation, using the results of previous analyses. These analyses included a stress analysis and explosion evaluations.

\subsubsection{Evaluation Procedure}

The results of the thermal analysis suggest that elevated temperatures within an explosionisolation wall and salt will be a localized phenomenon. During an explosion, which may potentially occur 20 years after closure of the first panel, two phenomena could affect the potential fracturing of the salt: (1) the expansion of the explosion products into existing fractures and (2) the potential reflection of sonic waves off free surfaces around the barrier. These effects were evaluated. 


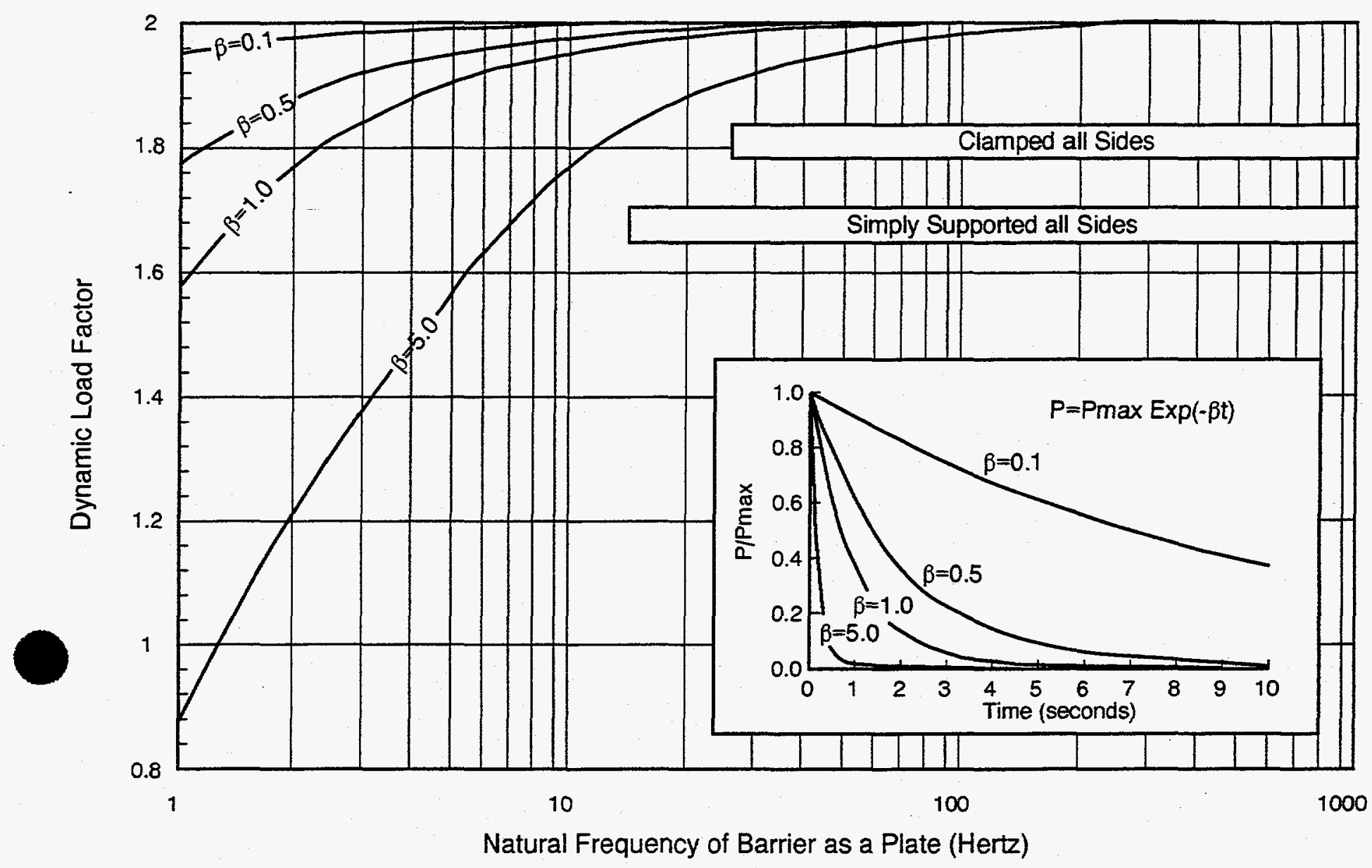

Range of Natural

Frequencies as a plate

$\beta$ Shape factor for experimental curve

Figure 2-16

Dynamic Load Factor Versus Frequency of the Concrete Wall as a Plate 


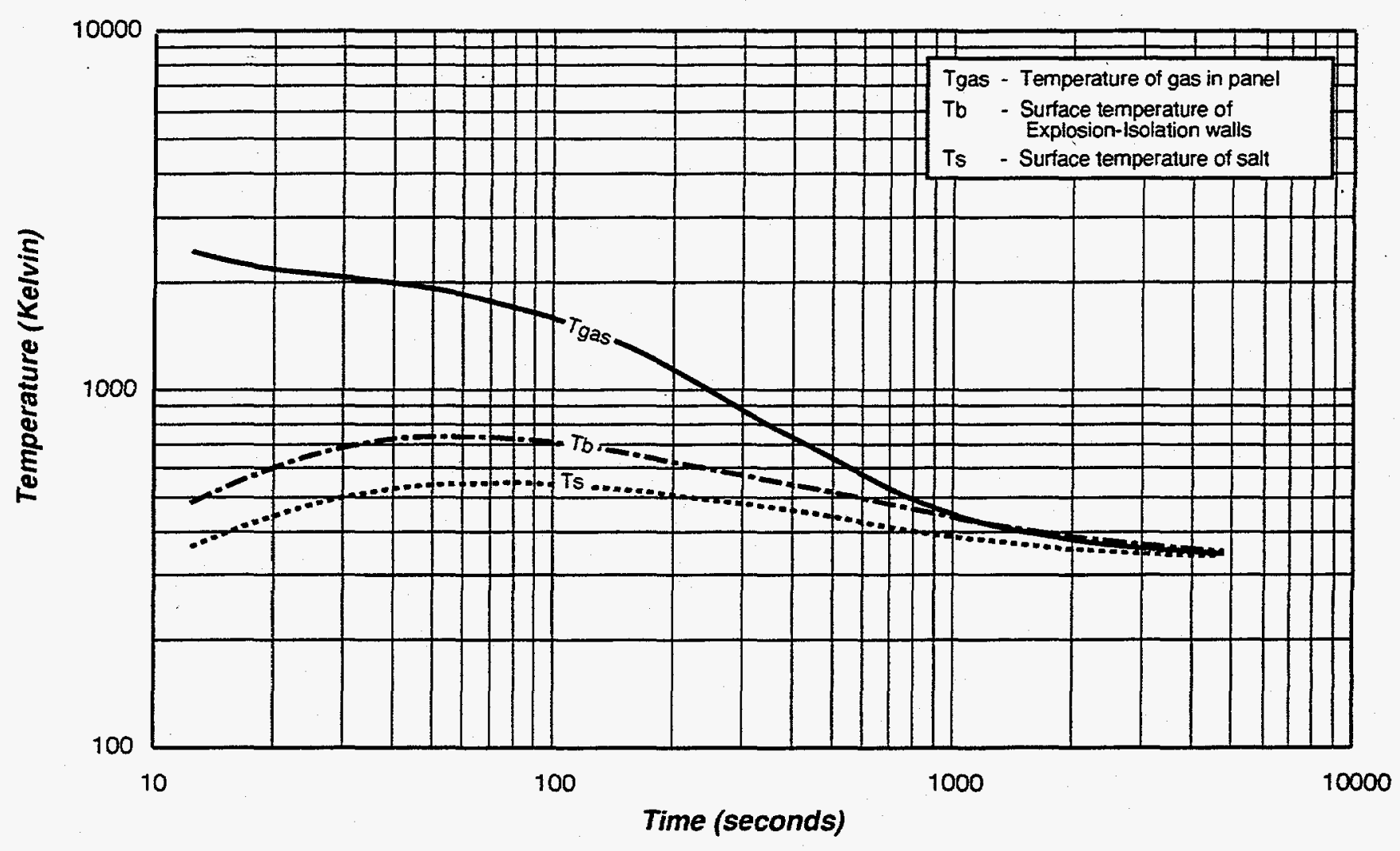

Figure 2-17

Temperature Variation with Time for Gas, Salt, and Explosion-Isolation Walls 


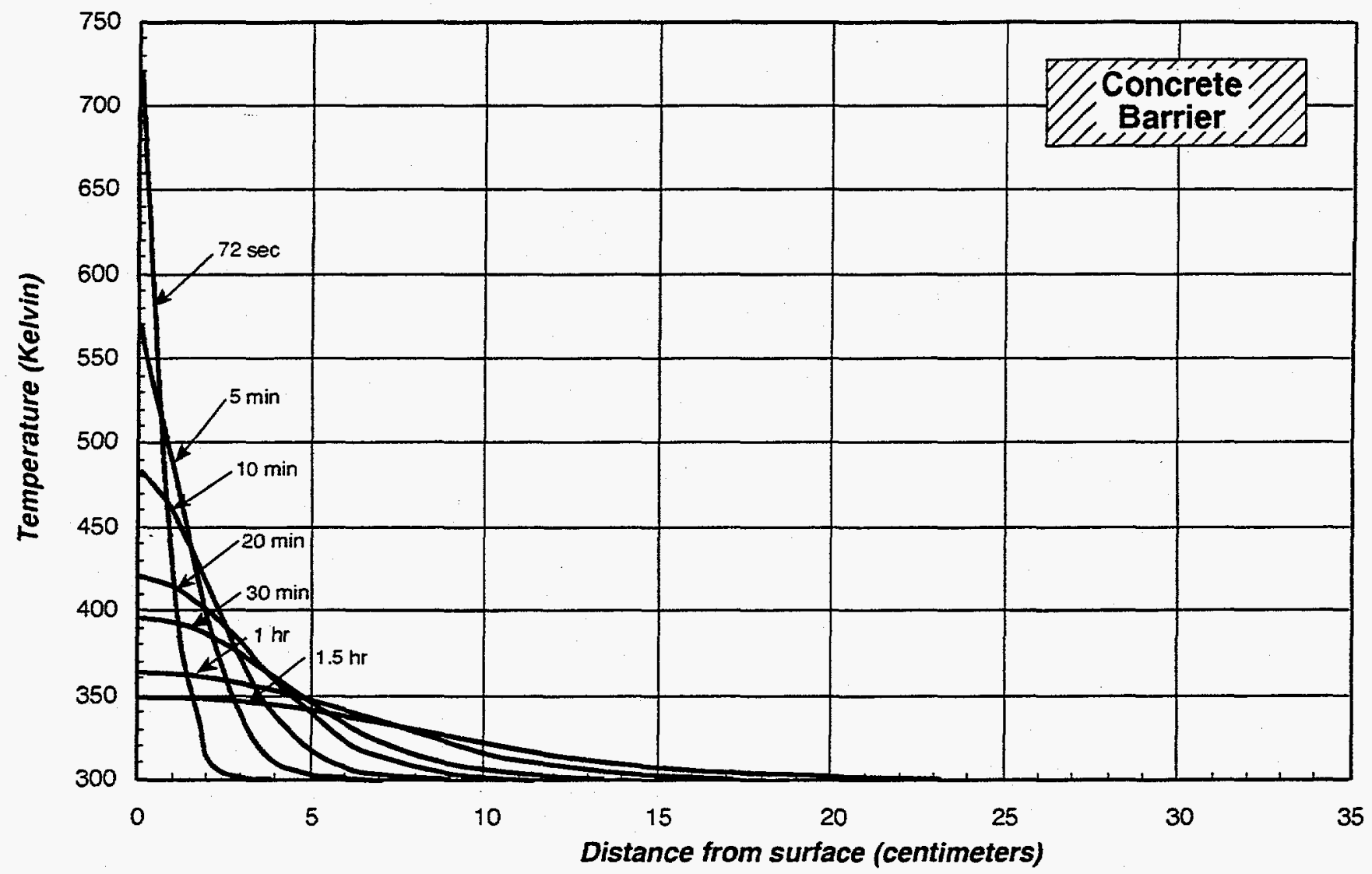

Figure 2-18

Temperature Distribution with Time for Concrete Barrier 


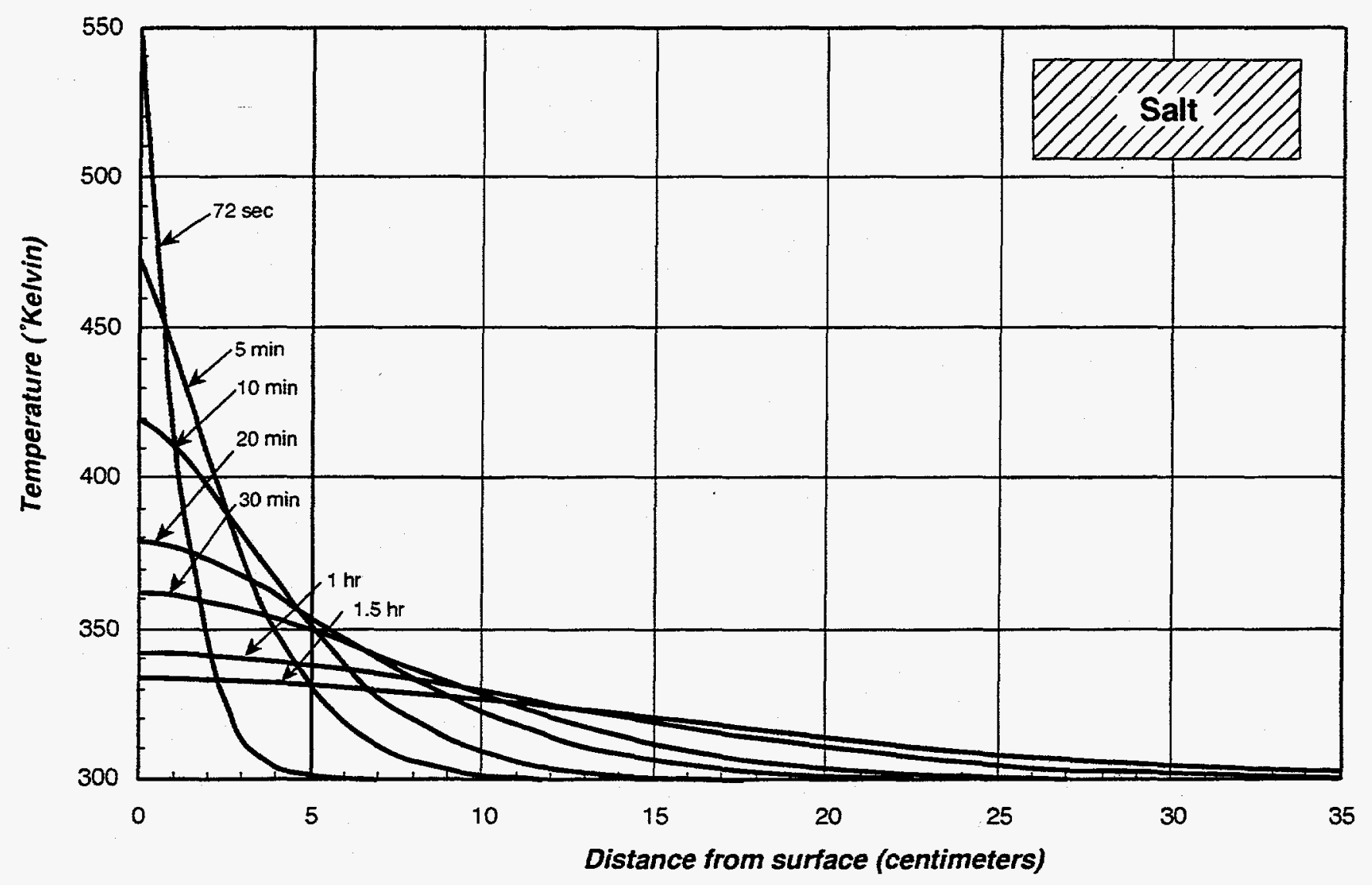

Figure 2-19

Temperature Distribution with Time for Salt 


\subsubsection{Evaluation Results}

The fractures in the roof and floor could be affected by the expansion of the gas products on the order of $240 \mathrm{psi}(1.7 \mathrm{MPa})$, which decay rapidly with time and attenuate with distance. Around the wall, the confining stress on the order of $1,450 \mathrm{psi}$ (10 MPa) could develop after 20 years, as presented in Section 2.1.3. Horizontal fracture propagation could occur around the concrete barrier only if the internal gas pressure exceeded the confining pressure. Because the peak internal pressure from the deflagration is only about one-fifth of the confining pressure, fractures would not propagate through or around the main wall.

Following an explosion, the wall would be subject to sonic waves that would impinge on the wall. As the sonic wave encountered a contrast in wall stiffness, a portion of the sonic wave would be refracted, and a portion would be reflected (Jaeger and Cook, 1972). This would result in minor tensile spalling of the isolation wall.

\subsubsection{Conclusions}

At the time of a potential explosion, the development of confining stress relative to the explosion pressure would prevent fracturing around the main concrete barrier. With the selection of a thick enough wall, the effects of a postulated methane explosion can be isolated from the main concrete barrier. 


\subsection{Design Description}

This chapter presents the final design selected from the evaluations performed in the previous chapter. It presents design modifications to cover a range of conditions that may be encountered in the underground and describes the design components for the panel-closure system. Finally, information is presented on the proposed construction for the panel-closure system.

\subsection{Design Concept}

The composite panel-closure system selected is (1) a standard concrete barrier, rectangular in shape, or (2) an enlarged tapered concrete barrier. Options (1) and (2) will be grouted along the interface and may contain explosion- or construction-isolation walls. Figure 3-1 illustrates these design components. The construction methods and materials to be used to implement the design have been proven in previous mining and construction projects. The standard concrete barrier without DRZ removal will most likely apply to future panel air-intake and air-exhaust drifts where the time duration between excavation and barrier emplacement is short. The enlarged concrete barrier with DRZ removal would apply to Panel 1 where a significant time lapse will occur between excavation and barrier emplacement. The design concept for the enlarged concrete barrier incorporates:

- A concrete barrier that is tapered to promote the rapid stress buildup on the host rock. The stiffness was selected to provide rapid buildup of compressive stress and reduction in shear stress in the host rock.

- The enlarged barrier requires DRZ removal just beyond Clay G and MB 139, and to a corresponding distance in the ribs to keep the tapered shape approximately spherical. The design includes DRZ removal and thereby limits VOC flow through the panel-closure system.

- The design of the panel-closure system includes either a construction- or an explosion-isolation wall designed to provide strength and deformational serviceability during the operational period. The length was selected to assure that uniform compression develops over a substantial portion of the structure and that end-shear loading that might result in fracturing of salt into the back is reduced.

\subsection{Design Options}

The design options consist of the following: 


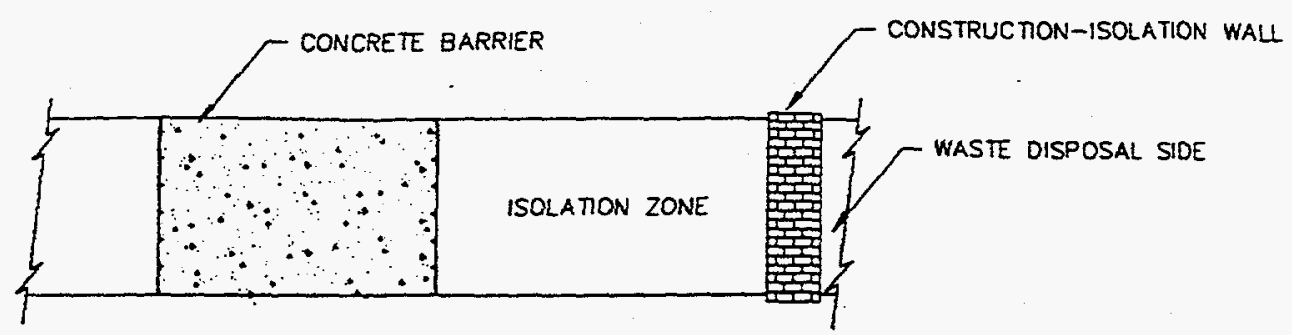
$\frac{\text { A. CONCRETE BARRIER WITHOUT DRZ REMOVED }}{\text { AND CONSTRUCTION ISOLATION WALL }}$

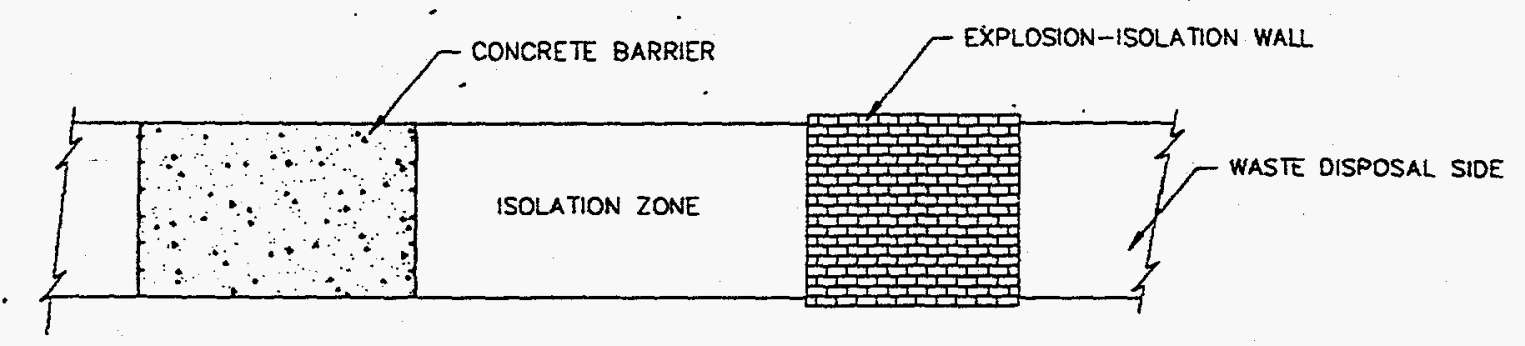

B. CONCRETE BARRIER WITHOUT DRZ REMOVED AND EXPLOSION ISOLATION WALL

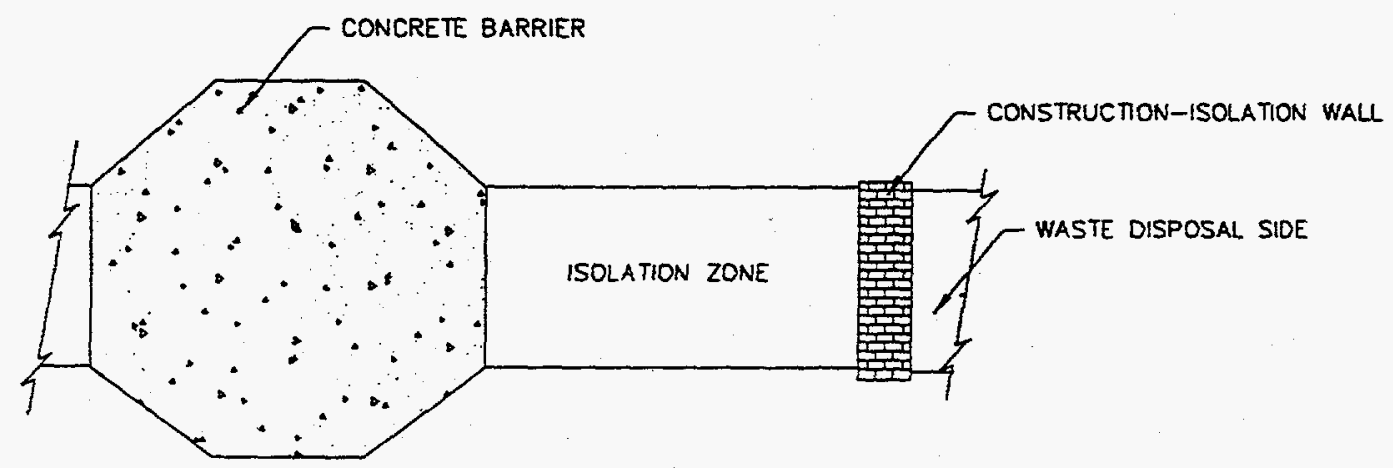

C. CONCRETE BARRIER WITH DRZ REMOVED AND CONSTRUCTION ISOLATION WALL

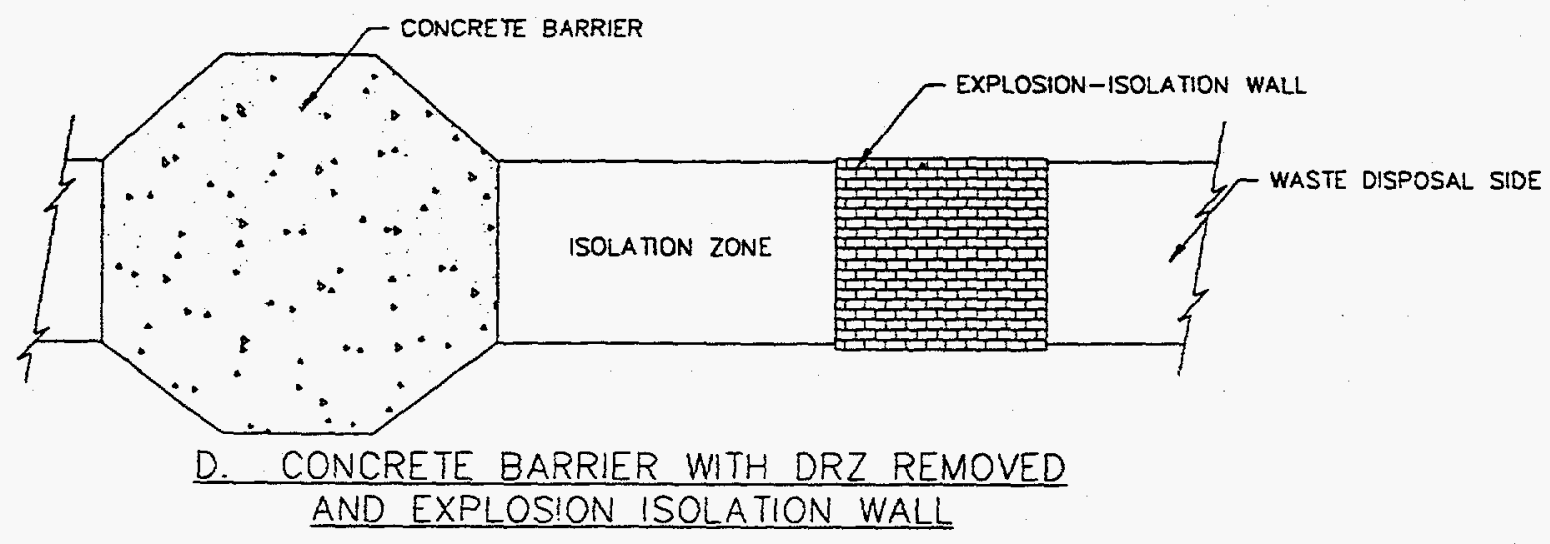

Figure 3-1

Main Concrete Barrier with Wall Combinations 
- An enlarged concrete barrier with the DRZ removed and a construction-isolation wall

- An enlarged concrete barrier with the DRZ removed and an explosion-isolation wall

- A rectangular concrete barrier without the DRZ removed and a construction-isolation wall

- A rectangular concrete barrier without the DRZ removed and an explosion-isolation wall.

In each case, interface grouting will be used for the upper barrier/salt interface. The process for selecting these options would depend on the subsurface conditions at the panel-closure system locations described in the following subsections.

\subsubsection{Selection of the Concrete Barrier}

The design provides flexibility to satisfy the design migration limit for the flow of VOCs out of the panel. An enlarged concrete barrier will be selected where air-intake and air-exhaust drifts have fractured with age resulting in significant flow of VOCs. These conditions apply to the most severe ground conditions in the air-intake and air-exhaust drifts of Panel 1. If ground conditions are more favorable such as might be the case for future panel entries, then the panel-closure system can be simplified to a standard concrete barrier, rectangular in shape, with a construction-isolation wall.

Several methods are available for detecting the location and extent of fractures in the DRZ (DOE, 1995). These methods include ground-penetrating radar and observation boreholes, which have already been used for underground fracture detection at the WIPP (DOE, 1995). These methods will be used to determine when conditions are favorable, and the standard concrete barrier can be used to limit/restrict VOC flow.

The GPR methods and other exploratory methods show where fractures are minimal in order to select an optimum location for the panel-closure system. In such areas, the design can be simplified to a standard concrete barrier without DRZ removal. The area with the least number of fractures as determined by these exploratory methods would mean that compressive stresses increase on the standard concrete barrier. The effective concrete barrier permeability will be reduced with time as stresses increase on the standard concrete barrier. 
GPR is a nondestructive electromagnetic reflection technique that is sensitive to variations in the dielectrical constant of rock salt. The use of GPR is a proven technology for detecting shallow fracture zones in the underground and will have practical value in determining the location of a panel-closure system (TT, 1993). GPR surveys perpendicular to the long axis and axial surveys of the drift would provide data to determine the optimum location for the main concrete barrier. Fractured rock will be removed as necessary for installation of the concrete barrier.

For future waste-emplacement panels, GPR will be used to monitor fracture development. Radar surveys could be conducted shortly after excavation to provide a baseline with which to compare future radar surveys. GPR will be used periodically to monitor the development of brittle deformation occurring in the new air-intake and air-exhaust drifts.

Observation boreholes will be drilled into the roof or floor of the new air-intake and airexhaust drifts and will be used for observation of fractures and bed separation. Observations can be made in the boreholes using a small video camera, or a scratch rod. A scratch rod survey will be performed in accordance with the current Excavation Effects Program (EEP) procedure.

The EEP was initiated in 1986 with the occurrence of fractures in Site and Preliminary Design Validation Room 3. The purpose of the EEP is to study fractures that develop as a result of underground excavation at the WIPP and to monitor those fractures. Borehole inspections have been successful for determining the fracturing and bed separation in the host rock. These inspections have been performed since 1983 (Francke and Terrill, 1993). This technique in addition to the above will be used to determine the optimum location for the panel-closure system.

\subsubsection{Selection of an Explosion- or Construction-Isolation Wall}

While no requirements for barricading waste areas exist under the MSHA, the intent of the regulations is to safely isolate abandoned areas from active workings using barricades of "substantial construction." The previous analysis (DOE, 1995) examined the issue of methane gas generation from TRU waste and its potential consequence in closed areas. The principal concern is the occurrence of an explosive mixture of methane and an ignition source, which would result in deflagration. If a methane explosion is considered possible, an explosionisolation wall of sufficient thickness will be used to resist dynamic and creep loads. In the absence of explosive conditions, a construction-isolation wall will be used. 


\subsection{Design Components}

The following subsections present system and components design features.

\subsubsection{Concrete Barrier}

The enlarged concrete barrier consists of plain concrete, with sufficient unconfined compressive strength and with an approximately circular cross-section excavated into the salt over the central portion of the barrier (Figure 3-2). The enlarged concrete barrier will be located at the optimum locations in the air-intake and air-exhaust drifts with the central portion extending just beyond Clay G and MB 139.

The enlarged concrete barrier will be placed in four cells, with construction joints perpendicular to the direction of potential air flow. The concrete strength will be selected according to the standards specified by the latest edition of the ACI code for plain concrete. The concrete will be placed through 6-inch- $(15-\mathrm{cm})$-diameter steel pipes and vibrated from outside the formwork. The formwork is designed to withstand the hydrostatic loads during construction, with minimal bracing onto exposed salt surfaces. This will be accomplished by placing a series of steel plates that are stiffened by angle iron, with load reactions carried by spacer rods. The spacer rods will be staggered to reduce potential flow along the rod surfaces through the barrier. Some exterior bracing will be required when the first cell is poured. All structural steel will be ASTM A36, with detailing, fabrication, and erection of structural steel in conformance with the latest edition of the AISC steel manual (AISC, 1989). After concrete placement, the formwork will be left in place.

The above design is for the most severe conditions expected to be encountered at the WIPP. If actual conditions are found to be more favorable (i.e., if the age of the entries at the time of emplacement is less, and if the fractured DRZ does not develop, or there is adequate design margin for the flow of VOCs), the design can be simplified to a rectangular barrier without DRZ removal (Figure 3-3).

\subsubsection{Explosion- and Construction-Isolation Walls}

An explosion-isolation wall, consisting of concrete-blocks, will mitigate the effects of a postulated methane explosion. The explosion-isolation wall consists of 3,500-psi (24-MPa) concrete blocks mortared together with cement (Figure 3-4).

The concrete block wall design complies with MSHA requirements (MSHA, 1987) because it uses incombustible materials of substantial construction. The explosion-isolation wall will be 


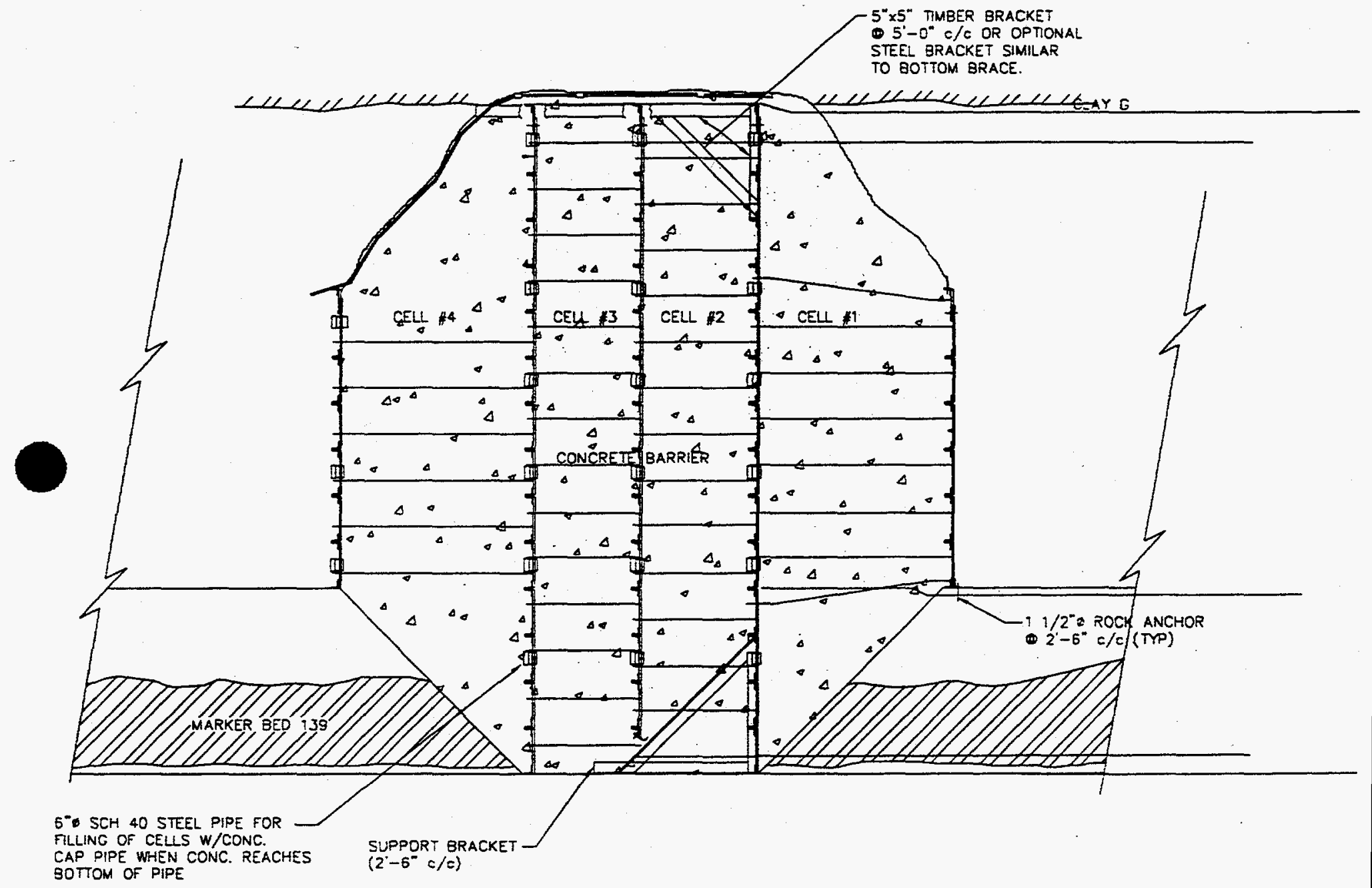

Figure 3-2

Concrete Barrier with DRZ Removal 
placed into the salt for support. The explosion-isolation walls are designed to resist creep loading from salt deformation. In the absence of the postulated methane explosion, the design will be simplified to a construction-isolation wall. The construction-isolation wall design provides temporary isolation during the time the main concrete barrier is being constructed.

\subsubsection{Interface Grouting}

After construction of the main concrete barrier, the interface between the main concrete barrier and the salt will be grouted through a series of grout-supply and air-return lines that will terminate in grout distribution collection boxes. The openings in these boxes will be protected during concrete placement (Figure 3-5). The grout boxes will be mounted near the top of the barrier. The grout will be injected through one distribution system, with air and return grout flowing through a second distribution system.

\subsection{Panel-Closure System Construction}

The construction methods and materials to be used to implement the design have been proven in previous mining and construction projects. The design uses common construction practices according to existing standards. The proposed construction sequence follows completion of the waste-emplacement activities in each panel: (1) Perform subsurface exploration to determine the optimum location for the panel closure system, (2) select the appropriate design option for the location, (3) prepare surfaces for the construction- or explosion-isolation walls (if required), (4) install these walls, (5) excavate for the enlarged concrete barrier (if required), (6) install concrete formwork, (7) emplace concrete for the first cell, (8) grout the completed cell, and (9) install subsequent formwork, concrete and grout until completion of the enlarged concrete barrier.

The explosion-isolation or construction-isolation walls will be located at some distance from the main concrete barrier. The host rock will be excavated 6 inches $(15 \mathrm{cms})$ around the entire perimeter prior to installing the explosion-isolation wall. The surface preparation will produce a level surface for placing the first layer of concrete blocks. Excavation may be performed by either mechanical or manual means.

Excavation for the enlarged concrete barrier will be performed using mechanical means, such as a cutting head on a suitable boom. The existing roadheader at the main barrier location in each drift is capable of excavating the back and the portions of the ribs above the floor level. Some manual excavation may be required in this situation as well. If mechanical means are not available, drilling boreholes and an expansive agent can be used to fragment the rock 
CLAY G

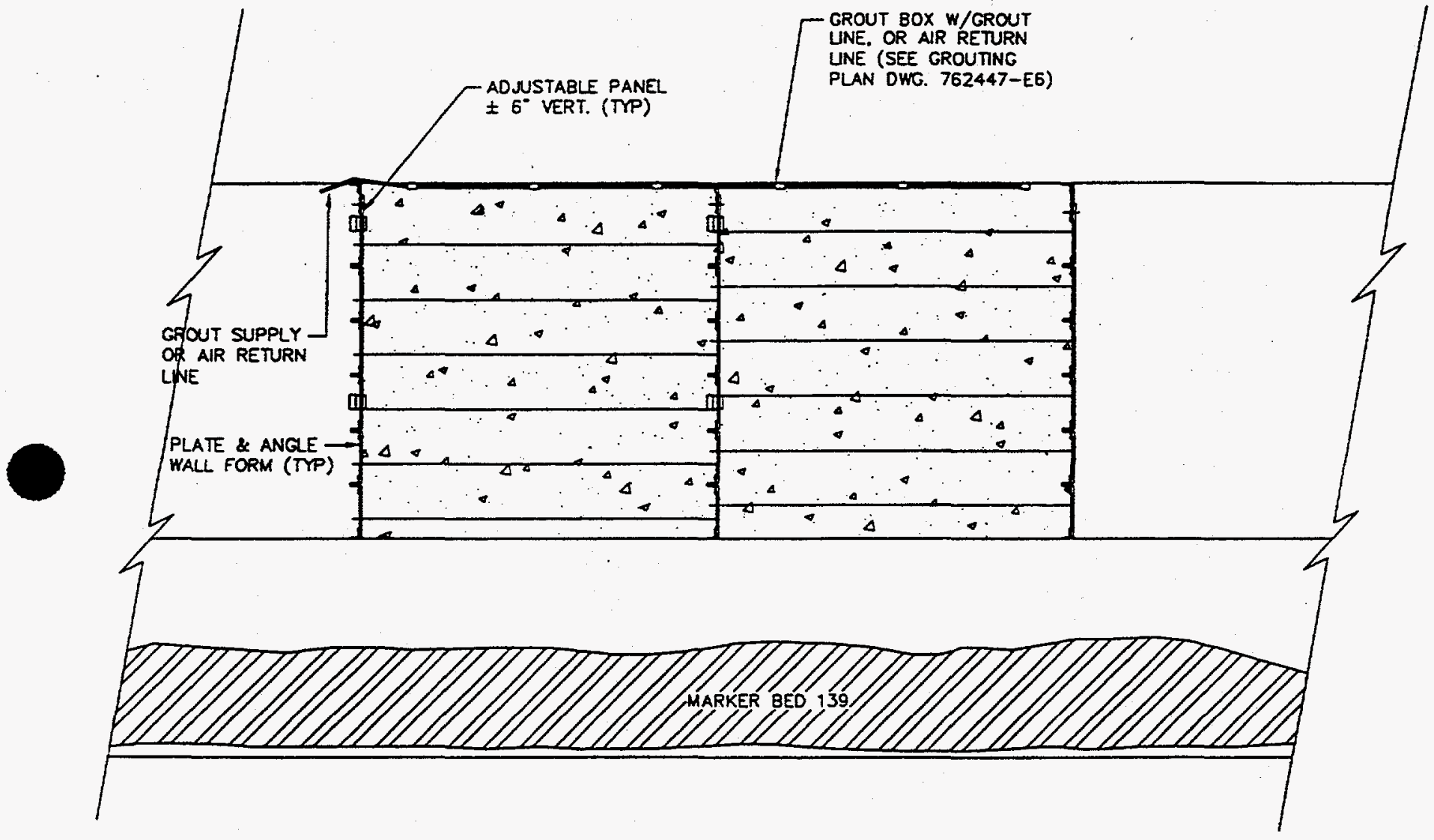

Figure 3-3

Concrete Barrier Without DRZ Removal 


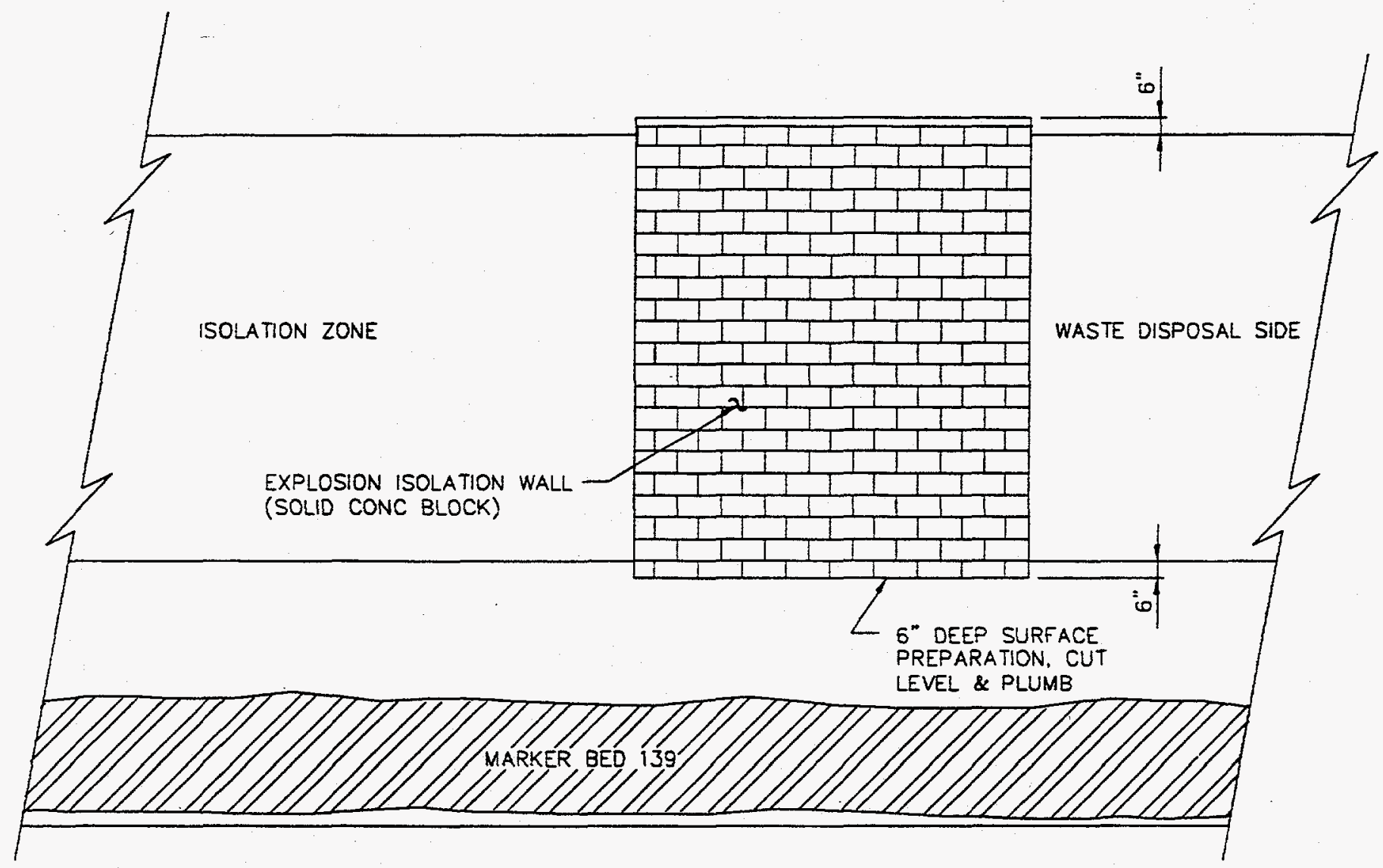

Figure 3-4

Explosion-Isolation Wall 
Plate and Angle Wall Form (Typical)

菅

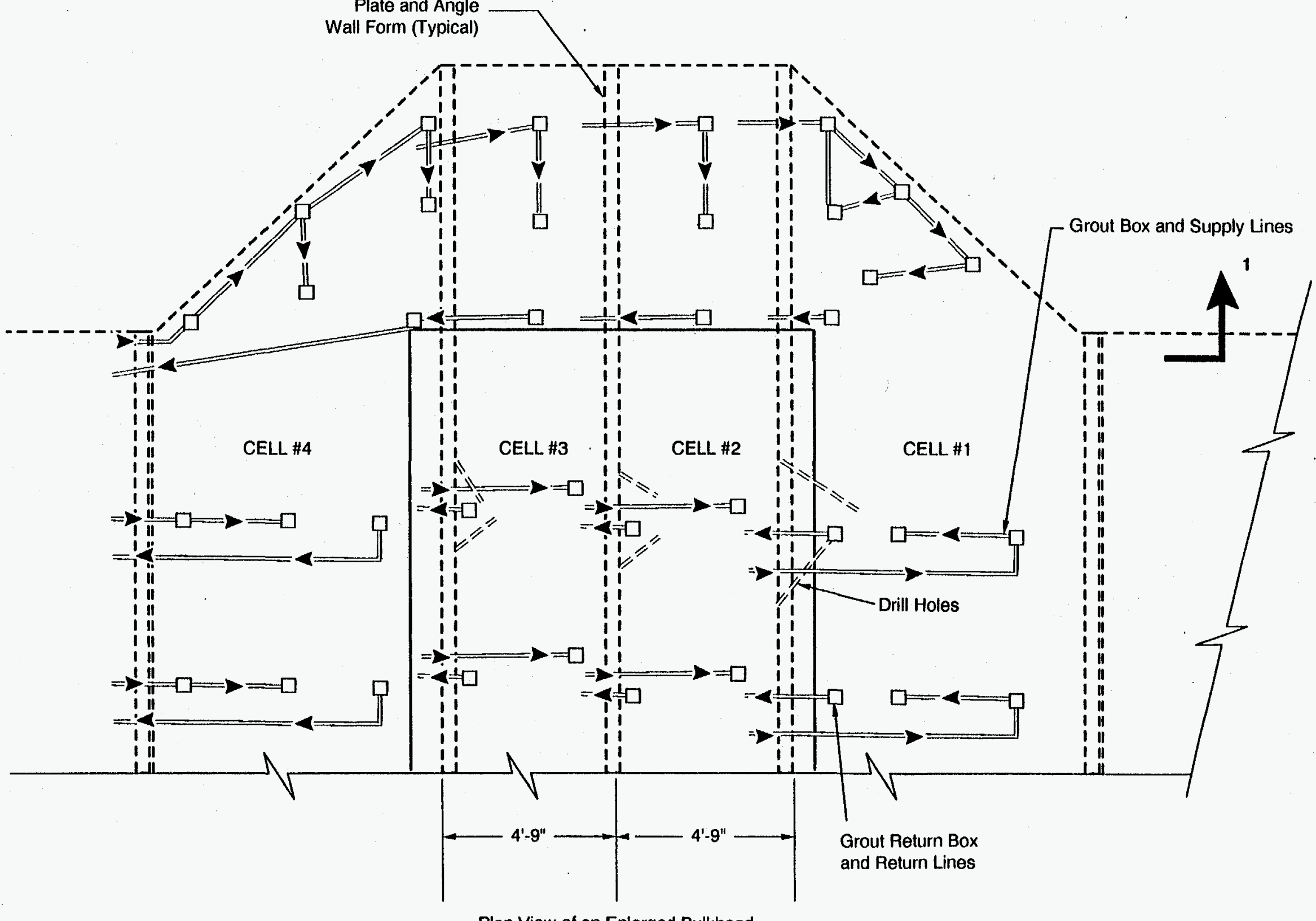

Plan View of an Enlarged Bulkhead

Figure 3-5

Grouting Details 
(Fernandez et al., 1989). Excavation will follow the lines and grades established for the design. The roof will be excavated to just above Clay $\mathrm{G}$ and then the floor to just below MB 139 to remove the DRZ. The tolerances for the enlarged concrete-barrier excavation are +6 to 0 inches $(+15$ to $0 \mathrm{~cm}$ ). In addition, loose or spalling rock from the excavation surface will be removed to provide an appropriate surface abutting the enlarged concrete barrier. The excavations will be performed according to approved ground control plans.

Following completion of the roof excavation for the enlarged barrier, the floor will be excavated. If mechanical means are not available, drilling boreholes and using an expansive agent to fragment the rock (Fernandez et al., 1989) is a method that can be used. Expansive agents would load the rock salt and anhydrite, producing localized tensile fracturing in a controlled manner, to produce a sound surface.

A batch plant at the surface or underground will be prepared for batching, mixing, and delivering the concrete to the underground in sufficient quantity to complete placement of the concrete within one form cell. The placement of concrete will be continuous until completion, with a target time for completing one section of 8 to 10 hours, allowing an additional 2 hours for cleanup of equipment.

Pumping equipment suitable for placing the concrete into the forms will be provided at the main concrete barrier location. After transporting, and prior to pumping, the concrete will be remixed to compensate for segregation of aggregate during transport. Batch concrete will be checked at the surface at the time of mixing and again at the point of transfer to the pump for slump and temperature. Admixtures may be added at the remix stage in accordance with the batch design. 


\subsection{Design Calculations}

Table 4-1 summarizes calculations to support the construction details for an explosionisolation wall, construction-isolation wall, and structural steel formwork for concrete barriers up to a 29-ft high. The codes for the explosion-isolation and construction-isolation wall are specified by the Uniform Building Code (International Conference of Building Officials, 1994), with related seismic design requirements. The external loads for the solid block wall are as developed in the methane-explosion and fracture propagation design evaluations.

\section{Table 4-1 \\ Constructability Design Calculations Index}

\begin{tabular}{|c|l|c|}
\hline Section & \multicolumn{1}{|c|}{ Design Area } & Category \\
\hline 1.0 & Explosion-isolation wall & $\mathrm{W}$ \\
\hline 2.0 & Explosion-isolation wall seismic check & $\mathrm{S}$ \\
\hline 3.0 & Formwork design & $\mathrm{F}$ \\
\hline
\end{tabular}

The structural formwork for all cells is designed in accordance with the AISC guidelines on allowable stress (AISC, 1989). Lateral pressures are developed using ACI 347R-88, using a standard concrete weighing 150 pounds per cubic foot $\left(2,410 \mathrm{~kg} / \mathrm{m}^{3}\right)$ with a slump of 8 inches $(20 \mathrm{~cm})$ or less. Design loadings reflect full hydrostatic head of concrete, with lifts spaced at $4 \mathrm{ft}(1.2 \mathrm{~m})$ intervals from bottom to top through portals, with no external vibration. All forms will remain in place. 


\subsection{Technical Specifications}

The specifications are in the engineering file room at the WIPP and are the property of

Westinghouse WID. These specifications are included as an attachment in Appendix G and summarized in Table 5-1.

\section{Table 5-1}

Technical Specifications for the WIPP Panel-Closure System

\begin{tabular}{|c|c|}
\hline \multicolumn{2}{|c|}{ Division 1 - General Requirements } \\
\hline Section 01010 & Summary of Work \\
\hline Section 01090 & Reference Standards \\
\hline Section 01400 & Contractor Quality Control \\
\hline Section 01600 & Material and Equipment \\
\hline \multicolumn{2}{|c|}{ Division 2 - Site Work } \\
\hline Section 02010 & Mobilization and Demobilization \\
\hline Section 02222 & Excavation \\
\hline Section 02722 & Grouting \\
\hline \multicolumn{2}{|c|}{ Division 3 - Concrete } \\
\hline Section 03100 & Concrete Formwork \\
\hline Section 03300 & Cast-in-Place Concrete \\
\hline \multicolumn{2}{|c|}{ Division 4 - Masonry } \\
\hline Section 04100 & Mortar \\
\hline Section 04300 & Unit Masonry System \\
\hline
\end{tabular}




\subsection{Drawings}

The drawings (Appendix $\mathrm{H}$ ) are in the engineering file room at the WIPP and are the property of the Westinghouse WID and summarized in Table 6-1.

Table 6-1

Panel-Closure System Drawings

\begin{tabular}{|c|l|}
\hline Drawing Number & \multicolumn{1}{|c|}{ Title } \\
\hline \hline $762447-E 1$ & Title Sheet \\
\hline $762447-E 2$ & Underground Waste Disposal Plan \\
\hline $762447-E 3$ & Air Intake Drift Construction Details \\
\hline $762447-E 4$ & Air Exhaust Drift Construction Details \\
\hline $762447-E 5$ & Construction and Explosion Barrier Construction Details \\
\hline $762447-E 6$ & Grouting and Miscellaneous Details \\
\hline
\end{tabular}




\subsection{Conclusions}

This chapter presents the conclusions for the detailed design activities of the panel-closure system. A design basis, including the operational requirements, the structural and material requirements, and the construction requirements, was developed that addresses the governing regulations for the panel-closure system. Table 7-1 summarizes the design basis for the panel-closure system and the compliance with the design basis. The panel-closure system design incorporates mitigative measures to address the treatment of fractures and therefore counter the potential migration of VOCs. Several alternatives were evaluated for the treatment of fractures. These included excavation and emplacement of a fully enlarged barrier with removal of the DRZ, excavation of the roof and emplacement of a partially enlarged barrier, and emplacement of a standard barrier with formation grouting.

To investigate several key design issues and to implement the design, design evaluations were performed. These design evaluations can be divided into evaluations satisfying the operational requirements of the system and evaluations satisfying the structural and materials requirements of the system. The conclusions reached from the evaluations addressing the operational requirements are as follows:

- Based on an air-flow model used to predict the mass flow rate of carbon tetrachloride through the panel-closure system for the alternatives, the air-flow analysis suggests that the fully enlarged barrier is the most protective for restricting VOCs during the operational period of 35 years.

- Results of the FLAC analyses show that the recommended enlarged configuration is a circular rib-segment excavated to Clay G and under MB 139. Interface grouting would be performed at the upper boundary of the concrete barrier.

- The results of the transverse plane-strain models show that high stresses would form in MB 139 following excavation, but that after installation of the panelclosure system, an increase in barrier-confining stress and a reduction in shear stress would result. The concrete barrier would provide substantial uniform confining stresses as the barrier is subjected to secondary salt creep.

- The removal of the fractured salt prior to installation of the main concrete barrier would reduce the potential for flexure. With the removal of MB 139 , the fractured salt stiffens the surrounding rock and results in the development of more uniform compression. 
Table 7-1

Compliance of the Design with the Design Requirements

\begin{tabular}{|c|c|c|c|c|}
\hline $\begin{array}{c}\text { Type of } \\
\text { Requirement }\end{array}$ & Requirement & Section & $\begin{array}{l}\text { Compliance with } \\
\text { Requirement }\end{array}$ & Notes on Compliance \\
\hline \multirow[t]{6}{*}{ Operational } & $\begin{array}{l}\text { Individual panels shall be closed in accordance with the } \\
\text { schedule of actual waste emplacement. }\end{array}$ & 2.1 .1 & Complies & $\begin{array}{l}\text { Gas-flow models used for design are } \\
\text { based on the waste-emplacement } \\
\text { operational schedule. }\end{array}$ \\
\hline & $\begin{array}{l}\text { The panel-closure system shall provide assurance that the limit } \\
\text { for the migration of volatile organic compounds (VOC) of } \\
\text { concern will be met at the point of compliance. To achieve this } \\
\text { assurance, the design shall consider the potential flow of VOCs } \\
\text { through the several components of the disturbed rock zone and } \\
\text { the panel-closure system. }\end{array}$ & $\begin{array}{l}2.1 .1 \\
2.1 .2\end{array}$ & Complies & $\begin{array}{l}\text { Gas-flow modeling shows that the VOC } \\
\text { flow is loss than the design migration } \\
\text { limit. }\end{array}$ \\
\hline & $\begin{array}{l}\text { The panel-closure system shall comply with its intended } \\
\text { functional requirements under loads generated from creep } \\
\text { closure and any internal pressure that might develop in the } \\
\text { disposal panel under reasonably anticipated conditions. }\end{array}$ & $\begin{array}{l}\text { 2.1.2, } \\
4.0\end{array}$ & Complies & $\begin{array}{l}\text { Stress analyses and design calculations } \\
\text { show that the panel-closure system } \\
\text { performs as intended. }\end{array}$ \\
\hline & $\begin{array}{l}\text { The panel-closure system shall comply with its intended } \\
\text { functional requirements under a postulated methane explosion. }\end{array}$ & $\begin{array}{l}2.2 .3 \\
2.2 .4 \\
4.0\end{array}$ & Complies & $\begin{array}{l}\text { The methane explosion studies, fracture } \\
\text { propagation studies, and supporting } \\
\text { design calculations show that the panel- } \\
\text { closure system performs as intended. }\end{array}$ \\
\hline & $\begin{array}{l}\text { The panel-closure system for each individual panel shall not } \\
\text { require routine maintenance during its operational life. }\end{array}$ & 3.2 & Complies & $\begin{array}{l}\text { Passive design components require no } \\
\text { routine maintenance. }\end{array}$ \\
\hline & $\begin{array}{l}\text { The panel-closure system shall address the most severe } \\
\text { ground conditions expected in the panel entries. If actual } \\
\text { conditions are found to be more favorable, this design can be } \\
\text { simplified and still satisfy the operational requirements of the } \\
\text { system. }\end{array}$ & $\begin{array}{l}2.1 .1 \\
2.1 .3 \\
3.2\end{array}$ & Complies & $\begin{array}{l}\text { Design is based upon flow and structural } \\
\text { analyses for the most severe expected } \\
\text { ground conditions. If conditions are less } \\
\text { severe, simpler design options are used. } \\
\text { The various design options accommodate } \\
\text { all expected conditions. }\end{array}$ \\
\hline
\end{tabular}


Table 7-1 (Continued)

\section{Compliance of Design with the Design Requirements}

\begin{tabular}{|c|c|c|c|c|}
\hline $\begin{array}{c}\text { Type of } \\
\text { Requirement }\end{array}$ & Requirement & Section & $\begin{array}{l}\text { Compliance with } \\
\text { Requirement }\end{array}$ & Notes on Compliance \\
\hline \multirow{2}{*}{$\begin{array}{l}\text { Design } \\
\text { configuration and } \\
\text { essential features }\end{array}$} & $\begin{array}{l}\text { The panel-closure system shall be emplaced in the air-intake } \\
\text { and air-exhaust drifts identified by Westinghouse (1995c) }\end{array}$ & 3.2 & Complies & $\begin{array}{l}\text { The design shows placement in the } \\
\text { designated areas for panel closure. }\end{array}$ \\
\hline & $\begin{array}{l}\text { The panel-closure system shall consist of a concrete barrier } \\
\text { and construction-isolation and explosion-isolation walls with } \\
\text { dimensions to satisfy the operational requirements of the } \\
\text { system. }\end{array}$ & $\begin{array}{l}3.2 \\
3.3\end{array}$ & Complies & $\begin{array}{l}\text { The panel-closure system design uses } \\
\text { the identified components with } \\
\text { dimensions to satisfy the operational } \\
\text { requirements of the system. }\end{array}$ \\
\hline \multirow[t]{2}{*}{ Safely } & $\begin{array}{l}\text { The design class for the panel-closure system shall be } 11 \mathrm{lb} \text {. } \\
\text { Design and construction shall follow conventional mining and } \\
\text { construction practices. }\end{array}$ & 3.4 & Complies & $\begin{array}{l}\text { Components are designed according to } \\
\text { Class Illb. The construction sequence } \\
\text { for the design followed conventional } \\
\text { mining practices. }\end{array}$ \\
\hline & $\begin{array}{l}\text { The structural analysis for the underground shall use the } \\
\text { empirical data acquired from the WIPP Excavation Effects } \\
\text { Program. }\end{array}$ & 2.1 .2 & Complies & $\begin{array}{l}\text { The structural analysis uses properties } \\
\text { that model creep closure for stress } \\
\text { analyses from data acquired in the WIPP } \\
\text { Excavation Effects Program. }\end{array}$ \\
\hline \multirow[t]{3}{*}{$\begin{array}{l}\text { Structural and } \\
\text { material }\end{array}$} & $\begin{array}{l}\text { The panel-closure system materials shall be compatible with } \\
\text { their emplacement environment and function. Surface } \\
\text { treatment between the host rock and the panel-closure system } \\
\text { shall be considered in the design. }\end{array}$ & 2.2 .1 & Complies & $\begin{array}{l}\text { The material compatibility studies showed } \\
\text { no degradation of materials and no need } \\
\text { for surface treatment. }\end{array}$ \\
\hline & $\begin{array}{l}\text { The selection and placement of concrete in the concrete barrier } \\
\text { shall address potential thermal cracking due to the heat of } \\
\text { hydration. }\end{array}$ & 2.2 .2 & Complies & $\begin{array}{l}\text { The heat generation studies show that } \\
\text { hydration temperatures are controlled by } \\
\text { appropriate selection of cement type and } \\
\text { placement temperature. }\end{array}$ \\
\hline & $\begin{array}{l}\text { The panel-closure system shall sustain the dynamic pressure } \\
\text { and subsequent temperature generated by a postulated } \\
\text { methane explosion. }\end{array}$ & $\begin{array}{l}2.2 .3 \\
2.2 .4 \\
4.0\end{array}$ & Complies & $\begin{array}{l}\text { The methane explosion study shows that } \\
\text { the explosion-isolation wall protects the } \\
\text { concrete barrier from pressure loading } \\
\text { and thermal loading. The fracture } \\
\text { propagation study shows that the system } \\
\text { performs as intended. }\end{array}$ \\
\hline
\end{tabular}


Table 7-1 (Continued)

Compliance of Design with the Design Requirements

\begin{tabular}{|l|l|l|l|l|}
\hline $\begin{array}{c}\text { Type of } \\
\text { Requirement }\end{array}$ & \multicolumn{1}{|c|}{ Requirement } & Section & $\begin{array}{l}\text { Compliance with } \\
\text { Requirement }\end{array}$ & \multicolumn{1}{|c|}{ Notes on Compliance } \\
\hline \hline Construction & $\begin{array}{l}\text { The panel-closure system shall use to the extent possible } \\
\text { normal construction practices according to existing standards. }\end{array}$ & 3.4 & Complies & $\begin{array}{l}\text { The specifications include normal } \\
\text { construction practices used in the } \\
\text { underground at WIPP and according to } \\
\text { the most current steel and concrete } \\
\text { specifications. }\end{array}$ \\
\cline { 2 - 5 } & $\begin{array}{l}\text { During construction of the panel-closure system, a quality } \\
\text { assurance/quality control program shall be established to verify } \\
\text { material properties and construction practices. }\end{array}$ & 3.4 & Complies & $\begin{array}{l}\text { The specifications include materials } \\
\text { testing to verify material properties and } \\
\text { construction practices. }\end{array}$ \\
\hline & $\begin{array}{l}\text { The construction specification shall take into account the shaft } \\
\text { and underground access capacities and services for materials } \\
\text { handling. }\end{array}$ & 3.4 & Complies & $\begin{array}{l}\text { The specifications allow construction } \\
\text { within the capacities of underground } \\
\text { access. }\end{array}$ \\
\hline
\end{tabular}


- The trade-off study also showed that a panel-closure system with an enlarged concrete barrier with the removal of the fractured salt roof and anhydrite in the floor was found to be the most protective.

The conclusions reached from the design evaluations addressing the structural and material requirements of the panel-closure system are as follows:

- Existing information on the heat of hydration of the concrete supports placing concrete with a low cement content to reduce the temperature rise associated with hydration. The slump at the required strength would be achieved through the use of plasticizers. A thermal analysis coupled with a salt creep analysis suggest installation of the enlarged barrier at or below ambient temperatures to adequately control hydration temperatures.

- In addition to installation at or below ambient temperatures, the concrete used in the main concrete barrier would exhibit the following:

- An 8 inch (0.2 meter) slump after 3 hours of intermittent mixing

- A less-than-25-degree Fahrenheit heat rise prior to installation

- An unconfined compressive strength of 4,000 psi (28 $\mathrm{MPa}$ ) after 28 days

- Volume stability

- Minimal entrained air.

- The trace amounts of brine from the salt at the repository horizon should not degrade the main concrete barrier for at least 35 years.

- In 20 years, the open passage above the waste stack would be reduced in size. Further, rooms with bulkheads at each end would be isolated in the panel. It is unlikely that a long passage with an open geometry would exist; therefore, the dynamic analysis considered a deflagration with a peak explosive pressure of 240 psi $(1.7 \mathrm{MPa})$.

- The heat-transfer analysis shows that elevated temperatures would occur within the salt and the explosion-isolation wall; however, the elevated temperatures will be isolated by the panel-closure system. Temperature gradients will not significantly affect the stability of the wall.

- The fractures in the roof and floor could be affected by expanding gas products reaching pressures of the order of $240 \mathrm{psi}(1.7 \mathrm{MPa})$. Because the peak internal pressure from the deflagration is only one fifth of the pressure, fractures could not propagate beyond the wall.

The design options to satisfy the design requirements for the panel-closure system include (1) a standard barrier, rectangular in shape, or (2) an enlarged concrete barrier, approximately 
spherical in shape. Options (1) and (2) will be grouted at the interface and may contain explosion- or construction-isolation walls.

The design provides flexibility to satisfy the design migration limit for the flow of VOCs out of the panels. An enlarged concrete barrier would be selected where the air-intake and airexhaust drifts have aged and where there is fracturing resulting in significant flow of VOCs. These conditions apply to the most severe ground conditions in the air-intake and air-exhaust drifts of Panel 1. If ground conditions are more favorable, such as might be the case for future panel entries, the design can be simplified to a standard concrete barrier rectangular in shape, with a construction isolation wall. GPR and observation boreholes are available for detecting the location and extent of fractures in the DRZ. These methods will be used to select the optimum location and appropriate panel-closure system.

The design is presented in this report as a series of calculations, engineering drawings, and technical performance specifications. The drawings illustrate the construction details for the system. The technical performance specifications cover the general requirements of the system, site work, concrete, and masonry. Information on the proposed construction method is also presented.

The design complies with all aspects of the design basis established for the WIPP panelclosure system. The design can be constructed in the underground environment with no special requirements at the WIPP. 


\subsection{References}

American Concrete Institute (ACI), 1994a, "Building Code Requirements for Structural Plain Concrete (ACI 318.1-89([92])," ACI Manual of Concrete Practice, American Concrete Institute, Detroit, Michigan.

American Concrete Institute (ACI), 1994b, "Guide for Measuring, Mixing, Transporting, and Placing Concrete (ACI 304R-89)," ACI Manual of Concrete Practice, American Concrete Institute, Detroit, Michigan.

American Concrete Institute (ACI), 1994c, "Specifications for Structural Concrete for Buildings (ACI 301-89)," American Concrete Institute, ACI Manual of Concrete Practice, Detroit Michigan.

American Concrete Institute (ACI), de, "Standard Practice for Selecting Proportions for Normal, Heavy Weight, and Mass Concrete (ACI 211.1-91)," American Concrete Institute, ACI Manual of Concrete Practice, Detroit Michigan.

American Concrete Institute (ACI), 1994e, " Guide to Formwork for Concrete (ACI 34794)," American Concrete Institute, ACI Manual of Concrete Practice, Detroit Michigan.

American Institute of Steel Construction (AISC), 1989, "Specification for the Design of Structural Steel Buildings," AISC Manual of Steel Construction, American Institute of Steel Construction, Inc., New York, New York.

American Society for Testing and Materials (ASTM), 1995a, "Standard Test Method for Laboratory Determination of Water (Moisture) Content of Soil and Rock," ASTM D 2216-92, American Society for Testing and Materials, Philadelphia, Pennsylvania.

American Society for Testing and Materials (ASTM), 1995c, "Standard Test Method for Sieve Analysis of Fine and Coarse Aggregates," ASTM C 136-95a, American Society for Testing and Materials, Philadelphia, Pennsylvania.

American Society for Testing and Materials (ASTM), 1995c, "Standard Specification for Ready-Mixed Concrete," ASTM C 94-94, American Society for Testing and Materials, Philadelphia, Pennsylvania.

American Society for Testing and Materials (ASTM), 1995d, "Standard Specification for Concrete Aggregates," ASTM C 33-93, American Society for Testing and Materials, Philadelphia, Pennsylvania.

American Society for Testing and Materials (ASTM), 1995e, "Standard Test Method for Compressive Strength of Cylindrical Concrete Specimens," ASTM C 39-94, American Society for Testing and Materials, Philadelphia, Pennsylvania. 
American Society for Testing and Materials (ASTM), 1995f, "Standard Specification for Masonry Cement," ASTM C91-95, American Society for Testing and Materials, Philadelphia, Pennsylvania.

American Society for Testing and Materials (ASTM), 1995g, "Standard Test Method for Heat of Hydration of Hydraulic Cement," ASTM C 186-94, American Society for Testing and Materials, Philadelphia, Pennsylvania.

American Society for Testing and Materials (ASTM), 1995h, "Standard Test Method for Time of Setting of Concrete Mixtures by Penetration Resistance," ASTM C 403-95, American Society for Testing and Materials, Philadelphia, Pennsylvania.

American Society for Testing and Materials (ASTM), 1995i, "Standard Specification for Aggregate for Masonry Mortar," ASTM C 144-93, American Society for Testing and Materials, Philadelphia, Pennsylvania.

American Society for Testing and Materials (ASTM), 1995j, "Standard Specification for Hydrated Lime for Masonry Purposes," ASTM C 207-91, American Society for Testing and Materials, Philadelphia, Pennsylvania.

American Society for Testing and Materials (ASTM), 1995k, "Standard Specification for Mortar for Unit Masonry," ASTM C 270-94, American Society for Testing and Materials, Philadelphia, Pennsylvania.

American Society for Testing and Materials (ASTM), 19951, "Standard Specification for Coal Fly Ash and Raw or Calcined Natural Pozzolan for Use as a Mineral Admixture in Portland Cement Concrete," ASTM C 618-94a, American Society for Testing and Materials, Philadelphia, Pennsylvania.

American Society for Testing and Materials (ASTM), 1995m, "Standard Specification for Concrete Building Brick," ASTM C 55-94a, American Society for Testing and Materials, Philadelphia, Pennsylvania.

American Society for Testing and Materials (ASTM), 1995n, "Test Method for Compressive Strength of Hydraulic Cement Mortars," ASTM C 109-95, American Society for Testing and Materials, Philadelphia, Pennsylvania.

American Society for Testing and Materials (ASTM), 1995o, "Standard Methods of Sampling and Testing Concrete Masonry Units," ASTM C 140-94a, American Society for Testing and Materials, Philadelphia, Pennsylvania.

American Society for Testing and Materials (ASTM), 1995p,"Standard Specification for Slump of Hydraulic Cement," ASTM C 143-90a, American Society for Testing and Materials, Philadelphia, Pennsylvania. 
American Society for Testing and Materials (ASTM), 1995q, "Standard Specification for Portland Cement," ASTM C 150-95, American Society for Testing and Materials, Philadelphia, Pennsylvania.

American Society for Testing and Materials (ASTM), 1995r, "Standard Practice for Laboratories Testing Concrete and Concrete Aggregates for Use in Construction and Criteria for Laboratory Evaluation," ASTM C 1077-95a, American Society for Testing and Materials, Philadelphia, Pennsylvania.

American Society for Testing and Materials (ASTM), 1995s, "Standard Practice for Accreditation of Testing Agencies for Unit Masonry," ASTM C 1093-88, American Society for Testing and Materials, Philadelphia, Pennsylvania.

American Society for Testing and Materials (ASTM), 1995t, "Standard Specification for Packaged Dry, Hydraulic-Cement Grout (Nonshrink)," ASTM C 1107-91a, American Society for Testing and Materials, Philadelphia, Pennsylvania.

American Society for Testing and Materials (ASTM), 1995u, "Standard Ready-Mixed Mortar for Unit Masonry," ASTM C 1142-94, American Society for Testing and Materials, Philadelphia, Pennsylvania.

American Society for Testing and Materials (ASTM), 1995v, "Standard Test Method for Preconstruction and Construction Evaluation of Mortars for Plain and Reinforced Unit Masonry," ASTM C 780-94, American Society for Testing and Materials, Philadelphia, Pennsylvania.

American Society for Testing and Materials (ASTM), 1995w, "Standard Specification for Agencies Engaged in Testing and/or Inspection of Materials Used in Construction," ASTM E 329-95, American Society for Testing and Materials, Philadelphia, Pennsylvania.

American Society for Testing and Materials (ASTM), 1995x, "Test Methods for Compressive Strength of Masonry Prisms," ASTM E 447-92, American Society for Testing and Materials, Philadelphia, Pennsylvania.

American Society for Testing and Materials (ASTM), 1995y, "Practice for Evaluating Agencies that Perform Nondestructive Testing," ASTM E 548-95, American Society for Testing and Materials, Philadelphia, Pennsylvania.

American Society for Testing and Materials (ASTM), 1995z, "Guide for General Criteria Used for Evaluating Laboratory Competence," ASTM E 543-94, American Society for Testing and Materials, Philadelphia, Pennsylvania.

American Society for Testing and Materials (ASTM), 1995aa, "Standard Specification for Structural Steel," ASTM A-36/A36M-91, American Society for Testing and Materials, Philadelphia, Pennsylvania. 
American Society for Testing and Materials (ASTM), 1995bb, "Standard Specification for Pipe, Steel, Black, and Hot-Dipped Zinc Coated Welded and Seamless," ASTM A-53-90b, American Society for Testing and Materials, Philadelphia, Pennsylvania.

American Society for Testing and Materials (ASTM), 1995cc, "Standard Specification for Structural Bolts, Steel, Heat-Treated 120/105 ksi Minimum Tensile Strength," ASTM A-32591c, American Society for Testing and Materials, Philadelphia, Pennsylvania.

American Society for Testing and Materials (ASTM), 1995dd, "Standard Specifications for Deformed and Plain Billet-Steel Bars for Concrete Reinforcement," ASTM A-615-95b, American Society for Testing and Materials, Philadelphia, Pennsylvania.

American Society for Testing and Materials (ASTM), 1995ee, "Standard Specification for Chemical Admixtures for Concrete," ASTM C 494-95, American Society for Testing and Materials, Philadelphia, Pennsylvania.

American Society for Testing and Materials (ASTM), 1995ff, "Standard Specification for Expansive Hydraulic Cement," ASTM C 845-90, American Society for Testing and Materials, Philadelphia, Pennsylvania.

American Society of Mechanical Engineers (ASME), 1994, "Quality Assurance Program Requirements for Nuclear Facilities," ASME NQA-1, American Society of Mechanical Engineers, New York, New York.

American Welding Society (AWS), 1994a,"Welding Terms and Definitions,"American Welding Society, AWS A3.-94, Miami, Florida.

American Welding Society (AWS), 1994b, "Structural Welding Code - Steel," AWS D1.1-94, American Welding Society, Miami, Florida.

American Welding Society (AWS), 1991,"Specification for Mild Steel Covered Arc Welding Electrodes," AWS A5.1-91, American Welding Society, Miami, Florida.

Biggs, J., 1964, Introduction to Structural Dynamics, McGraw Hill, New York, New York.

Carnahan, B., H. A. Luther, and J. O. Wilkes, 1990, Applied Numerical Methods, John Wiley \& Sons, New York, New York, Second Edition.

Case, J. B., and P. C. Kelsall, 1986, "Shaft-Seal Modeling and Analysis of the Small Scale Seal Performance Tests at the Waste Isolation Pilot Plant," IT Corporation, Albuquerque, New Mexico.

Case, J., J. Fernandez, and J. Tyburski, 1992, "Supporting Hydration Calculations for Small to Large Scale Tests in Unsaturated Tuffs," Waste Management Proceedings of the International High Level Radioactive Waste Management Conference, Las Vegas, Nevada. 
Cook, R., and J. Case, 1991, "Design and Construction Issues Associated with Sealing of a Repository in Salt," Waste Management '91, Proceedings of the Symposium on Waste Management, Tucson, Arizona, Vol. 2, pp. 735-742.

Fernandez, J. A., J. B. Case, C. A. Givens, and B. C. Carney, 1994, "A Strategy to Seal Exploratory Boreholes in Unsaturated Tuff," SAND93-1184, Sandia National Laboratories, Albuquerque, New Mexico.

Fernandez, J. A., T. E. Hinkebein, and J. B. Case, 1989, "Selected Analyses to Evaluate the Effect of the Exploratory Shafts on Repository Performance at Yucca Mountain," SAND85-0598, Sandia National Laboratories, Albuquerque, New Mexico.

Francke, C. T., and L. J. Terrill, 1993, "The Excavation Effects Program at the Waste Isolation Pilot Plant," Innovative Mine Design for the 21st Century, Proceedings of the International Congress on Mine Design, August 23-26, 1993, W. F. Bowden and J. F. Archibald, eds., Kingston, Ontario, Canada.

Freeze, A., and J. Cherry, 1979, Groundwater, Prentice Hall, Englewood Cliffs, New Jersey.

Gulick, C. W., and L. D. Wakeley, 1989, "Reference Properties of Cement-Based Plugging and Sealing Materials for the Waste Isolation Pilot Plant (WIPP)," Technical Report SL-89-17, U.S. Army Engineer Waterways Experiment Station, Vicksburg, Mississippi.

International Conference of Building Officials, 1994, The Uniform Building Code, 1994, ISSN0896-9655, International Conference of Building Officials, Whittier, California.

IT Corporation (IT), 1994, "Backfill Engineering Analysis Report," report prepared for Westinghouse Electric Corporation, Carlsbad, New Mexico.

IT Corporation (IT), 1993, "Ground-Penetrating Radar Surveys at the WIPP Site," January 1991 to February 1992, contractor report for Westinghouse Electric Corporation, Carlsbad, New Mexico.

Itasca Consulting Group, Inc. (Itasca), 1995, "FLAC User's Manual," Itasca Consulting Group, Inc., Minneapolis, Minnesota.

Jaeger, J. C., and N. G. W. Cook, 1972, Fundamentals of Rock Mechanics, John Wiley and Sons, New York, New York.

Krieg, R. D., 1984, "Reference Stratigraphy and Rock Properties for the Waste Isolation Pilot Plant," SAND83-1908, Sandia National Laboratories, Albuquerque, New Mexico.

Mathewson, C. C., 1981, Engineering Geology, The Charles E. Merrill Publishing Company, Columbus, Ohio, 450 pp. 
Mine Safety and Health Administration, 1987, "Safety Standards for Methane in Metal and Nonmetal Mines," Title 30, Code of Federal Regulations (CFR), Part 57 (30 CFR 57), U.S. Department of Labor, Mine Safety and Health Administration, Washington, D.C.

National Ready Mix Concrete Association (NRMCA), 1994, "QC Manual, Section 3, Plant Certification Checklist," National Ready Mix Concrete Association, Silver Spring, Maryland.

National Ready Mix Concrete Association (NRMCA), 1994, "Concrete Plant Standards of CPMB," National Ready Mix Concrete Association, Silver Spring, Maryland.

MRMCA, see National Ready Mix Concrete Association.

Peterson, E., P. Lagus, J. Brown, and K. Lie, 1985, "WIPP Horizon In Situ Permeability Measurements Final Report," SAND85-7166, Sandia National Laboratories, Albuquerque, New Mexico.

Roark, R. J., and W. C. Young, 1975, Formulas for Stress and Strain, McGraw Hill, New York.

U.S. Department of Energy (DOE), 1995, "Conceptual Design for Operational Phase Panel Closure Systems," DOE-WIPP-95-2057, U.S. Department of Energy, WIPP Project Office, Carlsbad, New Mexico.

U.S. Department of Energy (DOE), 1994a, "Panel 1 Utilization Plan," WIPP/WID-94-2027, Westinghouse Electric Corporation, Carlsbad, New Mexico.

U.S. Department of Energy (DOE), 1994b, "Geotechnical Analysis Report, July 1992 through June 1993," DOE-WIPP 94-006, U.S. Department of Energy, Washington, D.C.

U.S. Environmental Protection Agency (EPA), 1995, "Land Disposal Restrictions," Title 40, Code of Federal Regulations (CFR), Part 268 (40 CFR 268), U.S. Environmental Protection Agency, Washington, D.C.

Van Sambeek, L. L., and J. C. Stormont, 1987, "Thermal/Structural Modeling of Test Series A of the Small Scale Seal Performance Tests, Contractor Report," SAND87-7037, Sandia National Laboratories, Albuquerque, New Mexico.

Wakeley, L. D., T. S. Poole, and J. P. Burkes, 1994, "Durability of Concrete Materials in High-Magnesium Brine," SAND93-7073, Sandia National Laboratories, Albuquerque, New Mexico.

Wakeley, L. D., P. T. Harrington, and C. A. Weiss, Jr. 1993, "Properties of Salt-Saturated Concrete and Grout After Six Years In Situ at the Waste Isolation Pilot Plant," SAND93-7019, Sandia National Laboratories, Albuquerque, New Mexico. 
Westinghouse Electric Corporation (Westinghouse), 1995a, "Design Classification Determination," WP 09-CN3023, Rev. 0, Westinghouse Electric Corporation, Waste Isolation Division, Carlsbad, New Mexico.

Westinghouse Electric Corporation (Westinghouse), 1995b, "Underground Hazardous Waste Management Unit Closure Criteria for the Waste Isolation Pilot Plant Operational Phase, Predecisional Draft," WID/WIPP-Draft-2038, February 1995, Westinghouse Electric Corporation, Waste Isolation Division, Carlsbad, New Mexico.

Westinghouse Electric Corporation (Westinghouse), 1995c, "Underground Facilities Typical Disposal Panel," WID/WIPP-DWG 5I-W-214-W, Revision 0, Westinghouse Electric Corporation, Waste Isolation Division, Carlsbad, New Mexico. 


\section{APPENDIX A DERIVATION OF RELATIONSHIPS FOR THE AIR-FLOW MODELS}




\section{APPENDIX A \\ DERIVATION OF RELATIONSHIPS FOR THE AIR-FLOW MODELS}

\section{A1.0 Introduction}

This appendix shows the unrestricted and restricted air-flow models used to determine the performance of the panel closure system alternatives. These analyses are order-of-magnitude estimates of the volume of gas that might flow through the panel seal systems at the Waste Isolation Pilot Plant (WIPP).

\section{A2.0 Model for Unrestricted Flow of VOCs}

A model for the unrestricted flow of volatile organic compounds (VOC) was developed to predict the mass flow rates of VOCs and to compare this mass flow rate to the design migration limit for VOCs. As gas generation and panel volumetric creep closure proceed, a mixture of gases containing the VOC concentrations flows from each waste container. It is assumed for the unrestricted flow model that the headspace concentrations serve as a constant source of VOCs. This assumption is highly conservative, because most containers only have trace quantities of VOCs either trapped in the headspace or adsorbed on the surfaces of the various waste forms. It is believed that only a small number of waste containers have significantly greater sources of VOCs, such as a solvent-soaked rag or a can containing residual partially dried paint. Only these waste containers have a likelihood of maintaining a constant headspace VOC concentration as gas generation proceeds. However, the exact proportion of waste containers with higher VOC concentrations versus those with trace quantities is currently unknown. These data are based on results of the characterization of approximately 500 transuranic (TRU) mixed waste drums at the Idaho National Engineering Laboratory (INEL) and Rocky Flats.

The VOCs migrate due to advection from volumetric closure of the panel void space at a rate of about $28,250 \mathrm{ft}^{3}\left(800 \mathrm{~m}^{3}\right)$ per year. Gas generation for the waste inventory at a rate of 0.1 mole per drum per year $(8,200$ moles per panel per year) results in a volumetric flow rate of 7,060 $\mathrm{ft}^{3}\left(200 \mathrm{~m}^{3}\right)$ per year. Because flow is unrestricted, the VOCs migrate under a pressure of one atmosphere. Other assumptions in the unrestricted model are as follows: 
- Any gases released into the mine atmosphere would be reduced in concentration by $460,000^{1} \mathrm{cfm}$ of uncontaminated air. The mass flow rate of individual VOCs from individual panels following their closure is summed to determine the mass flow rate of VOCs through the exhaust shaft.

- This calculation considers the schedule for closure of individual panels as illustrated in Figure A-1 during the operational life of the WIPP. The VOC mass flow rate changes with time, with the maximum mass flow release occurring after 10 panel equivalents have been closed, about 25 years.

- Each VOC is analyzed in the calculations. Carbon tetrachloride is the most restrictive VOC in terms of satisfying the health-based levels for individual VOCs.

- Open panels of waste will not be considered as a source contributing to the emissions for a no-migration demonstration.

Considering only advection to result in the migration of VOCs, the mass-balance relationship is:

$$
C_{p} * Q_{p}=C_{e s} * Q_{e s}
$$

where

$$
\begin{aligned}
& C_{p}=\text { Head space concentration for an individual VOC } \\
& Q_{p}=\text { Flow rate of VOCs from the panel that may vary with time } \\
& C_{e s}=\text { Concentration of VOCs at the exhaust shaft. } \\
& Q_{e s}=\text { Underground ventilation flow rate for the exhaust shaft }
\end{aligned}
$$

Air dispersion modeling is used for evaluating the receptor concentrations at the WIPP site boundary based upon the exhaust shaft source term. The air dispersion modeling considers such factors as meteorological data, release velocity, release temperature, and proximity of the WIPP site boundary to the exhaust shaft. The results of the modeling are expressed as a ratio $\mathrm{R}$ of the concentration at the exhaust shaft to the concentration at at the WIPP site boundary:

$$
C_{\theta s} \leq R C_{h b l}
$$

This inequality can be expressed in terms of mass flow rate:

\footnotetext{
The design ventilation rate for the WIPP underground is 425,000 standard $\mathrm{cfm}$ (12,000 standard $\mathrm{m}^{3}$ per minute) under standard temperature and pressure conditions of 25 degrees Celsius and 1 atmosphere. The ventilation flow rate of $460,000 \mathrm{cfm}\left(13,025 \mathrm{~m}^{3}\right.$ per minute) is the observed ventilation rate at the repository horizon under actual temperature and pressure conditions.
} 


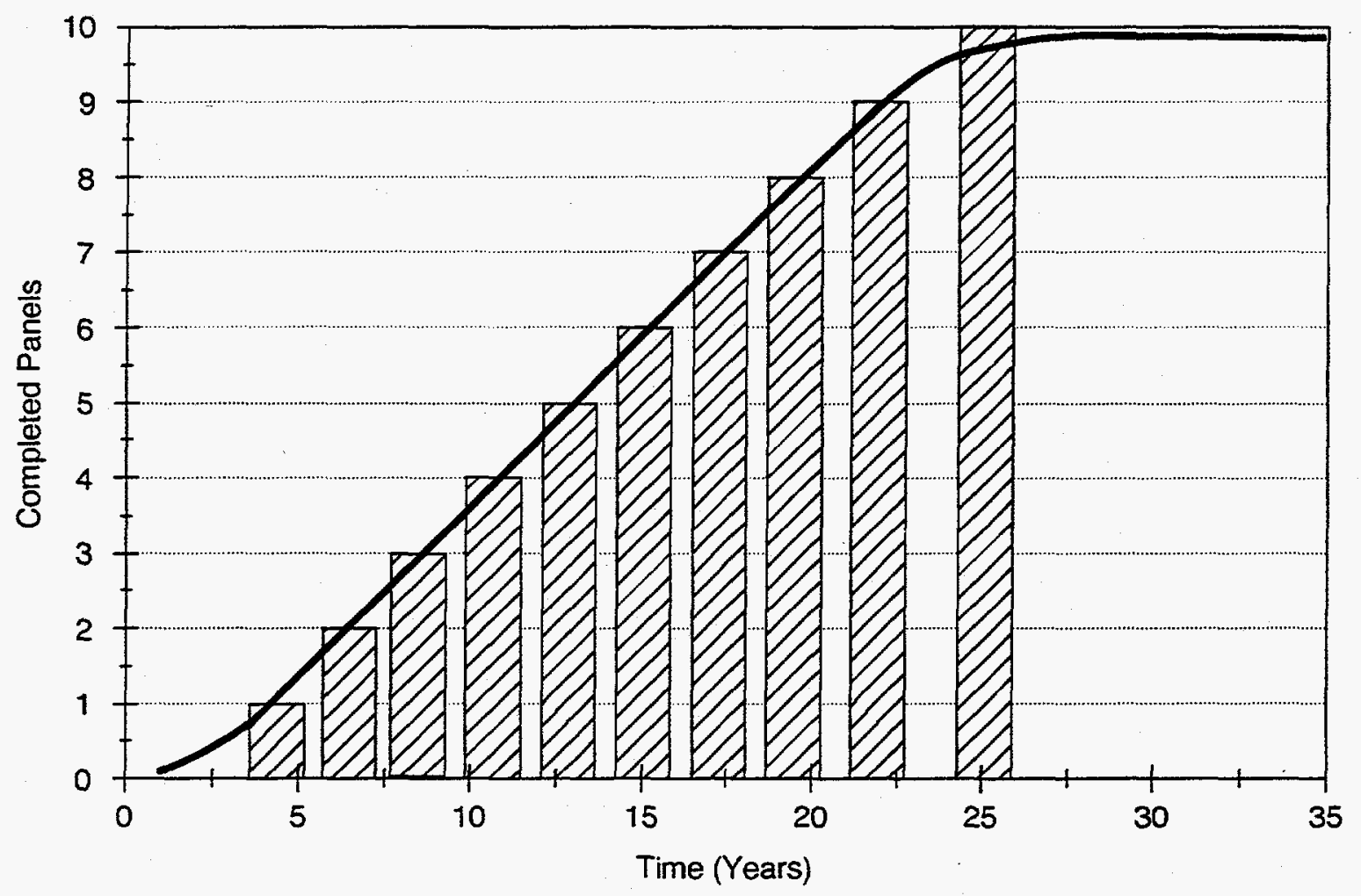

Figure A-1 Schedule for Panel Completion 


$$
\frac{C_{p} * Q_{p}}{Q_{e s}} * \frac{1}{R} \leq C_{h b 1}
$$

where

$$
\begin{aligned}
& \mathrm{R}=\begin{array}{l}
\text { Ratio of the concentrations at the exhaust shaft to the concentrations at the } \\
\text { WIPP site boundary }
\end{array} \\
& \mathrm{C}_{\mathrm{bbl}}=\text { Concentration to satisfy the health-based level for the individual VOC. }
\end{aligned}
$$

The ratio of the concentrations at the WIPP site boundary, R equals 10,753 , reflecting the substantial atmospheric dispersion in reducing the concentration of VOCs.

The flow rates of VOCs from the panels are calculated for two mechanisms, gas generation and volumetric closure, using the following:

$$
Q_{p}=Q_{g r}+Q_{c}
$$

where

$$
\begin{aligned}
& \mathrm{Q}_{\mathrm{gr}}=\text { Volumetric flow rate due to gas generation }{ }^{2}\left(200 \mathrm{~m}^{3} \text { per year per panel }\right) \\
& \mathrm{Q}_{c}=\begin{array}{l}
\text { Volumetric flow rate due to panel volumetric closure }\left(800 \mathrm{~m}^{3}\right. \text { per year per } \\
\text { panel }) .
\end{array}
\end{aligned}
$$

Table A-1 presents the closed panel release limits (migration limits) for VOCs based upon the health-based concentrations of individual VOCs. This inequality can be rewritten as:

$$
C_{p} \cdot Q_{p} \leq C_{h b i} \cdot Q_{\theta s} \cdot R
$$

Table A-2 presents for a single closed panel and ten equivalent closed panels, the release rate for individual VOCs at the end of the 35-year operating period.

For the WIPP site boundary, the VOC concentrations are reduced substantially in the atmosphere. The above analysis shows that the concentration at the WIPP site boundary would be approximately 4 orders of magnitude lower than the concentration at the exhaust shaft. The predicted VOC mass flow rates due to unrestricted flow suffice to comply with the

\footnotetext{
${ }^{2}$ The volumetric flow due to gas generation is calculated as the gas generation rate $(0.1$ moles per drum per year) times the number of drums within a panel times the specific volume under atmospheric pressure.
} 
Table A-1

Closed Panel Release Limits for VOCs

\begin{tabular}{|l|c|c|c|}
\hline \multicolumn{1}{|c|}{ Compound } & $\begin{array}{c}\text { WiPP Site Boundary Health- } \\
\text { Based Exposure Level } \\
\text { (micrograms per cubic meter) }\end{array}$ & $\begin{array}{c}\text { Exhaust Shaft Concentration } \\
\text { Migration Limit } \\
\text { (micrograms per cubic meter) }\end{array}$ & $\begin{array}{c}\text { Closed Ten Panel } \\
\text { Migration Limit } \\
\text { (grams per minute) }\end{array}$ \\
\hline \hline Carbon disulfide & 10.00 & 107,530 & 1,400 \\
\hline Carbon tetrachloride & 0.13 & 1,398 & 18 \\
\hline Chlorobenzene & 20.00 & 215,060 & 2,801 \\
\hline Chloroform & 0.09 & 968 & 13 \\
\hline 1,1 -dichloroethylene & 0.40 & 4,301 & 56 \\
\hline Methyl ethyl ketone & 1000.00 & $10,753,000$ & 140,045 \\
\hline Methylene chloride & 4.26 & 45,808 & 597 \\
\hline $1,1,2,2-t e t r a c h o r o e t h a n e$ & 0.35 & 3,764 & 49 \\
\hline Toluene & 400.00 & $4,301,200$ & 56,018 \\
\hline
\end{tabular}

Table A-2

Closed Panel Release Rates for VOCs

\begin{tabular}{|l|c|c|c|c|c|}
\hline \multicolumn{1}{|c|}{ Compound } & $\begin{array}{c}\text { Average Headspace } \\
\text { Concentration (milligrams } \\
\text { per cubic meter) }\end{array}$ & $\begin{array}{c}\text { Single-Panel } \\
\text { Volumetric- } \\
\text { Release Rate } \\
\text { (cubic meters } \\
\text { per minute) }\end{array}$ & $\begin{array}{c}\text { Ten-Panel } \\
\text { Volumetric- } \\
\text { Release Rate } \\
\text { (cubic meters } \\
\text { per minute) }\end{array}$ & $\begin{array}{c}\text { Single-Panel } \\
\text { Mass-Release } \\
\text { Rate (grams } \\
\text { per minute) }\end{array}$ & $\begin{array}{c}\text { Ten-Panel } \\
\text { Mass-Release } \\
\text { Rate } \\
\text { (grams per } \\
\text { minute) }\end{array}$ \\
\hline \hline Carbon disulfide & 0.41 & 0.0019 & 0.019 & $7.80 \times 10^{-7}$ & $7.80 \times 10^{-6}$ \\
\hline Carbon tetrachloride & 3625.77 & 0.0019 & 0.019 & $6.90 \times 10^{-3}$ & $6.90 \times 10^{-2}$ \\
\hline Chlorobenzene & 63.99 & 0.0019 & 0.019 & $1.22 \times 10^{-4}$ & $1.22 \times 10^{-3}$ \\
\hline Chioroform & 76.79 & 0.0019 & 0.019 & $1.46 \times 10^{-4}$ & $1.46 \times 10^{-3}$ \\
\hline 1,1 -dichloroethylene & 48.68 & 0.0019 & 0.019 & $9.26 \times 10^{-5}$ & $9.26 \times 10^{-4}$ \\
\hline Methyl ethyl ketone & 241.73 & 0.0019 & 0.019 & $4.60 \times 10^{-4}$ & $4.60 \times 10^{-3}$ \\
\hline Methylene chloride & 3387.03 & 0.0019 & 0.019 & $6.45 \times 10^{-3}$ & $6.45 \times 10^{-2}$ \\
\hline $1,1,2,2$-tetrachloroethane & 69.65 & 0.0019 & 0.019 & $1.33 \times 10^{-4}$ & $1.33 \times 10^{-3}$ \\
\hline Toluene & 105.51 & 0.0019 & 0.019 & $2.01 \times 10^{-4}$ & $2.01 \times 10^{-3}$ \\
\hline
\end{tabular}

a Westinghouse Electric Corporation, 1995, "Underground Hazardous Waste Management Unit Closure Criteria for the Waste Isolation Pilot Plant Operational Phase," WIDMIPP-2038, Westinghouse Electric Corporation, Waste isolation Division, Carisbad, Now Mexico. 
closed ten-panel migration limit based upon the health-based levels at the WIPP site boundary over the operational life of the repository.

\section{A3.0 Air Model}

The modeling assumptions for the restricted air-flow model are as follows:

- The gases are generated at a specified rate ( 0.10 moles per drum per year).

- The gases flow out of the panel entries according to Darcy's law under quasisteady state conditions.

- The gases within the pore space obey the ideal gas law

- The rates of gas generation, gas outflow, and change in compressive storage must balance.

- Hydrodynamic dispersion is neglected in the analysis.

After panel closure, the volume, moles of gas, and pressure are changing as functions of time. The ideal gas law (Hiller and Herber, 1960) is written as:

$$
p=\frac{n * R * T}{V}
$$

where

$$
\begin{aligned}
& \mathrm{p}=\text { Pressure } \\
& \mathrm{n}=\text { Moles of gas in the panel } \\
& \mathrm{R}=\text { Universal gas constant } \\
& \mathrm{T}=\text { Absolute temperature } \\
& \mathrm{V}=\text { Volume }
\end{aligned}
$$

Differentiating with respect to $t$ and using the chain rule, we obtain the following relationship:

$$
\frac{d p}{d t}=R * T * \frac{\frac{d n}{d t} * V-n * \frac{d V}{d t}}{V^{2}}
$$

The volumetric closure rate is negative and constant as discussed below. The rate at which gas enters the panel minus the rate that gas leaves the panel must equal the change in moles stored. We obtain the mass-balance relationship: 


$$
\frac{d n}{d t}=g_{r}-\frac{p}{R * T} * K_{s} * \frac{A}{L} * \frac{p-p_{a t m}}{\gamma}
$$

where

$$
\begin{aligned}
& \mathrm{g}_{\mathrm{r}}=\text { Panel gas generation rate } \\
& \mathrm{p}_{\mathrm{atm}}=\text { Atmospheric pressure } \\
& \gamma=\text { Air density } \\
& \mathrm{K}_{\mathrm{s}}=\text { Effective panel closure system conductivity } \\
& \mathrm{A}=\text { Cross-sectional area } \\
& \mathrm{L}=\text { Length of flow path }
\end{aligned}
$$

We define the conductance $(C)$ as:

$$
C=K_{s} * \frac{A}{L}
$$

and substituting into the ordinary differential equations (ODE), we obtain

$$
\begin{gathered}
\frac{d p}{d t}=R * T * \frac{g_{r}-\frac{p}{R * T} * C * \frac{p-p_{a t m}}{\gamma} * V-n * \frac{d V}{d t}}{V^{2}} \\
\frac{d n}{d t}=g_{r}-\frac{p}{R * T} * C * \frac{p-p_{a t m}}{\gamma}
\end{gathered}
$$

These two first-order coupled ODEs can be solved by a simple explicit finite difference technique:

$$
p_{j}=p_{j-1}+R * T * \frac{g_{r}-\frac{p_{j-1}}{R * T} * C * \frac{p_{j-1}-p_{a t m}}{\gamma} * V-n_{j-1} * \frac{d V}{d t}}{V^{2}} * \Delta t
$$




$$
n_{j}=n_{j-1}+g_{r}-\frac{p_{j-1}}{R * T} * C * \frac{p_{j-1}-p_{a t m}}{\gamma} \Delta t
$$

where

$$
\begin{array}{ll}
\mathrm{p}_{\mathrm{j}}, \mathrm{n}_{\mathrm{j}} & =\text { the pressure and moles of gas at the current time step } \\
\mathrm{P}_{\mathrm{j}-1}, \mathrm{n}_{\mathrm{j}-1} & =\text { the pressure and moles of gas at the previous time step }
\end{array}
$$

subject to the boundary condition that the initial pressure equals atmospheric pressure, and the initial moles of gas can be determined by the ideal gas law at initial volume and pressure. Further note that the volume can be expressed as the linear function:

$$
V(t)=\alpha * t+\beta
$$

where

$$
\begin{aligned}
& \alpha=\text { slope of the volume-time relationship } \\
& \beta=\text { intercept of volume-time relationship } \\
& t \quad=\text { time }
\end{aligned}
$$

These expressions can be substituted into the above explicit finite difference relationships, and the pressure and molar air flow rates determined as functions of time.

$$
\frac{d V}{d t}=\alpha
$$


APPENDIX B

CALCULATIONS IN SUPPORT OF PANEL GAS PRESSURIZATION DUE TO CREEP CLOSURE 


\section{APPENDIX B \\ CALCULATIONS IN SUPPORT OF PANEL GAS PRESSURIZATION DUE TO CREEP CLOSURE}

\section{B.1.0 Introduction}

This appendix presents the closure mechanisms and supporting calculations for panel volumetric closure for the analysis of gas pressurization within a closed panel at the Waste Isolation Pilot Plant (WIPP). The volume reduction is due to the panel volume change from viscoplastic creep closure of the walls, roof, and floor. As the walls, roof, and floor of the excavations converge, the total volume of the panel decreases. The volumetric closure of a panel is the result of several different mechanisms working in tandem. These mechanisms include:

- Viscoplastic creep of the salt toward the excavation

- Fracturing in the roof and floor caused by the deviatoric stresses around the excavation

- Bed separation at the clay seams in the roof and the floor.

The combination of these three mechanisms causes the observed convergence rates in Panel 1. Of these mechanisms, only creep of the salt reduces the total volume of the panel and pore space in the surrounding disturbed rock zone (DRZ). Fracturing in the roof and floor and bed separation transfer the void volume within the excavation to the DRZ. This void volume within the $D R Z$ is assumed to be interconnected with the open excavation. Therefore the total reduction in volume within the panel, based simply on room closure, overestimates the effective reduction in void volume. However, quantifying the amount of interconnected void space within the DRZ would require a much more detailed analysis. The total volume change calculated from the room closure measurements is therefore considered conservative.

Other assumptions made in this calculation are:

- The volumetric closure rates are constant after panel closure.

- The waste in the panel provides no significant resistance to creep closure during the initial 35 years. 
- The air volume is the total volume of the excavations minus the solid volume of the waste in drums or other waste packages. This is estimated to equal $138,000 \mathrm{ft}^{3}\left(3,908 \mathrm{~m}^{3}\right)$.

- The closure rate of each room in the panel equals the closure rate at the midpoint of the room.

- The length of each room or drift is constant; to simplify the calculations, only the width and height change with creep closure.

- The panel is comprised of seven rooms and two panel access drifts.

\section{B.2.0 Panel Volume Change Calculation}

The panel volume change calculation is performed by first calculating the initial panel volume, then calculating the room and drift closure rates, and finally calculating the panel volumetric closure rate. Following is a detailed description of each part of the calculation.

\section{B.2.1 Initial Panel Volume}

The initial panel volume is determined immediately after completion of excavation. The total volume is calculated by summing the individual room and drift volumes within the panel. These volumes are based on the as-built dimensions of the excavated rooms and drifts in Panel 1 (DOE, 1993). Table B-1 presents the room and drift dimensions and the calculated volume of each room and drift. The volume of the air-intake and air-exhaust drifts is not included. The total initial volume of Panel 1 is $1,669,434 \mathrm{ft}^{3}\left(47,273 \mathrm{~m}^{3}\right)$.

The total solid volume of the waste in a filled panel is $138,000 \mathrm{ft}^{3}\left(3,908 \mathrm{~m}^{3}\right)$ (DOE, 1994; Butcher, et al., 1991). Subtracting the waste volume from the total panel volume gives the total initial air volume $\left(1,531,434 \mathrm{ft}^{3}\left[43,365 \mathrm{~m}^{3}\right]\right)$ in the panel.

\section{B.2.2 Closure Rates}

Using convergence data from Panel 1 the average closure rates of the rooms and drifts are determined (DOE, 1993). Closure rates within the rooms and drifts are higher in the first five years after excavation. The roof-to-floor and wall-to-wall closure rates for each of the rooms and drifts are presented in Table B-2.

Because all of the excavations in Panel 1 are approximately $13 \times 33 \mathrm{ft}(4 \times 10 \mathrm{~m})$, the closure rates for each room or drift are the same. 
Table B-1

Initial Room and Drift Dimensions and Volume

of Panel 1

\begin{tabular}{|l|c|c|c|c|}
\hline \multicolumn{1}{|c|}{ Room or Drift } & \multicolumn{1}{|c|}{$\begin{array}{c}\text { Initial } \\
\text { Width } \\
(\mathrm{ft})\end{array}$} & $\begin{array}{c}\text { Initial } \\
\text { Height } \\
(\mathrm{ft})\end{array}$ & $\begin{array}{c}\text { Initial } \\
\text { Length } \\
(\mathrm{ft})\end{array}$ & $\begin{array}{c}\text { Initial } \\
\text { Volume } \\
\left(\mathrm{ft}^{3}\right)\end{array}$ \\
\hline \hline Room 1 & 33 & 13 & 300 & 128,700 \\
\hline Room 2 & 33 & 13 & 300 & 128,700 \\
\hline Room 3 & 33 & 13 & 300 & 128,700 \\
\hline Room 4 & 33 & 13 & 300 & 128,700 \\
\hline Room 5 & 33 & 13 & 300 & 128,700 \\
\hline Room 6 & 33 & 13 & 300 & 128,700 \\
\hline Room 7 & 33 & 14 & 300 & 138,600 \\
\hline $\begin{array}{l}\text { South 1950 panel access } \\
\text { drift }\end{array}$ & 33 & 14 & 848 & 391,776 \\
\hline $\begin{array}{l}\text { South 1600 from Room 1 to } \\
\text { Room 5 }\end{array}$ & 33 & 13 & 573 & 245,817 \\
\hline $\begin{array}{l}\text { South 1600 from Room 5 to } \\
\text { Room 7 }\end{array}$ & 33 & 14 & 262 & 121,044 \\
\hline Total Initial Panel Volume & & & & $1,669,437$ \\
\hline
\end{tabular}

\section{B.2.3 Volumetric Panel Closure Rate}

Using the closure rates from Table B-2, the dimensions of the rooms and drifts in Panel 1 can be calculated at the end of each progressive year or for subsequent years using the following equations.

For 0 to 5 years after excavation:

$$
V_{t}=\left(w_{i}-R_{H} t\right) \times\left(h_{i}-R_{v o} t\right) \times I_{i}
$$




\section{Table B-2}

Room and Drift Closure Rates

(DOE, 1993)

\begin{tabular}{|l|c|c|c|c|}
\hline \multirow{2}{*}{ Room or Drift } & \multicolumn{2}{|c|}{ Vertical Closure Rate } & \multicolumn{2}{c|}{ Horizontal Closure Rate } \\
\cline { 2 - 5 } & $\begin{array}{c}\text { 0 to 5 Years } \\
\text { (tt/yr) }\end{array}$ & $\begin{array}{c}>5 \text { Years } \\
\text { (ft/yr) }\end{array}$ & $\begin{array}{c}\text { 0 to 5 Years } \\
\text { (ft/yr) }\end{array}$ & $\begin{array}{c}>5 \text { Years } \\
\text { (tt/yr) }\end{array}$ \\
\hline \hline Room 1 & 0.3194 & 0.2109 & 0.2234 & 0.1160 \\
\hline Room 2 & 0.3194 & 0.2109 & 0.2234 & 0.1160 \\
\hline Room 3 & 0.3194 & 0.2109 & 0.2234 & 0.1160 \\
\hline Room 4 & 0.3194 & 0.2109 & 0.2234 & 0.1160 \\
\hline Room 5 & 0.3194 & 0.2109 & 0.2234 & 0.1160 \\
\hline Room 6 & 0.3194 & 0.2109 & 0.2234 & 0.1160 \\
\hline Room 7 & 0.3194 & 0.2109 & 0.2234 & 0.1160 \\
\hline South 1950 panel access dritt & 0.3194 & 0.2109 & 0.2234 & 0.1160 \\
\hline $\begin{array}{l}\text { South 1600 from Room 1 to } \\
\text { Room 5 }\end{array}$ & 0.3194 & 0.2109 & 0.2234 & 0.1160 \\
\hline $\begin{array}{l}\text { South 1600 from Room 5 to } \\
\text { Room 7 }\end{array}$ & 0.3194 & 0.2109 & 0.2234 & 0.1160 \\
\hline
\end{tabular}

For greater than 5 years after excavation:

$$
V_{t}=\left(w_{i}-R_{H} t\right) \times\left(h_{i}-R_{V 5}(t-5)-R_{V 0} 5\right) \times I_{i}
$$

where

$$
\begin{array}{ll}
\mathrm{V}_{\mathrm{t}} & =\text { Volume of the room at time } \mathrm{t} \\
\mathrm{t} & =\text { Time (in years) } \\
\mathrm{w}_{\mathrm{i}} & =\text { Initial room width } \\
\mathrm{h}_{\mathrm{i}} & =\text { Initial room height } \\
\mathrm{l}_{\mathrm{i}} & =\text { Initial room length } \\
\mathrm{R}_{\mathrm{H}} & =\text { Horizontal closure rate (ft/year) } \\
\mathrm{R}_{\mathrm{v} 0} & =\text { Vertical closure rate for first } 5 \text { years (ft/year) } \\
\mathrm{R}_{\mathrm{v} 5} & =\text { Vertical closure rate after } 5 \text { years (ft/year). }
\end{array}
$$

We obtain the incremental change in volume: 


$$
\Delta V=V_{1}-V_{2}
$$

where

$$
\begin{aligned}
& V_{1}=\text { Volume of room at time } t_{1}\left(\mathrm{ft}^{3}\right) \\
& V_{2}=\text { Volume of room at time } t_{2}\left(\mathrm{ft}^{3}\right) \\
& \Delta V=\text { Change in volume of room between time } t_{1} \text { and } t_{2}\left(\mathrm{ft}^{3}\right) \\
& t_{1}, t_{2}=\text { Years after excavation }
\end{aligned}
$$

The volume of all the rooms within the panel is calculated at the time of four years after excavation, when the waste is assumed to have been emplaced the amount of time required for waste emplacement (Table B-3). The total volume of the panel after four years is $1,469,112 \mathrm{ft}^{3}\left(41,601 \mathrm{~m}^{3}\right)$. The volume of the panel is then calculated at five years after excavation or one year after panel closure (Table B-3). This volume is $1,420,312 \mathrm{ft}^{3}$ $\left(40,219 \mathrm{~m}^{3}\right)$, and the volume reduction in that year is $48,800 \mathrm{ft}^{3}\left(1,382 \mathrm{~m}^{3}\right)$.

The initial volume in a closed panel after approximately four years is obtained from the total volume at four years $\left(1,469,112 \mathrm{ft}^{3}\left[41,601 \mathrm{~m}^{3}\right]\right)$ minus the solids volume $\left(138,000 \mathrm{ft}^{3}\right.$ $\left.\left[3,908 \mathrm{~m}^{3}\right]\right)$, or $1,331,112 \mathrm{ft}^{3}\left(37,693 \mathrm{~m}^{3}\right)$. This volume is used as the initial volume for the restricted air-flow model calculations.

The rate of change for panel volume is assumed to be constant for the first five years after excavation, because the vertical and horizontal closure rates are constant during this period. (Actually, rate of volume change over time decreases slightly with each year due to "corner effects," but this error is less than 2 percent and is considered insignificant.) Table B-3 also shows the panel volumes at 15 and 16 years after excavation and the change in volume between those years. The volumetric panel closure rate is $28,673 \mathrm{ft}^{3}$ per year $\left(812 \mathrm{~m}^{3}\right.$ per year). This is the rate in volume change per year in the panel from five to approximately 35 years after excavation.

At approximately 16 years after excavation, the roof comes in contact with the waste stack. Only 35 years after excavation does the waste stack begin to provide significant resistance to creep (approximately $2 \mathrm{MPa}$ ). This resistance is expected to slow the vertical convergence rate by some amount. 
Table B-3

Panel Volume at Various Times

\begin{tabular}{|l|c|c||c|c||}
\hline \multirow{2}{*}{ Room or Drift } & \multicolumn{4}{|c|}{ Volume of Room (tt) } \\
\cline { 2 - 5 } & At 4 Years & At 5 Years & At 15 Years & At 16 Years \\
\hline Room 1 & 112,914 & 109,069 & 85,662 & 83,401 \\
\hline Room 2 & 112,914 & 109,069 & 85,662 & 83,401 \\
\hline Room 3 & 112,914 & 109,069 & 85,662 & 83,401 \\
\hline Room 4 & 112,914 & 109,069 & 85,662 & 83,401 \\
\hline Room 5 & 112,914 & 109,069 & 85,662 & 83,401 \\
\hline Room 6 & 112,914 & 109,069 & 85,662 & 83,401 \\
\hline Room 7 & 122,545 & 118,633 & 94,879 & 92,583 \\
\hline $\begin{array}{l}\text { South 1950 panel access } \\
\text { drift }\end{array}$ & 346,395 & 335,337 & 268,191 & 261,702 \\
\hline $\begin{array}{l}\text { South 1600 from Room 1 } \\
\text { to Room 5 }\end{array}$ & 215,665 & 208,321 & 163,614 & 159,296 \\
\hline $\begin{array}{l}\text { South 1600 from Room 5 } \\
\text { to Room 7 }\end{array}$ & 107,023 & 103,607 & 82,861 & 80,856 \\
\hline \hline Total Volume of Panel 1 & $1,469,112$ & $1,420,312$ & $1,123,529$ & $1,094,856$ \\
\hline Change in Volume & & 48,800 & & 28,673 \\
\hline
\end{tabular}

\section{B.3.0 References}

Butcher, B. M., T. W. Thompson, R. G. VanBuskirk, N. C. Patti, 1991, "Mechanical Compaction of Waste Isolation Pilot Plant Simulated Waste," SAND90-1206, Sandia National Laboratories, New Mexico.

U.S. Department of Energy (DOE), 1993, "Geotechnical Analysis Report, July 1991 through June 1992," DOE-WIPP 93-019, U.S. Department of Energy, Washington D.C.

U.S. Department of Energy (DOE), 1994, "Panel One Utilization Plan," WIPP/WID-94-2027, Westinghouse Electric Corporation, Carlsbad, New Mexico. 


\section{APPENDIX C \\ FLAC MODELING OF THE PANEL CLOSURE SYSTEM}




\section{APPENDIX C FLAC MODELING OF THE PANEL CLOSURE SYSTEM}

Numerical modeling is considered one of the better methods available for quantifying the interaction of concrete barriers with the surrounding media. Therefore, a series of models have been developed for this report to evaluate the interaction of the main concrete barrier of the panel closure system with the surrounding salt for different alternatives and concrete barrier geometries. This appendix discusses the code used and describes the material constitutive models used in the stress analysis.

\section{C.1.0 The FLAC Code}

FLAC software has been used for numerical modeling of the underground excavations at the WIPP since 1991. FLAC is a two-dimensional explicit finite difference code that simulates the behavior of rock and soil-like structures. The WIPP Reference Creep Law is built into FLAC and has been verified to Nuclear Regulatory Commission standards (Itasca, 1995). In addition, all versions of FLAC used by the Westinghouse Waste Isolation Division have been verified against the WIPP Second Benchmark Problem (Krieg, 1984).

\section{C.2.0 Material Constitutive Models}

The material properties associated with the material constitutive models are given in Tables C-1 through C-3. These properties are the standard properties which have been used in previous WIPP geotechnical FLAC modeling such as the Backfill Engineering Analysis Report (BEAR) (IT, 1994). Note that the stress analysis of the concrete barrier also uses the same stress-strain relationship for the uncompacted crushed salt as was used in the BEAR. The stress analysis in Figure 4-4 used uncompacted crushed salt on one side of the enlarged concrete barrier and open void space on the other side. The crushed salt has subsequently been eliminated from the panel closure system final design. The symmetry in the principal stress plots for the enlarged concrete barrier analysis indicated that the presence or absence of the crushed salt does not significantly affect the stresses within the enlarged concrete barrier. Therefore, the FLAC analysis results presented in Figure 4-4 apply to the panel closure system final design. 
Table C-1 ${ }^{\mathrm{a}}$

FLAC ${ }^{b}$ Model Time-Dependent Material Properties

\begin{tabular}{|l|c|c|c|}
\hline \multicolumn{1}{|c|}{ Property } & Halite & Argillaceous Halite & Halite, 10\% Polyhalite \\
\hline Bulk modulus (GPa) & 20.7 & 20.7 & 22.1 \\
\hline Shear modulus $(\mathrm{GPa})$ & 12.4 & 12.4 & 13.2 \\
\hline Density $\left(\mathrm{kg} / \mathrm{m}^{3}\right)$ & 2,300 & 2,300 & 2,300 \\
\hline Activation energy $(\mathrm{cal} / \mathrm{mol})$ & 12,000 & 12,000 & 12,000 \\
\hline A & 4.56 & 4.56 & 4.56 \\
\hline B & 127 & 127 & 127 \\
\hline D (Pa-4/s) & $5.79 \times 10^{-36}$ & $1.74 \times 10^{-35}$ & $5.21 \times 10^{-36}$ \\
\hline $\mathrm{n}$ & 4.9 & 4.9 & 4.9 \\
\hline Gas constant (cal/mol K) & 1.987 & 1.987 & 1.987 \\
\hline Critical strain rate & $5.39 \times 10^{-8}$ & $5.39 \times 10^{-8}$ & $5.39 \times 10^{-3}$ \\
\hline
\end{tabular}

Table C-2 ${ }^{\mathrm{a}}$

FLAC $^{b}$ Elastic Material Properties

\begin{tabular}{|l|c|c|c|}
\hline \multicolumn{1}{|c|}{ Property } & Anhydrite & Polyhalite & Concrete \\
\hline \hline Bulk modulus (GPa) & 83.4 & 65.8 & 11.6 \\
\hline Shear modulus $(\mathrm{GPa})$ & 27.8 & 20.3 & 9.0 \\
\hline Density $\left(\mathrm{kg} / \mathrm{m}^{3}\right)$ & 2,300 & 2,300 & 2320 \\
\hline Cohesion $(\mathrm{MPa})$ & 27 & 17.2 & - \\
\hline Friction (degrees) & 29 & 46.5 & - \\
\hline
\end{tabular}

Table ${\mathrm{C}-3^{\mathrm{a}}}^{\mathrm{a}}$

FLAC ${ }^{b}$ Clay Seam Material Properties

\begin{tabular}{|l|c|}
\hline \multicolumn{1}{|c|}{ Property } & Value \\
\hline Normal stiffness $(\mathrm{Pa} / \mathrm{m})$ & $1.0 \times 10^{12}$ \\
\hline Shear stiffiness $(\mathrm{Pa} / \mathrm{m})$ & $5.0 \times 10^{10}$ \\
\hline Cohesion $(\mathrm{Pa})$ & 0.0 \\
\hline Friction (degrees) & 5 \\
\hline
\end{tabular}

aT, 1994

${ }^{\mathrm{b} F L A C} \quad=$ Fast Lagrangian Analysis of Continua

$\mathrm{GPa} \quad=$ Gigapascal(s)

$\mathrm{kg} / \mathrm{m}^{3}=$ Kilogram(s) per cubic meter

$\mathrm{cal} / \mathrm{mol}=$ Calorie(s) per mole

$\mathrm{Pa}^{-4.9} / \mathrm{s}=$ Pascal(s) to the negative 4.9 per second

$\mathrm{cal} / \mathrm{mol} \mathrm{K}=$ Calorie(s) per mole Kelvin

$\begin{array}{ll}\mathrm{A}, \mathrm{B}, \mathrm{n} & =\text { unitless model factors } \\ \mathrm{D} & =\text { model factor } \\ \mathrm{Pa} / \mathrm{m} & =\text { Pascal(s) per meter } \\ \mathrm{MPa} & =\text { Megapascal(s) }\end{array}$




\section{C.3.0 References}

IT Corporation (IT), 1994, "Backfill Engineering Analysis Report," report prepared for Westinghouse Electric Corporation, Carlsbad, New Mexico.

Itasca Consulting Group, Inc. (Itasca), 1995, "FLAC User's Manual," Itasca Consulting Group, Inc., Minneapolis, Minnesota.

Krieg, R. D., 1984, "Reference Stratigraphy and Rock Properties for the Waste Isolation Pilot Plant," SAND83-1908, Sandia National Laboratories, Albuquerque, New Mexico. 


\section{APPENDIX D \\ BRINE/CEMENT INTERACTIONS}




\section{APPENDIX D BRINE/CEMENT INTERACTIONS}

Concern about potentially deleterious constituents in the Waste Isolation Pilot Plant (WIPP) brines were initially raised when evidence of some minor concrete deterioration in the waste shaft key was noted. The cause is geochemical alteration of the concrete shaft liner and shaft grout by the brine present at the Rustler-Salado contact. Chemical constituents detected in brine samples included both organic and inorganic compounds that probably originated from dissolution of the concrete liner and grout materials used in the shaft construction. The presence of large amounts of organics that likely originated from the chemical grout appeared to have complexed the calcium present in the brine, interfering with the inorganic chemistry of the naturally occurring brine. The brines in contact with the waste shaft key were also found to be significantly higher in both chlorides and magnesium than the Salado Formation brine. These factors probably resulted in a Rustler/Salado brine chemistry more aggressive than that of the naturally occurring Salado brines that may contact the panel barrier.

Lankard Materials Laboratory (LML) (1992) concluded that there has been both a "physical attack" component and a "chemical attack" component acting upon the waste shaft key by brines. A "worst-case" scenario proposed by LML indicated that deterioration from both chemical and physical factors could result in a loss of material on the shaft side of the concrete liner at a rate of approximately 12 centimeters ( 5 inches) over a 50 -year period.

The very local deterioration of the waste shaft key concrete resulted in some reduction in its load-bearing capacity and some increase in its permeability to brine infiltration. In addition, exposure of chemical residue deposits to the air within the shaft may have created a spalling effect that also facilitated local concrete deterioration on the interior (shaft opening) side of the liner.

Sandia National Laboratories/New Mexico (SNL/NM) studied the effect of high-magnesium brine interactions on various candidate barrier materials (SNL/NM, 1994). High-magnesium brines are characteristic of the Rustler-Salado contact, which is the location of the waste shaft key. The study was intended to evaluate chemical impacts to mass-concrete barriers in the WIPP panels and to the Salado Formation. However, the results of the study were also used to evaluate the cause of the deterioration of the waste shaft key. IT Corporation (IT) (1994), 
in a separate study, also evaluated the geochemistry of brines associated with the waste shaft key near the Rustler-Salado Formation contact.

Both studies concluded that the brines have chemically reacted with the constituents in the concrete and grouts used in the waste shaft key liner. The SNL/NM (SNL/NM, 1994) study theorized that the loss of the liner's strength was facilitated by the loss of calcium from the concrete liner. SNL/NM noted that the magnesium present in the brine replaced calcium in the concrete, but the replacement process occurred as a delayed reaction. Magnesium replacement did not occur until after the structural integrity of the waste shaft key liner was already impacted negatively by the loss of calcium, which increased the porosity of the liner. This resulted in a more open and permeable microstructure not attributable solely to a weakening effect from magnesium replacement. Both the IT and SNL/NM studies supported the conclusion that the waste shaft key liner deterioration occurred only locally and in the outermost reaction zone of the liner, so that the structural integrity of the liner as a whole was not significantly impacted. SNL/NM proposed that further deterioration of the liner may be limited only to areas of the concrete liner that develop stress fractures.

Wakeley et al. (1993) studied salt-saturated concrete and grout emplaced in the floor of the WIPP repository six years before its retrieval. The concrete and grout used in the study were cementitious, rather than organic. In retrieving the concrete and grout plugs, the plugs were overcored to also retrieve some host rock.

The study concluded that little to no deterioration occurred to the concrete or grout and that general compressive strengths of the concrete and grout increased over time. The lowest compressive strength values were observed in samples taken from the disturbed rock zone. Reaction rims with increased permeability were noted on anhydrite surrounding the plugs, suggesting interaction between the grout or concrete and host rock. However, comparable evidence of a reaction with the concrete or grout was not seen. There was also evidence of dissolution of halite in the anhydrite zone near the plugs; however, the evidence also indicates that the presence of the halite facilitated better bonding between the grout or concrete and the host rock. Crystallization of new phases was also noted on free surfaces, indicating that strongly ionic magnesium-bearing fluids were present and moving. The fluid movement appeared to have no effect on the host rock other than to improve bonding.

The differences in the appearances, strengths, and phase assemblages between the grout/concrete plugs in the study discussed above and the waste shaft key liner concrete are 
different enough that two extremely different service environments can be inferred. The magnesium level and fluid transport are apparently much greater in the waste shaft key location, facilitating a greater degree of deterioration of the waste shaft key concrete than was noted in the plugs studied by Wakeley et al. (1993). The waste shaft key concrete liner was also composed of organic constituents, which appeared to be more reactive with the brine chemistry. The main concrete barrier will be located in a service environment similar to that studied by Wakeley et al. (1993), where very minor amounts of brine would contact the main concrete barrier.

\section{References}

IT Corporation (IT), 1994, "Geochemistry of Brines Recovered from the WIPP Waste Shaft in the Vicinity of the Rustler/Salado Contact," report prepared for Westinghouse Electric Corporation, Carlsbad, New Mexico.

Lankard Materials Laboratory (LML), 1992, "Laboratory Investigation of Factors Influencing the Deterioration of the Concrete Waste Handling Shaft Liner at the WIPP," I-2480-5, (July 1992) in "Waste Handling Shaft Concrete Liner Degradation Conclusions and Recommendations, Appendix A, DOE/WIPP 92-050, Waste Isolation Division, Westinghouse Electric Corporation, Carlsbad, New Mexico.

Sandia National Laboratories/New Mexico (SNL/NM), 1994, "Durability of Concrete Materials in High-Magnesium Brine," SAND93-7073, Sandia National Laboratories, Albuquerque, New Mexico.

Wakeley, L. D., P. T. Harrington, and C. A. Weiss, Jr., 1993, "Properties of Salt-Saturated Concrete and Grout After Six Years In Situ at the Waste Isolation Pilot Plant," SAND93-7019, Sandia National Laboratories, Albuquerque, New Mexico. 


\section{APPENDIX E \\ PREVIOUS STUDIES OF \\ PANEL-CLOSURE SYSTEM MATERIALS}




\section{APPENDIX E PREVIOUS STUDIES OF PANEL-CLOSURE SYSTEM MATERIALS}

In researching the available literature relating to panel-closure system designs and materials, studies on both long-term and short-term barrier performance were evaluated. The intended function of the main concrete barrier described in this report is to provide short-term (35 years) barrier capability until the repository host rock reconsolidates around the barrier. However, studies on long-term barrier performance were found useful for the panel-closure system material compatibility evaluation performed for this document. The results of these studies provided insight into the complex issues to be considered for selecting an appropriate concrete and grout for the panel-closure system.

Stormont (1987) studied small-scale seal performance tests (SSSPT). The SSSPTs were designed as in situ experiments to evaluate the performance of candidate seal materials. Barrier systems consisted of the barrier itself, the barrier-rock interface, and the surrounding rock. The system performance was evaluated using thermal/mechanical and fluid flow (both gas and brine) data generated by testing under expected repository conditions. Thermal, mechanical, and hydrologic performance of the barriers was evaluated. Test Series A consisted of a bulkhead constructed of salt-based concrete. Regarding hydration of the concrete, stresses and strains induced in the rock and the barrier were a result of hydration. Stresses and strains also resulted from the salt creep and from the panel-closure system material. Evaluation of these stresses and strains yielded information about the stability of the barrier system and the structural/fluid flow relationship. The permeabilities of the barrier material with respect to gas and brine were important for evaluating the potential for a repository breach scenario. Test Series A was conducted in geologic horizons that included bedded halite and interbeds of clay and anhydrite.

Three types of concrete were evaluated for the Test Series A study: salt-free concrete, salt concrete, and expansive salt-based concrete. The latter proved to yield the most favorable results due to its significant expansive properties, which create a tight interface; its workability (about 4 hours); and for its ability to inhibit dissolution of surrounding salt during cement hydration. 
Stormont (1988) also studied the performance of grout and concretes as constituents of main concrete barriers for the panel-closure system. The use of cementitious grouts within the disturbed rock zone adjacent to the main barrier was determined to be detrimental at times, as it could facilitate fracture propagation. To prevent the load reaction causing the fracture propagation, Stormont proposed the emplacement of rigid concrete at the main barrier location. Stormont's investigations of concrete to form the actual main barrier indicated that concrete is impermeable, and any associated leakage across the barrier would occur at the concrete/rock interface zone. Leakage could be attributed to concrete shrinkage and the integrity of the rock itself. However, Stormont noted that the presence of halite in the host rock would result in compressional forces exerted on the concrete barrier over time, with little or no leakage occurring.

SSSPT performed by Stormont (1988) and Finley and Tillerson (1992) evaluated salt-based concrete, bentonite, and salt blocks for barrier performance. In the salt-based concrete barriers, both brine and gas migration across the barrier-rock interface were retarded by salt creep adjacent to the barrier and the expansive properties of the salt-based concrete. The saltbased concrete barriers also withstood significant back-pressure forces. Bentonite and salt blocks did not perform as satisfactorily with respect to their load-bearing capacities or fluid permeabilities.

Hansen et al. (1994) discussed barrier materials for vertical shaft environments in terms of the barriers' long- and short-term components. The single long-term component envisaged in their studies was reconsolidated salt, especially engineered to achieve a barrier function in approximately 100 years. However, short-term materials included concrete, bentonite, grout, chemical seal rings, and potential alternatives, although the alternatives were not included in a reference barrier design. Each barrier component had a functional requirement to prevent the passageways from becoming the preferred passageways for transport of brines or gases to or from the repository. Short-term components provided barriers to brine and groundwater inflow to the consolidating and long-term members and to the repository. The composition of each selected barrier was based on experience in the mining industry, assurance of function through test results, and compatibility with the stratigraphy in which the barrier was placed. The authors looked at specific geologic horizons with respect to their ability to prevent brine and gas flow.

Test Series B (Peterson et al., 1987) more likely approximated the configuration of the proposed panel barrier, which will be emplaced in a horizontal drift leading to the waste- 
emplacement panels. The type of material used in the testing was a salt-saturated expansive concrete, as was used in Test Series A.

In both the A and B test series, the parameter of primary interest was the barrier permeability. For calculational purposes, it was assumed that all flow goes through the barrier. However, some flow may enter the surrounding formation as well, although it is difficult to determine and quantify. Factors affecting measured flow rates through the barrier would include the pressure under which the brine was flowing. If a brine was saturated with respect to its liquid phase at ambient conditions, added pressures may decrease its saturation and encourage dissolution of the surrounding halite.

In one test, barrier brine flow rate decreased slowly with time; this is an important consideration when modeling long-term response. Possible mechanisms causing this decrease include precipitation, healing, or creep closure of open pore spaces. Estimates of brine and gas permeabilities depend strongly on the degree of pore saturation.

Only gas-flow tests were performed in the B Series. All of the barriers leaked (though at slow rates) in the B Series tests. No leakage occurred at the barrier/formation interface. Leaks were associated with a small formation fracture and with an instrumentation bundle. Gas-flow tests performed approximately one year later indicated no leakage associated with the barriers.

Test Series C (Stormont et al., 1987) consisted of salt and salt-bentonite block barrier material emplaced in a horizontal drift within almost pure halite. Four barriers were composed of salt blocks, and four barriers consisted of salt-bentonite blocks. Four of the barriers, two representing each type of material described above, were evaluated without instrumentation, for fluid flow and permeability testing. Instrumentation and cabling are often leak paths for such testing. The instrumentation used in the other barriers measured deformations and pressures and provided other important data. The data suggest that crushed salt provides very little resistance to closure until the crushed salt is very dense. Deformation experiments were designed to verify or refute this evidence.

Principal advantages to salt-block emplacements as opposed to mechanical or pneumatic backfilling were that initial porosity of the crushed or granular salt was minimized, reducing the time required for effective or complete salt consolidation. This in turn reduced the likelihood of brine influx from the surrounding strata that could impede the consolidation 
process. Block emplacements also allowed considerable control over production and emplacement. Blocks could be tailored to achieve certain properties, such as addition of bentonite or moisture.

Experiments with different types of blocks indicated that the relative density of the blocks increased with the maximum particle size used. Further, blocks cured in humid environments became extremely friable and unviable. Within the Waste Isolation Pilot Plant (WIPP) facility, the humidity of the ventilation air is below the critical humidity of 75 percent (the air will take moisture from the salt).

Blocks cured at ambient conditions were the most resilient in that they resisted chipping and shattering. Their "toughness" was a result of the development of an indurated "skin" from particle caking. Caking occurs when moisture at particle contacts is evaporated, resulting in bridging and microcrystalline growth that essentially cements the particles together. However, an indurated skin may also hinder consolidation at the interfaces between blocks from a lack of available water believed necessary for rapid consolidation.

The purpose of adding bentonite to salt blocks was to reduce the permeability without requiring extensive consolidation. Data collected indicated that permeabilities to brines and water fell off to microdarcy values somewhere between 25 and 50 percent bentonite by weight. For this experiment, a 1:1 ratio of salt to bentonite was used. Over 90 percent of the bentonite was composed of the clay mineral montmorillonite. Water was also introduced into the mixture.

Salt/bentonite blocks cured in the humid environment took sufficient moisture from the air to become extremely friable, and therefore, unviable. Under covered conditions, less moisture was lost. Salt/bentonite blocks were also tougher than salt-only blocks. Also, greater amounts of moisture contributed to a tougher block than the addition of less moisture.

The use of mortars was necessary to fill the voids between the blocks and the borehole wall. Mortar was generally only emplaced into the interface and not between blocks. The mortars were composed of the same materials as the blocks.

In summary, both types of blocks were found to lose excessive moisture to the dry mine atmosphere unless they were covered between the time of production and the time of emplacement. Initial fluid flow testing of the salt/bentonite barriers revealed that erosion 
along the block/rock interface occurred when the brine was introduced too rapidly to allow the bentonite to take up the water and swell to shut down flow paths. Subsequent testing with slower introduction of brine confirmed this result, that is, salt/bentonite blocks could be effective barriers to brine flow. Structural measurements provided data to test laboratory models of salt consolidation. To date, the measurements do not contradict model predictions of the barriers providing little resistance to hole closure until they become very dense.

The concrete and grout used in the above-referenced study were developed by Gulick and Wakeley (1989). They proposed expansive salt-saturated concrete (ESC) and grout mixtures that yielded favorable results for suitability as panel barrier and grout materials during the in-place testing at the WIPP repository. The grout composition was summarized in the text of this report in Section 2.2.1. The formulation for the ESC is shown in Table E-1.

Table E-1

Expansive Salt-Saturated Concrete

\begin{tabular}{|l|c|}
\hline \multicolumn{1}{|c|}{ Component } & Percent of Total Mass \\
\hline \hline Class H cement & 9.03 \\
\hline Chem comp III & 6.03 \\
\hline Cal seal (plaster) & 1.80 \\
\hline Class C fly ash & 5.10 \\
\hline Fine aggregate & 34.11 \\
\hline Coarse aggregate & 34.58 \\
\hline Sodium chloride & 2.50 \\
\hline Defoaming agent & 0.21 \\
\hline Sodium citrate & 0.11 \\
\hline Water (iced) & 6.60 \\
\hline
\end{tabular}

Class $\mathrm{H}$ cement is a standard oil-well cement. It has been used extensively in grouts and concretes in underground applications. Class $\mathrm{C}$ fly ash contributes expansive properties to the concrete. Cal Seal (a plaster of paris manufactured by Haliburton) also develops expansive properties in mixtures containing Class $\mathrm{H}$ cement. Expansive components that are added to the concrete or grout mixtures enhance bonding between the concrete or grout and the host rock. The addition of sodium chloride to the mixture is necessary to assure that the water 
content of the concrete or grout is in equilibrium with the host rock. This prevents dissolutioning, and also inhibits or reduces deterioration of the concrete or grout. Defoaming agents inhibit air entrainment in the concrete or grout mixture.

\section{References}

Finley, R. E., and J. R. Tillerson, 1992, "WIPP Small Scale Performance Test-Status and Impacts," SAND91-2247, Sandia National Laboratories, Albuquerque, New Mexico.

Gulick, C. W., and L. D. Wakeley, 1989, "Reference Properties of Cement-Based Plugging and Sealing Materials for the Waste Isolation Pilot Plant (WIPP)," Technical Report SL-89-17, U.S. Army Engineer Waterways Experiment Station, Vicksburg, Mississippi.

IT Corporation (IT), 1994, "Backfill Engineering Analysis Report," report prepared for Westinghouse Electric Corporation, Carlsbad, New Mexico.

Hansen, F. D., M. S. Lin, and L. L. Van Sambeek, 1993, "Concepts for Operational Period Panel Seal Design at the WIPP," SAND93-0729, Sandia National Laboratories, Albuquerque, New Mexico.

Peterson, E. W., P. L. Lagus, and K. Lie, 1987, "Fluid Flow Measurements of Test Series A and B for the Small Scale Seal Performance Tests," SAND87-7041, Sandia National Laboratories, Albuquerque, New Mexico.

Stormont, J. C., 1988, "Preliminary Seal Design Evaluation for the Waste Isolation Pilot Plant," SAND87-3083, Sandia National Laboratories, Albuquerque, New Mexico.

Stormont, J. C., 1987, "Small-Scale Seal Performance Test Series 'A' Thermal/Structural Data Through the 180th Day," SAND87-0178, Sandia National Laboratories, Albuquerque, New Mexico.

Stormont, J. C., E. W. Peterson, and P. L. Lagus, 1987, "Summary of the Observations About WIPP Facility Horizon Flow Measurements Through 1986," SAND87-0176, Sandia National Laboratories, Albuquerque, New Mexico. 


\section{APPENDIX F \\ HEAT TRANSFER MODEL DERIVATION METHANE EXPLOSION}




\section{APPENDIX F \\ HEAT TRANSFER MODEL DERIVATION METHANE EXPLOSION}

Under the conditions of a postulated methane explosion within the panel, the temperature of the gas is raised by the combustion process to an initial value $T_{g}$ init with time $t=0$ corresponding to initial conditions in the panel. Subsequently, the gas temperature in the panel decreases as heat is transferred to the surrounding salt and to the two explosionisolation walls in the air-intake and air-exhaust drifts of each panel.

At time $t=0$ the pressure in the panel is $P_{\text {init }}$ based on panel closure due to creep and the elevation in pressure resulting from the explosion. Thus, the rise time of the temperature is not considered in the model.

At time $t=0$, the volume of the panel is $V_{\text {init }}$ and is assumed to remain constant throughout the cooling of the gas in the panel because of the short duration of the explosion. This means that the effect of creep on the panel volume is assumed negligible during the postulated explosion. The initial volume is given by:

$$
V_{\text {init }}=V_{\text {panel }}-V_{\text {waste }}-V_{\text {creep }}
$$

where

$$
\begin{aligned}
& \mathrm{V}_{\text {init }}=\text { Initial volume } \\
& \mathrm{V}_{\text {panel }}=\text { Volume of the panel } \\
& \mathrm{V}_{\text {waste }}=\text { Volume of the waste } \\
& \mathrm{V}_{\text {creep }}=\text { Volume reduction due to creep }
\end{aligned}
$$

and is taken as given at the start of the heat transfer analysis and assumed to remain constant during the transfer of heat to the panel walls, roof, and floor.

\section{F.1.0 Heat Balance}

Assuming a constant volume is equivalent to stating that any creep closure of the panel volume during the explosion and subsequent cooling can be neglected. 


$$
\frac{d Q_{\text {volume of gas }}}{d t}=q A_{\text {walls }, \text { floor }, \text { roof }}
$$

where $\mathrm{Q}_{\text {volume of gas }}$ represents the heat contained in the hot gases subsequent to an explosion, $\mathrm{q}$ is the heat flux rate at the boundaries of the panel volume, and $A_{\text {walls, floor, roof }}$ is the surface area of the panel volume.

Following D'Appolonia (1978) it is conservatively assumed that the heat transfer to the surrounding walls, floor, roof, is related to the rate of change of enthalpy of the reaction products gas. Thus, the heat content of the room is given by:

$$
\frac{d Q_{\text {volume of gas }}}{d t}=n C_{p} \frac{d T_{g}}{d t}
$$

where $\mathrm{n}$ is the number of moles of gas in the room subsequent to the explosion, $\mathrm{T}_{\mathrm{g}}$ is the gas temperature, and $C_{p}$ is the heat content of the gas at constant pressure. Thus,

$$
n C_{p} \frac{d T_{g}}{d t}=q A_{\text {walls, floor, roof }}
$$

\section{F.2.0 Moles of Gas}

The gas in the panel subsequent to the explosion is a mixture of the combustion products of the explosive gas which is taken to be a mixture of methane, $\mathrm{CH}_{4}$ and air. Because methane can explode with other than a stoichiometric air/methane mixture (i.e., the methane concentration in air for an explosion to occur is a range as opposed to a single value), it is impossible to determine the number of moles of combustion product gas precisely. Thus, it is assumed that the explosion occurs with a stoichiometric air/methane mixture.

\footnotetext{
${ }^{1}$ The specific heat at constant volume is used even though the explosion or rapid combustion of the methane-air mixture occurs at constant volume because the rate of change of enthalpy as opposed to internal energy has been used.
} 


\section{F.2.1 Mixture}

The stoichiometric reaction for methane is (Bodartha, 1980):

$$
\mathrm{CH}_{4}+2 \mathrm{O}_{2}=\mathrm{CO}_{2}+2 \mathrm{H}_{2} \mathrm{O}
$$

with the moles of air given by:

$$
n_{\text {air }}=4.77(2)=9.54 \text { mole air/mole methane }
$$

or 9.54 moles of air are required to provide 2 moles of oxygen. Using a ratio of 9.54 moles of air per mole of methane, the total moles of gas at the time of the explosion would be:

$$
n=(9.54+1) n_{C H 4}
$$

The number of moles of nitrogen in the air and in the combustion products gas is $3.77(2)=$ 7.54 moles/mole of methane (Bodartha, 1980). Thus,

$$
\begin{aligned}
& 7.54 \text { moles } \mathrm{N}_{2}+2 \text { moles } \mathrm{O}_{2}+1 \text { mole } \mathrm{CH}_{4}= \\
& 7.54 \text { moles } \mathrm{N}_{2}+1 \text { mole } \mathrm{CO}_{2}+2 \text { moles } \mathrm{H}_{2} \mathrm{O}
\end{aligned}
$$

On a molar basis the reaction products are $71.5 \%$ nitrogen, $9.5 \%$ carbon dioxide, and $19 \%$ water vapor. This compares with a reaction product that is $72.9 \%$ nitrogen, $11.6 \%$ carbon dioxide and $15.5 \%$ water vapor when propane is burned at a stoichiometric ratio (D'Appolonia, 1978). Also, 10.54 moles of the methane-air mixture produces 10.54 moles of reaction products. Thus, the number of moles of air/methane prior to the explosion is the same as the number of moles of the product gas and the above relation for $\mathrm{n}$ will be used to compute the heat content in a panel prior to cooling.

$$
n_{\text {gas }}=10.54 n_{C H 4}
$$

Substituting (2) into (1),

$$
10.54 n_{C H 4} C_{p} \frac{d T_{g}}{d t}=q A_{\text {walls, floor, roof }}
$$




$$
\frac{d T_{g}}{d t}=\frac{q A_{\text {walls, floor, roof }}}{10.54 n_{C H 4} C_{p}}
$$

is the differential equation for the time rate of change of the gas temperature in the panel following an explosion.

\section{F.2.2 Specific Heat}

The specific heat, $\mathrm{Cp}$, of the combustion products of the explosion is required by equation (3). In general, the specific heat is a function of temperature over large temperature ranges. Figure C-1 shows plots of specific heats of the combustion products of stoichiometric propane-air mixtures and methane-air mixtures based on data from D'Appolonia (1978) and Reid, et al., (1977). The curves for propane-air mixtures are shown for comparison between the Reid, et al. data and the D'Appolonia data.

For an explosion temperature on the order of 2400 degrees kelvin $\left({ }^{\circ} \mathrm{K}\right)$, and using an average of the wall temperature and gas temperature to evaluate the specific heat, the temperature dependence curve will be evaluated in the region of $1400^{\circ} \mathrm{K}$ which is about the maximum useful temperature for the Reid, et al. data.

As shown on Figure F-1, the Reid et al. (1977) and D'Appolonia (1978) data agree well up to a temperature of approximately $1400^{\circ} \mathrm{K}$. At the greater temperatures Reid et al. (1977), and other data indicate a decrease in specific heat with greater temperatures which is not consistent with expectation.

Figure F-2 shows a comparison of Reid et al. (1977) and the D'Appolonia (1978) data multiplied by 0.961 , the ratio of specific heats for a methane-air mixture to a propane-air mixture at $300^{\circ} \mathrm{K}$. Below $1400^{\circ} \mathrm{K}$ the agreement is very good. Above $1400^{\circ} \mathrm{K}$ the curve based on the D'Appolonia data remains valid. Therefore, the specific heat of the combustion products formed from a stoichiometric methane air mixture as a function of temperature is ${ }^{2}$

$$
C_{p}=1.29 \times 10^{-3} T+7.3353-\frac{32682}{T^{2}}
$$

\footnotetext{
${ }^{2}$ Equation (4) was obtained by multiplying Equation (9) of Appendix B of D'Appolonia [1978] by 0.961.
} 


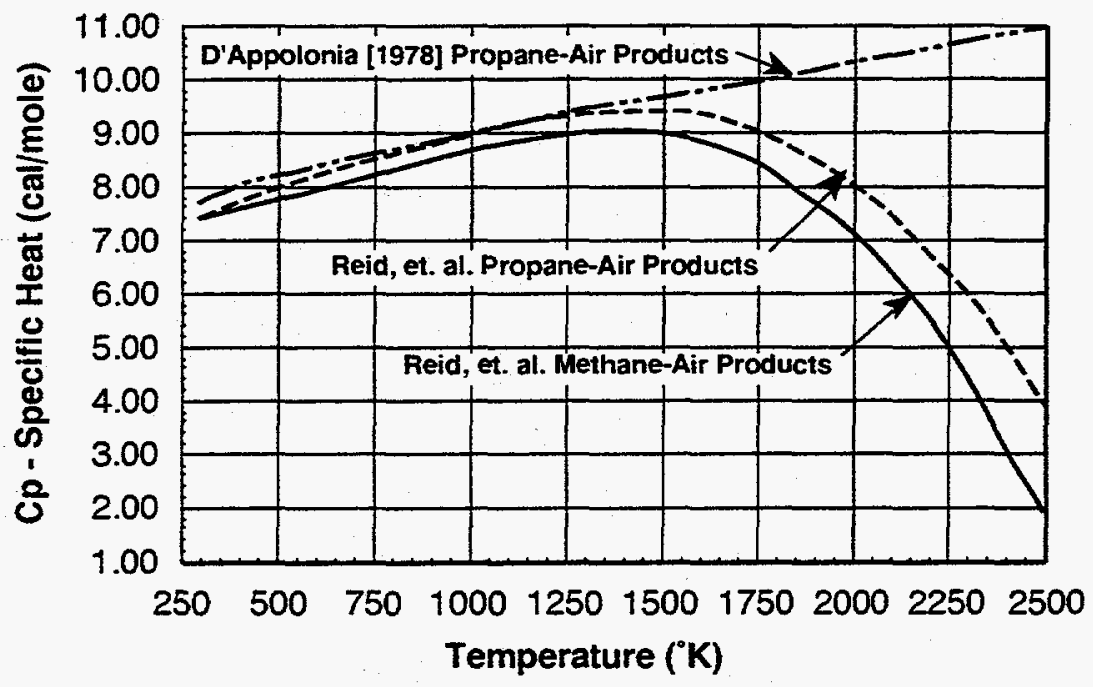

Figure F-1

Specific Heat as a Function of Temperature 


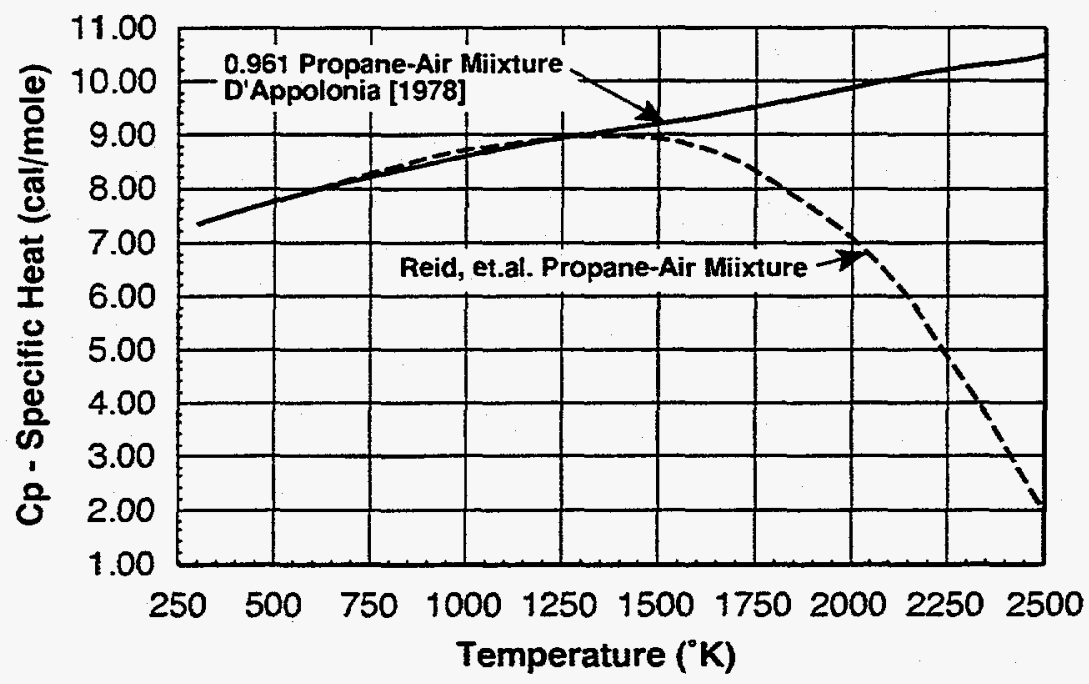

Figure F-2

Specific Heat for Methane-Air Stochiometric Mixture 


\section{F.3.0 Heat Transfer to the Walls, Floor, Etc.}

Heat is transferred from the gas to the surrounding walls, floor and roof of the panel rooms by both convection and radiation. Heat is then transferred into the walls, floor, roof, via conduction. Thus, the rate of heat conduction into the salt or the wall is governed by the rate at which heat can be conducted into the solids.

\section{F.3.1 Radiation Heat Transfer}

Heat transferred from the gas to the walls, floor, roof, is given by:

$$
q_{r s}=\sigma\left(T_{g}^{4}-T_{w}^{4}\right)
$$

where $q_{r s}$ is the heat flux to the walls, floor, roof, $\sigma$ is the Stefan-Boltzmann constant $\left(1.35 \times 10^{-12} \mathrm{cal} / \mathrm{cm}^{2}-\mathrm{sec}^{\circ} \mathrm{K}\right)$, and $\mathrm{T}_{\mathrm{w}}$ is the temperature of the walls, floor, and roof.

The majority of the surface area of the panel available for heat transfer via both radiation and convection is salt. However, a small portion of the total area will be the inner face of the explosion-isolation wall (or construction-isolation well). Because the wall, floor, roof temperature is controlled by the time dependent conduction of heat into either the walls, floor, roof or the wall faces, and the diffusivities and conductivities of the salt and wall, floor, roof material may be different, the radiation heat transfer is divided into two components.

The radiative heat transfer to the salt $\left(\mathrm{T}_{w s}\right)$ is:

$$
q_{r s}=\sigma\left(T_{g}^{4}-T_{w s}^{4}\right)
$$

and the radiative heat transfer to the explosion-isolation wall $\left(T_{w b}\right)$ is:

$$
q_{r b}=\sigma\left(T_{g}^{4}-T_{w b}^{4}\right)
$$

The combined radiative heat transfer to the walls, floors, roof is:

$$
Q_{r}=q_{r s} A_{s}+q_{r b} A_{b}
$$

or 


$$
Q_{r}=\sigma\left(A_{s}\left[T_{g}^{4}-T_{w s}^{4}\right]+A_{b}\left[T_{g}^{4}-T_{w b}^{4}\right]\right)
$$

where $A_{b}=$ Area of the walls, and $A_{s}=$ area of the salt.

Equation (5) comprises the radiation portion of the right hand side of the differential equation, (3), for the rate of gas temperature in the panel.

\section{F.3.2 Convection Heat Transfer}

In addition to radiation, heat is transferred to the walls, floor, roof, and explosion-isolation walls by natural convection. In subsequent discussion, walls denote all exposed surface area of salt within a panel. Explosion-isolation walls denote the surface area of the expendable walls placed in the sealed air-intake and air-exhaust drifts of the panel.

\section{F.3.2.1 Heat Transfer from Gas to the Walls}

In addition to radiation, heat is transferred to the walls, floor, roof, and explosion-isolation walls via natural convection. The heat flux due to convection $\left(q_{c}\right)$ is given by:

$$
q_{c}=h\left(T_{b}-T_{w}\right)
$$

where $\mathrm{h}=$ Film coefficient.

As for the case of radiation, the majority of heat transfer by convection will occur to the surrounding salt. However, a portion will be transferred to the explosion-isolation wall. Because the temperature of the explosion-isolation wall may be different from the temperature of the salt, the convective heat transfer is divided into the two components analogous to the radiation heat transfer. For the salt, the convection heat transfer is:

$$
q_{c s}=h\left(T_{g}-T_{w s}\right)
$$

and for the explosion-isolation walls:

$$
q_{c b}=h\left(T_{s}-T_{w b}\right)
$$

The combined radiative heat transfer $\left(\mathrm{Q}_{c}\right)$ to the walls, floors, roof, and explosion-isolation walls is: 


$$
q_{c b}=h\left(T_{g}-T_{w b}\right)
$$

The combined radiative heat transfer $\left(Q_{c}\right)$ to the walls, floors, roof, and explosion-isolation walls is:

assuming that the heat transfer coefficient does not change with location or material.

$$
Q_{c}=q_{c N a C l} A_{s}+q_{c b} A_{b}
$$

Theoretically the convective heat transfer coefficient is different for the face of the explosionisolation walls, which are vertical compared with the heat transfer coefficient for the roof and floor faces of the panel which are horizontal. Neglecting the difference in heat transfer coefficient due to geometric differences, the above two equations for the heat flow to the walls, floor, roof, and explosion-isolation walls can be combined to give

$$
Q_{c}=h\left(A_{s}\left[T_{g}-T_{w s}\right]+A_{b}\left[T_{g}-T_{w b}\right]\right)
$$

Equation (6) gives the convective heat transfer portion of the right hand side of Equation (3). Combining (3), (5) and (6),

$$
\frac{d T_{g}}{d t}=-\frac{Q_{c}+Q_{r}}{10.54 n_{C H 4} C_{p}}
$$

where the negative sign indicates that $Q_{c}$ and $Q_{r}$ represent heat transferred out of the system consisting of the gas in the room. These same quantities then represent heat transferred into the surrounding salt and explosion-isolation wall.

\section{F.3.2.2 Convection Coefficient}

Assuming the convection coefficient is the same at all surfaces and following the methods developed in D'Appolonia (1978), with all units in the centimeter-gram-second (cm-g-sec) system of units, 


$$
N_{u}=0.13\left[P_{r} G_{r}\right]^{1 / 3}
$$

where $P_{\mathrm{r}}$ is the Prandtl number and $\mathrm{G}_{\mathrm{r}}$ is the Grashof number. The Prandtl number is essentially constant and is taken as 0.71 regardless of pressure and temperature. The Grashof number is given by

$$
G_{r}=\frac{g \beta L^{3}\left(T_{g}-T_{w}\right)}{v^{2}}
$$

where $g$ is the acceleration of gravity, $\beta$ is the volume coefficient of thermal expansion and $v$ is the kinematic viscosity of the gas. For ideal gases,

$$
\beta=\frac{1}{T_{g}}
$$

and the kinematic viscosity is given by

$$
v=\frac{\mu}{\rho}
$$

where $\mu$ is the absolute viscosity $\rho=$ mass density. Substituting for $n$ and $\beta$ in the expression for the Grashof number,

$$
G_{r}=\frac{g \rho^{2} L^{3}\left(T_{g}-T_{w}\right)}{T_{m} \mu^{2}}
$$

where

$$
T_{m}=\frac{T_{g}+T_{w}}{2}
$$

is the average of the gas and surface temperature.

Substituting for the Grashof number and Prandtl number in the expression for the Nusselt number, 


$$
\begin{gathered}
N_{u}=0.13\left(0.71 \frac{g \rho^{2} L^{3}\left[T g-T_{w}\right]}{T_{m} \mu^{2}}\right)^{1 / 3} \\
N_{u}=0.146 L\left(\frac{g \rho^{2}}{\mu^{2}}\left[\frac{T_{g}-T_{w}}{T_{g}+T_{w}}\right]\right)^{1 / 3}
\end{gathered}
$$

and substituting for the Nusselt number in the expression for the convection coefficient,

$$
h=0.146 k_{g}\left(\frac{g \rho^{2}}{\mu^{2}}\left[\frac{T_{g}-T_{w}}{T_{g}+T_{w}}\right]\right)^{1 / 3}
$$

Since the thermal conductivity of the gas is given by ${ }^{3}$

$$
\begin{gathered}
k_{g}=6.4 \times 10^{-5}\left(\frac{T_{m}}{300}\right)^{.75} \\
h=9.34 \times 10^{-6}\left(\frac{T_{g}+T_{w}}{600}\right)^{75}\left(\frac{g \rho^{2}}{\mu^{2}}\left[\frac{T_{g}-T_{w}}{T_{g}+T_{w}}\right]\right)^{1 / 3}
\end{gathered}
$$

Figure F-3 shows $\mathrm{h}$ as a function of surface temperature based on a gas temperature of $2400^{\circ} \mathrm{K}$ and density and viscosity consistent with conditions at the time of an explosion.

Assuming that no additional gas is generated subsequent to the explosion, the density of the gas after the explosion is the same as before the explosion since mass is conserved. Thus, the gas density after the explosion is the molecular weight of $\mathrm{n}$ moles of methane plus $9.54 \mathrm{n}$ moles of air divided by the initial volume,

${ }^{3} D^{\prime}$ Appolonia [1978]. 


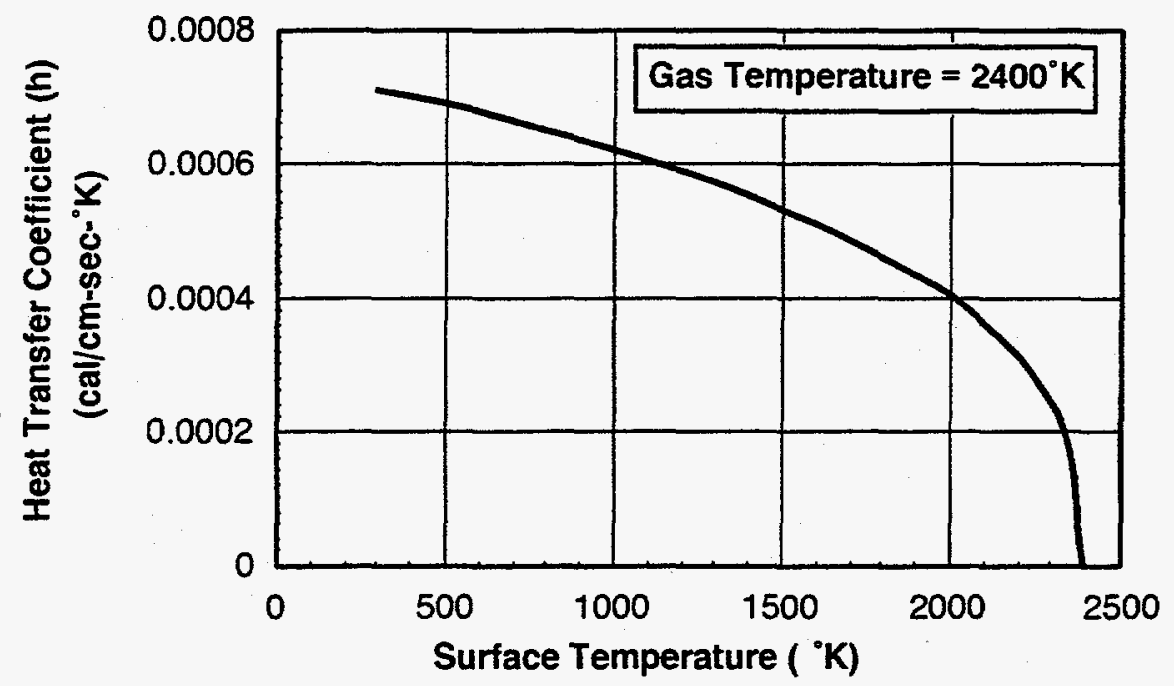

Figure F-3

Convection Heat Transfer Coefficient Versus Temperature 


$$
\begin{gathered}
\rho=n\left(\frac{M_{w \mathrm{CH} 4}+9.54 M_{w \text { air }}}{V_{\text {init }}}\right) \\
\rho=n\left(\frac{16+9.54(29)}{V_{\text {init }}}\right) \\
\rho=\frac{292.66 n}{V_{\text {init }}} \\
\mu=1.85 \times 10^{-4}\left(\frac{T_{m}}{300}\right)^{0.67}
\end{gathered}
$$

and the viscosity is given by (D'Appolonia, 1978), where the viscosity is evaluated at the average of the surface and gas temperatures.

Because there will be two different surface temperatures, one corresponding to the salt, and one for the explosion-isolation wall, there will be different convective heat transfer coefficients as well.

\section{F.3.3 Conduction Into the Walls, Floor, Roof, and Explosion-Isolation Walls}

The temperature which controls the heat transfer from the gas via radiation and convection is controlled by the rate at which heat is conducted into the walls, roof, floor, and explosionisolation walls. The diffusion of heat into the walls, floor, roof, and explosion-isolation walls is assumed to be governed by a one-dimensional, semi-infinite thermal diffusion model. If the temperature penetrates the explosion-isolation walls, the model is changed to be thermal diffusion across a slab of finite thickness with an ambient gas temperature on the side in the isolation zone.

Thermal diffusion into the walls, floor, roof, and explosion-isolation walls is governed by the partial differential equation, 


$$
\alpha^{\frac{\partial^{2} T}{\partial x^{2}}}=\frac{\partial T}{\partial t}
$$

where $\alpha$ is the thermal diffusivity, $\mathrm{T}$ is the temperature, $\mathrm{x}$ is the distance into the wall, floors, roof, or explosion-isolation walls, and $t$ is time. At $x=0$ the flow of heat into the walls, floor, roof, or explosion-isolation walls is governed by the boundary condition,

$$
-k \frac{\partial T}{\partial x}=q_{\text {in }}
$$

where $q_{i n}$ is the heat flux into the walls, etc. from the gas via convection and radiation and $k$ is the thermal conductivity. Because the thermal diffusivity and conductivity for salt is different from that of the explosion-isolation wall, two conduction models are required.

\section{F.3.3.1 Heat Conduction to the Salt}

The first involves the heat transferred from the gas to the salt and is governed by the partial differential equation,

$$
\alpha_{s} \frac{\partial^{2} T_{s}}{\partial x^{2}}=\frac{\partial T_{s}}{\partial t}
$$

where $\alpha_{s}$ is the thermal diffusivity of salt which is a function of temperature. Figure F-3 shows plots of thermal diffusivity for halite, anhydrite, argillaceous halite and polyhalite (Krieg, 1983). Figure F-4 also shows data from D'Appolonia (1978) that used the relation

$$
\alpha_{s}=\frac{10}{T_{s}}
$$

for salt. The D'Appolonia temperature dependence yields slightly higher values compared with the Waste Isolation Pilot Plant (WIPP) data, but indicates a consistency in the data. For purposes of the post-explosion heat transfer analysis the temperature dependent data for salt has been used. 


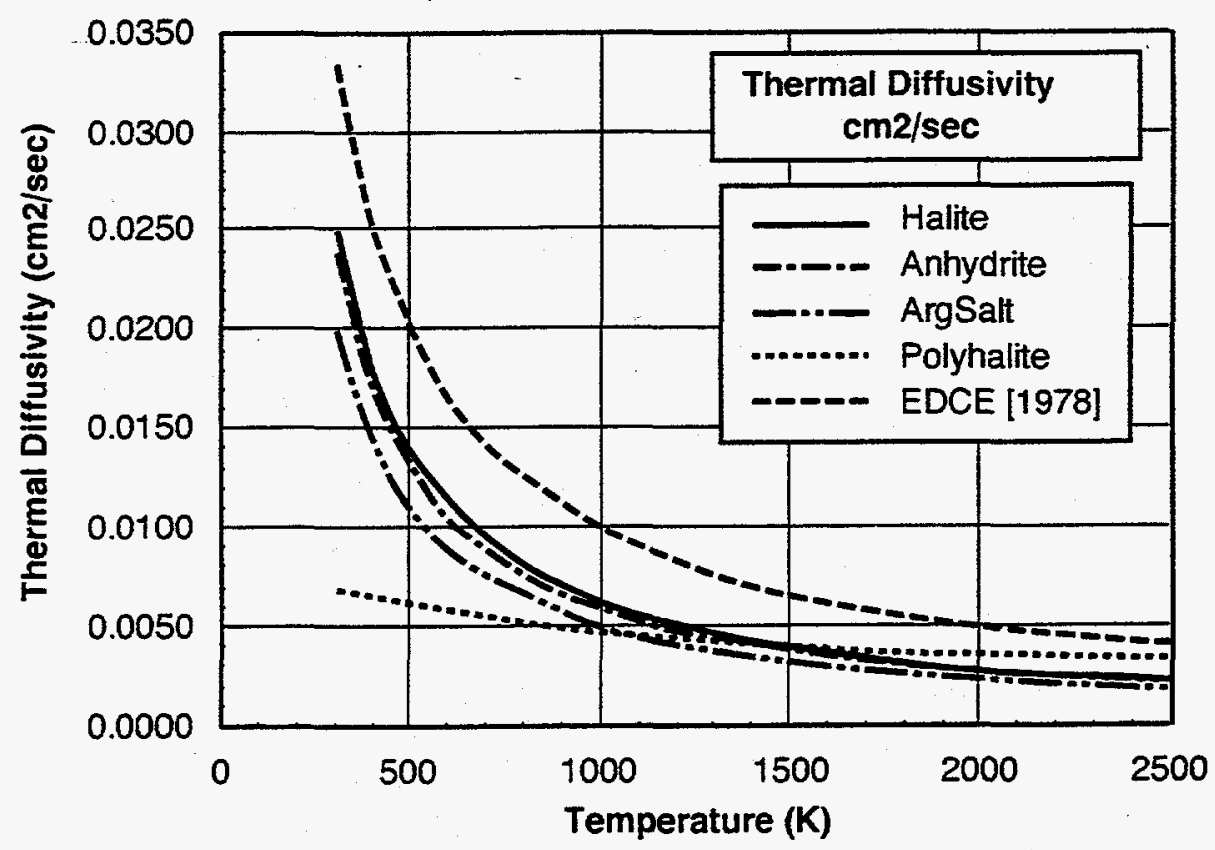

Figure F-4

Thermal Diffusivity of WIPP Geologic Materials 


$$
\alpha_{s}=0.025\left[\frac{300}{T_{s}}\right]^{.14}
$$

The boundary condition at the surface of the salt is:

$$
-k_{s} \frac{\partial T_{s}}{\partial x}=q_{s r}+q_{s c}
$$

where $\mathrm{k}_{\mathrm{s}}$ is the thermal conductivity of the salt. Figure F-4 shows plots of thermal conductivities for the same materials as a function of temperature. Again, the thermal conductivity from D'Appolonia (1978):

$$
k_{s}=\frac{4.5}{T_{s}}
$$

is also shown on Figure F-5 to check the consistency of the WIPP data. Again, the thermal conductivity for halite was used for the post-explosion heat transfer analysis.

$$
k_{s}=0.012\left[\frac{300}{T_{s}}\right]^{1.14}
$$

The terms $\mathrm{q}_{\mathrm{sr}}$ and $\mathrm{q}_{\mathrm{sc}}$ in (13i) couple the heat conduction into the salt with the rate of cooling of the gas via equations ( 7 ) through (10). In addition to the boundary conditions given by (12i), initial conditions at time $t=0$ are required. It is assumed that at $t=0$ the salt is at the ambient temperature in the panel, $T_{\text {amb }}$. Equations (11i) through (14i) with the initial conditions form the complete problem for the temperature in the salt as a function of time as the gas cools following the explosion.

\section{F.3.3.2 Heat Conduction to the Explosion-Isolation Walls}

The second model involves the heat transferred from the gas to the explosion-isolation walls and is governed by the partial differential equation,

$$
\alpha_{b} \frac{\partial^{2} T_{b}}{\partial x^{2}}=\frac{\partial T_{b}}{\partial t}
$$




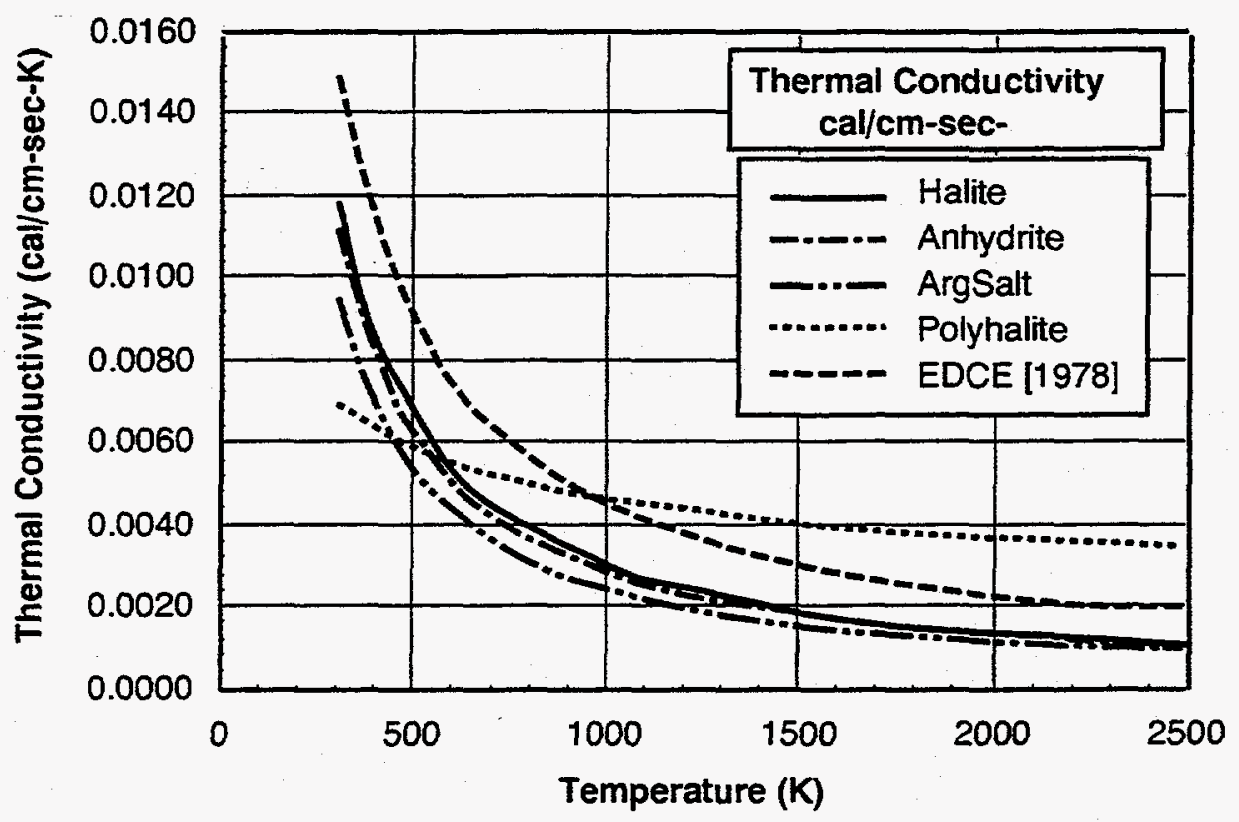

Figure F-5

Thermal Conductivity of WIPP Geologic Materials 
where $\alpha_{b}$ is the thermal diffusivity of explosion-isolation walls. If the explosion-isolation walls are concrete, the thermal diffusivity does not vary with temperature (D'Appolonia, 1978),

$$
\alpha_{s}=0.005
$$

The boundary condition is:

$$
-k_{b} \frac{\partial T_{b}}{\partial x}=q_{b r}+q_{b c}
$$

where $q_{b r}=$ heat flux for the salt, $q_{b c}=$ heat flux for explosion-isolation walls, and $k_{b}$ is the thermal conductivity of the walls. Again, if the explosion-isolation walls are concrete, the thermal conductivity is constant (D'appolonia, 1978).

$$
k_{b}=0.002
$$

Analogous to the case for salt, the terms $q_{b r}$ and $q_{b c}$ in (13ii) couple the heat conduction into the salt with the rate of cooling of the gas via equations (7) through (10). At $t=0$ the explosion-isolation walls are at the ambient temperature at the panel level, $T_{\text {amb }}$.

\section{F.4.0 Numerical Model}

Equations (1) through (14) were solved using a computer program based on an explicit finite difference representation of the equations. In subsequent discussion the following symbols are used,

$$
\begin{aligned}
\tau= & \text { time step } \Delta \mathrm{t} \\
\varepsilon & =\text { distance between mesh points, } \Delta \mathrm{x}, \text { in finite difference representation of } \\
& \text { semi-infinite solid used to model the explosion-isolation walls. } \\
\mathrm{n}= & \text { subscript denoting the value of a variable at time } \mathrm{t} . \\
\mathrm{n}+1= & \text { subscript denoting the value of a variable at time } \mathrm{t}+\tau . \\
\mathrm{m}= & \text { subscript denoting the value of a variable at mesh point } \mathrm{m} \text { in a finite } \\
& \text { difference representation of a semi-infinite solid. } \mathrm{m}=0 \text { corresponds to the } \\
& \text { boundary } \mathrm{x}=0 . \\
\mathrm{T}_{g \mathrm{n}}= & \text { gas temperature at time } \mathrm{t} . \\
\mathrm{T}_{\mathrm{s0}}= & \text { temperature at } \mathrm{x}=0 \text { in salt. } \\
\mathrm{T}_{\mathrm{b} 0}= & \text { temperature at } \mathrm{x}=0 \text { in an explosion-isolation wall. } \\
\mathrm{T}_{\mathrm{sma}}= & \text { temperature in salt at mesh point } \mathrm{m} \text { and time } \mathrm{n} . \\
\mathrm{T}_{\mathrm{bmn}}= & \text { temperature in explosion-isolation walls at mesh point } \mathrm{m} \text { and time } \mathrm{n} . \\
\alpha_{\mathrm{sm}}= & \text { thermal diffusivity in salt at mesh point } \mathrm{m} \text { (function of temperature). }
\end{aligned}
$$


$\alpha_{b m}=$ thermal diffusivity of explosion-isolation wall material at mesh point $\mathrm{m}$ (may be constant or a function of temperature).

$\mathrm{q}_{\mathrm{rsn}}=$ heat flux to wall (salt) via radiation at time point $\mathrm{n}$.

$\mathrm{q}_{\mathrm{rbn}}=$ heat flux to explosion-isolation wall via radiation at time point $\mathrm{n}$.

$\mathrm{q}_{\mathrm{csn}}=$ heat flux to wall (salt) via convection at time point $\mathrm{n}$.

$\mathrm{q}_{\mathrm{cbs}}=$ heat flux to explosion-isolation wall via convection at time point $\mathrm{n}$.

Where symbols are used for parameters that are a function of temperature and consequently also a function of time, the subscripts $\mathrm{n}$ and $\mathrm{n}+1$ refer to whether the parameter is evaluated at $\mathrm{t}$ or $\mathrm{t}+\Delta \mathrm{t}$.

\section{F.4.1 Overview of Computer Program}

Figure F-6 provides a simplified flow chart of the computer program used to solve the equations in the model in explicit finite difference form.

\section{F.4.2 Finite Difference Formulation}

For the first past through the calculational loop $\mathrm{n}=0$ and the gas temperature is set to $T_{\mathrm{g} 0}$, the initial temperature. Based on the assumption of constant volume during the explosion, the temperature is related to the pressure by,

$$
T_{g^{0}}=T_{g^{a m b}}\left(\frac{P_{0}}{P_{a m b}}\right)=8 T_{g a m b}
$$

where

$$
\begin{aligned}
& \mathrm{T}_{\text {gamb }}=\text { the gas temperature prior to the explosion } \\
& \left.\mathrm{P}^{\mathrm{amb}}=\text { the gas pressure prior to the explosion (taken as } 2 \mathrm{~atm}\right) \\
& \left.\mathrm{P}_{0}=\text { the gas pressure caused by the explosion (taken as } 16 \mathrm{~atm}\right) \\
& \mathrm{T}_{\mathrm{g} 0}=\text { the gas temperature caused by the explosion which is the initial gas } \\
& \text { temperature for the cooling analysis. }
\end{aligned}
$$

The initial temperature of the salt $\left(\mathrm{T}_{\mathrm{smo}}\right)$ and explosion-isolation walls $\left(\mathrm{T}_{\mathrm{bmo}}\right)$ for the heat conduction calculations are set to the ambient temperature at all mesh points. 


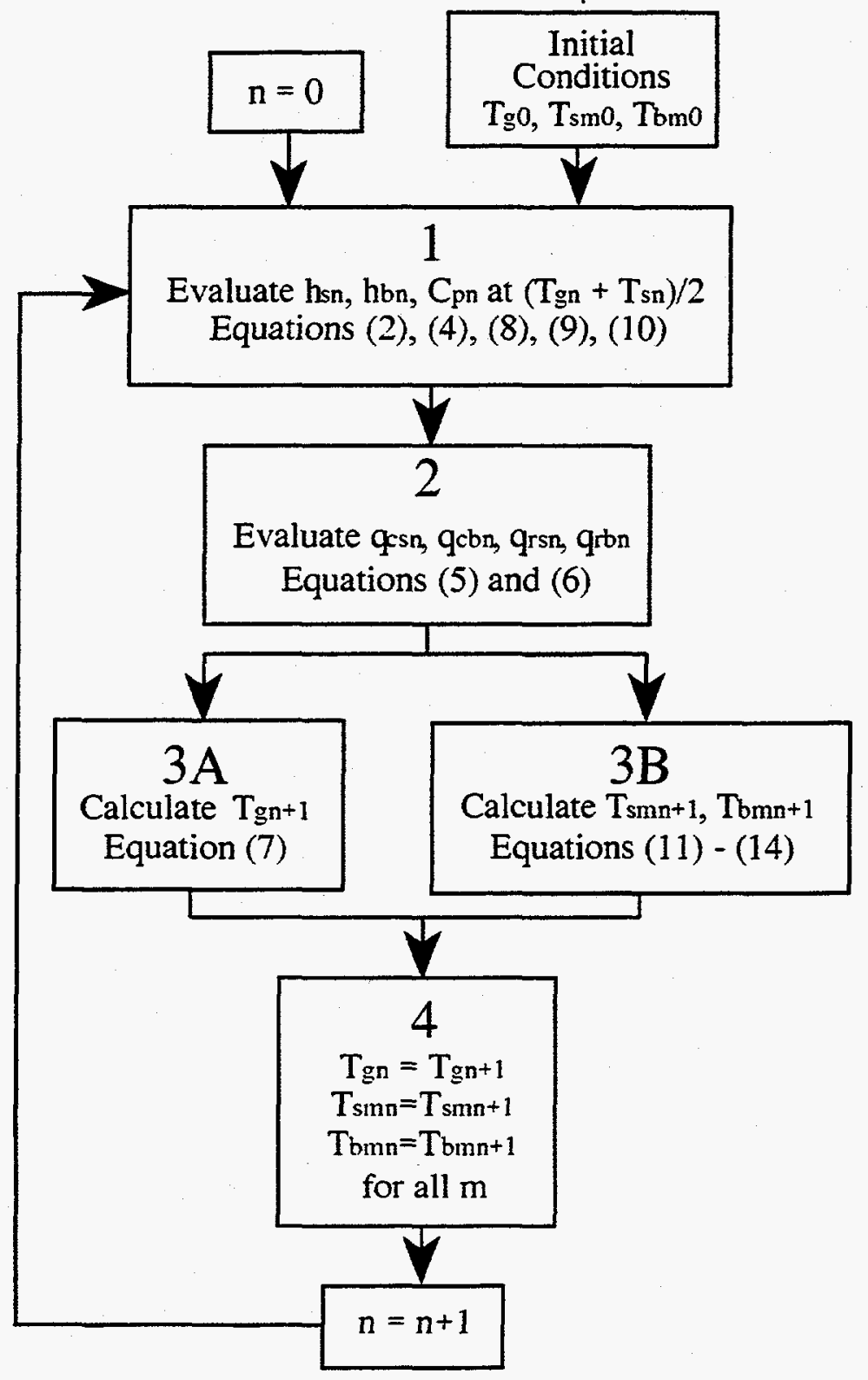

Figure F-6

Program Flow Chart 


$$
\begin{aligned}
& T_{s m o}=T_{a m b} m=1 . . M \\
& T_{b m o}=T_{a m b} m=1 . . M
\end{aligned}
$$

where $M$ is the maximum mesh point number used in the finite difference representation of the semi-infinite solid. $T_{a m b}$ is the ambient temperature of the salt and explosion-isolation wall at the time of the explosion.

\section{F.4.2.1 Program Section 1}

Section 1 of the program (Figure F-3) calculated the parameters required for the determination of the heat fluxes from the hot gas to the cooler walls. These calculations are performed initially based on values for $n=0$, initial conditions. Subsequently, they are evaluated based on the temperature values at time point $n$.

Thus,

$$
\begin{aligned}
& \mu_{s n}=1.85 \times 10^{-4}\left(\frac{T_{g n}+T_{s 0 n}}{600}\right)^{0.67} \\
& \mu_{b n}=1.85 \times 10^{-4}\left(\frac{T_{g n}+T_{b 0 n}}{600}\right)^{0.67}
\end{aligned}
$$

where

$$
\begin{aligned}
\mu_{s n}= & \text { viscosity of the salt } \\
\mu_{b n}= & \text { viscosity of the explosion-isolation wall } \\
T_{g n}= & \text { gas temperature at time point } n \\
T_{s 0 n}= & \text { wall temperature of the salt at time point } n \text {, which is the } m=0 \text { mesh point of } \\
& \text { the finite difference representation of the semi-infinite solid used to model heat } \\
& \text { conduction into the salt } \\
T_{b 0 n}= & \text { surface temperature of the explosion-isolation wall. }
\end{aligned}
$$

Since the initial surface temperatures of the salt and the walls are the same, the initial value of $\mu$ will be the same at both the salt and the walls. However, with time as the surface temperature of the explosion-isolation walls varies from the surface temperature of the salt, the values of $\mu$ will be different for the salt compared with the walls. This plays a role in 
having different convection heat transfer coefficients at the salt compared with the explosionisolation walls.

The convection heat transfer coefficients are given by (8) below.

$$
\begin{aligned}
& h_{s n}=9.34 \times 10^{-6}\left(\frac{T_{g n}+T_{s 0 n}}{600}\right)^{75}\left(\frac{g \rho^{2}}{\mu_{s n}^{2}}\left[\frac{T_{g n}-T_{s 0 n}}{T_{g n}+T_{s 0 n}}\right]\right)^{1 / 3} \\
& h_{b n}=9.34 \times 10^{-6}\left(\frac{T_{g n}+T_{b 0 n}}{600}\right)^{75}\left(\frac{g \rho^{2}}{\mu_{b n}^{2}}\left[\frac{T_{g^{n}}-T_{b 0 n}}{T_{g^{n}}+T_{b 0 n}}\right]\right)^{1 / 3}
\end{aligned}
$$

The density, $\rho$, remains constant by virtue of the constant volume and constant number of moles. The acceleration of gravity, $g$, also remains constant for all time points.

The specific heat of the gas which is required for Section 3A of the program is given by (4) below.

$$
C_{p n}=6.45 \times 10^{-4}\left(T_{g n}+T_{s 0 n}\right)+7.3353-\frac{130728}{\left(T_{g n}+T_{s 0 n}\right)^{2}}
$$

Because the specific heat is a bulk property of all of the gas in the panel, it is affected by all of the surface area in the panel. Because the surface area of the salt is orders of magniture larger than the surface area of the explosion-isolation walls, the specific heat at each time is based solely on the surface temperature of the salt.

\section{F.4.2.2 Program Section 2}

The heat flux rates to the walls as well as the total heat transfer rates to the walls via convection and radiation are calculated in Section 2 of the program. Flux is required for the boundary condition for the heat conduction analysis of Section 3B and total heat flow is required for the change in gas temperature calculation in Section $3 \mathrm{~A}$.

The total heat flow values are given by (5) and (6) which for time step $\mathrm{n}$ become where $h_{s \mathrm{~s}}$ and $h_{b \mathrm{~b}}$ are given by (18). The total heat flows are used in Section $3 \mathrm{~A}$ of the program evaluates the time rate of change of the gas temperature using equation (7). 


$$
\begin{gathered}
Q_{r n}+\sigma\left(A_{s}\left[T_{g^{n}}^{4}-T_{s 0 n}^{4}\right]+A_{b}\left[T_{b n}^{4}-T_{b 0 n}^{4}\right]\right) \\
Q_{c n}=A_{s s n} h_{s n}\left(T_{g^{n}}-T_{s 0 n}\right)+A_{b} h_{b n}\left(T_{g n}-T_{b n}\right)
\end{gathered}
$$

The total heat flows at time step $\mathrm{n}$ given by (20) are heat flow out of the gas occupying the panel volume and into the explosion-isolation walls. For the heat flow into the explosionisolation walls, the areas, $A_{s}$ and $A_{b}$ cancel from the equations representing the boundary conditions at $\mathrm{x}=0$ for the transient heat conduction problems solved in Section $3 \mathrm{~B}$ of the program. Thus, for Section 3B, the heat flux values are required. These are the same as (20) without the areas.

$$
\begin{gathered}
q_{r n}=\sigma\left(\left[T_{g^{n}}^{4}-T_{s 0 n}^{4}\right]+\left[T_{g^{n}}^{4}-T_{b 0 n}^{4}\right]\right) \\
q_{c n}=h_{s n}\left(T_{g^{n}}-T_{s 0 n}\right)+h_{b n}\left(T_{b n}-T_{b n}\right)
\end{gathered}
$$

where $\mathrm{q}_{\mathrm{m}}$ and $\mathrm{q}_{\mathrm{cn}}$ are the heat fluxes due to radiation and convection.

For the total heat flow and heat flux due to radiation, the Stefan-Boltzmann constant is taken to be constand for all values of temperature and hence time.

$$
\sigma=1.355 \times 10^{-12}
$$

\section{F.4.2.3 Program Section 3}

Section 3 comprises the main body of the program.

\section{F.4.2.3.1 Program Section 3A}

Equation (7) governs the rate of change of gas temperature in the panel volume. Using the explicit finite difference approximation,

$$
\frac{d T_{g}}{d t}=\frac{1}{\tau}\left(T_{g^{n+1}}-T_{b n}\right)
$$


where $\tau=\Delta t$ is the time increment, Equation (7) becomes

$$
T_{g^{n+1}}=T_{g^{n}}-\tau\left(\frac{Q_{c n}+Q_{r n}}{10.54 n_{C H 4} C_{p n}}\right)
$$

where $\mathrm{Q}_{\mathrm{cn}}, \mathrm{Q}_{\mathrm{m}}$, and $\mathrm{C}_{\mathrm{pn}}$ are given by (20) and (19) and $\mathrm{n}_{\mathrm{CH} 4}$ is an input representing the moles of methane in the panel volume at the time of the explosion. Equation (23) gives the gas temperature in the panel at time $t+\Delta t$ in terms of the gas temperature at time $t$ and the total heat flow values at time $t$.

\section{F.4.2.3.2 Program Section 3B}

Section 3B of the program is the most complex. It solves two transient heat conduction problems assuming that the walls, floor, roof, and explosion-isolation walls are semi-infinite solids having thermal conductivities and diffusivities that may or may not be temperature dependent. In the case of the walls, floor and roof, the panel volume the conductivity and diffusivity of salt is dependent on temperature. Assuming that the explosion-isolation wall material is concrete, the conductivity and diffusivity of the explosion-isolation wall are independent of temperature.

Because of the temperature dependence of the conductivity and diffusivity of the salt, and the time-dependent spatial temperature distribution into the walls, floor and roof, the conductivity that is required for the boundary condition at $\mathrm{x}=0$ varies with time and the thermal diffusivity varies in both time and space. The partial differential equation for transient heat conduction when the diffusivity varies spatially is given by:

$$
\frac{\partial}{\partial x}\left(\alpha \frac{\partial T}{\partial x}\right)=\frac{\partial T}{\partial t}
$$

which can be expanded as:

$$
\left(\frac{\partial \alpha}{\partial x}\right)\left(\frac{\partial T}{\partial x}\right)+\alpha \frac{\partial^{2} T}{\partial x^{2}}=\frac{\partial T}{\partial t}
$$

Using the finite difference approximations, 


$$
\begin{gathered}
\frac{\partial \alpha}{\partial x}=\frac{1}{2 \varepsilon}\left(\alpha_{m+1}-\alpha_{m-1}\right) \\
\alpha \frac{\partial^{2} T}{\partial x^{2}}=\frac{\alpha_{m}}{\varepsilon^{2}}\left(T_{m-1}-2 T_{m}+T_{m+1}\right) \\
\frac{\partial T}{\partial x}=\frac{1}{2 \varepsilon}\left(T_{m+1}-T_{m-1}\right)
\end{gathered}
$$

where $e=\Delta x$, the left hand side of equation (b) becomes

$$
\begin{gathered}
\left(\frac{\partial T}{\partial x}\right)\left(\frac{\partial T}{\partial x}\right)+\alpha \frac{\partial^{2} T}{\partial x^{2}}= \\
\frac{1}{4 \varepsilon^{2}}\left(\left[\alpha_{m+1}-\alpha_{m-1}\right]\left[T_{m+1}-T_{m-1}\right]+4 \alpha_{m} T_{m-1}-8 \alpha_{m} T_{m}+4 \alpha_{m} T_{m+1}\right)
\end{gathered}
$$

or

$$
\begin{gathered}
=\frac{1}{4 \varepsilon^{2}}\left(\alpha_{m+1} T_{m+1}-\alpha_{m+1} T_{m-1}-\alpha_{m-1} T_{m+1}+\alpha_{m-1} T_{m-1}\right)+ \\
\frac{1}{4 \varepsilon^{2}}\left(4 \alpha_{m} T_{m-1}-8 \alpha_{m} T_{m}+4 \alpha_{m} T_{m+1}\right) \\
4 \varepsilon^{2}\left(\left[\frac{\partial \alpha}{\partial x}\right]\left[\frac{\partial T}{\partial x}\right]_{+\alpha} \frac{\partial^{2} T}{\partial x^{2}}\right)= \\
v_{m-1}\left(\alpha_{m-1}+4 \alpha_{m}-\alpha_{m+1}\right)-8 \alpha_{m} T_{m}+T_{m+1}\left(\alpha_{m+1}+4 \alpha_{m}-\alpha_{m-1}\right)
\end{gathered}
$$

Using an explicit finite difference representation of the time derivative as used in Section $3 \mathrm{~A}$.

$$
\frac{\partial T_{m}}{\partial t}=\frac{1}{\Delta t}\left(T_{m n+1}-T_{m n}\right)
$$

Substituting (f) and (g) into the partial differential equation (a), 


$$
\begin{gathered}
T_{m-1 n}\left(\alpha_{m-1}+4 \alpha_{m}-\alpha_{m+1}\right)-8 \alpha_{m} T_{m n}+T_{m+1 n}\left(\alpha_{m+1}+4 \alpha_{m}-\alpha_{m-1}\right)= \\
\frac{1}{N}\left(T_{m n+1}-T_{m n}\right)
\end{gathered}
$$

where

$$
N=\frac{\Delta t}{4 \varepsilon^{2}}
$$

is analogous to the modulus for the case of constant diffusion. Solving (h) for $T_{m n+1}$

$$
\begin{gathered}
T_{m n+1}= \\
T_{m-1 n} N\left(\alpha_{m-1}+4 \alpha_{m}-\alpha_{m+1}\right)-(8 N-1) \alpha_{m} T_{m n}+T_{m+1 n} N\left(\alpha_{m+1}+4 \alpha_{m}-\alpha_{m-1}\right)
\end{gathered}
$$

For the case of constant diffusivity,

$$
\alpha_{m-1}=\alpha_{m}=\alpha_{m+1}=\alpha
$$

with

$$
M=\frac{\alpha \Delta t}{\varepsilon^{2}}=4 \alpha N
$$

equation (j) becomes

$$
T_{m n+1}=M\left(T_{m+1 n}+T_{m-1 n}\right)-(2 M-1) T_{m n}
$$

which is the finite difference equation for the case of constant diffusivity (Carslaw and Jaeger, 1959). Thus, equation (j) reduces to the correct equation when the diffusivity is constant and is the finite difference equation for the case of variable diffusivity.

For a numerical stability criteria,

$$
M<0.5
$$

the corresponding relation for the case of variable diffusivity becomes equation (n) for all $\mathrm{m}$. 


$$
\operatorname{MAX}\left(\alpha_{m} N\right)<0.125
$$

The thermal conductivity and thermal diffusivity at each time point are evaluated from the temperature at that time and space as given previously for the temperature variation of the conductivity and diffusivity.

The boundary condition at $\mathrm{x}=0$, is the same as for the case of constant diffusivity,

$$
-k_{n} \frac{\partial T_{n}}{\partial x}=q_{r n}+q_{c n}
$$

where $\mathrm{q}_{\mathrm{m}}$ and $\mathrm{q}_{\mathrm{m}}$ are determined in Section 2. Using the finite difference relationship (Carslaw and Jaeger, 1959),

$$
\frac{\partial T_{n}}{\partial x}=\frac{1}{2 e}\left(-3 T_{0 n}+4 T_{1 n}-T_{2 n}\right)
$$

equation (o) becomes:

$$
\begin{gathered}
-\frac{k_{n}}{2 \varepsilon}\left(-3 T_{0 n}+4 T_{1 n}-T_{2 n}\right)=q_{r n}+q_{c n} \\
3 T_{0 n}-4 T_{1 n}+T_{2 n}=\frac{2 \varepsilon}{k_{n}}\left(q_{r n}+q_{c n}\right)
\end{gathered}
$$

Substituting for $\mathrm{q}_{\mathrm{rn}}$ and $\mathrm{q}_{\mathrm{cn}}$ :

$$
3 T_{0 n}-4 T_{1 n}+T_{2 n}=\eta_{n}\left(T_{g^{n}}-T_{0 n}\right)+\gamma_{n}\left(T_{g^{n}}^{4}-T_{0 n}^{4}\right)
$$

where

$$
\eta_{n}=\frac{2 \varepsilon h_{n}}{-k_{n}}
$$

and

Using the identity

and defining 


$$
\begin{gathered}
\gamma_{n}=\frac{2 \varepsilon \sigma}{k_{n}} \\
\mathrm{~T}_{\mathrm{gn}}^{4}-\mathrm{T}_{0 \mathrm{n}}^{4}=\left(T_{g^{n}}-T_{0 n}\right)\left(T_{g^{n}}+T_{0 n}\right)\left(T_{g^{n}}^{2}+T_{0 n}^{2}\right) \\
f_{n}=\left(T_{g^{n}}+T_{0 n}\right)\left(T_{g n}^{2}+T_{0 n}^{2}\right) \\
3 T_{0 n}-4 T_{1 n}+T_{2 n}=\left(\eta_{n}+\gamma_{n} f_{n}\right)\left(T_{g^{n}}-T_{0 n}\right)
\end{gathered}
$$

For the case of both convection and radiation equation ( $u$ ) is a fourth order equation in $T_{0 \mathrm{n}}$ and has to be solved using a numerical technique such as Newton-Raphson iteration. Since the effect of radiation heating of the walls, floor, roof, and explosion-isolation walls leads to a more rapid cooling of the combustion gas following the explosion, and temperatures effects on the salt or explosion-isolation material is worse for longer durations, it is conservative to neglect radiation heat transfer. In this case, equation (u) becomes linear:

$$
3 T_{0 n}-4 T_{1 n}+T_{2 n}=\eta_{n}\left(T_{g n}-T_{0 n}\right)
$$

which can be solved directly for $\mathrm{T}_{0 \mathrm{n}}$ :

$$
T_{0 n}=\frac{4 T_{1 n}-T_{2 n}+\eta_{n} T_{g^{n}}}{3+\eta_{n}}
$$

At each time the field equations are solved based on the previous time. The boundary condition $(w)$ is then applied.

Equations $(j)$ and (u) are formulated for both the salt comprising the walls, floor, and roof and for the explosion-isolation walls. As noted, the field equations for variable diffusivity reduce appropriately to the special case of a constant diffusivity so the above equations are sufficiently general to handle both the material of the explosion-isolation wall and the salt.

\section{F.4.2.4 Program Section 4}

In Section 4 of the program, the temperature values at time $t+\Delta t(n+1)$ become the new values at time $t(n)$. The time counter, $n$, is incremented by 1 and the program returns to Section 1 to compute the solution at the subsequent time step. 


\section{F.4.3 Initial Volume, Surface Area and Number of Moles}

The volume of gas to be cooled via heat transfer to the walls, roof, floor, and explosionisolation walls following an explosion is taken to correspond to the effective panel volume at the time when the air-methane mixture in the panel enters the explosive range. The effective volume is defined as:

$$
V_{\text {eff }}=\phi V
$$

where $\mathrm{V}$ is the panel volume considering closure of the panel and $\Phi$ is the porosity which accounts for the waste emplaced in the panel. Figure F-7 shows a plot of the effective volume as a function of time.

Based on Figure 4.2 of the Conceptual Design Report (DOE, 1995), the methane-air mixture in the panel volume enters the explosive range at 25 years. From Figure F-7 this corresponds to a panel volume of $1.6 \times 10^{10} \mathrm{~cm}^{3}$ at the time the postulated explosion occurs.

The surface area at the time of the postulated explosion was obtained from the volume at the time the methane air mixture enters the explosive range at 25 years and the initial ratio of surface area to volume.

$$
A_{s}=\left(\frac{A_{\text {sinit }}}{V_{\text {init }}}\right) V
$$

Figure F-8 shows a plot of panel surface area as a function of time.

Based on the air-methane mixture entering the explosive range at 25 years, the surface area at the time of the explosion is $1.6 \times 10^{8} \mathrm{~cm}^{2}$. The area of two 14 foot $\times 14$ foot explosionisolation walls is $1.82 \times 10^{5} \mathrm{~cm}^{2}$. Thus the area of the explosion-isolation walls is

$$
\frac{1.82 \times 10^{5}}{1.6 \times 10^{8}}=0.0014=0.14 \%
$$

of the total surface area. 


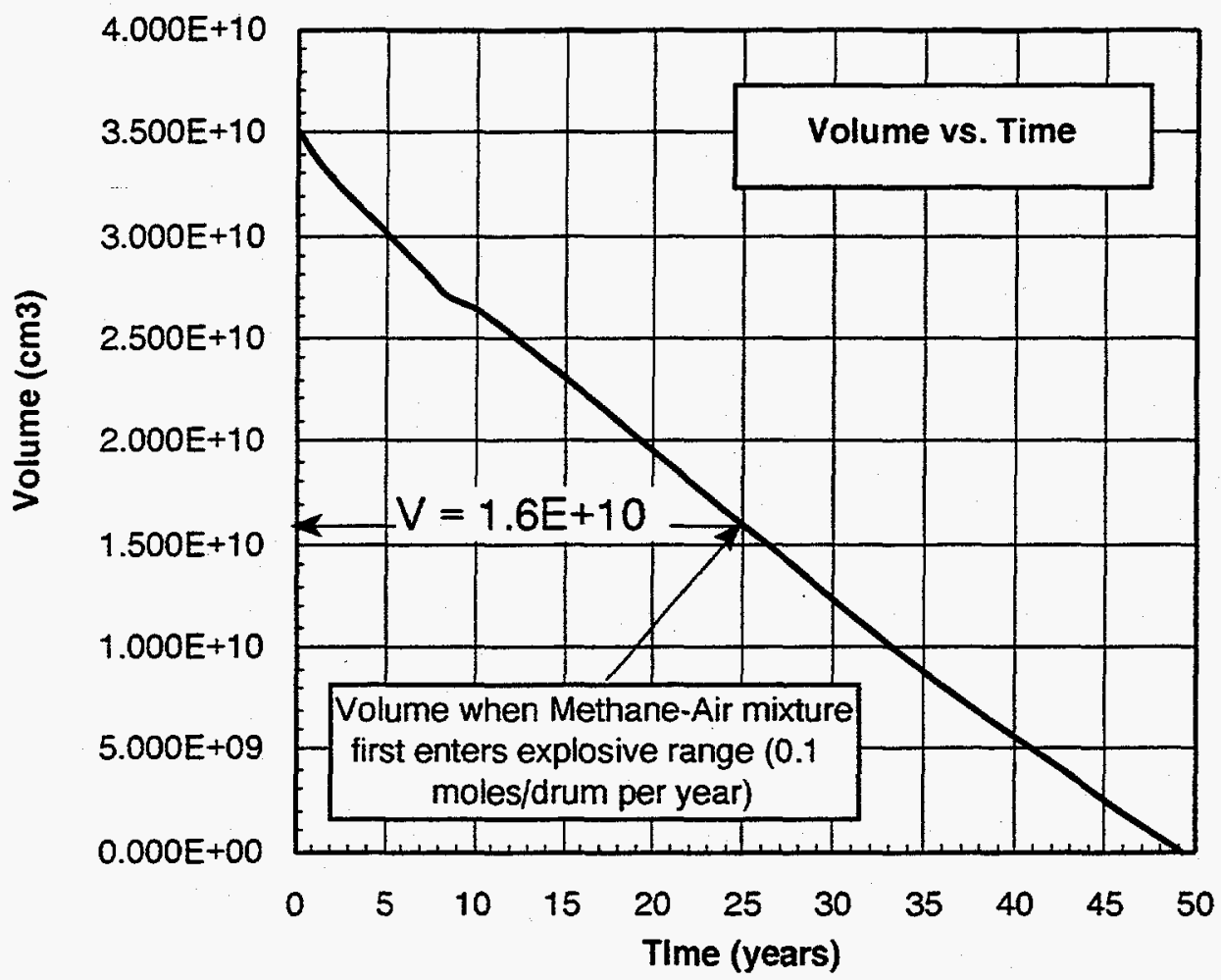

Figure F-7

Effective Panel Volume vs Time 


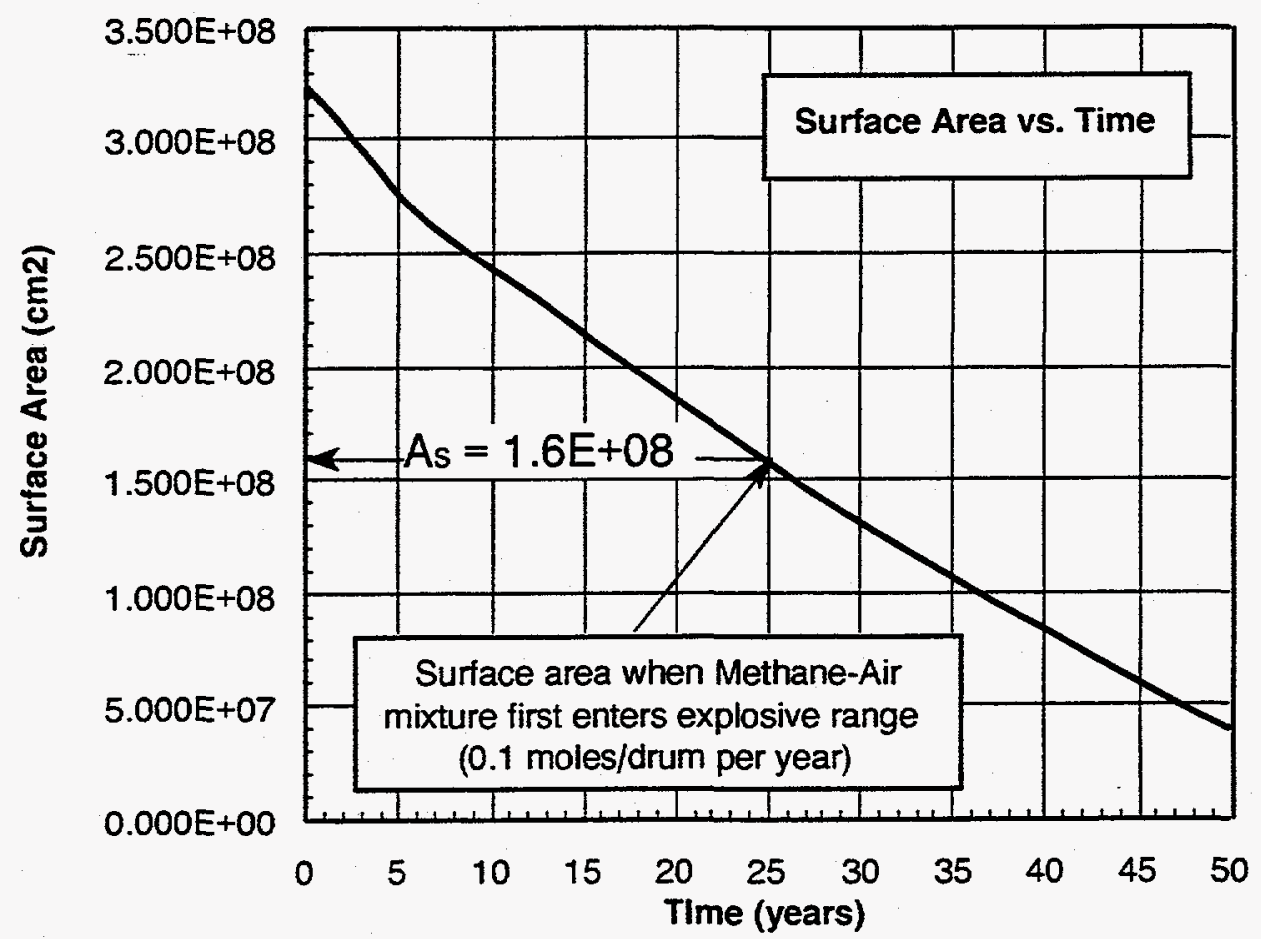

Figure F-8

Surface Area Rooms, Floor and Roof vs Time 
The number of moles of combustion gas is found using the ideal gas law based on an initial pressure of 16 atmospheres (atm) and an initial temperature of $2,400{ }^{\circ} \mathrm{K}$.

$$
n=\frac{p V}{R T}
$$

with

$$
\begin{aligned}
& \mathrm{R}=82.06 \mathrm{~cm}^{3} \text {-atm/mol- }{ }^{\circ} \mathrm{K} \text { (ideal gas law constant) } \\
& \mathrm{P}=16 \mathrm{~atm} \\
& \mathrm{~V}=1.6 \times 10^{10} \\
& \mathrm{~T}=2400^{\circ} \mathrm{K} \\
& n=\frac{16 \times\left(1.6 \times 10^{10}\right)}{82.06 \times 2400} \\
& n=1.3 \times 10^{6} \text { moles }
\end{aligned}
$$

The program uses the number of moles of methane and air independently to calculate the density. Thus,

$$
\begin{gathered}
10.54 n_{C H 4}=1.3 \times 10^{6} \\
n_{C H 4}=1.233 \times 10^{5} \\
n_{\text {air }}=9.54 \times n_{C H 4}=1.176 \times 10^{6}
\end{gathered}
$$

The density is given by

$$
\frac{\left(1.233 \times 10^{5}\right)(16)+\left(1.176 \times 10^{6}\right)(29)}{1.6 \times 10^{10}}=0.002255
$$

\section{F.5.0 Results}

The numerical formulation discussed in Section 4.0 was executed using a spatial grid size, $\varepsilon-1 \mathrm{~cm}$ and a time increment, $\tau=10$ seconds. No problems with numerical stability were encountered using these values. 
At time $t=0$, the initial heat transfer from the combustion gas to the salt and explosionisolation walls results is a large temperature gradient at the surface. To represent this gradient accurately using a finite difference formulation would require an extremely small grid spacing as the initial temperature gradient extends only an infinitesimal distance into the surface. Using a grid spacing sufficiently small to accurately characterize the initial gradient would be prohibitive, relative to the number of mesh points and time steps required.

The initial conditions for the finite difference calculations were determined by using an exact solution for the case of constant convective heat transfer coefficient and constant gas temperature. The use of the closed form solution to determine the initial conditions assumes that the change in gas temperature over small initial times is small and that the heat transfer coefficient is weakly dependent on the temperature difference between the gas and the surfaces of the salt and explosion-isolation walls. Based on the closed form solution, the initial conditions for the finite difference model were taken at a time of 12.7 seconds following the explosion. For shorter initial times, the gradient had not propagated sufficiently far into the surfaces to be represented with a $1 \mathrm{~cm}$. grid spacing. Thus, the initial time for the finite difference calculations was 12.7 seconds with initial temperatures based on the closed form solution.

Figure F-9 shows the gas temperature, salt temperature (walls, floor, and roof) and explosionisolation wall temperature as a function of time following the explosion. Figure F-10 shows the temperature distribution into the explosion-isolation walls at various times following the explosion. Figure F-11 shows the temperature distribution into the salt at various times following the explosion.

Figure F-9 shows that the temperature of the gas has nearly reached the initial ambient conditions after about 2 hours. Over that span of time, elevated temperature in the explosionisolation wall has a maximum extent of $15 \mathrm{~cm}$ (about 6 inches) into the explosion-isolation wall. Since the explosion-isolation wall is at least 36 inches $(91.4 \mathrm{~cm}$ ) thick, the elevated temperature will not reach the opposite side of the wall. Thus, the assumption of a semi-infinite body in the numerical model is not violated.

A comparison of the results shown on Figure F-9 with the results given in D'Appolonia (1978) is favorable. The ratios of surface area and volume used in D'Appolonia (1978) as well as the initial pressures are not the same as used for this analysis. The temperatures shown on Figure F-9 are slightly higher than those predicted for a pressure of $9 \mathrm{~atm}$ as shown 


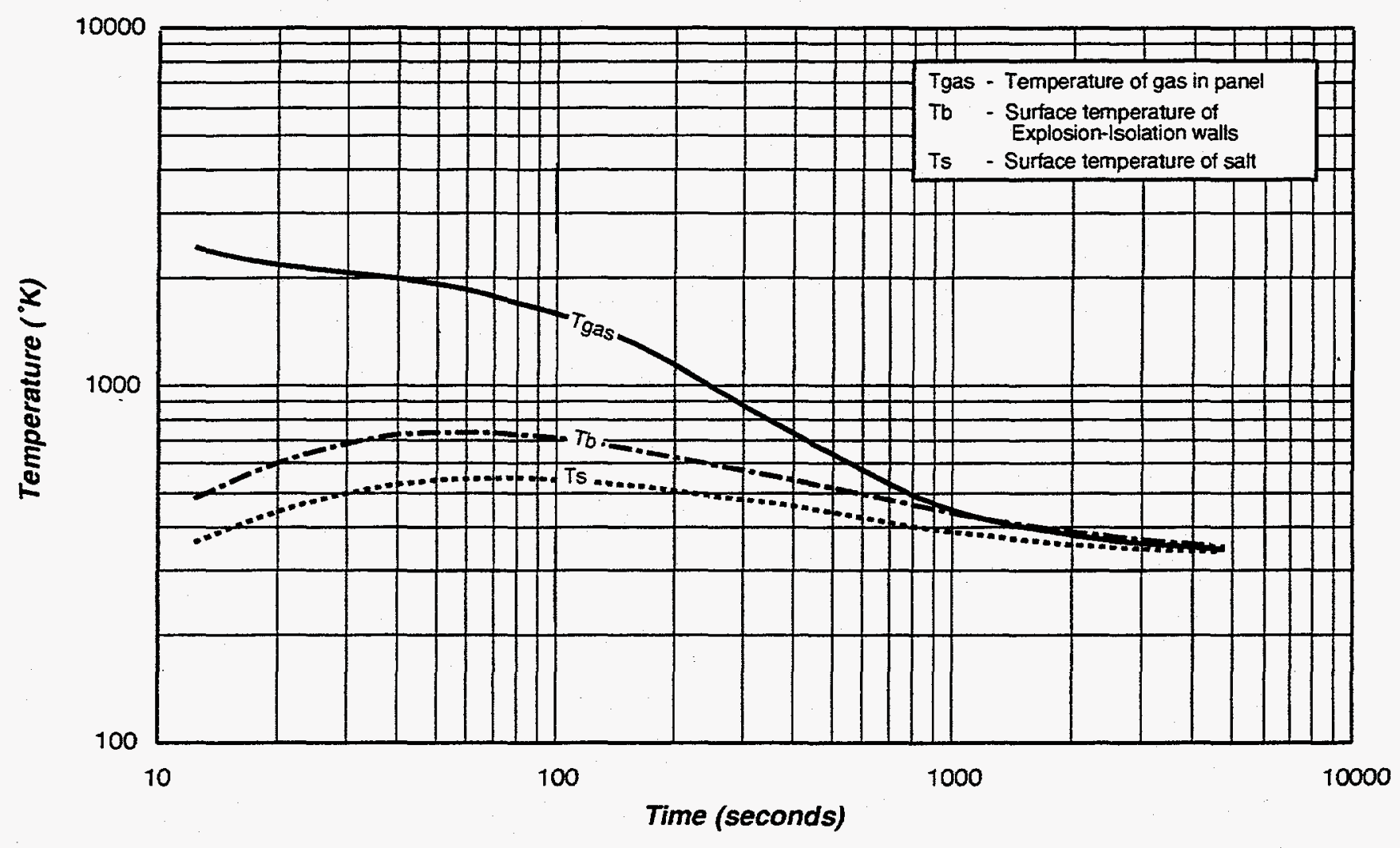

Figure F-9

Temperature Variation with Time for Gas, Salt, and Explosion-Isolation Walls 


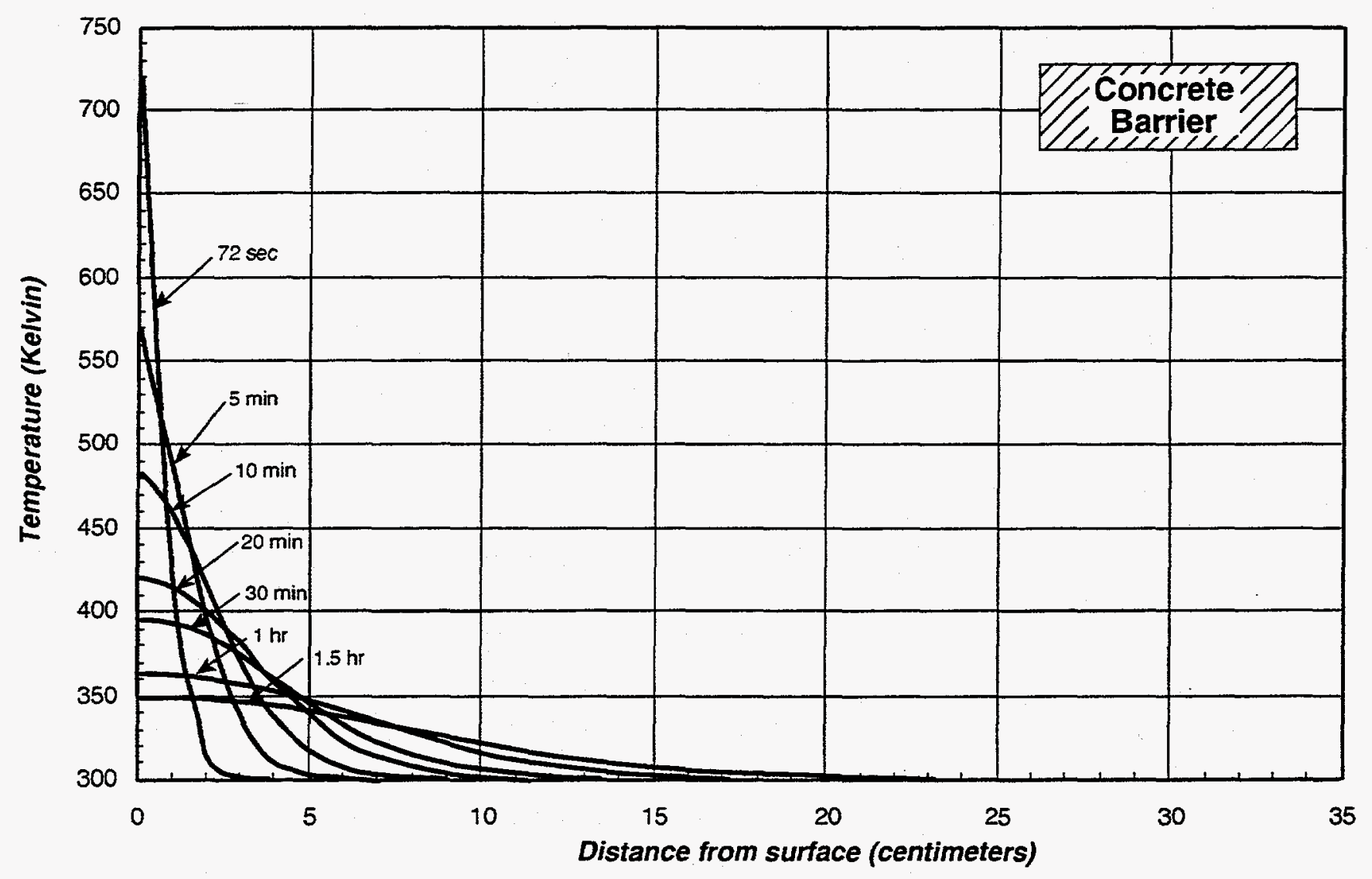

Figure F-10

Temperature Distribution with Time for Concrete Barrier 


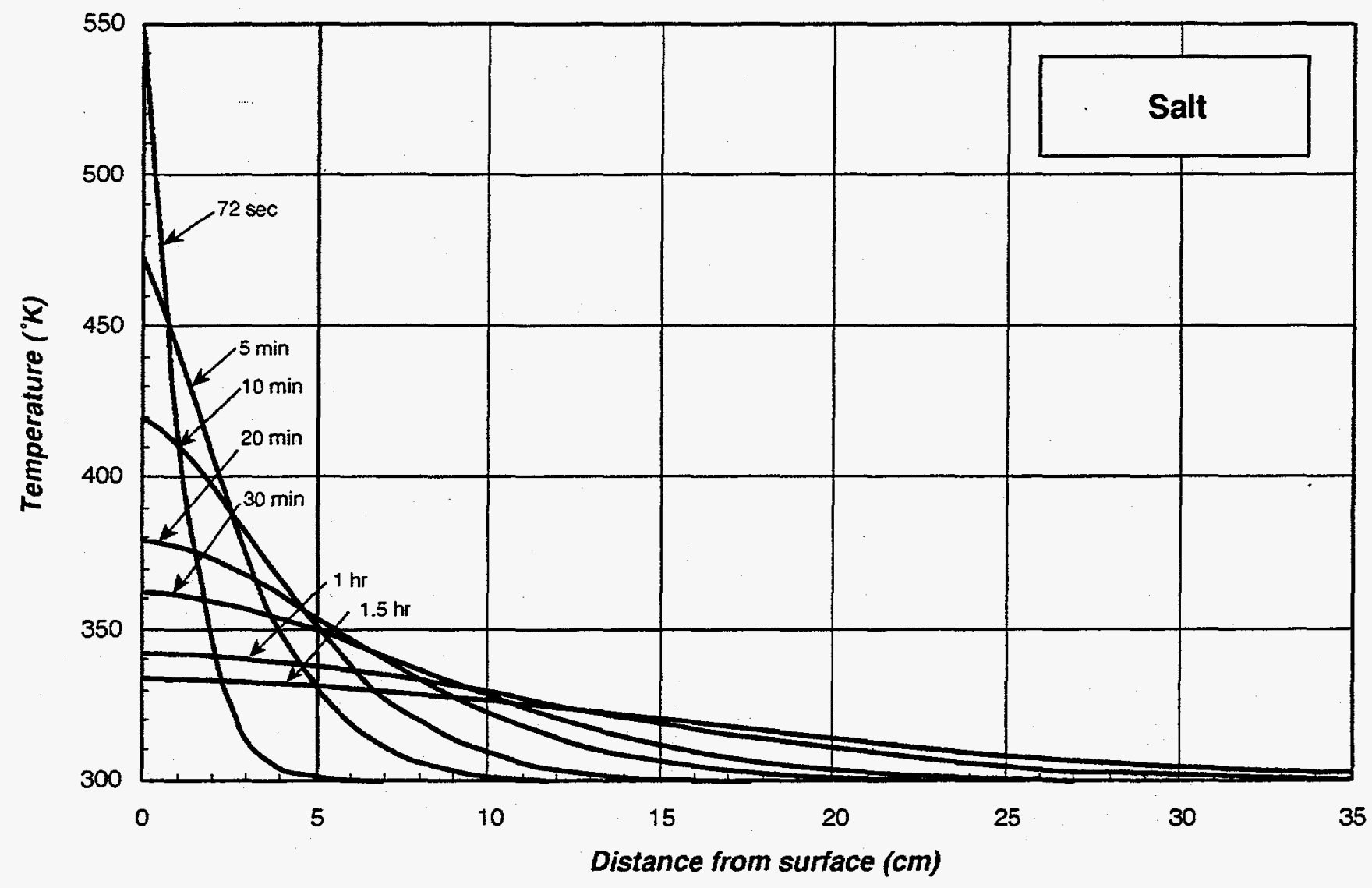

Figure F-11

Temperature Distribution with Time for Salt 
in D'Appolonia [1978]. This is as expected since the initial pressure affects the number of moles which determines the rate of temperature decay in the gas. This is illustrated by comparison of the results for $9 \mathrm{~atm}$ with those for $27 \mathrm{~atm}$ shown in D'Appolonia (1978). The favorable comparison of the results shown on Figure F-9 with those of D'Appolonia (1978) provides verification of the numerical model used in these analyses.

\section{F.6.0 References}

Bodurtha, F. T., 1980, Industrial Explosion Prevention and Control, McGraw-Hill Book Company, New York, New York.

Carslaw, H. S., and J. C. Jaeger, 1959, Conduction of Heat in Solids, 2nd ed., Oxford at the Clarendon Press, Oxford, England.

D'Appolonia Consulting Engineers, 1978, "Potential for Hydrocarbon Explosions and Probable Related Impacts in Mechanically Mined Underground Crude Oil Storage Facilities," D’Appolonia Consulting Engineers, Pittsburg, Pennsylvania.

Krieg, R. D., 1983, "Reference Stratigraphy and Rock Properties for the Waste Isolation Pilot Plant (WIPP) Project," SAND83-1908, Sandia National Laboratories, Albuquerque, New Mexico.

Reid, R. C., J. M. Prausnitz, and T. K. Sherwood, 1977, The Properties of Gases and Liquids, 3rd ed., McGraw-Hill Book Company, New York, New York.

U.S. Department of Energy (DOE), 1995, "Conceptual Design for Operational Phase Panel Closure Systems," DOE-WIPP-95-2957, U.S. Department of Energy, WIPP Project Office, Carlsbad, New Mexico. 
APPENDIX G

TECHNICAL SPECIFICATIONS 


\title{
SECTION 01010
}

\section{SUMMARY OF WORK}

\author{
PART 1 - GENERAL
}

\subsection{Scope}

This section includes:

- Scope of Work

- Definitions and Abbreviations

- Drawings

- Work by Others

- Contractors Use of Site

- Contractors Use of Facilities

- Work Sequence

- Work Plan

- Submittals

\subsection{Scope of Work}

The Contractor shall furnish all labor, materials, equipment and tools to perform operations in connection with the construction of two (2) panel closure systems for each panel, one of each to be installed in the air intake drift and the air exhaust drift of a waste-emplacement panel, as shown on the drawings and called for in these specifications.

Four (4) possible arrangements of the concrete barrier and isolation walls are shown on the attached Figure 1 "Plan Variations." The specific requirements for the panel closure system will be determined by the Westinghouse WID prior to the time of installation and will be defined in the contract documents.

- Concrete barrier with disturbed rock zone (DRZ) removal up through clay seam $\mathrm{G}$ and down through marker bed 139 (MB 139) in combination with a construction isolation wall (Sketch A).

- Concrete barrier with DRZ removal in combination with an explosion isolation wall (Sketch B.)

- Concrete barrier without DRZ removal in combination with construction isolation wall (Sketch C).

- Concrete barrier without DRZ removal in combination with an explosion isolation wall (Sketch D). 


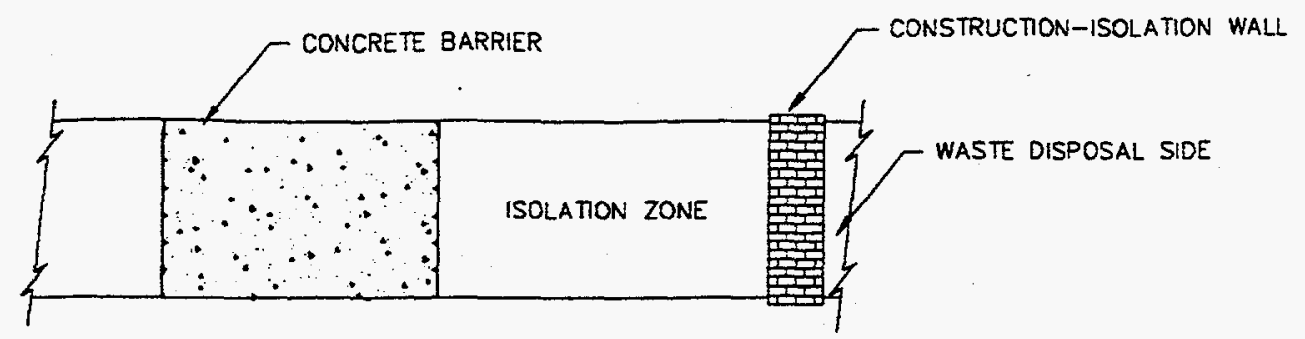

\section{A. CONCRETE BARRIER WITHOUT DRZ REMOVED AND CONSTRUCTION ISOLATION WALL}

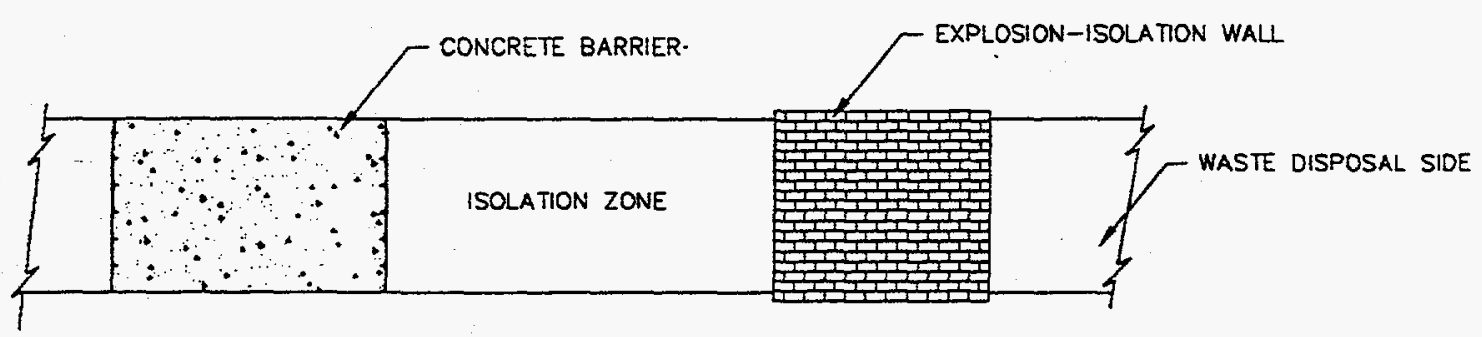

B. CONCRETE BARRIER WITHOUT DRZ REMOVED AND EXPLOSION ISOLATION WALL

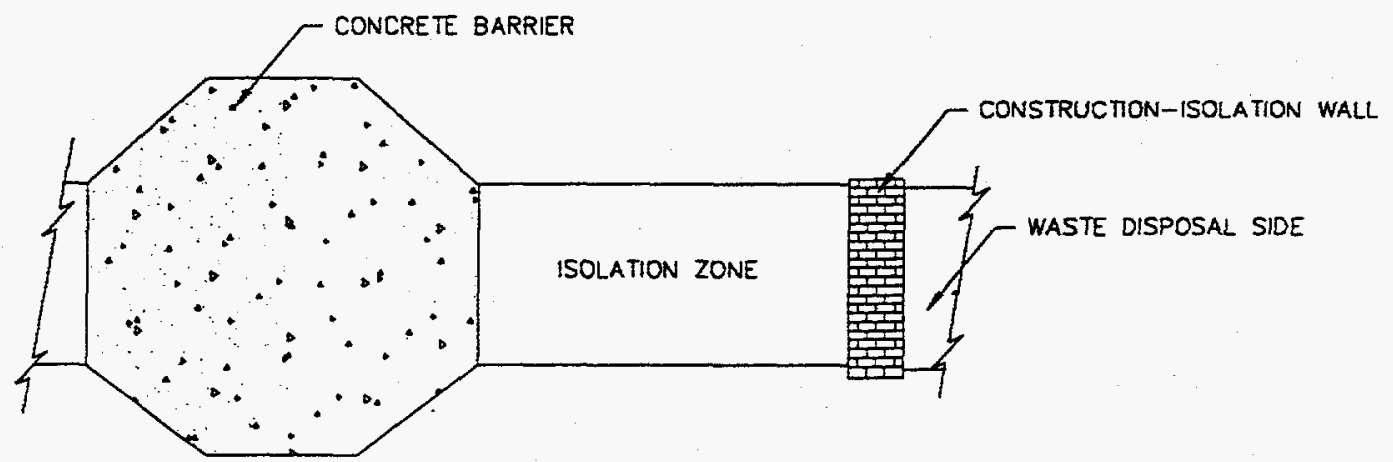

\section{CONCRETE BARRIER WITH DRZ REMOVED AND CONSTRUCTION ISOLATION WALL}

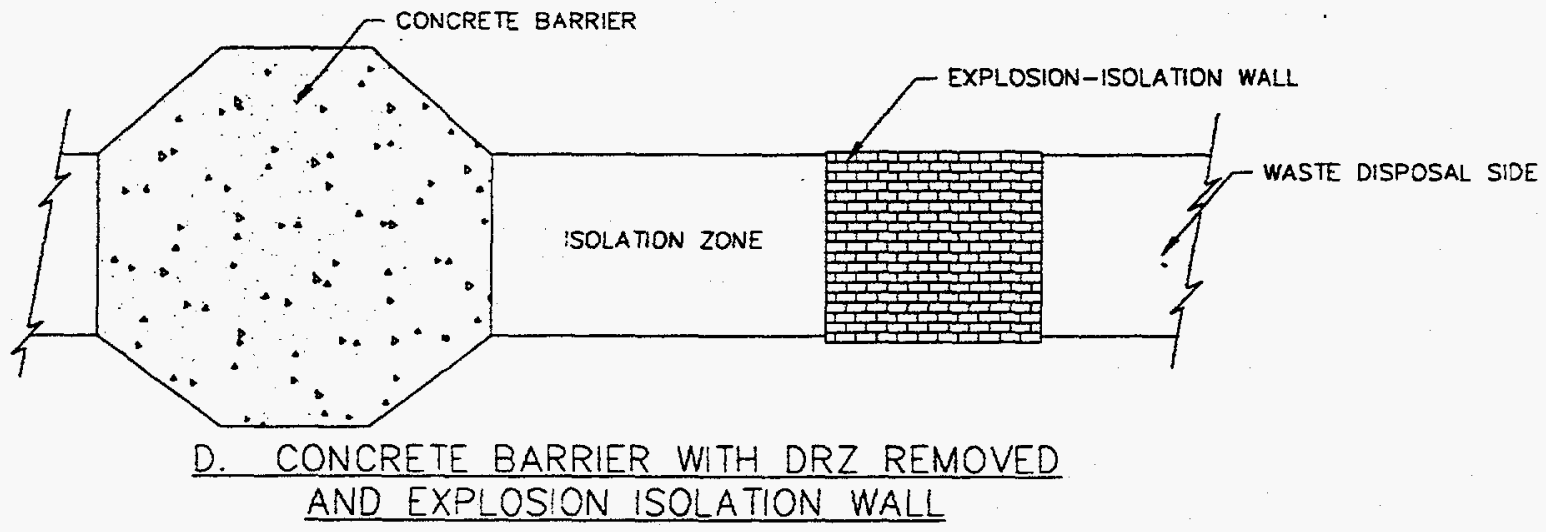

Figure 1

Plan Variations 
The scope of work shall include but not be limited to the following units of work:

- Develop work plan, health and safety plan (HASP) and contractors quality control plan (CQCP)

- Prepare and submit all plans requiring approval

- Mobilize to site

- Coordinate construction with operations

- Perform the following for the air intake entry and the air exhaust entry.

- Excavate the surface preparation for the explosion (or construction) isolation wall

- Construct the explosion (or construction) isolation wall

- Excavate the DRZ if required by contract

- Install the form work for the concrete barrier

- Place concrete for the concrete barrier

- Grout the interface of concrete barrier/back wall

- Provide contact grouting along the contact surface (if required by the engineer)

- Clean up construction areas in underground and above ground

- Submit all required record documents

- Demobilize from site

\subsection{Definitions and Abbreviations}

\section{Definitions}

Contact-handled waste-Contact-handled defense transuranic (TRU) waste with a surface dose rate not to exceed 200 millirem per hour.

Concrete barrier-A barrier placed in the access drifts of a panel to restrict the mass flow rate of volatile organic compounds (VOC).

Concrete block-Concrete used for construction of either an explosion-isolation wall or a construction-isolation wall.

Construction-isolation wall-A wall immediately adjacent to the panel waste-emplacement area that is made of concrete block, with mortar or of steel to isolate construction personnel from coming into contact with the waste. 
Creep-Plastic deformation of salt under deviatoric stress.

Design migration limit-A mass flow rate that results in an exposure of the affected individual that is at least 1 order of magnitude below the health-based exposure levels for VOCs during the Waste Isolation Pilot Plant (WIPP) operational period.

Disturbed rock zone (DRZ)-A zone surrounding underground excavations where stress redistribution occurs with attendant dilation and fracturing.

Explosion-isolation wall-A concrete-block wall adjacent to the panel waste-emplacement area with mortar that can sustain the pressure and temperature transients of a methane explosion.

Health-based concentration level-The annual average concentration level for a VOC in air that must not be exceeded at the point of compliance.

Health-based migration limit-The mass flow rate of a VOC from all closed panels that results in the health-based concentration level at the point of compliance.

Hydration temperature-The transient temperature developed by a cementitious material due to the hydration of the cement.

Interface grouting - Grouting performed through grout boxes and pipe lines to fill the void at the concrete barrier/back-wall interface.

Methane explosion-A postulated deflagration caused by the buildup of methane gas to explosive levels.

Partial closure-The process of rendering a part of the hazardous waste management unit in the underground repository inactive and closed according to approved facility closure plans. The partial-closure process is considered complete after partial-closure activities are performed in accordance with approved Resource Conservation and Recovery Act (RCRA) partial closure plans.

Point of compliance-The operating point of compliance for VOC health-based exposure levels at the WIPP, which is the WIPP site boundary.

Remote-handled waste-Any of the various forms of high beta-gamma defense TRU waste requiring remote-handling due to a surface dose rate exceeding 200 millirem per hour.

Standard barrier-A concrete barrier emplaced into the panel-access drifts without major excavation of the surrounding rock. 
Volatile Organic Compound (VOC)-Any VOC comprising the land-disposal-restricted indicator VOC constituents in the WIPP waste inventory.

Westinghouse-Westinghouse Electric Corporation, Waste Isolation Division (WID) as the construction management authority.

\section{Abbreviations/Acronyms}

ACI American Concrete Institute

AISC $\quad$ American Institute for Steel Construction

ANSI American National Standards Institute

ASTM American Society for Testing and Materials

AWS American Welding Society

CFR Code of Federal Regulations

DOE U.S. Department of Energy

DRZ disturbed rock zone

EPA U.S. Environmental Protection Agency

MB $139 \quad$ Marker Bed 139

MSHA U.S. Mining Safety and Health Administration

NMAC New Mexico Administrative Code

NMED New Mexico Environment Department

RCRA Resource Conservation and Recovery Act

SMC Salado Mass Concrete

USACE U.S. Army Corps of Engineers

WID Waste Isolation Division

WIPP Waste Isolation Pilot Plant

\subsection{List of Drawings}

The following drawings are made apart of this specification:

762447-E1 Panel closure system, air intake and exhaust drifts, title sheet

762447-E2 Panel closure system, underground waste-emplacement panel plan

762447-E3 Panel closure system, air intake drift, construction details

762447-E4 Panel closure system, air exhaust drift, construction details

762447-E5 Panel closure system, construction and explosion walls, construction details

762447-E6 Panel closure system, air intake and exhaust drifts, grouting and miscellaneous details

\subsection{Work by Others}

Survey 
All survey work to locate the barriers and walls, control and confirm excavation, and complete the work will be supplied by Westinghouse. All survey measurements for record purposes will also be performed by Westinghouse. The Contractor shall be responsible for verifying the excavation dimensions to develop the form work to fit the excavation.

\section{Excavation}

The Westinghouse WID may elect to perform certain portions of the work, notably the excavation. The work performed by the Westinghouse will be defined prior to the contract.

\subsection{Contractor's Use of Site}

\section{Site Conditions}

The site is located near Carlsbad, New Mexico, as shown on the site location maps and the title sheet drawing. The underground arrangements and location of the WIPP wasteemplacement panels are shown on the plan view drawing. The work described above is to construct the concrete barriers in the air intake and exhaust drifts of one of the panels upon completion of the disposal phase of that panel. The waste-emplacement panels are located approximately 2,150 feet below the ground surface. The Contractor shall visit the site and become familiar with the site and site conditions prior to preparing his bid proposal.

\section{Contractor's Use of Site}

Areas at the ground surface will be designated for the Contractor's use in assembling and storing his equipment and materials. The Contractor shall utilize only those areas designated.

Limited space within the underground area will be designated for the Contractor's use for storage of material and setup of equipment.

\section{Coordination of Contractor's Work}

The Contractor is advised that on-going waste emplacement and excavation operations are being conducted throughout the period of construction of the panel barrier system. The Contractor shall coordinate his construction operations with that of the waste emplacement and mining operations. All coordination shall be through Westinghouse WID.

\subsection{Contractor's Use of Facilities}

Existing facilities at the site which are available for use by the Contractor are:

- WIPP roadheader

- Waste shaft conveyance

- Salt skip hoist

- (1) 20 ton forklift 
- (1) 40 ton forklift

- 460 volt AC, 3 phase power

- Water (underground, at waste shaft only) (above ground, at location designated by Engineer)

Additional information on these facilities is presented in Section 02010.

\subsection{Work Sequence}

Work Sequence shall be as shown on the drawings and directed by Westinghouse WID .

\subsection{Work Plan}

The Contractor shall prepare and submit for approval by Westinghouse WID a Work Plan fully describing his proposed construction operation. The work plan shall define all proposed equipment. The work plan shall also include the method of excavation, grouting, and pumping concrete. The work plan shall also contain such items as control of surface dust emissions. No work shall be performed prior to approval of the Work Plan.

\subsection{Health and Safety Plan (HASP)}

The Contractor shall obtain, review, and agree to applicable portions of the existing WIPP Safety Manual, WP 12-1. The Contractor shall prepare and submit for approval to Westinghouse, a project-specific HASP taking into account all applicable sections of the WIPP Safety Manual. The Contractor shall also perform a Job Hazard Analysis in accordance with WP 12-111.

\subsection{Contractor Quality Control Plan (CQCP)}

The Contractor shall prepare and submit for approval to Westinghouse a CQCP identifying all personnel and procedures to produce an end product which complies with the contract requirements. The CQCP shall comply with all Westinghouse WID requirements and Section 01400, Contractor Quality Control, of this specification.

\subsection{Submittals}

Submittals shall be in accordance with Westinghouse WID Submittal Procedures and as required by the individual specifications.

\section{PART 2 - PRODUCTS}

(Not used)

\section{PART 3 - EXECUTION}

(Not Used) 
SECTION 01010

SUMMARY OF WORK 


\section{SECTION 01090}

\section{REFERENCE STANDARDS}

\section{PART 1 - GENERAL}

\subsection{Scope}

This section includes:

- Provision of Reference Standards at Site.

- Acronyms used in Contract Documents for Reference Standards. Source of Reference Standards.

\subsection{Quality Assurance}

For products or workmanship specified by association, trade, or Federal Standards, comply with requirements of the standard, except when more rigid requirements are specified or are required by applicable codes.

Conform to reference by date of issue current on the date of the owner-contractor agreement.

The Contractor shall obtain copy of the standards referenced in the individual specification sections. Maintain a copy at jobsite during submittals, planning, and progress of the specific work, until completion of work.

Should specified reference standards conflict with the contract documents, request clarification from the Engineer before proceeding.

\subsection{Schedule of References}

Various publications are referenced in other sections of the specifications to establish requirements for the work. These referenced are identified by documents number and title. The addresses of the organizations whose publications are referenced are listed below.

$\mathrm{ACI}$ ACI International

P.O. Box 19150

Detroit,MI 48219-0150

$\mathrm{Ph}: 313-532-2600$

Fax: $313-533-4747$ 
AITC

American Institute of Timber Construction

7012 So. Revere Parkway, Suite 140

Englewood, CO 80112

$\mathrm{Ph}:$ 303-792-9559

Fax: 303-792-0669

AISC

American Institute of Steel Construction

One E. Wacker Dr., Suite 3100

Chicago, IL 60601-2001

$\mathrm{Ph}: 312-670-2400$

Fax: 312-670-5403

ANSI

American National Standards Institute

11 West 42nd St.

New York NY 10036

pH: $212-642-4900$

Fax: 212-302-1286

API

American Petroleum Institute

1220 L. St., NW

Washington, DC 20005

$\mathrm{Ph}:$ 202-682-8375

Fax: 202-962-4776

ASTM American Society for Testing and Materials 1916 Race St.

Philadelphia, PA 19103

Ph: 610-832-9585

Fax: 215-977-9679

AWS

American Welding Society

550 LeJeune Road

Miami, FL 33135

Ph: 800-443-9353

Fax: 305-443-7559

CFR

Code of Federal Regulations

Government Printing Office

Washington, DC 20402

$\mathrm{Ph}: 202-783-3238$

Fax: 202-223-7703 


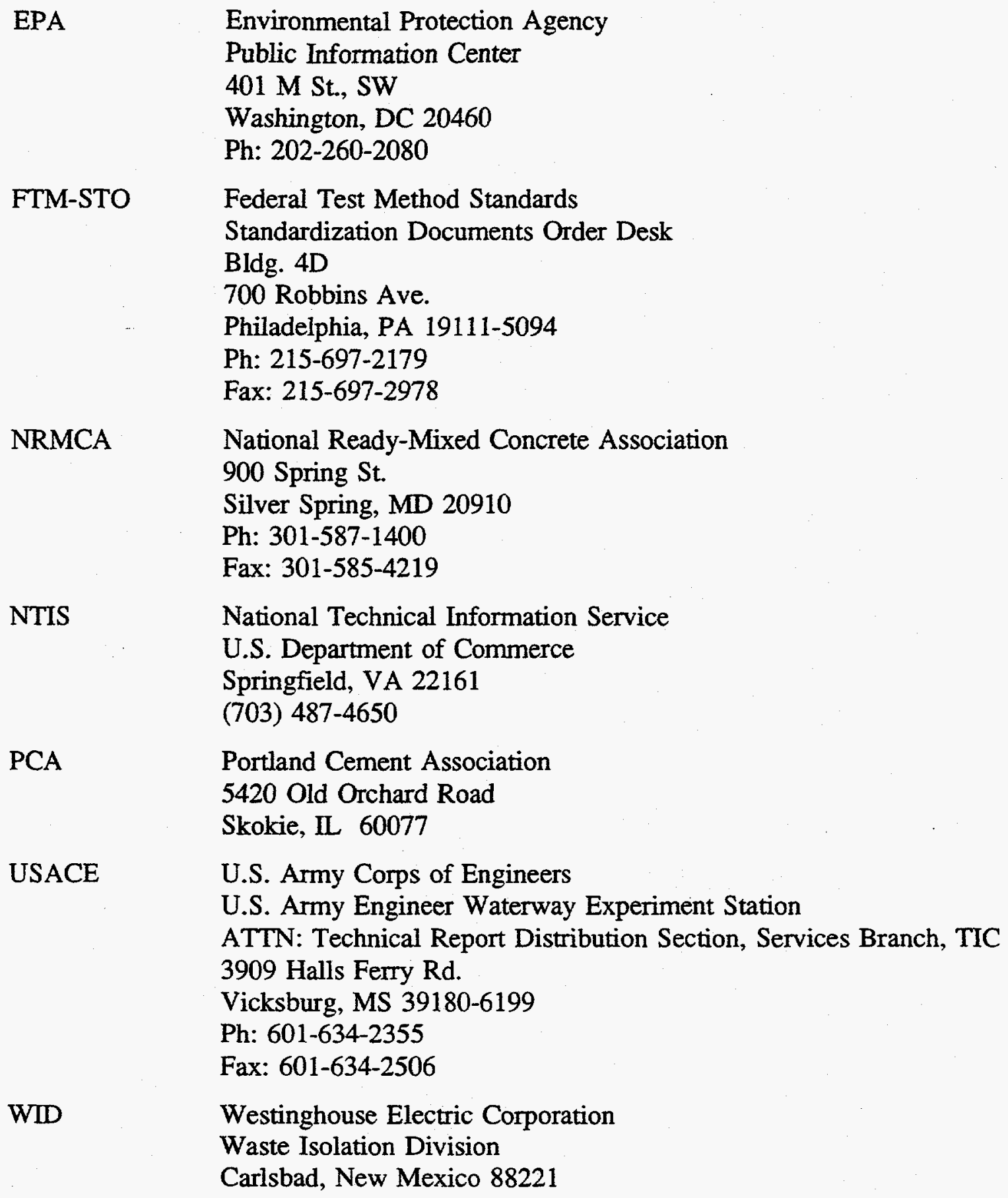

PCA Portland Cement Association 5420 Old Orchard Road Skokie, IL 60077

USACE U.S. Army Corps of Engineers

U.S. Army Engineer Waterway Experiment Station

ATTN: Technical Report Distribution Section, Services Branch, TIC 3909 Halls Ferry Rd.

Vicksburg, MS 39180-6199

$\mathrm{Ph}:$ 601-634-2355

Fax: 601-634-2506

WID Westinghouse Electric Corporation

Waste Isolation Division

Carlsbad, New Mexico 88221

End of Section 
SECTION 01090

REFERENCE STANDARDS 


\section{SECTION 01400 \\ CONTRACTOR QUALITY CONTROL}

PART 1 - GENERAL

\subsection{Scope}

This section includes:

- Contractor Quality Control Plan (CQCP)

- Reference Standards

- Quality Assurance

- Tolerances

- Testing Services

- Inspection Services

- Submittals

\subsection{Related Sections}

- 01090 - Reference Standards

- 01600 - Material and Equipment

- 02222 - Excavation

- 02722 - Grouting

- 03100 - Concrete Formwork

- 03300 - Cast-in-Place Concrete

- 04100 - Mortar

- 04300 - Unit Masonry System

\subsection{Contractor Quality Control Plan}

The Contractor shall prepare and submit for approval by Westinghouse WID, a Quality Control Plan, as described in Section 3.2. No work shall be performed prior to approval of the Contractor's Quality Control Plan.

\subsection{References and Standards}

Refer to individual specification sections for standards referenced therein, and to Section 01090 - Reference Standards for general listing.

Standards referenced in this section are as follows:

ASTM C1077-95a Practice for Laboratories Testing Concrete and Concrete Aggregates for Use in Construction and Criteria for Laboratory Evaluation 
ASTM C1093-88 Practice for Accreditation of Testing Agencies for Unit Masonry

ASTM E329-95 Practice for Use in the Evaluation of Inspection and Testing Agencies as Used in Construction

ASTM E543-95 Practice for Determining the Qualification of Nondestructive Testing Agencies

ASTM E548-94 Practice for Preparation of Criteria for Use in the Evaluation of Testing Laboratories and Inspection Bodies

\subsection{Quality Assurance}

- Monitor quality control over suppliers, manufacturers, products, services, site conditions, and workmanship, to produce work of specified quality

- Comply with specified standards as minimum quality for the work except where more stringent tolerances, codes, or specified requirements indicate higher standards or more precise workmanship

- Perform work by persons qualified to produce required and specified quality

- Verify that field measurements are as indicated on shop drawings

- Secure products in place with positive anchorage devices designed and sized to withstand stresses, vibration, physical distortion, or disfigurement.

\subsection{Tolerances}

Monitor excavation fabrication and installation tolerance control of work and products to produce acceptable work. Do not permit tolerances to accumulate.

Adjust products to appropriate dimensions; position before securing products in place.

\subsection{Testing Services}

Unless otherwise indicated by Westinghouse WID, the Contractor shall employ an independent firm to perform the testing services and other services specified in the individual specification sections, and as required by Westinghouse WID. Testing and source quality control may occur on or off the project site.

The testing laboratory shall comply with applicable sections of the reference standards and shall be authorized to operate in the state in which the project is located.

Testing equipment shall be calibrated at reasonable intervals with devices of an accuracy traceable to either the National Bureau of Standards or accepted values of natural physical constants. 


\subsection{Inspection Services}

The Contractor shall employ an independent firm to perform inspection services as a supplement to the Contractor's quality control as specified in the individual specification sections, and as required by Westinghouse WID. Inspection may occur on or off the project site.

The inspection firm shall comply with applicable sections of the reference standards.

\subsection{Submittals}

The Contractor shall submit a Contractors' Quality Control Plan as described herein.

Prior to start of work, the Contractor shall submit for approval, the testing laboratory name, address, telephone number and name of responsible officer of the firm. He shall also submit a copy of the testing laboratory compliance with the reference ASTM standards, and a copy of report of laboratory facilities inspection made by Materials Reference Laboratory of National Bureau of Standards with memorandum of remedies of any deficiencies reported by the inspection.

Prior to start of work, the Contractor shall submit for approval the inspection firm name, address, telephone number and name of responsible officer of the firm. He shall also submit the personnel proposed to perform the required inspection, along with their individual qualifications and certifications (Example: Certified AWS Welding Inspector.)

\section{PART 2 - PRODUCTS}

Not used.

\section{PART 3 - EXECUTION}

\subsection{General}

The Contractor is responsible for quality control and shall establish and maintain an effective quality control system. The quality control system shall consist of plans, procedures, and organization necessary to produce an end product which complies with the contract requirements. The system shall cover all construction operations, both on site and off site, and shall be keyed to the proposed construction sequence. The project superintendent will be held responsible for the quality of work on the job. The project superintendent in this context shall mean the individual with the responsibility for the overall management of the project including quality and production. 


\subsection{Quality Control Plan}

\subsubsection{General}

The Contractor shall furnish for review and approval by Westinghouse WID, not later than 30 days after receipt of notice to proceed, the Contractor Quality Control (CQC) Plan proposed to implement the requirements of the Contract. The plan shall identify personnel, procedures, control, instructions, test, records, and forms to be used. Construction will be permitted to begin only after acceptance of the CQC Plan.

\subsubsection{Content of the CQC Plan}

The CQC Plan shall include, as a minimum, the following to cover all construction operations, both on site and off site, including work by subcontractors, fabricators, suppliers, and purchasing agents:

- A description of the quality control organization, including a chart showing lines of authority and acknowledgment that the CQC staff shall implement the control system for all aspects of the work specified. The staff shall include a CQC System Manager who shall report to the project superintendent.

- The name, qualifications (in resume format), duties, responsibilities, and authorities of each person assigned a CQC function.

- Description of the CQC System Manager's responsibilities and delegation of authority to adequately perform the functions of the CQC System Manager, including authority to stop work which is not in compliance with the contract. The CQC System Manager shall issue letters of direction to all other various quality control representatives outlining duties, authorities, and responsibilities.

- Procedures for scheduling, reviewing, certifying, and managing submittals, including those of subcontractors, off site fabricators, suppliers, and purchasing agents. These procedures shall be in accordance with Westinghouse WID Submittal Procedures.

- Control, verification, and acceptance testing procedures for each specific test to include the test name, specification paragraph requiring test, feature of work to be tested, test frequency, and person responsible for each test. (Laboratory facilities will be subject to approval by Westinghouse WID.)

- Procedures for tracking construction deficiencies from identification through acceptable corrective action. These procedures will establish verification that identified deficiencies have been corrected.

- Reporting procedures, including proposed reporting formats. 
- A list of the definable features of work. A definable feature of work is a task which is separate and distinct from other tasks and has separate control requirements. It could be identified by different trades or disciplines, or it could be work by the same trade in a different environment. Although each section of the specifications may generally be considered as a definable feature of work, there are frequently more than one definable feature under a particular section. This list will be submitted to Westinghouse WID for approval.

\subsubsection{Acceptance of Plan}

Acceptance of the Contractor's plan is required prior to the start of construction. Acceptance is conditional and will be predicated on satisfactory performance during the construction. The Owner reserves the right to require the Contractor to make changes in his CQC Plan and operations including removal of personnel, as necessary, to obtain the quality specified.

\subsubsection{Notification of Changes}

After acceptance of the CQC Plan, the Contractor shall notify Westinghouse WID in writing of any proposed change. Proposed changes are subject to acceptance by Westinghouse WID.

\subsection{Quality Control Organization}

\subsubsection{General}

The requirements for the CQC organization are a CQC System Manager and sufficient number of additional qualified personnel supplemented by independent testing and inspection furms as required by the specifications, to ensure contract compliance. The Contractor shall provide a CQC organization which shall be at the site at all times during progress of the work and with complete authority to take any action necessary to ensure compliance with the contract. All CQC staff members shall be subject to acceptance by Westinghouse WID.

\subsubsection{CQC System Manager}

The Contractor shall identify as CQC System Manager an individual within his organization at the site of the work who shall be responsible for overall management of CQC and have the authority to act in all CQC matters for the Contractor. The CQC System Manager shall be a graduate engineer, with a minimum of five years construction experience on construction similar to this contract. This CQC System Manager will be employed by the prime Contractor. The CQC System Manager shall be assigned no other duties. An alternate for the CQC System Manager will be identified in the plan to serve in the event of the System Manager's absence. The requirements for the alternate will be the same as for the designated CQC System Manager.

\subsubsection{CQC Personnel}

In addition to CQC personnel specified elsewhere in the contract, the Contractor shall provide as part of the CQC organization specialized personnel or third party inspectors to assist the CQC System Manager. These individuals shall be employed by the prime Contractor; be 
responsible to the CQC System Manager; have the necessary education and/or experience. These individuals shall have no other duties other than quality control.

\subsubsection{Organizational Changes}

The Contractor shall maintain his CQC staff at full strength at all times. When it is necessary to make changes to the CQC staff the Contractor shall revise the CQC Plan to reflect the changes and submit the changes to Westinghouse WID for acceptance at the Contractors' expense.

\subsection{Tests}

\subsubsection{Testing Procedure}

The Contractor shall perform specified or required tests to verify that control measures are adequate to provide a product which conforms to contract requirements. Upon request, the Contractor shall furnish to Westinghouse WID duplicate samples of test specimens for possible testing by Westinghouse WID. Testing includes operation.and/or acceptance tests when specified. The Contractor shall procure the services of an approved testing laboratory. The Contractor shall perform the following activities and record and provide the following data:

- Verify that testing procedures comply with contract requirements.

- Verify that facilities and testing equipment are available and comply with testing standards.

- Check test instrument calibration data against certified standards.

- Verify that recording forms and test identification control number system, including all of the test documentation requirements, have been prepared.

- Results of all tests taken, both passing and failing tests, will be recorded on the CQC report for the date taken. Specification paragraph reference, location where tests were taken, and the sequential control number identifying the test will be given. If approved by Westinghouse WID, actual test reports may be submitted later with a reference to the test number and date taken. An information copy of tests performed by an off site or commercial test facility will be provided directly to Westinghouse WID. Failure to submit timely test reports as stated may result in nonpayment for related work performed and disapproval of the test facility for this contract.

\subsection{Testing Laboratory}

The testing laboratory shall provide qualified personnel to perform specified sampling and testing of products in accordance with specified standards, and ascertain compliance of materials and mixes with requirements of Contract Documents. The testing laboratory shall promptly notify Westinghouse WID and Contractor of any observed irregularities or nonconformance of Work or Products. 
Reports indicating results of tests, and compliance (or noncompliance) with the contract documents will be submitted in accordance with Westinghouse WID submittal procedures.

The Contractor shall cooperate with the independent testing firm, furnish samples, storage, safe access, and assistance by incidental labor as required. Testing by the independent firm does not relieve the contractor of the responsibility to perform the work to the contract requirements.

The laboratory may not:

- Release, revoke, alter, or enlarge on requirements of the contract

- Approve or accept any portion of the work

- Assume any duties of the Contractor.

The laboratory has no authority to stop the work.

\subsection{Inspection Services}

The inspection firm shall provide qualified personnel at site to supplement the Contractor's Quality Control Program to perform specified inspection of Products in accordance with specified standards. He shall ascertain compliance of materials and mixes with requirements of Contract Documents, and promptly notify the CQC System Manager, Westinghouse WID and the Contractor of observed irregularities or non-conformance of Work or Products. The inspector does not have the authority to stop the work. The inspector shall refer such cases to the CQC System Manager who has the authority to stop work (see Section 3.2.2).

Reports indicating results of the inspection and compliance (or noncompliance) with the contract documents will be submitted in accordance with Westinghouse WID submittal procedures.

The Contractor shall cooperate with the independent inspection firm, furnish samples, storage, safe access and assistance by incidental labor, as requested.

Inspection by the independent firm does not relieve the Contractor of the responsibility to perform the work to the contract requirements.

\subsection{Completion Inspection}

\subsubsection{Pre-Final Inspection}

At the completion of all work the CQC System Manager shall conduct an inspection of the work and develop a "punch list" of items which do not conform to the approved drawings and specifications. Once this is accomplished the Contractor shall notify Westinghouse WID that the facility is complete and is ready for the "Prefinal" inspection. Westinghouse WID will perform this inspection to verify that the facility is complete. A "Final Punch List" will be developed as a result of this inspection. The Contractor's CQC System Manager shall ensure 
that all items on this list have been corrected and notify Westinghouse WID so that a "Final" inspection can be scheduled. Any items noted on the "Final" inspection shall be corrected in a timely manner. These inspections and any deficiency corrections required by this paragraph will be accomplished within the time slated for completion of the entire work.

\subsubsection{Final Acceptance Inspection}

The final acceptance inspection will be formally scheduled by Westinghouse WID based upon notice from the Contractor. This notice will be given to Westinghouse WID at least 14 days prior to the final acceptance inspection and must include the Contractor's assurance that all specific items previously identified to the Contractor as being unacceptable, along with all remaining work performed under the contract, will be complete and acceptable by the date scheduled for the final acceptance inspection.

\subsection{Documentation}

The Contractor shall maintain current records providing factual evidence that required quality control activities and/or tests have been performed. These records shall include the work of subcontractors and suppliers and shall be on an acceptable form that includes, as a minimum, the following information:

- Contractor/subcontractor and their area of responsibility.

- Operating plant/equipment with hours worked, idle, or down for repair.

- Work performed each day, giving location, description, and by whom.

- Test and/or quality control activities performed with results and references to specifications/drawings requirements. List deficiencies noted along with corrective action.

- Quantity of materials received at the site with statement as to acceptability, storage, and reference to specifications/drawings requirements.

- Submittals reviewed, with contract reference, by whom, and action taken.

- Off-site surveillance activities, including actions taken.

- Instructions given/received and conflicts in plans and/or specifications.

- Contractor's verification statement.

These records shall indicate a description of trades working on the project; the number of personnel working; weather conditions encountered; and any delays encountered. These records shall cover both conforming and deficient features and shall include a statement that equipment and materials incorporated in the work and workmanship comply with the contract. The original and one copy of these records in report form shall be furnished to Westinghouse 
WID daily. Reports shall be signed and dated by the CQC System Manager. The report from the CQC System Manager shall include copies of test reports and copies of reports prepared by all subordinate quality control personnel.

\subsection{Notification of Noncompliance}

Westinghouse WID will notify the Contractor of any detected noncompliance with the foregoing requirements. The Contractor shall take immediate corrective action after receipt of such notice. Such notice, when delivered to the Contractor at the worksite, shall be deemed sufficient for the purpose of notification. If the Contractor fails or refuses to comply promptly, Westinghouse WID may issue an order stopping all or part of the work until satisfactory corrective action has been taken. No part of the time lost due to such stop orders shall be made the subject of claim for extension of time or for excess costs or damages by the Contractor.

End of section. 


\title{
SECTION 01600
}

\section{MATERIAL AND EQUIPMENT}

\author{
PART 1 - GENERAL
}

\subsection{Scope}

This section includes:

- Equipment

- Products

- Transportation and handling

- Storage and protection

- Substitutions

\subsection{Related Sections}

- 01010 - Summary of Work

- 01400 - Contractor Quality Control

- 02010 - Mobilization and Demobilization

- 02222 - Excavation

- 02722 - Grouting

- 03100 - Concrete Formwork

- 03300 - Cast-in-Place Concrete

- 04100 - Mortar

- 04300 - Unit Masonry System

\subsection{Equipment}

The Contractor shall specify his proposed equipment in the Work Plan. Power equipment for use underground shall be either electrical or diesel engine driven. All diesel engine equipment shall be certified for use underground.

\subsection{Products}

The Contractor shall specify in the Work Plan, or in subsequently required submittals the proposed products including, but not limited to the grout mix and its components, concrete mix and its components, mortar mix and its components, formwork, and masonry. The proposed products shall be supported by laboratory test results as required by the specifications. All products shall be subject to approval by Westinghouse WID. 


\subsection{Transportation and Handling}

- Transport and handle products in accordance with manufacturer's instructions.

- Promptly inspect shipments to ensure that products comply with requirements, quantities are correct, and products are undamaged.

- Provide equipment and personnel to handle products by methods to prevent soiling, disfigurement, or damage.

\subsection{Storage and Protection}

- Store and protect products in accordance with manufacturers' instructions.

- Store with seals and labels intact and legible.

- Store sensitive products in weather tight, climate controlled, enclosures in an environment favorable to product.

- For exterior storage of fabricated products, place on sloped supports above ground.

- Cover products subject to deterioration with impervious sheet covering. Provide ventilation to prevent condensation and degradation of products.

- Store loose granular materials on solid flat surfaces in a well-drained area. Prevent mixing with foreign matter.

- Provide equipment and personnel to store products by methods to prevent soiling, disfigurement, or damage.

- Arrange storage of products to permit access for inspection. Periodically inspect to verify products are undamaged and are maintained in acceptable condition.

\subsection{Substitutions}

\subsubsection{Equipment Substitutions}

The Contractor may substitute equipment for that proposed in the Work Plan subject to Westinghouse WID's approval. The Contractor shall demonstrate the need for the substitution, and the applicability of the proposed substitute equipment.

\subsubsection{Product Substitutions}

The Contractor may not substitute products after the proposed products have been approved by Westinghouse WID unless he can demonstrate that the supplier/source of that product no longer exists in which case he shall submit alternate products with lab test results to 
Westinghouse WID for approval. In the case that product is a component in a mix, the Contractor shall perform mix testing using that component and submit laboratory test results.

\section{PART 2 - PRODUCTS}

Not used.

\section{PART 3 - EXECUTION \\ Not used.}

End of section. 
SECTION 01600

MATERIAL AND EQUIPMENT 


\section{SECTION 02010}

\section{MOBILIZATION AND DEMOBILIZATION}

\section{PART 1 - GENERAL}

\subsection{Scope}

This section includes:

- Mobilization of equipment and facilities to site

- Contractor use of site

- Use of existing facilities

- Demobilization of equipment and facilities

- Site cleanup

\subsection{Related Sections}

- 01010 - Summary of Work

- 01600 - Material and Equipment

\section{PART 2 - PRODUCTS}

Not used.

\section{PART 3 - EXECUTION}

\subsection{Mobilization of Equipment and Facilities to Site}

Upon authorization to proceed, the Contractor shall mobilize his equipment and facilities to the jobsite. Equipment and facilities shall be as specified, and as defined in the Contractor's Work Plan. The Contractor shall erect the batch plant and assemble his equipment and materials in the areas designated by Westinghouse WID. Facilities shall be located as near as practical to the existing utilities.

Westinghouse WID will provide utilities ( 460 volt $\mathrm{AC}, 3$ phase, and water) at designated locations. The Contractor shall be responsible for all hookups and tie-ins required for his operations.

The Contractor shall be responsible for providing his own office, storage, and sanitary facilities. 
Areas will be designated for the Contractor's use in the underground area in the vicinity of the panel closure system installation. These areas are limited.

\subsection{Use of Site}

The Contractor shall use only those areas specifically designated for his use by Westinghouse WID. The Contractor shall limit his on-site travel to the specific routes required for performance of his work, and designated by Westinghouse WID.

\subsection{Use of Existing Facilities}

Existing facilities at the site which are available for use by the Contractor are:

- WIPP roadheader

- Waste shaft conveyance

- Salt skip hoist

- (1) 20 ton forklift

- (1) 40-ton forklift

- 460 Volt AC, 3 phase power

- Water (in mine, at waste shaft only-above ground at location designated by Westinghouse WID).

The Contractor shall arrange for use of the facilities with Westinghouse WID and coordinate his actions/requirements with that of the ongoing operations.

Use of water in the underground will be restricted. No washout or cleanup will be permitted in the underground. Above ground washout/cleanup or equipment will be allowed in the areas designated by Westinghouse WID.

The Contractor is cautioned to be aware of the physical dimensions of the waste conveyance and the air lock (see Figures 2 and 3, attached).

The Contractor shall be responsible for any damage incurred by the existing site facilities as a result of his operations. Any damage shall be reported immediately to Westinghouse WID and repaired at the Contractor's cost.

\subsection{Demobilization of Equipment and Facilities}

At completion of this work, the Contractor shall demobilize his equipment and facilities from the job site. The batch plant shall be disassembled and removed along with any unused material. All Contractor's equipment and materials shall be removed from the mine and all disturbed areas restored. Utilities shall be removed to their connection points unless otherwise directed by Westinghouse WID. 


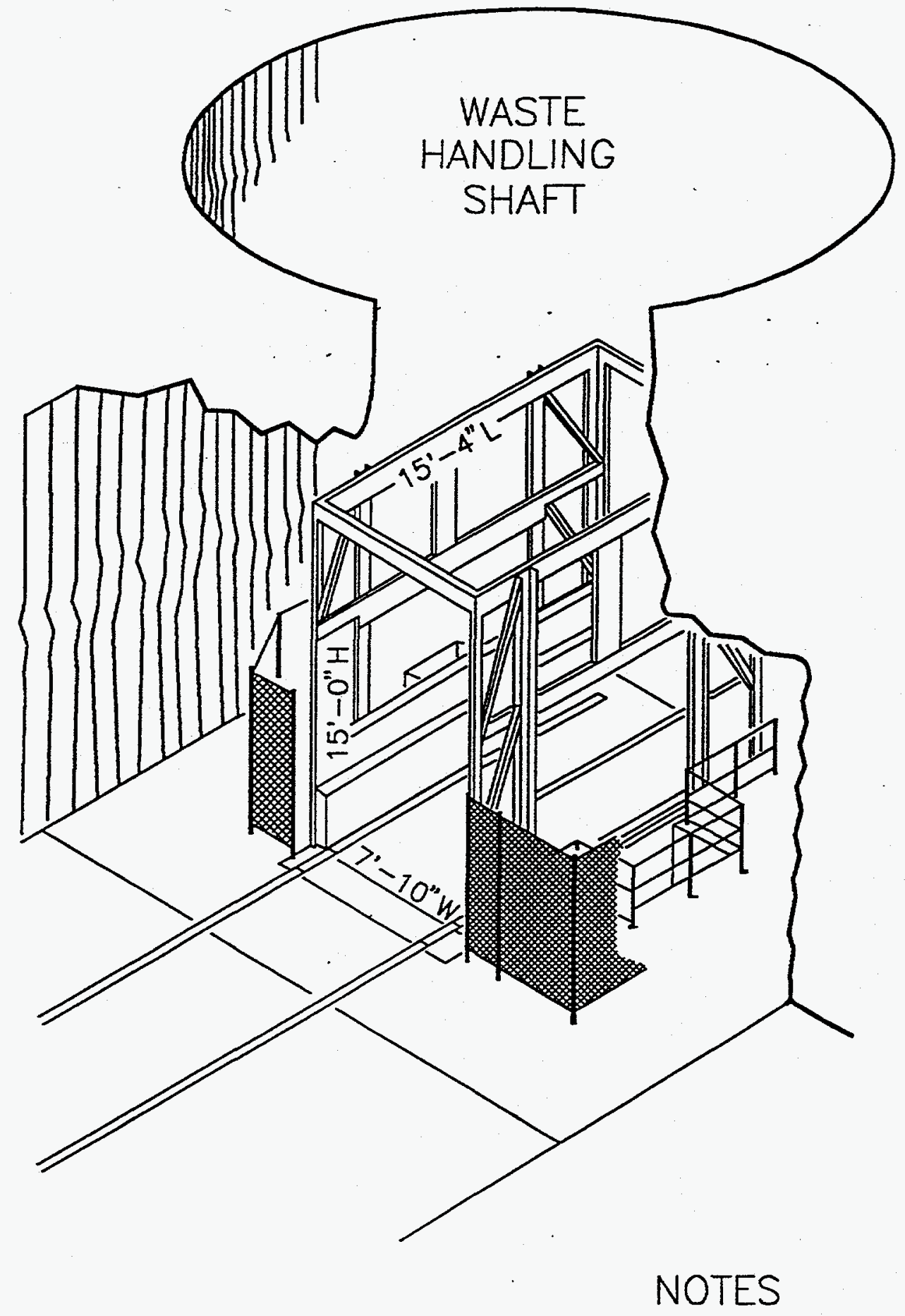

(1) CAGE DIMENSIONS SHOWN ARE INSIDE.

(2) WASTE HOIST DESIGN CAPACITY IS 80,000 LBS.

Figure 2

Waste Handling Shaft Cage Dimensions 


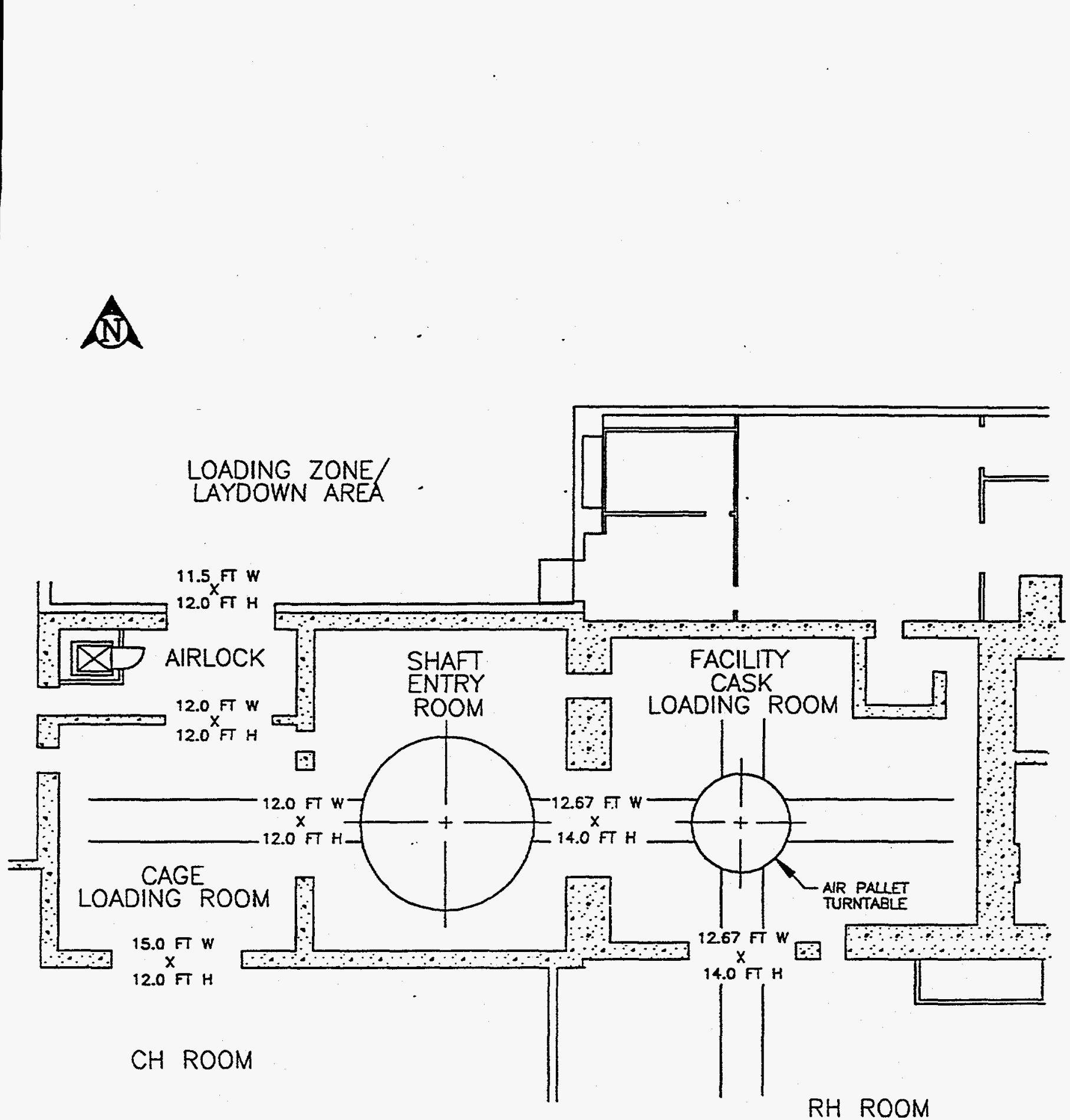

Figure 3

Waste Shaft Collar and Airlock Arrangement 


\subsection{Site Cleanup}

At conclusion of the work, the Contractor shall remove all trash, waste, debris, excess construction materials, and restore the affected areas to its prior condition, to the satisfaction of Westinghouse WID. A final inspection of the areas will be conducted by Westinghouse WID and the Contractor before final payment is approved.

End of section. 
SECTION 02010

MOBILIZATION AND DEMOBILIZATION 


\section{SECTION 02222}

\section{EXCAVATION}

\section{PART 1 - GENERAL}

\subsection{Scope}

This section includes:

- Excavation for main concrete barrier

- Excavation for surface preparation and levelling of base areas for isolation walls

- Disposition of excavated materials.

\subsection{Related Sections}

- 01010 - Summary of Work

- 01600 - Material and Equipment

- 03100 - Concrete Form Work

- 04300 - Unit Masonry System.

\subsection{Reference Documents}

"Reference Stratigraphy and Rock Properties for the Waste Isolation Pilot Plant (WIPP) Project" by R.D. Krieg-Sandia National Laboratory Document Sand 83-1908. [Available through National Technical Information Service (NTIS).]

\subsection{Field Measurements and Survey}

All survey required for performance of the work will be provided by Westinghouse WID. To develop the concrete formwork to fit the excavation, the Contractor shall be responsible for verifying the excavation dimensions.

\section{PART 2 - PRODUCTS}

Not used.

\section{PART 3 - EXECUTION}

\subsection{Excavating for Concrete Barrier}

Excavation for the main concrete barrier shall be performed to the lines and grades shown on the drawings. Excavate the back a minimum of 1 inch to 3 inches beyond clay seam $\mathrm{G}$, and the floor a minimum of 1 inch to 3 inches below the anhydride marker bed 139 (MB-139) to 
assure removal of the disturbed rock zone (DRZ). Excavation shall be performed utilizing mechanical means such as a cutting head on a suitable boom, by drilling boreholes and using an expansive agent to fragment the rock or other competent equipment or methods submitted to Westinghouse WID for review and approval. The use of explosives is prohibited. The existing WIPP roadheader mining machine may also be available for use. The Contractor is to determine availability and coordinate proposed use of the roadheader with Westinghouse WID. The existing roadheader is capable of excavating the back and the portions of the ribs above the floor level. However, it is not capable of excavating the portion below floor level.

The tolerances for the concrete barrier excavation shall be +6 inches, to 0 inch. In addition, the Contractor is to remove all loose or spalling rock from the excavation surface to provide a sound surface abutting the concrete barrier. The Contractor shall provide and install roof bolts for support as required for personnel protection and approved ground control plans.

\subsection{Excavating for Surface Preparation and leveling of Base Areas for Isolation Walls}

The Contractor shall excavate a 6-inch surface preparation around the entire perimeter of the isolation walls. The surface preparation in the floor shall be made level to produce a surface for placing the first course of block in the isolation walls. Tolerances for the leveled portion of the surface preparation are \pm 1 inch. Excavation may be performed by either mechanical or manual means. Use of explosives is prohibited.

\subsection{Disposition of Excavated Materials}

The Contractor shall remove all excavated materials from the panel-access drift where they are excavated. Excavated materials shall be removed from the mine via the salt skip to the surface, where they will be disposed on site at a location as directed by Westinghouse WID.

\subsection{Field Measurements and Survey}

All survey required for performance of the work will be provided by Westinghouse WID. The Contractor shall protect all survey control points, bench marks, etc., from damage by his operations. WID will verify by survey that the Contractor has excavated to the required lines and grades. The Contractor shall be responsible for verifying the excavation dimensions to develop concrete formwork to fit the excavation. No form work or block work is to be erected until this survey is completed. The Contractor is to coordinate the survey work with his operations to assure against lost time. The Contractor shall notify Westinghouse WID at least 24 hours prior to the time surveying is required

End of section. 
SECTION 02222

EXCAVATION 


\section{SECTION 02722}

\section{GROUTING}

\section{PART 1 - GENERAL}

\subsection{Scope}

This section includes:

- Grouting of concrete barrier.

\subsection{Related Sections}

- 01010 - Summary of Work

- 01400 - Contractor Quality Control

- 01600 - Material and Equipment

- 03100 - Concrete Form Work

- 03300 - Cast-in-Place Concrete

\subsection{References}

ASTM C1107-91a Standard Specification for Dry, Hydraulic Cement Grout (Nonshrink)

ASTM C109/ Test Method for Compressive Strength of Hydraulic Cement Mortars C109M-95

\subsection{Submittals for Review and Approval}

Thirty days prior to the initiation of grouting, the Contractor shall submit to Westinghouse WID for review and approval, the following:

- Type of grout proposed

- Product data:

- Manufacturer's specification and certified laboratory tests for the manufactured grout, if proposed

- Certified laboratory tests for the salt-saturated grout, if proposed, using project-specific materials 
- Proposed grouting method, including equipment and materials and construction sequence in Work Plan.

\subsection{Submittals for Construction}

Daily grouting report indicating the day, date, time of mixing and delivery, quantity of grout placed, water used, pressure required, problems encountered, action taken, quality control data, testing results, etc., no later than 24 hours following construction.

\section{PART 2 - PRODUCTS}

\subsection{Grout Materials}

Grout used for grouting in connection with fresh water/plain cement concrete shall be nonshrink, cement-based grout, Five Star 110 as manufactured by Five Star Products Inc., 425 Stillson Road, Fairfield, Connecticut 06430 or approved equal. Mixing and installation shall be in accordance with the manufacturer's recommendations.

As an alternate to the above grout, in connection with the Salado Mass concrete mix, the Contractor shall use, subject to the approval of Westinghouse WID, a salt saturated grout. The following formulation is suggested to the Contractor as an initiation point for selection of the grout mix. Salt saturated grout strength shall be 4500 psi at 28 days.

\section{Salt-Saturated Grout (BCT-1F)}

\begin{tabular}{|l|c|}
\hline \multicolumn{1}{|c|}{ Component } & Percent of total Mass (wt.) \\
\hline \hline Class H cement & 48.3 \\
\hline Class C fly ash & 16.2 \\
\hline Cal Seal (plaster - from Halliburton) & 5.7 \\
\hline Sodium chloride & 7.9 \\
\hline Dispersant & 0.78 \\
\hline Defoamer & 0.02 \\
\hline Water & 21.1 \\
\hline
\end{tabular}

Water for mixing shall be of potable quality, free from injurious amounts of oil, acid, alkali, salt, or organic matter, sediments, or other deleterious substances, as specified for concrete, Section 03300-2.3. 


\subsection{Product Data}

If the Contractor proposes to utilize a manufactured nonshrink cement-based grout, he shall submit complete manufacturer's specifications for the product, along with certified laboratory test results of the material.

If the Contractor proposes to utilize the salt-saturated grout in connection with the Salado Mass concrete mix, he shall submit manufacturer's/supplier's specifications for the component materials, and certified laboratory test results for the resultant mix.

\section{PART 3 - EXECUTION}

\subsection{General}

The Contractor shall furnish all labor material, equipment, and tools to perform all operations in connection with the grouting.

Grout delivery and return lines for interface grouting shall be installed in the form work or in the area to be grouted to provide uniform distribution of the grout as shown on the drawings. The exact location of the boxes and lines shall be determined in the field. Additional grout. delivery and return lines and boxes may be required by Westinghouse WID.

Pumps shall be positive displacement piston type pump designed for grouting service capable of operating at a discharge pressure of $100 \mathrm{psi}$. The Contractor shall supply a standby pump to be utilized in the event of a breakdown of the primary unit.

Mixers shall be high velocity "colloidal" type with a rotary speed of 1,200 to $1,500 \mathrm{rpm}$. Grout shall be mixed to a pumpable mix as per the manufacturer's recommendations.

Mixing water shall be accurately metered to control the consistency of the grout.

The Contractor shall provide all necessary valves, gages, and pressure hoses.

Water for mixing is available at the waste shaft. The Contractor is cautioned that no free water discharges or spills are permitted in the mine. All cleanup and washout operations shall be performed at the ground surface.

Potential spill areas in the underground shall be identified by the Contractor in the work plan. The Contractor shall provide measures to contain suitable containment. Isolation measures shall include, but are not limited to, lining with a membrane material (PVC, hypalon, HDPE), draped curtains (polyethylene,PVC, etc.), corrugated sheet metal protective walls or a combination of these and other measures.

If salt-saturated grout is selected for use, the Contractor shall make provisions to accurately proportion the components. Proportioning shall be by weighing. Sufficient quantities of dry 
components shall be developed prior to initiation of the grouting to perform the work so as not to incur delays during the mixing/placing sequence.

\subsection{Interface Grouting of Concrete Barrier}

After each cell of the concrete barrier has been allowed to cure for a period of seven days, or as directed by Westinghouse WID, the Contractor shall interface grout the remaining space between the back wall and the top surface of the concrete barrier.

Each cell of the concrete barrier shall be grouted before the next adjacent cell is formed and concrete placed. Grout delivery and return lines shall be installed with the form work as shown and called for on the drawings, or as directed by Westinghouse WID.

The placing of grout, unless otherwise directed by Westinghouse WID shall be continuous until completed. Grouting shall progress from lower to higher grout pipes. Grouting shall proceed through a single delivery line until grout escapes from the adjacent return line. The Contractor shall then secure these lines and move to the next adjacent set of delivery and return lines. Pressure shall be adjusted to adequately deliver the grout to the forms, as witnessed by grout in the return line.

The grouting operation shall be conducted in a manner such that it does not affect the stability of the concrete barrier structure.

\subsection{Contact Grouting}

After completion of interface grouting if directed by Westinghouse WID, the Contractor shall contact grout to fill any remaining voids at the concrete barrier/back wall interface. Contact grouting includes all operations to drill, clean, and grout holes installed in the concrete barrier.

The Contractor shall drill and grout the interface zone to the main concrete barrier as directed by Westinghouse WID.

The location, direction, and depth of each grout hole shall be as directed by Westinghouse WID. The order in which the holes are drilled and the manner in which each hole is drilled and grouted, the proportions of the water used in the grout, the time of grouting, the pressures used in grouting, and all other details of the grouting operations shall be as directed by Westinghouse WID.

Wherever required, contact grouting will entail drilling the hole to a limited depth, installing a packer, and performing grouting.

\subsubsection{Drilling}

The holes shall be drilled with rotary-type drills. Drilling grout holes with percussion-type drills will not be permitted except as approved by Westinghouse WID. 
The requirements as to location, depth, spacing, and direction of the holes shall be as directed by Westinghouse WID.

The minimum diameter shall be approximately $11 / 2$ inches.

When the drilling of each hole or stage of has been completed, compressed air will be used to flush out drill cuttings. The hole shall then be temporarily capped or otherwise suitably protected to prevent the hole from becoming clogged or obstructed until it is grouted.

\subsubsection{Materials for Contact Grouting}

Standard weight black steel pipe conforming to ASTM A-53 shall be set in the concrete in the locations as directed by Westinghouse WID. All pipe and fittings shall be furnished by the Contractor.

The size of the grout pipe for each hole and the depth of the holes for setting pipe for grouting shall be as directed by Westinghouse WID. Care shall be taken to avoid clogging or obstructing the pipes before being grouted, and any pipe that becomes clogged or obstructed from any cause shall be cleaned satisfactorily or replaced.

The packers shall be furnished by the Contractor and shall consist of expansible tubes or rings of rubber, leather, or other suitable material attached to the end of the grout supply pipe. The packers shall be designed so that they can be expanded to seal the drill hole at the specified locations and when expanded shall be capable of withstanding without leakage, for a period of 5 minutes, air pressure equal to the maximum grout pressures to be used.

\subsubsection{Grouting Procedures}

Different grouting pressures will be required for grouting different sections of the grout holes. Pressures as high as necessary to deliver the grout but which, as determined by trial, are safe against concrete displacement shall be used in the grouting.

If, during the grouting of any hole, grout is found to flow from adjacent grout holes or connections in sufficient quantity to interfere seriously with the grouting operation or to cause appreciable loss of grout, such grout holes and connections shall be capped temporarily. Where such capping is not essential, holes shall be left open to facilitate the escape of air as the grout is forced into other holes. Before the grout has set, the grout pump shall be connected to adjacent capped holes and to other holes from which grout flow was observed, and grouting of all holes shall be completed. If during the grouting of any hole, grout is found to flow from points in the barrier, any parts of the concrete structure, or other locations, such flows or leaks shall be plugged or caulked by the Contractor as directed by Westinghouse WID.

As a safeguard against concrete displacement, excessive grout travel, or while grout leaks are being caulked, Westinghouse WID may require the reduction of the pumping pressure, intermittent pumping, or the discontinuance of pumping. 
The consistency of the grout mix shall be varied, as directed by Westinghouse WID, depending on the conditions encountered. Where the grout hole or connection continues to take a large amount of grout after the mix has been thickened, Westinghouse WID may require that pumping be done intermittently, waiting up to 8 hours between pumping periods to allow grout in the barrier to set. After the grouting is complete, the pressure shall be maintained by means of stopcocks, or other suitable valve that it will be retained in the holes or connections being grouted.

\subsection{Cleanup}

No clean-up or washing of equipment with water is allowed in the underground. No free water spills are permitted. All clean out or wash out requiring water will be performed above ground at the location approved by Westinghouse WID. See note above regarding potential spill areas in Section 3.1 - General.

\subsection{Quality Control}

The Contractor shall provide a third-party quality control inspector at the site throughout the grout placement operations. The inspector shall determine that the grout mix is properly proportioned and properly mixed to the approved consistency. The inspector shall sample and make one set of grout cubes for compression testing for every 50 cubic feet of grout placed, or fraction thereof, for each day of grout placement.

End of section. 
SECTION 02722

GROUTING 


\section{SECTION 03100 \\ CONCRETE FORMWORK}

\section{PART 1 - GENERAL}

\subsection{Scope}

This section includes:

- Formwork for cast-in-place concrete with shoring, bracing, and anchorage

- Accessory items, grout pipes, concrete delivery pipes.

\subsection{Related Sections}

- 01010 - Summary of Work

- 01400 - Contractor Quality Control

- 01600 - Material and Equipment

- 02722 - Grouting

- 03300 - Cast-in-Place Concrete

- 04300 - Unit Masonry System

\subsection{References}

ACI 301-89 Specifications for Structural Concrete for Buildings

ACI 318-89(92) Building Code Requirements for Reinforced Concrete

ACI 347-94 Recommended Practice for Concrete Formwork

ASTM A-36/ Standard Specification for Structural Steel

A36M-91

ASTM A-53-90b Standard Specification for Pipe, Steel, Black, and Hot-Dipped Zinc Coated Welded and Seamless

ASTM A-325-91c Standard Specification for Structural Bolts, Steel, Heat-Treated 120/105 ksi Minimum Tensile Strength

ASTM A-615-95b Standard Specifications for Deformed and Plain Billet-Steel Bars for Concrete Reinforcement

AWS A3.0-94 Welding Terms and Definitions 
AWS A5.1-91 Specification for Mild Steel Covered Arc Welding Electrodes

AWS D1.1-94 Structural Welding Code-Steel

AISC Manual of Steel Construction Latest Edition

\subsection{Submittals}

The Contractor shall submit the following supporting documentation for the adequacy of the formwork 30 days prior to initiation of work at site:

- Shop detail drawings with appropriate calculations to support the adequacy of the formwork.

- Mill test certification of materials utilized in construction of the forms.

- Details of installation contained in the Contractor's Work Plan.

\subsection{Quality Assurance}

The design and detail of the formwork shall be conducted under direct supervision of a professional structural Engineer experienced in design of this work. Responsibilities include:

- Fabricating formwork in accordance with AISC manual of steel construction.

- Performing all welding in accordance with AWS D1.1 structural welding code.

- Performing all bolting in accordance with AISC specification for structural joints using ASTM A325 or A490 bolts.

- Performing work in accordance with ACI 301, 318, and 347, AISC and AWS standards. Maintain one copy of all standards at site.

\section{PART 2 - PRODUCTS}

\subsection{Form Materials}

Forms for the concrete barrier shall be constructed of ASTM A-36 steel.

Pipe inserts shall be ASTM A-53 black standard weight pipe.

Form spacers shall be ASTM A-36 round stock.

Bolts shall be ASTM A325 high strength structural bolts. 
Grout pipes shall be ASTM A-53 standard weight pipe or flex conduit as shown on the drawings.

Rock anchors shall develop strength equal to or greater than ASTM A-36 round stock.

Welding electrodes shall conform to AWS A5.1.

\section{PART 3 - EXECUTION}

\subsection{General}

The Contractor shall furnish all labor material equipment and tools to perform all operations in connection with the design, detail, fabrication and erection of the formwork and the fabrication and installation of grout pipes for the main concrete barrier. All work shall be performed according to standards referred to in Paragraph 1.3.

The Contractor may, at his option submit an alternate design or modify the design shown on the drawings, subject to the approval of Westinghouse WID. All designs must be supported by design calculations stamped and sealed by a registered professional engineer.

The Contractor shall furnish, fabricate and install all grout pipes and grout boxes for both the concrete barrier and the isolation walls.

\subsection{Shop Drawings}

The Contractor shall design and detail all formwork for the concrete barrier, complete with any required bracing and shoring for the concrete barrier as shown on the drawings, in accordance with ACI 318 and 347 and the AISC manual of steel construction.

The details shall incorporate provision for adjusting and modifying the formwork to suit the excavation. Excavation tolerances are given in Section 02222 Excavation.

The Contractor shall be responsible for verifying the excavation dimensions to develop the concrete formwork to fit the excavation.

Prior to fabrication, the Contractor shall submit shop drawings complete with supporting calculations for review/approval by Westinghouse WID 30 days prior to initiating work. The contractor shall incorporate all Westinghouse WID's comments, revisions, resolve all questions and resubmit drawings for final approval prior to proceeding with fabrication.

\subsection{Fabrication}

The Contractor shall fabricate all formwork and ancillary items in accordance with the latest edition of the AISC Manual of Steel Construction and the approved detail drawings. 
Formwork shall contain all inserts for grouting and pumping concrete. Sufficient valving shall be provided on inserts to allow shut off of concrete and grout to prevent back flow through the form work.

All welding shall be in accordance with AWS D1.1 structural welding code including operator and procedure certifications. Elements shall be welded using E-7018 low hydrogen electrodes. Panels shall be piece marked to correspond to the erection drawing(s) and sequence at fabrication.

\subsection{Installation}

\subsubsection{Grout Pipes}

The Contractor shall furnish, fabricate, and install all grout pipes and boxes as approved by Westinghouse WID. Grout pipes and boxes shall be attached to the back surface using masonry anchors as shown on the drawings or other approved methods. Grout pipes shall be connected to the inserts installed in the permanent forms and securely fastened to the formwork. All grout pipes will be blown out with compressed air after installation and prior to closure of the formwork to assure they are clean and free from debris or obstructions. Grout pipes shall then be temporarily capped to prevent entry of foreign matter until ready for grouting. The Contractor shall apply masking tape to the grout box openings to prevent concrete infiltration during concrete placement.

\subsubsection{Formwork}

The steel formwork for the concrete barrier is to remain in place at completion of each segment of the barrier, therefore all formwork shall be free from oil, grease, rust, dirt, mud or other material that would prevent bonding by the concrete. Forms will not be oiled or receive application of release agent.

The Contractor shall install formwork at the locations shown on the drawings to the lines and grades shown. Forms are to be mortar tight. The Contractor shall adjust the formwork to suit the contour of the excavation. Rock may be trimmed or chipped to suit where interferences are encountered. Where overexcavation has occurred in excess of the designedin adjustability of the formwork, modifications shall be proposed to Westinghouse WID for his approval prior to installation. Installation of the formwork shall be reviewed and approved by Westinghouse WID prior to proceeding with concrete installation.

The Contractor shall provide a sealant or gasket material subject to the approval of Westinghouse WID.

\subsection{Quality Control}

The Contractor shall arrange for and contract with an approved third party inspector to provide inspection/testing services for the fabrication and installation of the formwork and ancillary items, as required by the QA/QC plan. 
The Contractor shall furnish certified mill test reports for all materials utilized in the fabrication.

All welding shall be in accordance with AWS D1.1 structural welding code. The Contractor shall furnish welding operator and procedure certifications for all operators and procedures utilized.

Fabricated components shall be inspected for dimension and overall quality. Welds shall be inspected by an AWS certified welding inspector.

The inspector shall visually inspect the installation for fit-up and dimensionally for location.

\subsection{Handling, Shipping, Storage}

The Contractor shall handle, ship, and store fabricated components with care to avoid damage. Stored components shall be placed on timbers or pallets off the ground to keep the units clean. Components shall be tarped while in outdoor storage. Components that become spattered or contaminated with mud will be thoroughly cleaned during erection, and prior to concrete emplacement. Damaged components will be rejected by the inspector and replaced by the contractor at his cost.

End of section. 
SECTION 03100

CONCRETE FORMWORK 


\section{SECTION 03300}

\section{CAST-IN-PLACE CONCRETE}

\section{PART 1 - GENERAL}

\subsection{Scope}

This section includes:

- Cast-in-place concrete for concrete barrier

- Concrete mix design.

\subsection{Related Sections}

- 01010 - Summary of Work

- 01400 - Contractor Quality Control

- 01600 - Material and Equipment

- 02222 - Excavation

- 02722 - Grouting

- 03100 - Concrete Formwork

\subsection{References}

ACI 211.1-91

ACI $318.1-89(92)$

ACI 304R-89

ASTM C 33-93

ASTM C 39-94

ASTM C 94-94

ASTM C 136-95a

ASTM C 143-90a
Standard Practice for Selecting Proportions for Normal, Heavy Weight, and Mass Concrete

Building Code Requirements for Structural Plain Concrete

Guide for Measuring, Mixing, Transporting, and Placing Concrete

Standard Specification for Concrete Aggregates

Standard Test Method for Compressive Strength of Cylindrical Concrete Specimens

Standard Specification for Ready-Mixed Concrete

Standard Test Method for Sieve Analysis of Fine and Coarse Aggregates

Standard Specification for Slump of Hydraulic Cement Concrete 
ASTM C 150-95

ASTM C 186-94

ASTM C 403/

C 403M-95

ASTM C 494-95

ASTM C 618-94a

ASTM C $845-90$

ASTM D 2216-92

USACE CRD-C 36

USACE CRD-C 48

API 10

NRMCA

NRMCA

Westinghouse WID Standards

WIPP-DOE-71 Design Criteria Waste Isolation Pilot Plant, Revised Mission Concept -- IIA (DOE, 1984)

WP 03-1

WP 09-010

WP 09-CN3021

WP 09-024
Standard Specification for Portland Cement

Standard Test Method for Heat of Hydration of Hydraulic Cement

Standard Test Method for Time of Setting of Concrete Mixtures by Penetration Resistance

Standard Specification for Chemical Admixtures for Concrete

Standard Specification for Coal Fly Ash and Raw or Calcined Natural Pozzolam for Use as an Admixutre in Portland Cement Concrete

Standard Specification for Expansivce Hydraulic Cement

Standard Test Method for Laboratory Determination of Water (moisture) Content of Soil and Rock

Method of Test for Thermal Diffusivity of Concrete

Standard Test Method for Water Permeability of Concrete

Cements

Check List for Certification of Ready Mixed Concrete Production Facilities

Concrete Plant Standards
WIPP Startup and Acceptance Test Program (Westinghouse, 1993b)

Design Development Testing (Westinghouse, 1991)

Component Numbering (Westinghouse, 1994a)

Configuration Management Board/Engineering Change Proposal (ECP) (Westinghouse, 1994b) 


\subsection{Submittals for Review/Approval}

The Contractor shall submit the following for approval 30 days prior to initiating any work at the site:

Type of concrete proposed

Product Data - Laboratory test data and trial mix data for the proposed concrete to be utilized for the concrete barrier.

Proposed method of installation, including equipment and materials in work plan.

\subsection{Submittals at Completion}

Laboratory test data developed during the installation of the concrete barrier.

\subsection{Quality Assurance}

Perform work in accordance with the Contractor's Quality Control Plan and referenced ACI and ASTM standards.

Acquire cement, aggregate and component materials from the same source throughout the work.

\section{PART 2 - PRODUCTS}

\subsection{Cement}

Portland cement shall conform to ASTM C150 Type II modified with Pozzolan or IV for plain cement concrete or API 10 Class $\mathrm{H}$ oil well cements. Cement utilized in the mix shall be Portland cement, Type II modified with pozzolan or type IV, to limit the heat of hydration of the resultant mix. The source of the cement to be used shall be indicated and manufacturer's certification that the cement complies to the applicable standard shall be provided with each shipment.

\subsection{Aggregates}

Aggregates shall be quartz aggregates conforming to the requirements of ASTM C33.

Fine aggregate shall meet the requirements of ASTM C33 having a fineness modulus in the range of 2.80 to 3.00 .

Coarse aggregate maximum size shall be $11 / 2$ inches and shall be clean, cubical, angular, 100 percent crushed aggregate without flat or elongated particles.

The source of the aggregate is to be indicated and test reports certifying that the aggregate complies with the applicable standard are to be submitted for approval with the trial mix data. 


\subsection{Water}

Water used in mixing concrete shall be of potable quality, free of injurious amounts of oil, acid, alkali, organic matter, or other deleterious substances.

Water shall conform to the provisions in ASTM C94, and in addition, shall conform to the following:

- $\mathrm{pH}$ not less 6.0 or greater than 8.0

- Carbonates and/or bicarbonates of sodium and potassium: $1000 \mathrm{ppm}$ maximum

- Chloride ions (C1): $250 \mathrm{ppm}$ maximum

- Sulfate ions $\left(\mathrm{SO}_{4}\right): 1000 \mathrm{ppm}$ maximum

- Iron content: $0.3 \mathrm{ppm}$ maximum

- Total solids: $2000 \mathrm{ppm}$ maximum

When ice is used in concrete mix, the water used for making ice shall meet all of the above requirements.

The source of water is to be indicated and certified copies of test data from an approved laboratory confirming that the water to be used meets the above requirements shall be submitted for approval with the trial mix data.

\subsection{Admixtures}

Pozzolan shall conform to ASTM C618. Sampling and testing of pozzolans shall conform to ASTM C311. Approximately 5 percent by weight of pozzolan may be used to replace cement in the mixes when approved.

All admixtures shall conform to ASTM C-494. The source of any admixtures proposed are to be indicated and certified copies of test data from an approved laboratory shall be submitted for approval with the trial mix.

\subsection{Target Properties of the Concrete Mix}

The Contractor shall develop and proportion a plain cement concrete mix for use in constructing the concrete barrier. The Contractor shall demonstrate by trial mix that the proposed concrete meets the following properties: 
Target properties for Barrier Concrete

\begin{tabular}{ll}
\hline \multicolumn{1}{c}{ Property } & \multicolumn{1}{c}{ Comment } \\
\hline 4-hr working time & $\begin{array}{l}\text { Indicated by 8-inch slump (ASTM C 142) } \\
\text { after 3-hr intermittent mixing. Max 10-inch } \\
\text { slump at mixing. }\end{array}$ \\
Less than $25^{\circ} \mathrm{F}$ heat rise prior to placement & $\begin{array}{l}\text { Difference between initial condition and } \\
\text { temperature after } 4 \mathrm{hr} .\end{array}$ \\
4,000 psi compressive strength $\left(\mathrm{f}_{\mathrm{c}}\right)$ & At 28 days after casting (ASTM C 39) \\
Volume stability & $\begin{array}{l}\text { Length change between }+0.05 \text { percent and } \\
-0.02 \text { percent (ASTM C 490) }\end{array}$ \\
Minimal entrained air & 2 percent to 3 percent air
\end{tabular}

The Contractor shall use water reducing agents, plasticizers and other admixtures to achieve the slump and workability of the mix without adding excessive mixing water or excessive water-cement ratio. All admixtures shall conform to ASTM C-294.

The Contractor shall provide certified copies of test data from an approved laboratory demonstrating compliance with the above target properties.

In addition to the target properties the Contractor shall provide certified test data for the trial mix for the following properties:

- Heat of hydration

- Concrete Set

- Thermal Diffusivity

- Water Permeability
ASTM C-186

ASTM C-403

USACE CRD-C36

USACE CRD-C43

\subsection{Salado Mass Concrete}

The Contractor may elect to utilize the Salado Mass concrete in preference to developing a plain cement concrete. If Salado Mass concrete is selected, the Contractor shall demonstrate that the Salado Mass concrete meets the target properties shown above. Recommended initial proportioning of the Salado Mass concrete is as follows: 


$\begin{array}{lc}\text { Class H cement (API 10) } & 4.93 \\ \text { Chem Comp III (ASTM C-845 Type K) } & 2.85 \\ \text { Class F fly ash (ASTM C-618) } & 6.82 \\ \text { Fine aggregate } & 33.58 \\ \text { Coarse aggregate } & 43.02 \\ \text { Sodium chloride } & 2.18 \\ \text { Defoaming agent } & 0.15 \\ \text { Sodium citrate } & 0.09 \\ \text { Water } & 6.38\end{array}$

The Contractor shall prepare a trial mix and provide certified test data from an approved testing laboratory for slump, compressive strength, heat rise, heat of hydration, concrete set time, thermal diffusivity, and water permeability as indicated above for the plain concrete mix.

\section{PART 3 - EXECUTION}

\subsection{General}

The Contractor shall provide all labor material, equipment and tools necessary to develop, supply, mix, transport and place mass concrete in the forms as shown on the drawings and called for in these specifications. All work shall be according to the standard references in paragraph 1.3.

The Contractor will be required to provide and erect on the site a batch plant, suitable to store, handle, weight and deliver the proposed concrete mix. The batch plant shall be certified to NRMCA standards. The batch plant shall be erected on site in the location as directed by Westinghouse WID.

The Contractor shall batch, mix, and deliver to the underground, sufficient quantity of concrete to complete placement of concrete within one form section, as shown on the drawings. Once begun, placement of concrete in a section shall be continuous until completed. Target time for concreting one section is eight to ten hours allowing an additional two hours for clean up of equipment, for a total 10- to 12-hour shift. 
It is expected that addition of water to the dry materials and mixing of the concrete will occur at the ground surface with transport of wet concrete to a pump at the underground level where it will be pumped into the forms.

The Contractor is to provide all transport vehicles or means to transfer the wet concrete from the mixer truck to the pump. It is expected that the Contractor will use the waste conveyance hoist to transfer from the ground surface to the mine level. The Contractor is to familiarize himself with the dimensions of the waste conveyance and the airlock in order to provide suitable transport vehicles. The Contractor is also to familiarize himself with the capacity and speed of the conveyance to allow transfer of sufficient concrete to sustain the continuing placement of concrete. (See Figures 2 and 3 attached to Section 02010 - Mobilization and Demobilization).

The Contractor shall determine the horizontal distance to the entry where placement of the concrete barrier is to occur, and develop a route, with the approval of Westinghouse WID for traffic flow within the underground.

Details of the logistics for handling the concrete shall be included in the Contractors' Work Plan, and submitted to Westinghouse WID for approval prior to start of work at the site.

Potential spill areas in the underground shall be identified by the Contractor in the Work Plan. The Contractor shall provide measures to contain and isolate any water from contact with the halite in these areas. Suitable containment isolation measures shall include but are not limited to, lining with a membrane material (PVC, hypalon, HDPE), draped curtains (polyethylene, PVC, etc.), corrugated sheet metal protective walls or a combination of these and other measures.

\subsection{Pumping Concrete}

The Contractor shall provide pumping equipment suitable for placing the concrete into the forms. The Contractor at a minimum, shall provide an operating and a spare pump, to be used in the event of breakdown of the primary unit. After transporting and prior to pumping the concrete shall be remixed to compensate for segregation of aggregate during transport. The Contractor shall indicate the equipment proposed for pumping (manufacturer, model, type, capacity, pressure and remixing at the point of delivery in the Work Plan).

Each batch of concrete shall be checked at the surface at the time of mixing and again at the point of transfer to the pump for slump and temperature, and shall conform to the following:

- Max. slump at mixing - 10 inches

- Max. slump at delivery to pump - 8 inches

- Max. temperature at placement $=70^{\circ} \mathrm{F}$

Note: No water is to be added to the mix after the initial mixing and slump are determined. 
The Contractor shall connect to the pipe ports fabricated into the forms for delivery of the concrete, beginning with the lowest ports first. Pumping shall continue until concrete is seen in the adjacent port at which time the delivery hose will be transferred to that port and the first port capped.

Pumping shall continue moving laterally then upward until the entire form is filled and the pour is completed.

\subsection{Coordination of Work}

The Contractor is to coordinate his work mixing, transporting, and placing the mass concrete with the on-going operations in the underground. Coordination of use of the facilities and existing equipment shall be through Westinghouse WID.

\subsection{Clean-Up}

No clean up or washing of equipment with water will be allowed in the underground. No free water spills are permitted in the underground. All clean-out or wash-out requiring water will be performed above ground at the location approved by Westinghouse WID.

\subsection{Quality Control}

The Contractor shall provide a third-party quality control inspector at the site throughout the concrete placement. The inspector shall be responsible for determining that the batch plant is proportioning the mix according to the approved proportions. The batch plant shall provide a print out of batch quantities for each truck delivered to the mine. The inspector shall also determine the slump for each batch as it is mixed and allow additional water to be added until the initial slump is achieved. No additional water is to be added after this time. Temperature will also be recorded at this time.

The inspector shall also determine the slump and temperature following the remixing when concrete is transferred to the pump. Concrete not meeting or exceeding the specification is to be rejected and removed from the underground.

Concrete test cylinders to determine unconfined compression strength shall be taken by the inspection at the delivery from remixer to the pump in the underground. Four (4) cylinders shall be made for each 50 cubic yards of concrete placed. Cylinders shall be sealed with polyethylene and taped and field cured at ambient temperatures in the mine adjacent to the concrete barrier area. Two (2) samples shall be tested at 7 days and the remaining two (2) at 28 days.

End of section. 


\section{SECTION 04100}

\section{MORTAR}

\section{PART 1 - GENERAL}

\subsection{Scope}

This section includes:

- Mortar for Isolation Wall Construction.

\subsection{Related Sections}

- 01010 - Summary of Work

- 01400 - Contractor Quality Control

- 01600 - Material and Equipment

- 04300 - Unit Masonry System

\subsection{References}

ASTM C91-95 Standard Specification for Masonry Cement

ASTM C144-93 Standard Specification for Aggregate for Masonry Mortar

ASTM C150-95 Standard Specification for Portland Cement

ASTM C207-91 Standard Specification for Hydrated Lime for Masonry Purposes

ASTM C270-94 Standard Specification for Mortar for Unit Masonry

ASTM C780-94 Standard Test Method for Preconstruction and Construction Evaluation of Mortars for Plain and Reinforced Unit Masonry

ASTM C1142-94 Ready-Mixed Mortar for Unit Masonry

ASTM E447-92 Test Methods for Compressive Strength of Masonry Prisms

\subsection{Submittals for Review and Approval}

The Contractor shall submit for approval the following 30 days prior to the initiation of work at the site.

Design mix. 
Certified laboratory tests for the proposed design mix, indicating conformance of mortar to property requirements of ASTM C270, and test and evaluation reports to ASTM C780.

\subsection{Submittals at Completion}

Certified laboratory test results for the construction testing of mortar mix.

\subsection{Quality Assurance}

Perform work in accordance with the Contractor's Quality Control Plan and referenced ASTM standards. Acquire cement, aggregate, and component materials from the same source throughout the work.

\subsection{Delivery Storage Handling}

Maintain packaged materials clean, dry and protected against dampness, freezing and foreign matter.

\section{PART 2 - PRODUCTS}

\subsection{Mortar Mix}

The Contractor shall provide mortar for Isolation Walls, which shall be in conformance with ASTM C270 type M, using the property specification (3,000 psi at 28 days).

Sand for mortar shall conform to ASTM C144.

Water used for mixing mortar shall be of potable quality, free of injurious amounts of oil, acid alkali, organic matter, sediments, or other deleterious substances, as specified for Concrete, Section 03300 2.3.

The supply of materials as defined in the design mix shall remain the same throughout the job.

\section{PART 3 - EXECUTION}

\subsection{General}

The Contractor shall furnish all labor material equipment and tools to perform all operations in connection with supplying and mixing mortar for constructing the isolation walls.

The Contractor shall fully describe his proposed mortar mixing operation, including proposed equipment and materials in the Work Plan. 


\subsection{Mortar Mixing}

Mortar shall be machine-mixed with sufficient water to achieve satisfactory workability. Maintain sand uniformly damp immediately before the mixing process. If water is lost by evaporation, retemper only within one and one half hours of mixing. Use mortar within two hours of mixing at ambient temperature of $85^{\circ}$ in the mine.

\subsection{Installation}

The Contractor shall install mortar to the requirements of Section 04300 Unit Masonry System.

\subsection{Field Quality Control}

The Contractor shall provide a third party Quality Control Inspector to perform all sampling and testing to confirm that the mortar mix conforms to the proposed mix properties developed in the design mix.

Construction testing of mortar mix shall be in accordance with ASTM C780 for compression strength. Four (4) prism specimens shall be taken for each $50 \mathrm{cu}$. ft. of mortar or fraction thereof placed each day.

End of Section. 
SECTION 04100 MORTAR 


\section{SECTION 04300}

\section{UNIT MASONRY SYSTEM}

\section{PART 1 - GENERAL}

\subsection{Scope}

This section includes:

- Concrete Masonry Units

\subsection{Related Sections}

- $01010 \quad$ Summary of Work

- 01400 Contractor Quality Control

- $01600 \quad$ Material and Equipment

- 02722 Grouting

- 03100 Concrete Formwork

- 04100 Mortar

\subsection{References}

ASTM C55-94a Standard Specification for Concrete Building Brick

ASTM C140-94a Standard Method of Sampling and Testing Concrete Masonry Units

\subsection{Submittals for Revision and Approval}

The Contractor shall submit for approval the following 30 days prior to initiation of the work at the site.

Certified laboratory test results for the proposed solid masonry units.

\subsection{Quality Assurance}

Perform the work in accordance with the Contractor's Quality Control Plan.

\section{PART 2 - PRODUCTS}

\subsection{Concrete Masonry Units}

Concrete masonry units shall be solid (no cavities or cores), load bearing high-strength units having a minimum compressive strength of 3500 psi. Concrete masonry units shall be tested 
in accordance with ASTM C140. All other aspects of the concrete masonry units shall comply with ASTM C55, Type I Moisture Controlled.

Nominal modular size shall be $8 \times 8 \times 16$ inches, or as otherwise approved by Westinghouse WID.

Concrete brick shall comply with ASTM C55, Grade N, Type I (moisture controlled) having a minimum compressive strength of 3500 psi (Avg. 3 units) or 3000 psi for individual unit.

\subsection{Mortar}

Mortar shall be as specified in Section 04100 Mortar.

\section{PART 3 - EXECUTION}

\subsection{General}

The Contractor shall furnish all labor, material, equipment and tools to perform all operations of installing Unit Masonry Isolation Walls to the lines and grades shown on the drawings.

The Contractor shall examine the excavation of the entry to affirm that the keys have been properly leveled and cut to the appropriate depths, at the proper locations prior to any to any work.

\subsection{Installation}

The Contractor shall install the isolation walls using concrete masonry units as specified above. Masonry units shall be installed with $3 / 8$-inch mortar joints with full mortar bedding and full head joints. Masonry units shall be installed in running bond with headers every third course. Masonry units shall be mortared tight to the ribs and the back wall to provide a seal all around the isolation wall.

Concrete brick may be used as required for fit-up around grout pipes, or minimizing the dimensional fit-up at the top or sides of the isolation walls as approved by Westinghouse WID. The interface between the top of the isolation wall and the back wall shall be completely mortared to provide full contact between the back and the block wall.

\subsection{Field Quality Control}

The Contractor shall provide a third-party Quality Control Inspector to inspect the installation of the Concrete Masonry Unit Isolation Walls. Inspection and testing of the mortar shall be in accordance with Section 04100 Mortar.

End of Section 
SECTION 04300

UNIT MASONRY SYSTEM 


$$
=
$$




\section{NOTICE}

Page(s) size did not permit electronic reproduction. Information may be purchased by the general public from the National Technical Information Service, U.S. Department of Commerce, Springfield, VA 22161 (Area Code 703-487-4650). DOE and DOE contractors may purchase information by contacting DOE's Office of Scientific and Technical Information, P.O. Box 62, Oak Ridge, TN 37831, Attn: Information Services (Area Code 423-576-8401). 